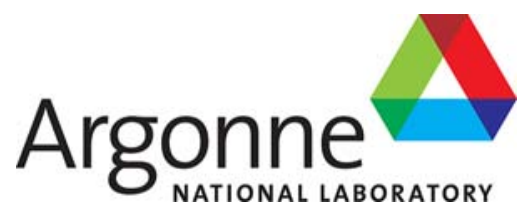

ANL/GTRI/TM-14/2

\title{
Analysis of the KUCA Type-A Experiments
}

Nuclear Engineering Division 


\begin{abstract}
About Argonne National Laboratory
Argonne is a U.S. Department of Energy laboratory managed by UChicago Argonne, LLC under contract DE-AC02-06CH11357. The Laboratory's main facility is outside Chicago, at 9700 South Cass Avenue, Argonne, Illinois 60439. For information about Argonne and its pioneering science and technology programs, see www.anl.gov.
\end{abstract}

\title{
DOCUMENT AVAILABILITY
}

Online Access: U.S. Department of Energy (DOE) reports produced after 1991 and a growing number of pre-1991 documents are available free via DOE's SciTech Connect (http://www.osti.gov/scitech/)

Reports not in digital format may be purchased by the public from the National Technical Information Service (NTIS):

U.S. Department of Commerce

National Technical Information Service

5301 Shawnee Rd

Alexandra, VA 22312

www.ntis.gov

Phone: (800) 553-NTIS (6847) or (703) 605-6000

Fax: (703) 605-6900

Email: orders@ntis.gov

Reports not in digital format are available to DOE and DOE contractors from the Office of Scientific and Technical Information (OSTI):

U.S. Department of Energy

Office of Scientific and Technical Information

P.O. Box 62

Oak Ridge, TN 37831-0062

www.osti.gov

Phone: (865) 576-8401

Fax: (865) 576-5728

Email: reports@osti.gov

\footnotetext{
Disclaimer

This report was prepared as an account of work sponsored by an agency of the United States Government. Neither the United States Government nor any agency thereof, nor UChicago Argonne, LLC, nor any of their employees or officers, makes any warranty, express or implied, or assumes any legal liability or responsibility for the accuracy, completeness, or usefulness of any information, apparatus, product, or process disclosed, or represents that its use would not infringe privately owned rights. Reference herein to any specific commercial product, process, or service by trade name, trademark, manufacturer, or otherwise, does not necessarily constitute or imply its endorsement, recommendation, or favoring by the United States Government or any agency thereof. The views and opinions of document authors expressed herein do not necessarily state or reflect those of the United States Government or any agency thereof, Argonne National Laboratory, or UChicago Argonne, LLC.
} 
ANL/GTRI/TM-14/2

\section{Analysis of the KUCA Type-A Experiments}

prepared by

G. Aliberti, J. A. Morman, J. G. Stevens, J. Roglans-Ribas

Nuclear Engineering Division, Argonne National Laboratory

January 31, 2013 



\section{SUMMARY}

The Kyoto University Critical Assembly (KUCA) experiments were launched in 2000 at the Kyoto University Research Reactor Institute (KURRI) with the main objective to establish measurement techniques of neutronic parameters in subcritical systems and to investigate the accuracy of the neutronic design of an Accelerator Driven Subcritical Reactor (ADSR). Due to the continuing interest in nonproliferation issues, new studies are being performed on these assemblies with the purpose to investigate the feasibility of converting the KUCA cores to the use of low-enriched uranium (LEU) fuel.

The KUCA facility consists of the solid-moderated and -reflected type-A and -B cores, and the watermoderated and -reflected type- $\mathrm{C}$ core. The present document describes the analysis carried out at Argonne National Laboratory (Argonne) on the KUCA type-A cores. In particular, calculated results of the KUCA ADSR benchmark assemblies and of the feasibility studies on the conversion of the KUCA dry cores from highly-enriched uranium (HEU) to LEU are presented. 


\section{CONTENTS}

SUMMARY . V

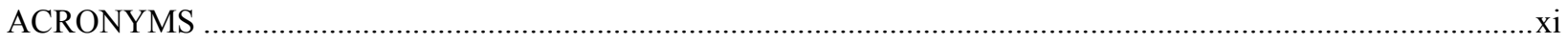

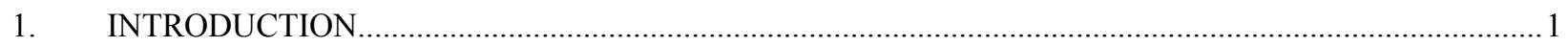

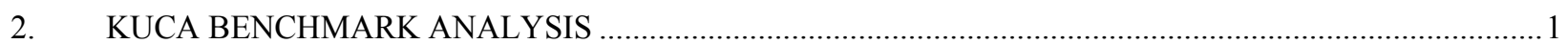

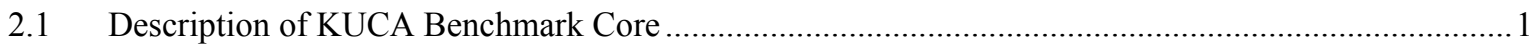

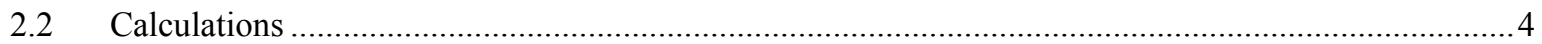

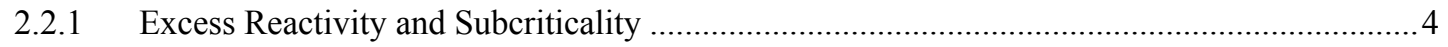

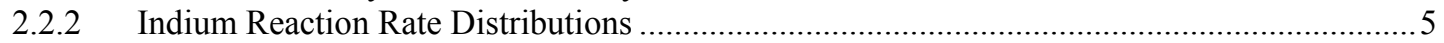

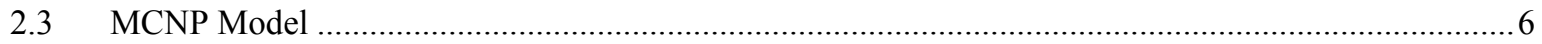

2.4 Approximations, Assumptions and Missing Model ............................................................................... 14

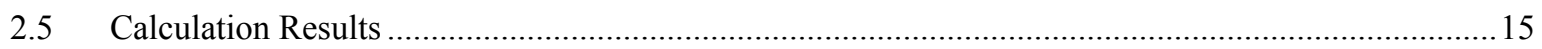

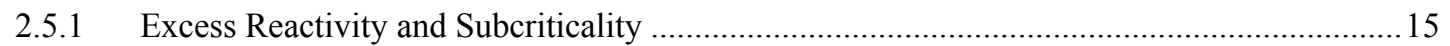

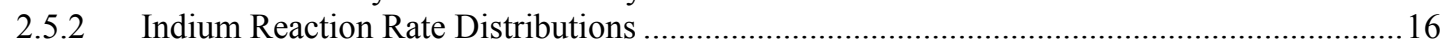

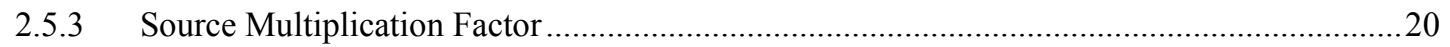

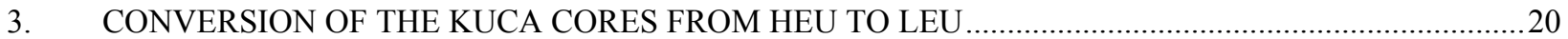

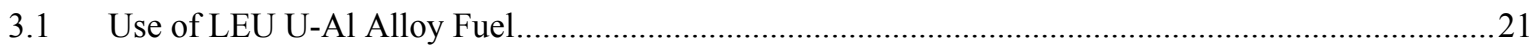

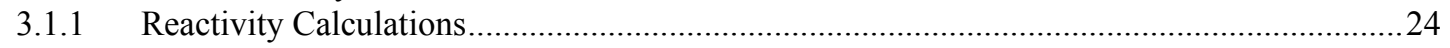

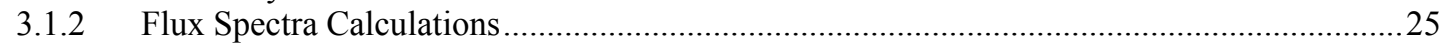

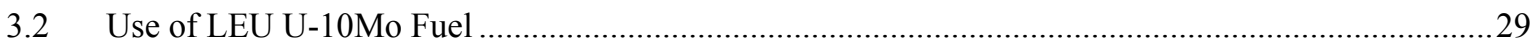

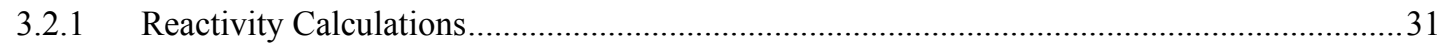

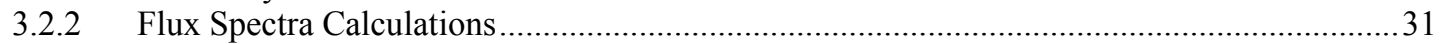

3.3 Feasibility Studies on the Conversion of KUCA Type-A Cores with Different Moderator-to-

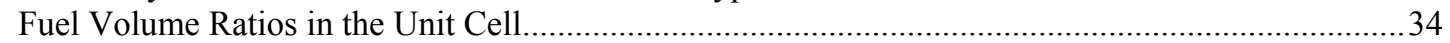

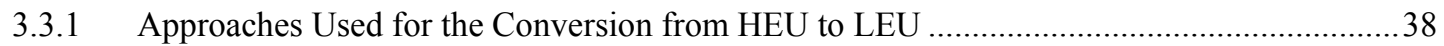

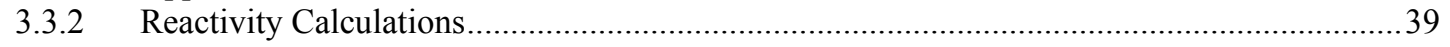

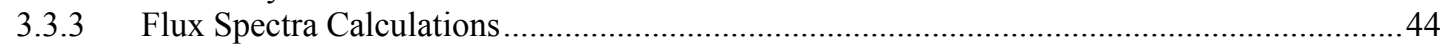

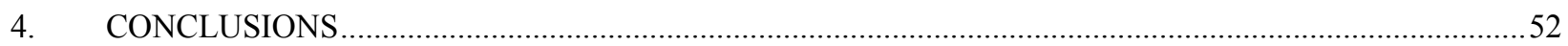

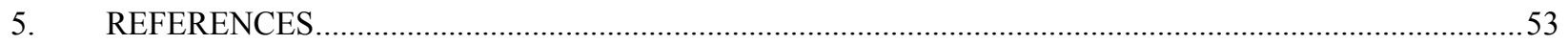

APPENDIX. MCNP INPUT FOR KUCA I-1 WITH SUBCRITICAL ROD CONFIGURATION...........................54 


\section{FIGURES}

Figure 1. No Neutron Shield and No Beam Duct Core (Series-I: Case I-1) ........................................................2

Figure 2. Neutron Shield and Small Beam Duct (s') Core (Series-I: Case I-2)......................................................2

Figure 3. Neutron Shield and Large Beam Duct (s) Core (Series-I: Case I-3) . ..........................................................

Figure 4. Neutron Shield and No Beam Duct Core (Series-I: Case I-4)..................................................................

Figure 5. No Neutron Shield, No Beam Duct and No SV Core (Series-II: Case II-1) . .................................................

Figure 6. No Neutron Shield, No Beam Duct and SV Core (Series-II: Case II-2), ...................................................

Figure 7. No Neutron Shield, Large Beam Duct (s) and SV Core (Series-II: Case II-3)............................................

Figure 8. No Neutron Shield, Small Beam Duct (s') and SV Core (Series-II: Case II-4). .........................................4

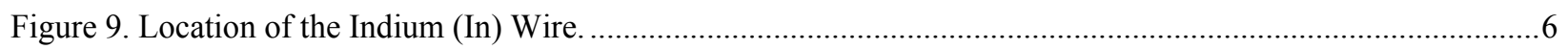

Figure 10. Sideways View of Fuel Assembly "F”...........................................................................................

Figure 11. Sideways View of Fuel Assembly "SV” with Void. ..........................................................................

Figure 12. Sideways View of Partial Fuel Assembly “26”...................................................................................

Figure 13. Description of Fuel "F”, Partial Fuel "26" and Fuel "SV” Assemblies......................................................8

Figure 14. Description of Neutron Shield and Beam Duct "b", "bs" and "bs"'........................................................

Figure 15. Description of Neutron Shield and Beam Duct "f", "fs" and "fs"', ........................................................

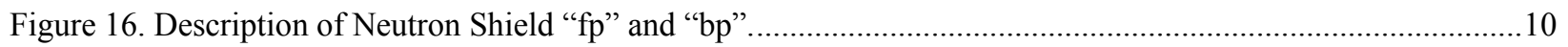

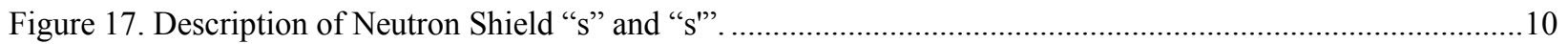

Figure 18. Description of Fuel Assembly at KUCA....................................................................................

Figure 19. Description of Polyethylene (Aluminum) Reflector at KUCA. .............................................................11

Figure 20. Description of the Fuel Assembly, Polyethylene Reflector and Control Rod at KUCA...........................12

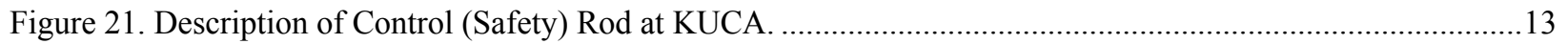

Figure 22. Actual Position of Control (Safety) Rod (Actual Position = Measured Position $-11.4 \mathrm{~cm})$...................13

Figure 23. Adopted Representation of Assembly “12"...........................................................................................14

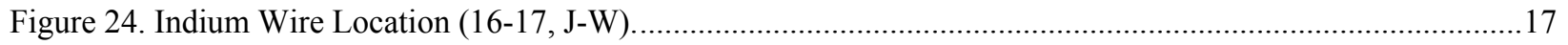

Figure 25. Calculated Indium Absorption Rate Distributions (Case I-1 to Case I-4) in MCNP Units: Rate

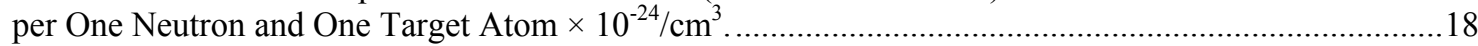

Figure 26. Measured Indium Wire Reaction Rate Distributions along the Vertical Direction Shown in Figures (Case I-1 to Case I-4).

Figure 27. Calculated Indium Absorption Rate Distributions (Case II-1 to Case II-4) in MCNP Units: Rate per One Neutron and One Target Atom $\times 10^{-24} / \mathrm{cm}^{3}$.

Figure 28. Measured Indium Wire Reaction Rate Distributions along the Vertical Direction Shown in Figures (Case II-1 to Case II-4). .....

Figure 29. KUCA Configuration Series-I, Case I-1 with Additional Fuel Assemblies Using U-Al LEU Fuel...........21

Figure 30. KUCA Configuration Series-I, Case I-1 after Adding 56 Fuel Assemblies (KUCA I-1+56). .................22

Figure 31. Configuration Series-I, Case I-2 after Adding 56 Fuel Assemblies (KUCA I-2+56).............................23

Figure 32. KUCA Configuration Series-I, Case I-3 after Adding 56 Fuel Assemblies (KUCA I-3+56)...................23

Figure 33. KUCA Configuration Series-I, Case I-4 after Adding 56 Fuel Assemblies (KUCA I-1+56)..................24 
Figure 34. Flux Spectra at the Positions A and B of KUCA I-1+56 with U-Al LEU Fuel.......................................25

Figure 35. Flux Spectra at the Position B of KUCA I-1 HEU and KUCA I-1+56 with U-Al LEU Fuel. ..................26

Figure 36. Flux Spectra at the Positions A and B of KUCA I-2+56 with U-Al LEU Fuel.......................................26

Figure 37 Flux Spectra at the Position B of KUCA I-2 HEU and KUCA I-2+56 with U-Al LEU Fuel. ....................27

Figure 38. Flux Spectra at the Positions A and B of KUCA I-3+56 with U-A1 LEU Fuel.......................................27

Figure 39. Flux Spectra at the Position B of KUCA I-3 HEU and KUCA I-3+56 with U-Al LEU Fuel...................28

Figure 40. Flux Spectra at the Positions A and B of KUCA I-4+56 with U-Al LEU Fuel........................................28

Figure 41. Flux Spectra at the Position B of KUCA I-4 HEU and KUCA I-4+56 with U-Al LEU Fuel. ..................29

Figure 42. Sideways View of Fuel Assembly "F”" Using LEU U-10Mo Plates without Al Clad................................31

Figure 43. Sideways View of Fuel Assembly "F” Using LEU U-10Mo Plates with Al Clad. ..................................31

Figure 44. Flux Spectra at Positions A and B of KUCA I-1 with LEU U-10Mo and No Cladding...........................32

Figure 45. Flux Spectra at Positions A and B of KUCA I-1 with LEU U-10Mo and Al Cladding............................33

Figure 46. Flux Spectra at Position B of HEU and LEU KUCA I-1 Configurations. .................................................33

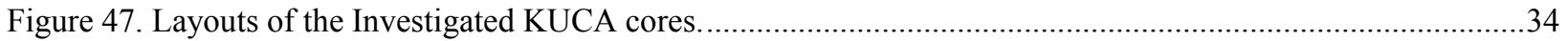

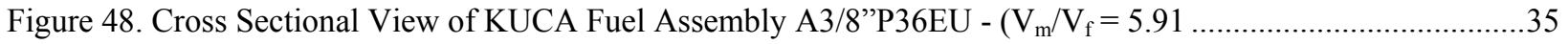

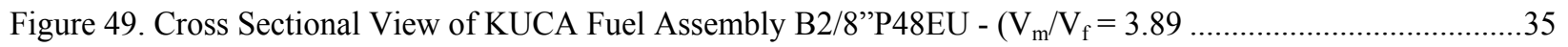

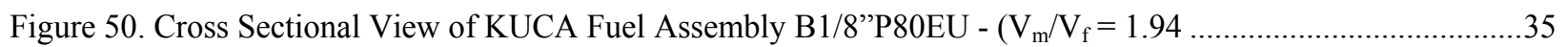

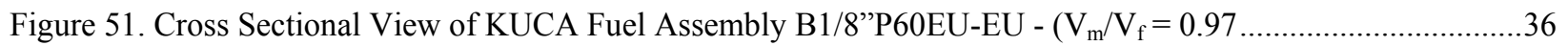

Figure 52. Cross Sectional View of KUCA Fuel Assembly B1/8"P48EU-EU-EU - $\left(\mathrm{V}_{\mathrm{m}} / \mathrm{V}_{\mathrm{f}}=0.65 \ldots \ldots \ldots \ldots \ldots \ldots \ldots \ldots . . . . . . . .36\right.$

Figure 53. KUCA A3/8',P36EU: Detail of Reflector Layout Kept the Same for all Configurations..........................38

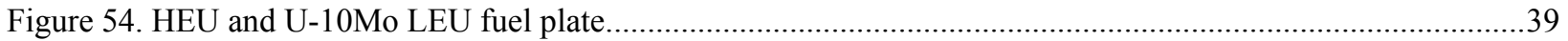

Figure 55. Alternative LEU Fuel Loading for KUCA B1/8'’P60EU-EU and B1/8'’P48EU-EU-EU........................41

Figure 56. Flux Spectra Comparison for the KUCA HEU Configurations. .............................................................45

Figure 57. Flux Spectra Comparison for the KUCA LEU Configurations with the Same H-to-U235 Atom Ratios in the Fuel Unit Cell of the Corresponding HEU Configurations................................................45

Figure 58. Flux Spectra Comparison for the KUCA A3/8''P36EU Configuration in the HEU and LEU Cases with the Same H-to-U235 Atom Ratios $(\mathrm{H} / \mathrm{U} 5=316.45)$ in the Fuel Unit Cell. 46

Figure 59. Flux Spectra Comparison for the KUCA B2/8'P48EU Configuration in the HEU and LEU Cases with the Same H-to-U235 Atom Ratios $(\mathrm{H} / \mathrm{U} 5=206.96)$ in the Fuel Unit Cell.

Figure 60. Flux Spectra Comparison for the KUCA B1/8'"P80EU Configuration in the HEU and LEU Cases with the Same H-to-U235 Atom Ratios (H/U5 = 103.48) in the Fuel Unit Cell.

Figure 61. Flux Spectra Comparison for the KUCA B1/8' 'P60EU-EU Configuration in the HEU and LEU Cases with the Same H-to-U235 Atom Ratios $(\mathrm{H} / \mathrm{U} 5=51.74)$ in the Fuel Unit Cell.

Figure 62. Flux Spectra Comparison for the KUCA B1/8' $\mathrm{P} 48 \mathrm{EU}-\mathrm{EU}-\mathrm{EU}$ Configuration in the HEU and LEU Cases with the Same H-to-U235 Atom Ratios (H/U5 = 34.49) in the Fuel Unit Cell. 48

Figure 63. Flux Spectra Comparison for the KUCA A3/8''P36EU Configuration in the HEU Case and the LEU Cases with Different Thicknesses of the U-10Mo Foil.

Figure 64. Flux Spectra Comparison for the KUCA B1/8' P80EU Configuration in the HEU Case and the LEU Cases with Different Thicknesses of the U-10Mo Foil. 
Figure 65. Flux Spectra Comparison for the LEU KUCA A3/8'P36EU Configuration With and Without Aluminum Edge Around the U-10Mo Foils.

Figure 66. Flux Spectra Comparison for the LEU KUCA B1/8'"P80EU Configuration With and Without Aluminum Edge Around the U-10Mo Foils.

Figure 67. Flux Spectra Comparison for the KUCA B1/8' 'P60EU-EU Configuration with HEU and LEU Loadings of Same $\mathrm{k}_{\mathrm{eff}}$ 


\section{TABLES}

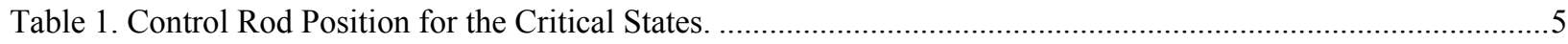

Table 2. Calculated and Measured Reactivity Values [pcm] ...............................................................................15

Table 3. Impact of Nuclear Data on Calculated Reactivity Values [pcm] for the KUCA I-1 Excess

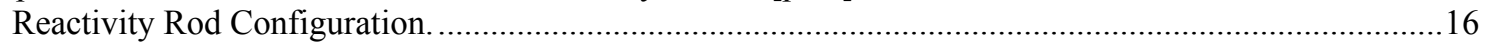

Table 4. Calculated Source Multiplication Factors and Eigenvalues. ......................................................................20

Table 5. Calculated Reactivity [pcm] for the LEU U-Al Configurations.............................................................24

Table 6. Number Densities [at/(barn $\times \mathrm{cm})$ ] of High Enriched (93\%) U-Al, Low Enriched (19.75\%) U-Al

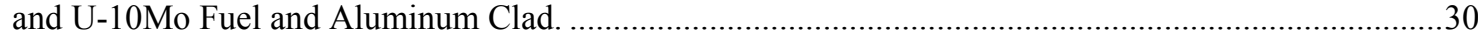

Table 7. Calculated and Measured Reactivity (pcm, using ENDF/B-VII.0 Data)....................................................31

Table 8. Calculated (Experimental) Multiplication Factor Values of HEU and U-10Mo LEU KUCA

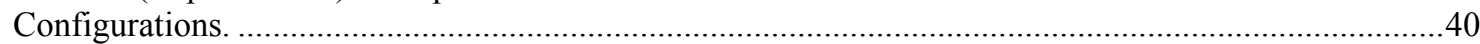

Table 9. Calculated Multiplication Factor Values of U-10Mo LEU KUCA Configurations. ....................................42

Table 10. Calculated Multiplication Factor Values of HEU and LEU KUCA Cores in Reactivity Excess and

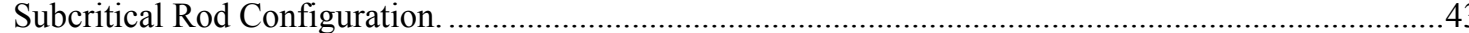

Table 11. Calculated Multiplication Factor Values of the Alternative Loadings of LEU KUCA Cores with Low H/U5 in Excess Reactivity and Subcritical Rod Configuration........................................................43

Table 12. Location of Assemblies for Flux Spectra Determination in the KUCA Cores. ...........................................44

Table 13. Calculated Multiplication Factor Values for KUCA B1/8"P60EU-EU in the Subcritical Rod 


\section{ACRONYMS}

$\begin{array}{ll}\text { ADSR } & \text { Accelerator Driven Subcritical Reactor } \\ \text { DOE } & \text { U. S. Department of Energy } \\ \text { GTRI } & \text { Global Threat Reduction Initiative } \\ \text { HEU } & \text { Highly-enriched Uranium } \\ \text { KUCA } & \text { Kyoto University Critical Assembly } \\ \text { KURRI } & \text { Kyoto University Research Reactor Institute } \\ \text { LEU } & \text { Low-enriched Uranium } \\ \text { MCNP } & \text { Monte Carlo N-Particle }\end{array}$





\section{PRELIMINARY ANALYSIS OF THE KUCA DRY CORE EXPERIMENTS}

\section{INTRODUCTION}

The US Department of Energy (DOE) Global Threat Reduction Initiative (GTRI) research reactor conversion program is part of the global non-proliferation effort to minimize and, to the extent possible, eliminate the use of highly-enriched uranium (HEU) in civil nuclear applications by working to convert research reactors to the use of low-enriched uranium (LEU) fuel throughout the world.

In this frame, the Kyoto University Research Reactor Institute (KURRI) and Argonne National Laboratory (Argonne) established a collaboration to explore the feasibility of converting the Kyoto University Critical Assembly (KUCA) from HEU to LEU.

A series of KUCA experiments was started in 2000 at KURRI with the main objective to establish measurement techniques for neutronics parameters in subcritical systems and to investigate the accuracy of the neutronics designs of an Accelerator Driven Subcritical Reactor (ADSR). The ADSR was primarily conceived for producing energy by transmutation of minor actinides and long-lived fission products and has attracted worldwide attention in recent years because of its safety characteristics and potential for burning plutonium and nuclear waste.

To evaluate the techniques and the ADSR concept, a benchmark was developed and reported by KURRI [1] describing the analysis of several KUCA configurations.

Due to the global interest in non-proliferation issues, new studies are being performed on these configurations with the purpose to investigate the feasibility of converting the KUCA cores to the use of LEU fuel.

The KUCA consists of the solid-moderated and -reflected type-A and -B cores, and of the watermoderated and -reflected type-C core. The present document describes results of the analyses carried out at Argonne on the KUCA type-A cores. In these assemblies, the core is reflected by polyethylene and the fuel region is obtained by stacking highly enriched (93\%) uranium-aluminum (U-Al) alloy and polyethylene plates. With the use of an external pulsed neutron generator, $14 \mathrm{MeV}$ neutrons produced by D-T (deuterium - tritium) reactions are injected into the subcritical core through the polyethylene reflector.

The Argonne analyses of the KUCA benchmark (benchmark specifications, requested calculations, obtained results and comparison with the measurements) are presented in Section 2 along with a detailed description of the MCNP5 model that was developed for the simulation. Section 3 presents the feasibility studies on the conversion of the KUCA dry assemblies to the use of LEU, using both U-Al alloy and U-10Mo fuel plates. Conclusions are summarized in Section 4.

\section{KUCA BENCHMARK ANALYSIS}

KUCA benchmark configurations were developed and reported for the analysis of the solidmoderated and -reflected type-A KUCA cores [1]. After a brief overview of the benchmark specifications and a detailed description of the adopted calculation model, results of the calculations are presented in this section for reactivity's, indium reaction rate distributions and source multiplication factors.

\subsection{Description of KUCA Benchmark Core}

The type-A benchmark configurations for which calculations have been performed are shown in Figures 1 through 8. 
The KUCA cores under study are reflected by polyethylene and the fuel region is obtained by the stacking plates made of $93 \%$ enriched U-Al alloy and polyethylene. The desired level of subcriticality is obtained systematically by insertion of control or safety rods, or both.

A pulsed neutron generator is combined with the A-core for the purpose of injecting $14 \mathrm{MeV}$ pulsed neutrons into the subcritical system through the polyethylene reflector. In some configurations, a neutron shield and a beam duct are installed in the reflector region for directing the high-energy neutrons generated in the tritium target (located outside the polyethylene reflector) to the fuel region. The deuteron beam is accelerated up to $160 \mathrm{keV}$ in beam energy, $4.5 \mathrm{~mA}$ in beam current with a $10 \mu \mathrm{s}$ in pulse width and a $500 \mathrm{~Hz}$ pulse repetition rate. At a lower beam peak intensity of about $0.5 \mathrm{~mA}$ and a pulse width of up to $100 \mu \mathrm{s}$, and the repetition rate can be varied from a few $\mathrm{Hz}$ to $30 \mathrm{kHz}$, providing up to $1 \times 10^{8} \mathrm{n} / \mathrm{s}$.

Activation foils are located in relevant matrix positions, including $(15, \mathrm{~K})$ and at the tritium target (refer to Figures 1 through 8 for assembly locations) for neutron spectrum measurements. The activation foils are $45 \mathrm{~mm} \times 45 \mathrm{~mm}$ with a thickness varying between 3 and $5 \mathrm{~mm}$. Foil materials are selected to cover a range of activation energy values as wide as possible for the $14 \mathrm{MeV}$ neutrons. The experimental results of the reaction rates of all irradiated activation foils are obtained by measuring the total counts of the peak energy of $\gamma$-rays emitted from specific isotopes produced by neutron capture and normalized by the counts of another irradiated foil at the location of the tritium target.

In the present calculations, only the foils contained in the $5 \mathrm{~cm} \times 5 \mathrm{~cm}$ void region of the fuel assembly "SV" (see Section 2.3 for details) have been modeled. In the absence of specific information, no foils have been modeled at the location of the tritium target.

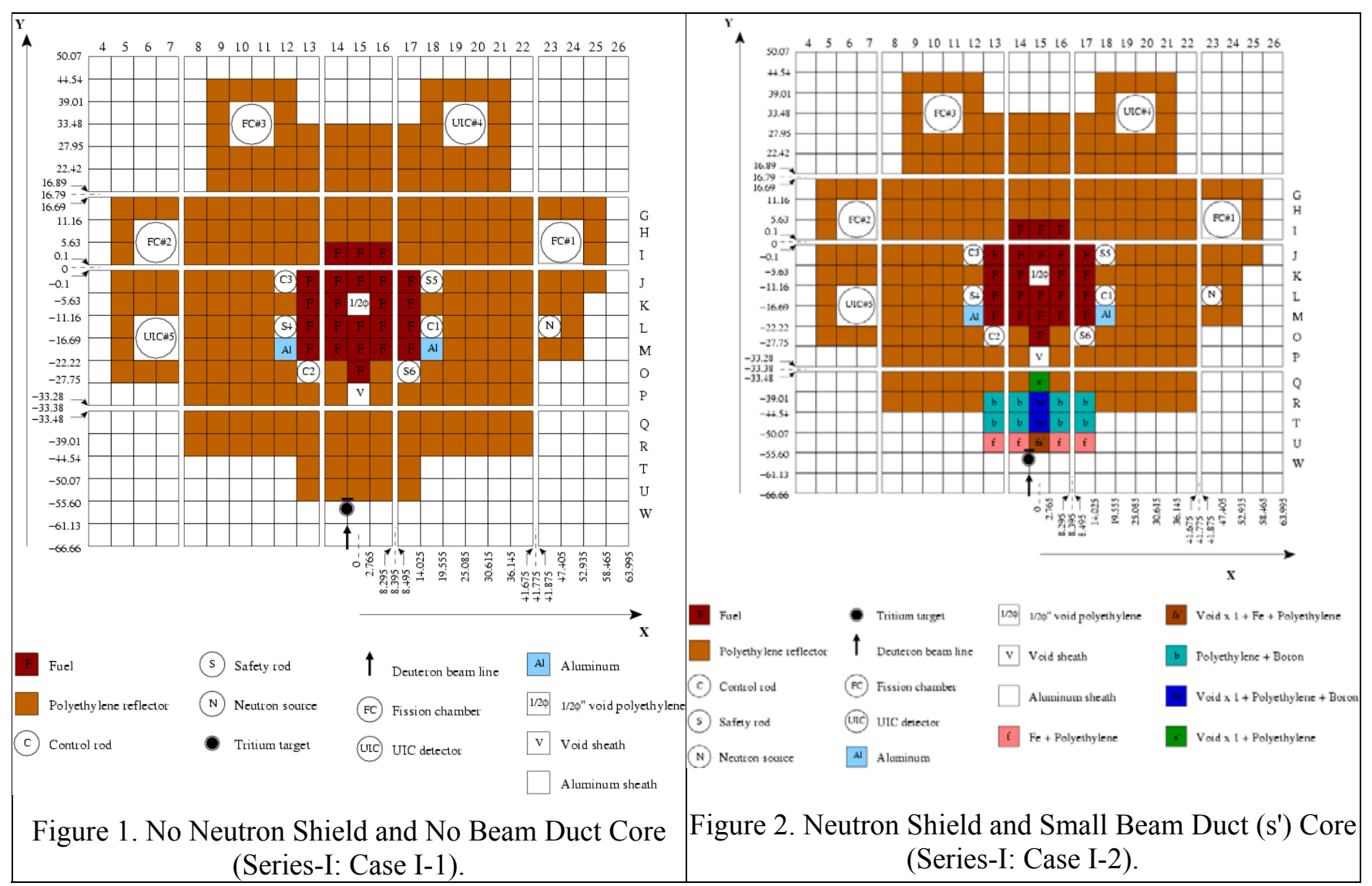




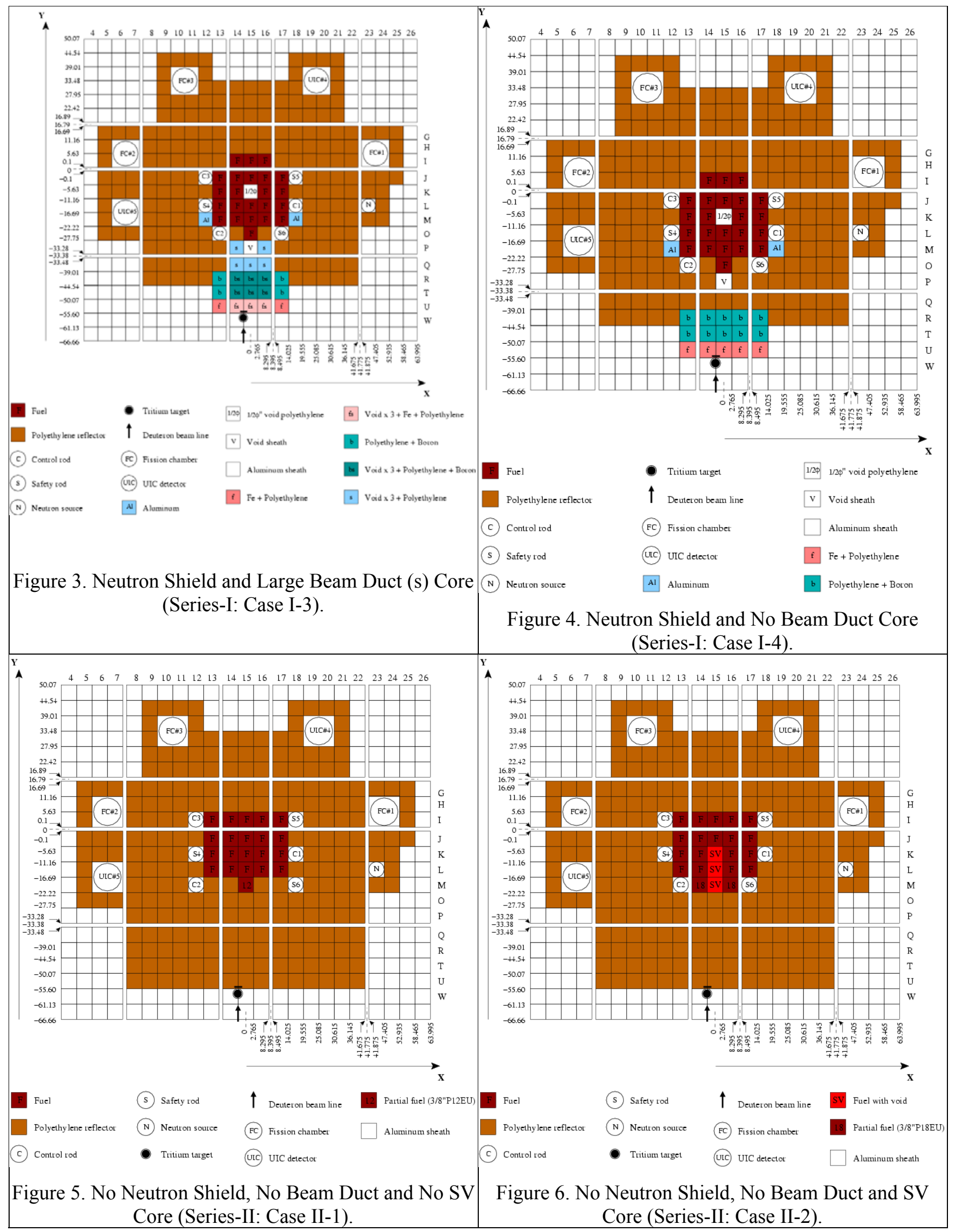




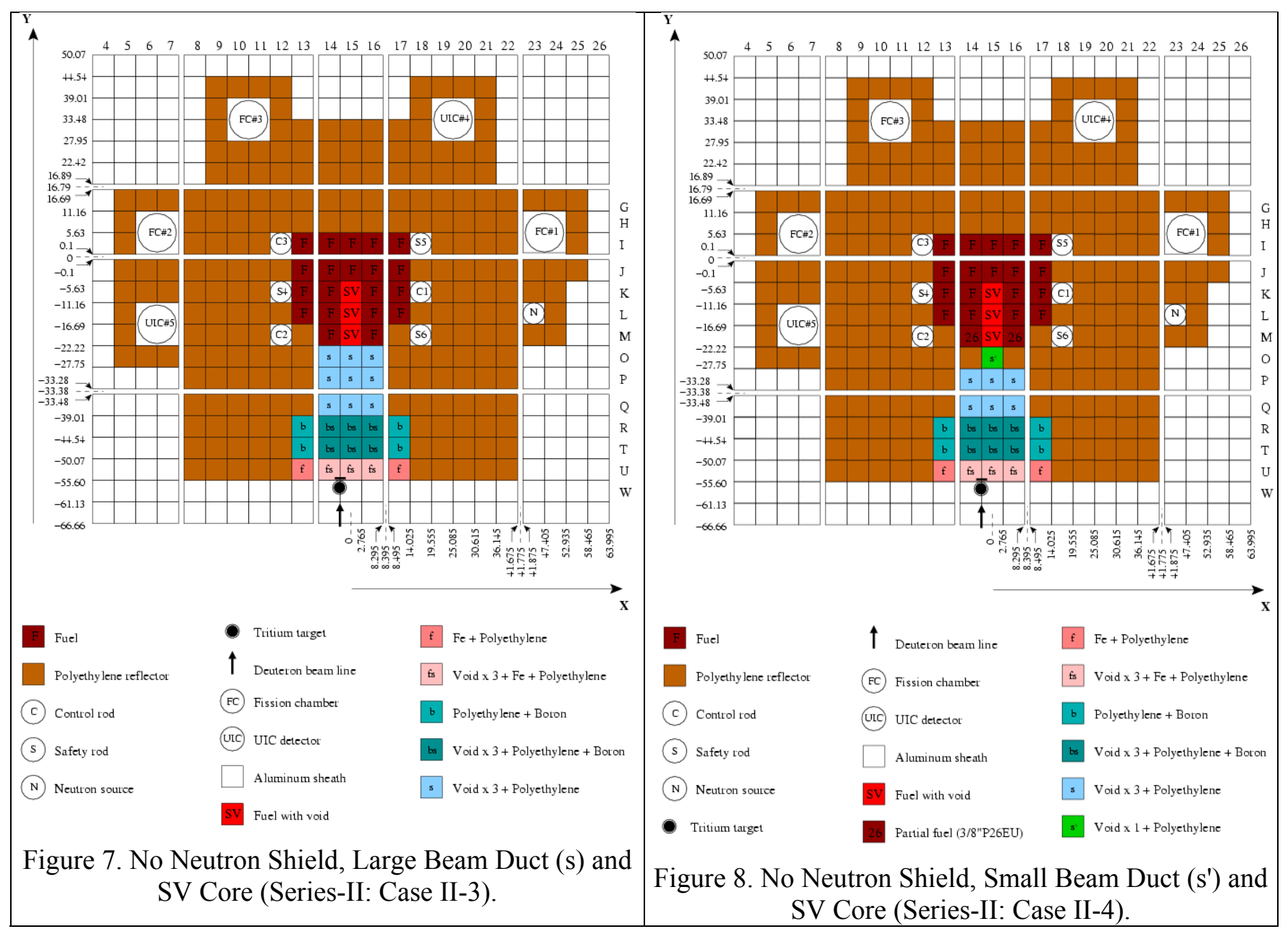

\subsection{Calculations}

The calculations performed for the KUCA benchmarks are essentially for reactivity values and indium reaction rate distributions at selected positions. Details of these calculations are presented in this section.

\subsubsection{Excess Reactivity and Subcriticality}

In the KUCA cores the critical state is maintained by adjusting the positions of the control rods, and the subcritical state is obtained by insertion of the control or safety rods, or both. For eigenvalue calculations, it is necessary to consider the effect of the activation foils set in the void region of the "SV" assemblies shown in Figures 6,7 and 8.

Reactivity calculations were performed with three different control rod configurations:

1. All control and safety rods are fully withdrawn (axial rod position at $Z=120 \mathrm{~cm}$; refer to Section 2.3 for details on control and safety rods). In this document, this case is referred as the "excess reactivity" control rod configuration.

2. All safety rods are completely withdrawn and control rods $\mathrm{C} 1, \mathrm{C} 2$ and $\mathrm{C} 3$ are fully inserted (axial rod position at $Z=11.4 \mathrm{~cm}$; refer to Section 2.3 for details on control and safety rods). In this document, this case is referred as the "subcritical" control rod configuration. 
3. All safety rods are completely withdrawn and the control rods are at the measured critical position as indicated in Table 1 for each configuration.

Table 1. Control Rod Position for the Critical States.

\begin{tabular}{|l|c|c|c|c|}
\hline Configuration & C1 $(\mathrm{mm})$ & C2 $(\mathrm{mm})$ & C3 $(\mathrm{mm})$ & S4-S6 $(\mathrm{mm})$ \\
\hline KUCA I-1 & U.L. ${ }^{(*)}$ & U.L. & 524.34 & U.L. \\
\hline KUCA I-2 & U.L. & U.L. & 548.21 & U.L. \\
\hline KUCA I-3 & U.L. & U.L. & 745.54 & U.L. \\
\hline KUCA I-4 & U.L. & U.L. & 525.52 & U.L. \\
\hline KUCA II-1 & U.L. & U.L. & 635.94 & U.L. \\
\hline KUCA II-2 & 637.48 & U.L. & U.L. & U.L. \\
\hline KUCA II-3 & U.L. & U.L. & 742.48 & U.L. \\
\hline KUCA II-4 & U.L. & U.L. & 553.24 & U.L. \\
\hline (*) U.L.: Upper Limit (1200 mm) \\
\hline
\end{tabular}

\subsubsection{Indium Reaction Rate Distributions}

Reaction rate distributions were calculated along the indium (In) wire (1.5-mm diameter and $60-\mathrm{cm}$ long) that is set at the axial (vertical) position (between 16,J-W and 17,J-W) shown in Figures 1 through 8 (see details in Figure 9). The experimental results of the In wire are obtained by measuring total counts of the peak energy of $\gamma$-rays emitted from ${ }^{115} \operatorname{In}\left(n, n^{\prime}\right){ }^{115 m}$ In reactions and normalized by the counts of another irradiated In foil $\left(20 \times 20 \times 1 \mathrm{~mm}^{3}\right)$ set at the location of the tritium target. 


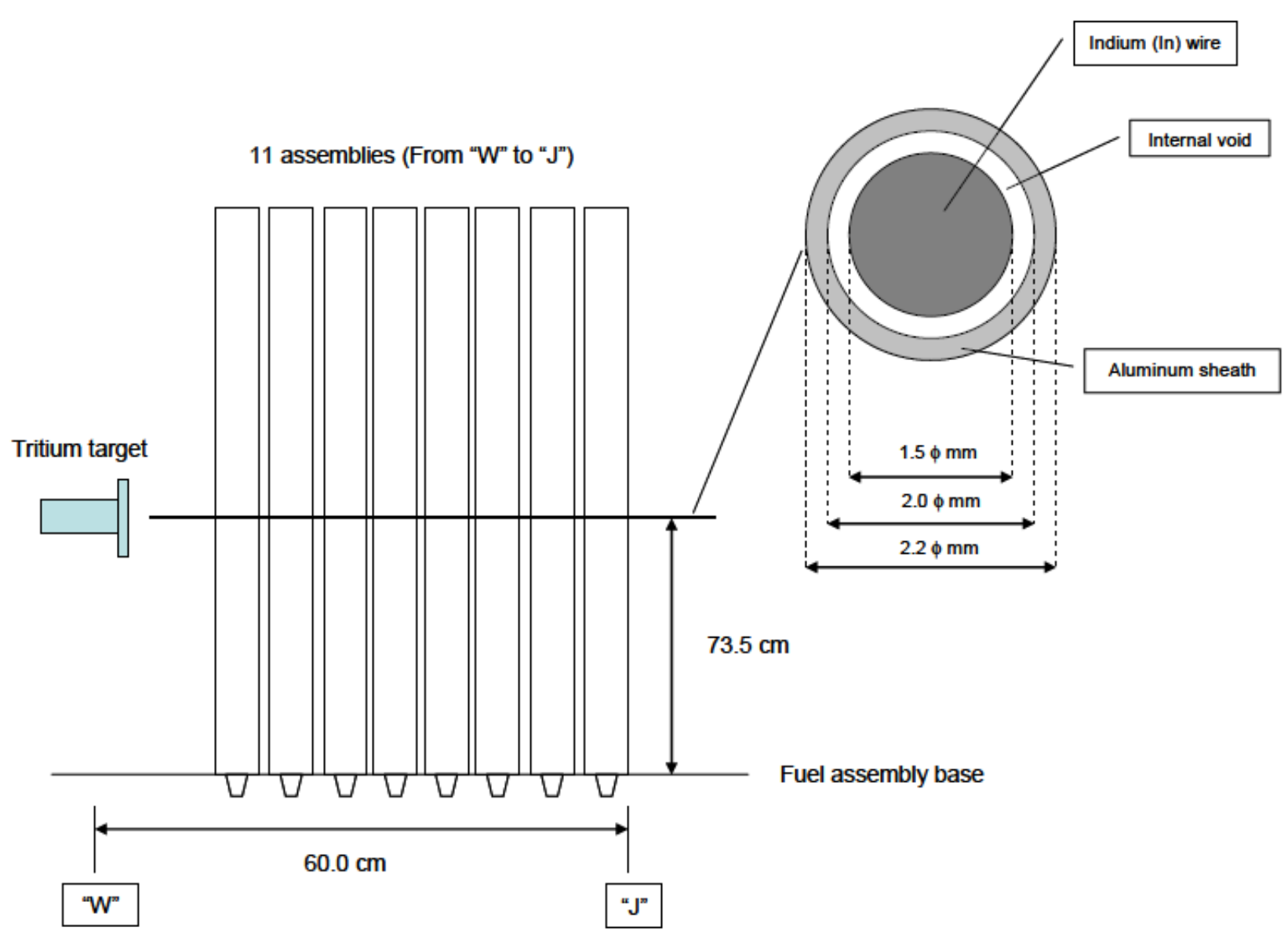

Figure 9. Location of the Indium (In) Wire.

\subsection{MCNP Model}

Calculations were performed using MCNP Version 5 with ENDF/B-VII.0 cross sections, plus several comparison calculations using other cross section sets. Models were developed to accurately represent each component of the fuel, control rods, safety rods and reactor structures.

The materials used in the KUCA cores are in the form of rectangular parallelepipeds, nominally 2-in. square. with thicknesses ranging between 1/16 in. and 2 in. The upper and lower parts of the fuel assemblies are polyethylene reflector layers more than 50-cm long, as shown in Figures 10 through 13. The reference fuel assemblies are formed of 2 -in. x 2-in. square unit cells having one $93 \%$ enriched U-Al plate, 1/16-in. thick, and two polyethylene plates of 1/8-in. thick and 1/4-in. thick (see Figures 10 through 12). Multiple unit cells are placed together to form the core region of each assembly. In the absence of details on the axial locations, the $\mathrm{Ni}, \mathrm{Al}, \mathrm{Fe}$ and In foils used for spectrum measurements have been placed exactly at the center of the void region of the "SV" assembly (see Figure 11). The functional height of the core is approximately $40 \mathrm{~cm}$. The MCNP model was developed by explicitly describing all single $\mathrm{U}-\mathrm{Al}$ and polyethylene plates.

The tritium target is not located at the center of the core. To compensate for this, a neutron shield and beam duct is installed in the polyethylene radial reflector region. The main purpose of installing the neutron shield and the beam duct is to direct the largest possible number of high-energy neutrons generated in the target region to the center of the core. For shielding the high-energy and thermal neutrons, the neutron shield consists of several materials inserted into the core, as shown in Figures 14 through 17: the iron $(\mathrm{Fe})$ is for shielding the high-energy neutrons generated in the target region by inelastic scattering reactions and the polyethylene containing $10 \mathrm{wt} \%$ boron is for shielding the thermal neutrons, moderated by scattering reactions in the reflector region. The beam duct for directing the 
collimated high-energy neutrons to the core region by streaming effect is constructed as shown in Figures $13,14,15$ and 17.

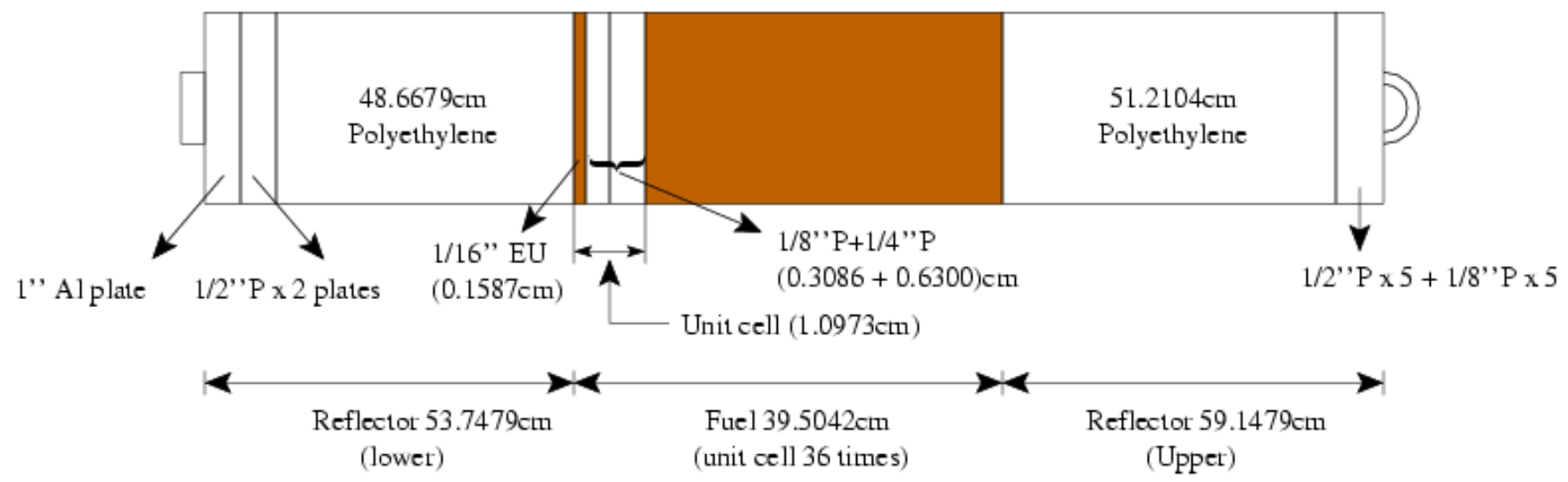

Figure 10. Sideways View of Fuel Assembly "F".

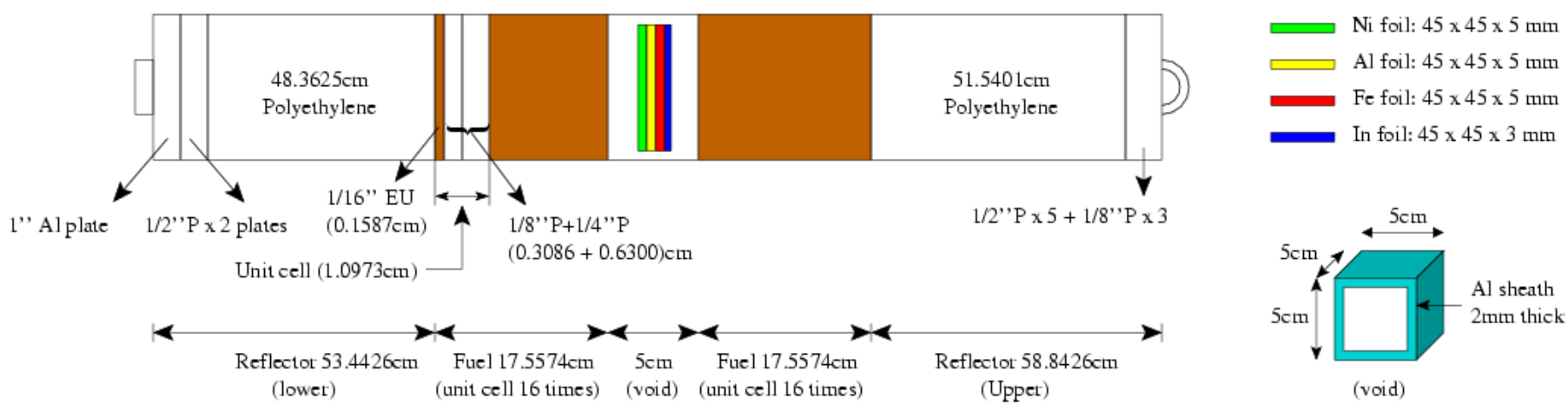

Figure 11. Sideways View of Fuel Assembly "SV” with Void.

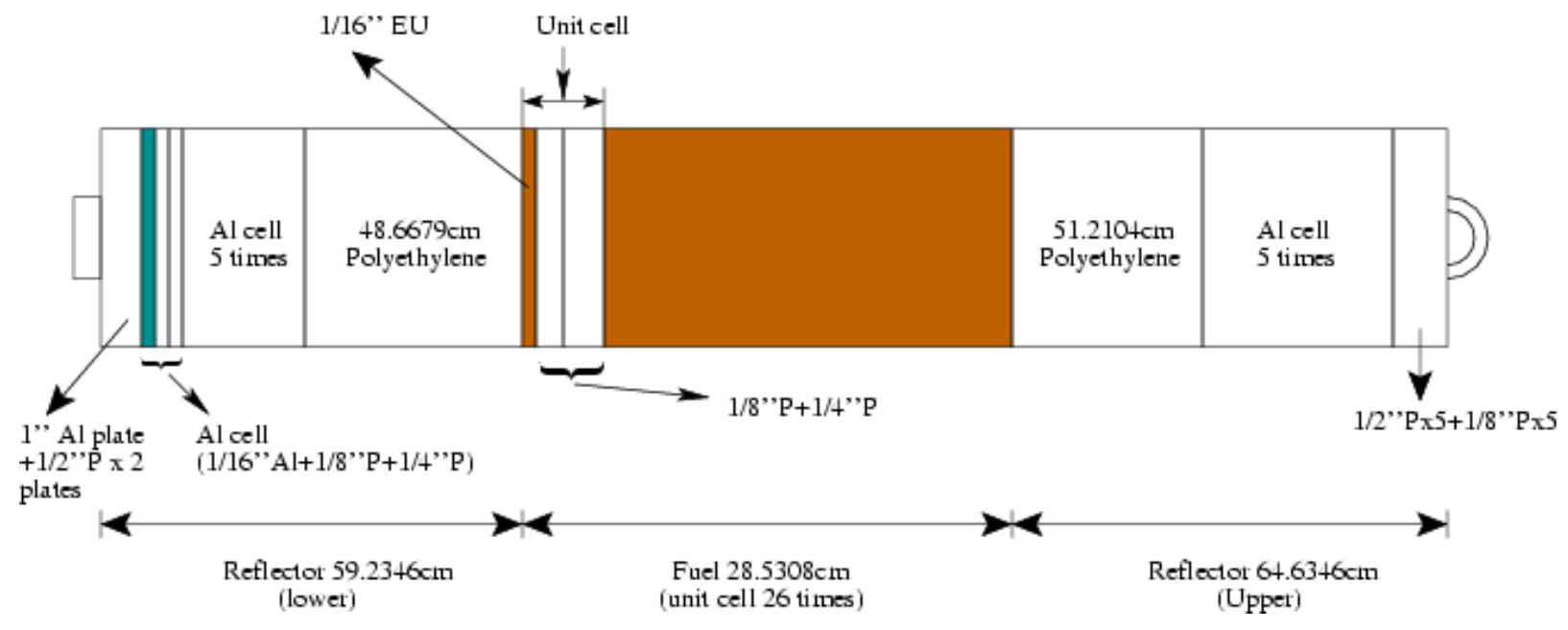

Figure 12. Sideways View of Partial Fuel Assembly "26”. 


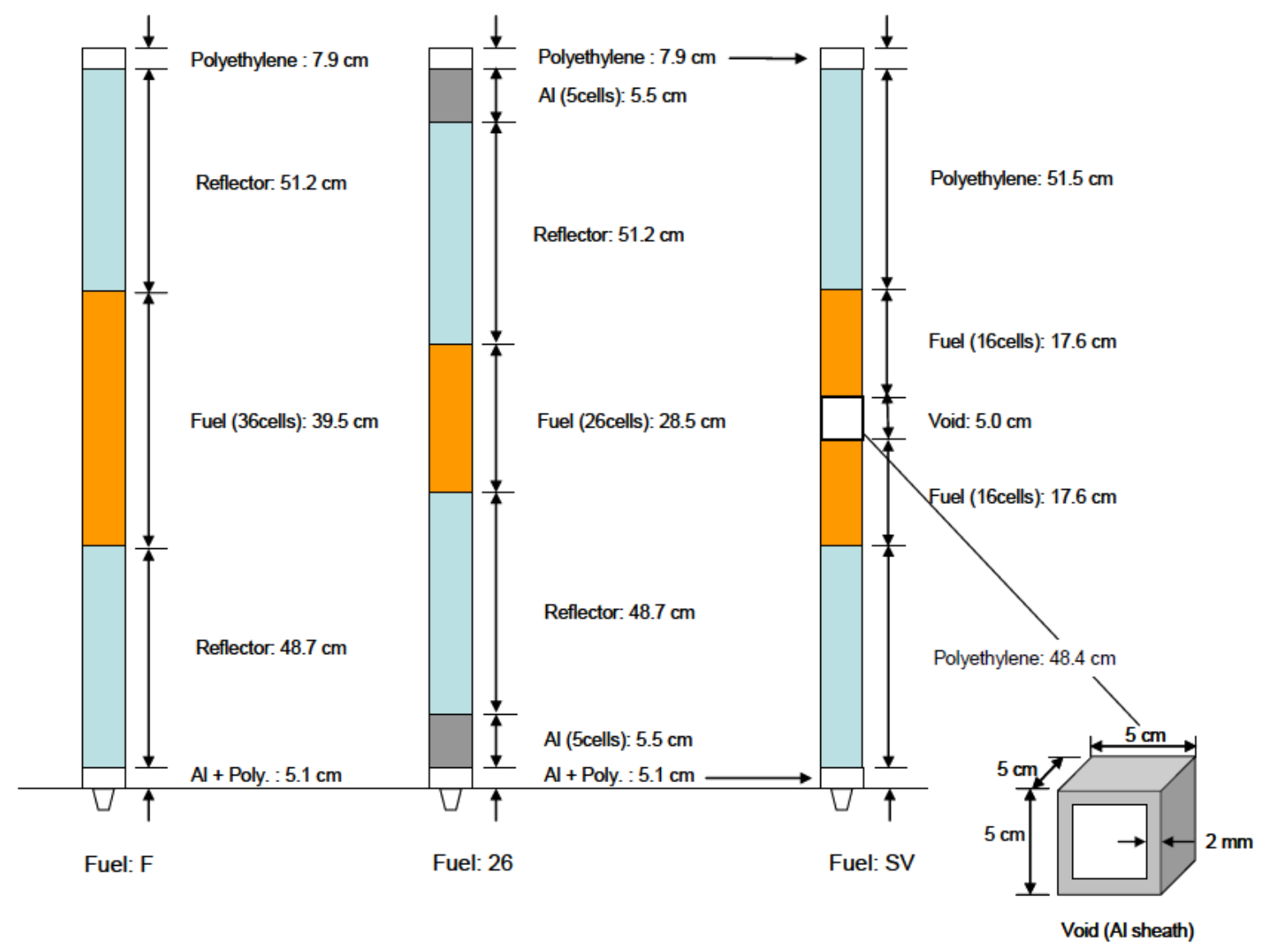

Figure 13. Description of Fuel "F", Partial Fuel "26" and Fuel "SV" Assemblies. 


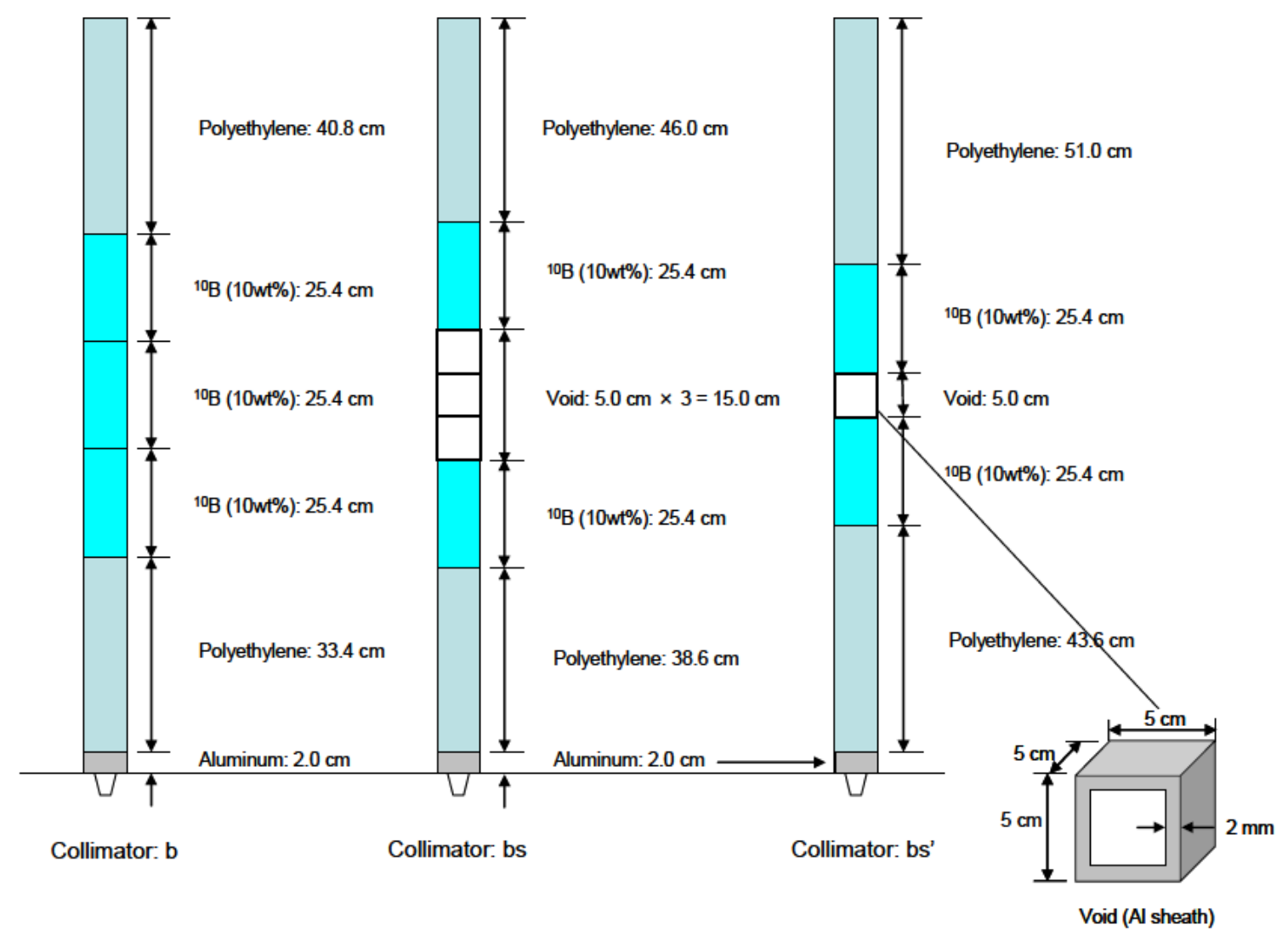

Figure 14. Description of Neutron Shield and Beam Duct "b", "bs" and "bs"”.

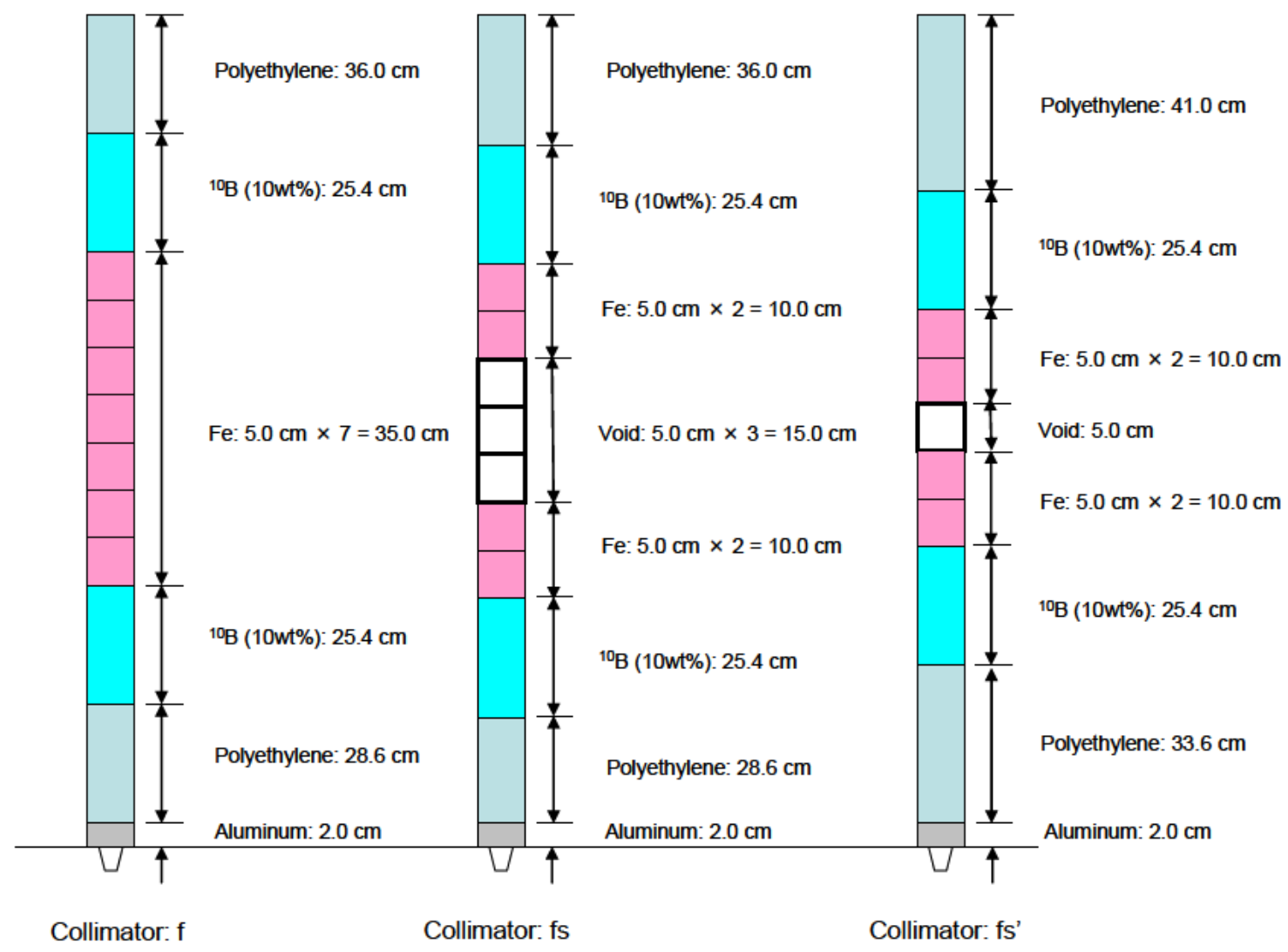

Figure 15. Description of Neutron Shield and Beam Duct "f", "fs" and "fs"'. 


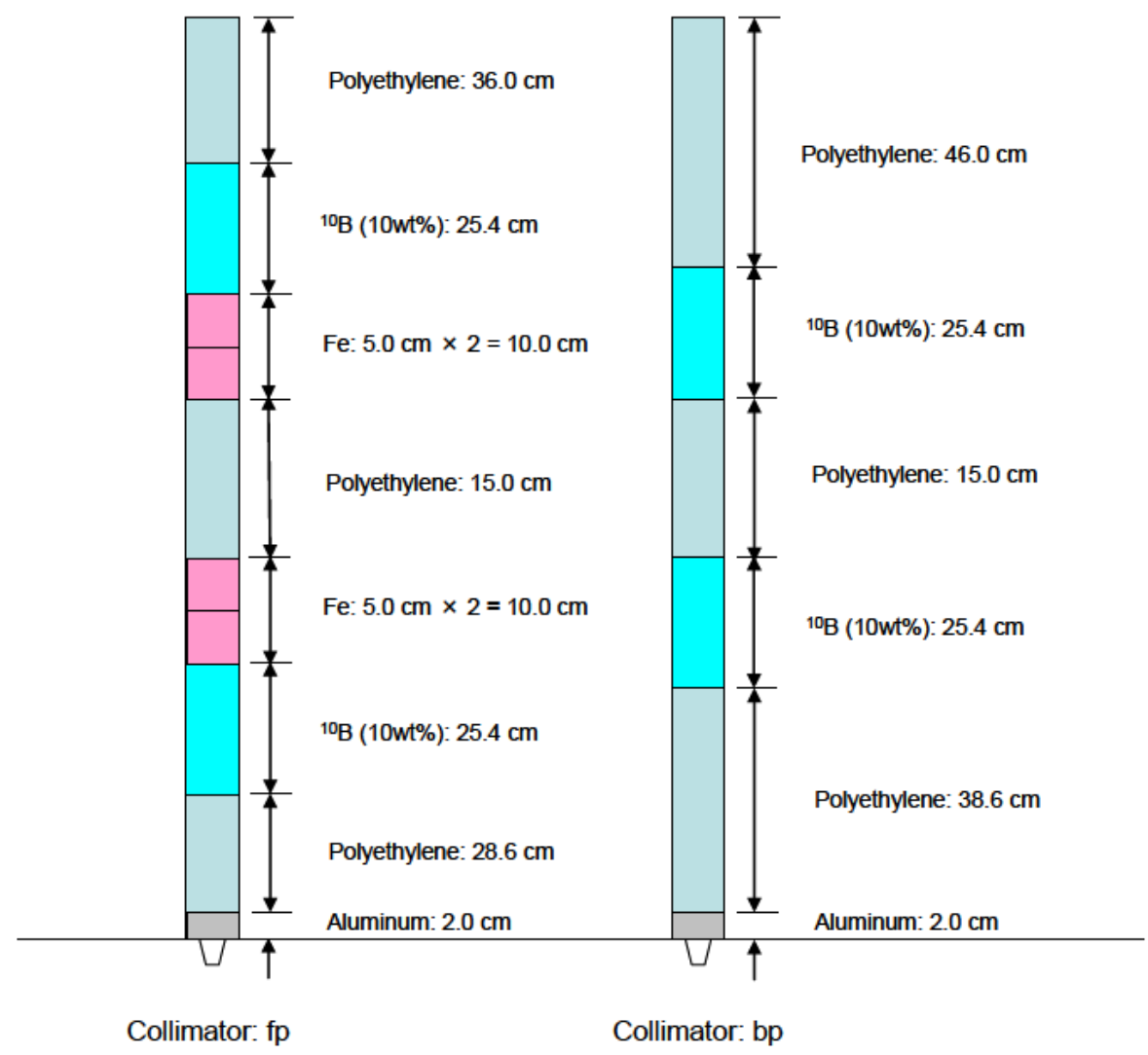

Figure 16. Description of Neutron Shield "fp" and "bp".

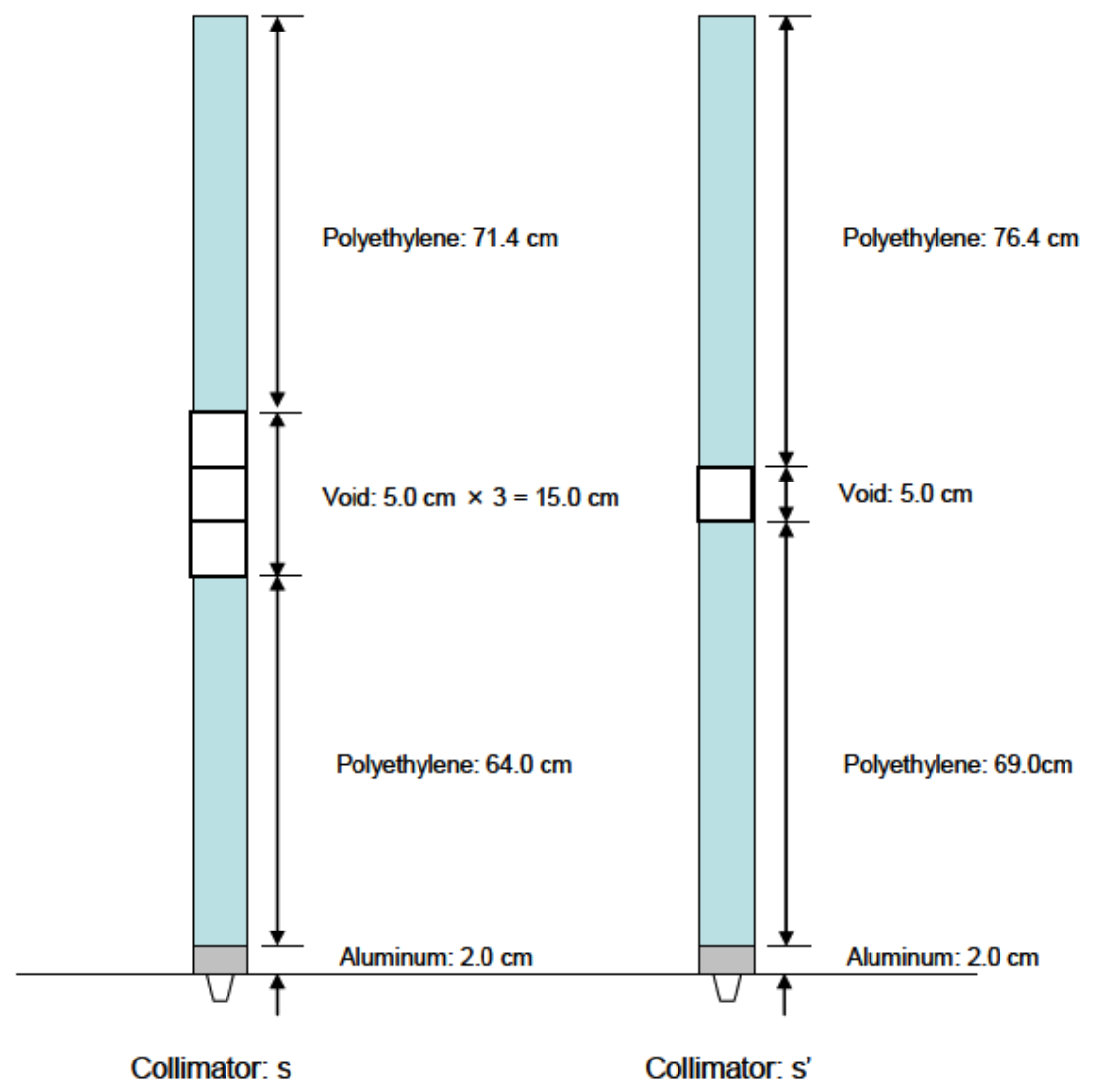

Figure 17. Description of Neutron Shield "s" and "s"'. 
All fuel and reflector/shield rods are inserted in aluminum tubes as shown in Figures 18 and 19. These tubes are generally separated by 1-mm gap. However, referring to Figures 1 through 8, the gap separating assemblies 7-8, 13-14, 16-17, and 22-23 along the vertical direction and the gap separating assemblies F-G, I-J, and P-Q along the horizontal direction, is increased to $3 \mathrm{~mm}$. These details are shown in Figure 20.

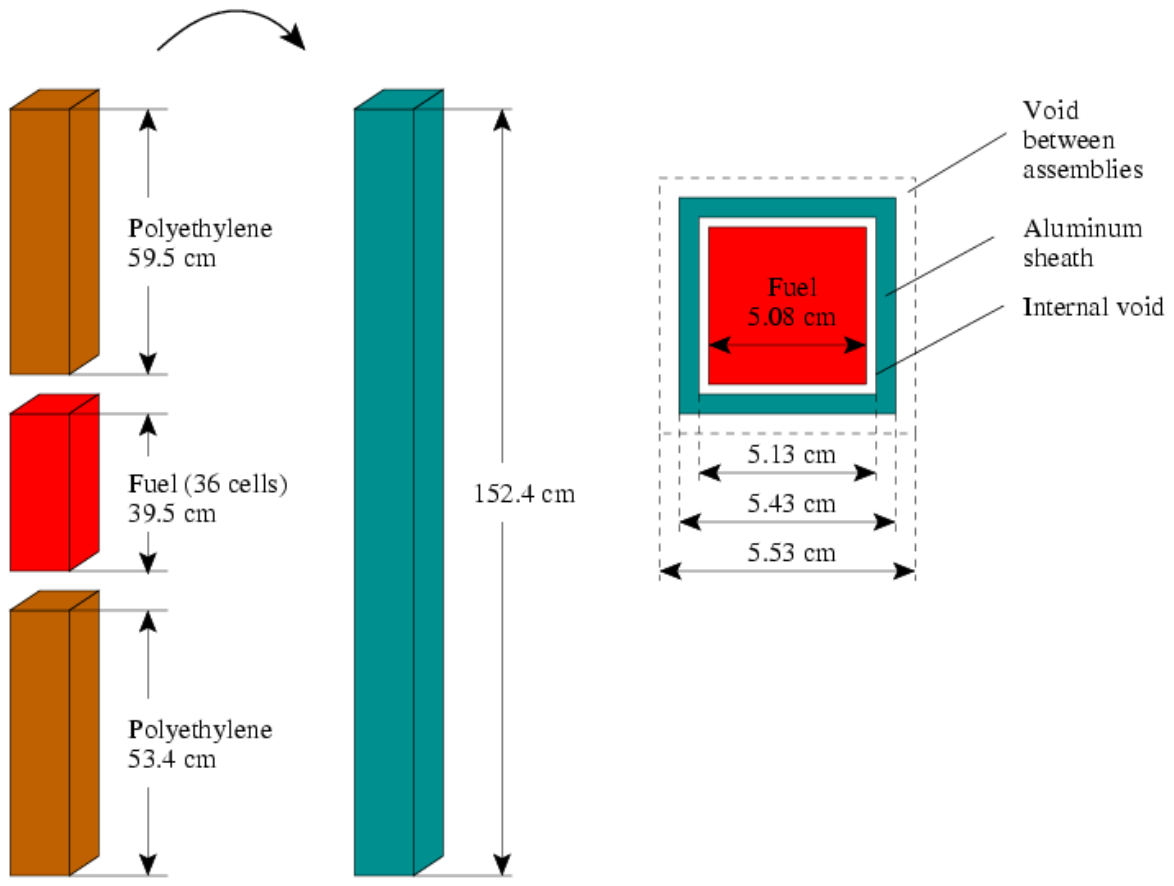

Figure 18. Description of Fuel Assembly at KUCA.

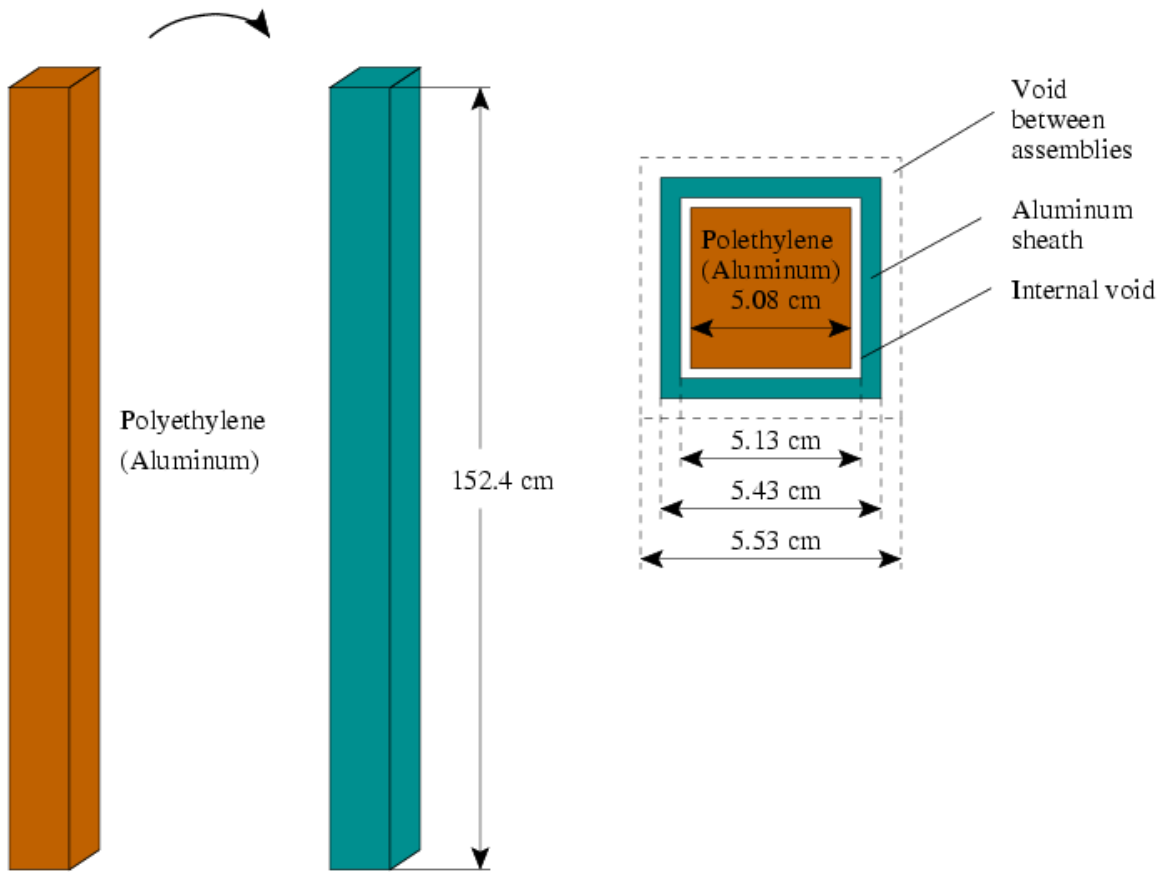

Figure 19. Description of Polyethylene (Aluminum) Reflector at KUCA. 


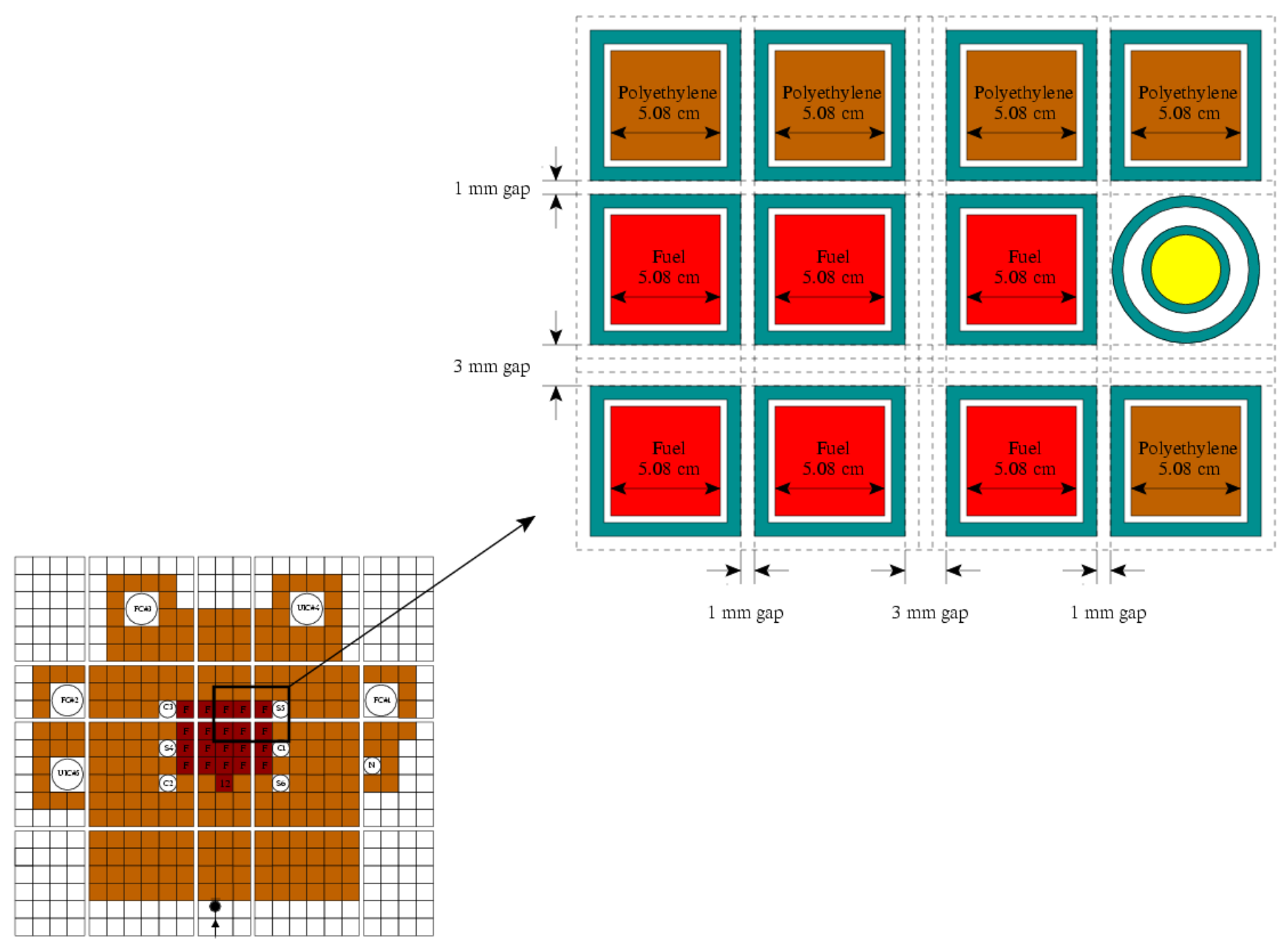

Figure 20. Description of the Fuel Assembly, Polyethylene Reflector and Control Rod at KUCA.

According to the benchmark specifications, the control and safety rods are modeled as shown in Figure 21. Figure 22 gives a schematic representation for the specification of the control rod position. It is noted that the zero point of the measured rod position is the upper surface of the $\mathrm{Al}$ on the shock absorber that is $11.4 \mathrm{~cm}$ above the fuel assembly base. 


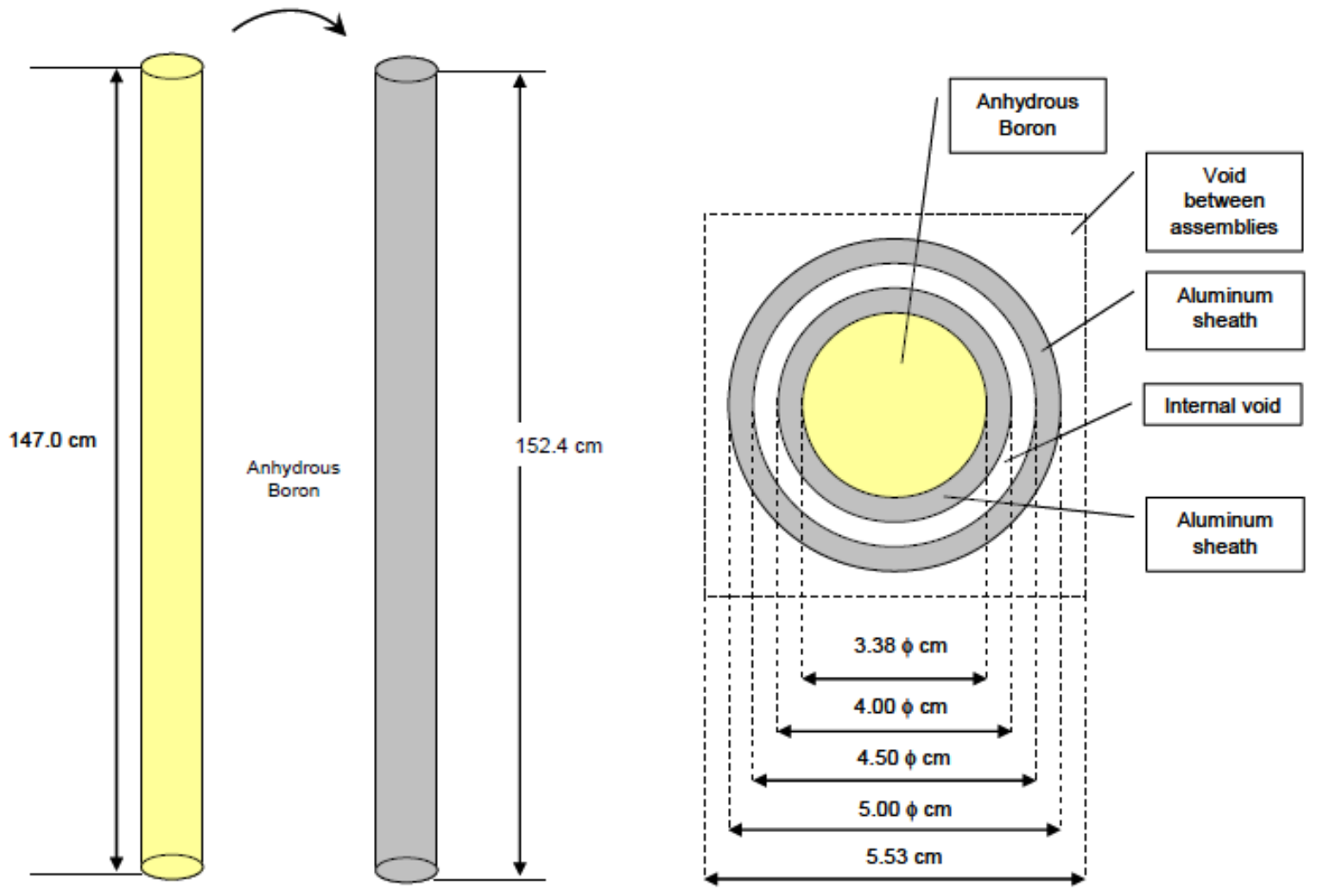

Figure 21. Description of Control (Safety) Rod at KUCA.

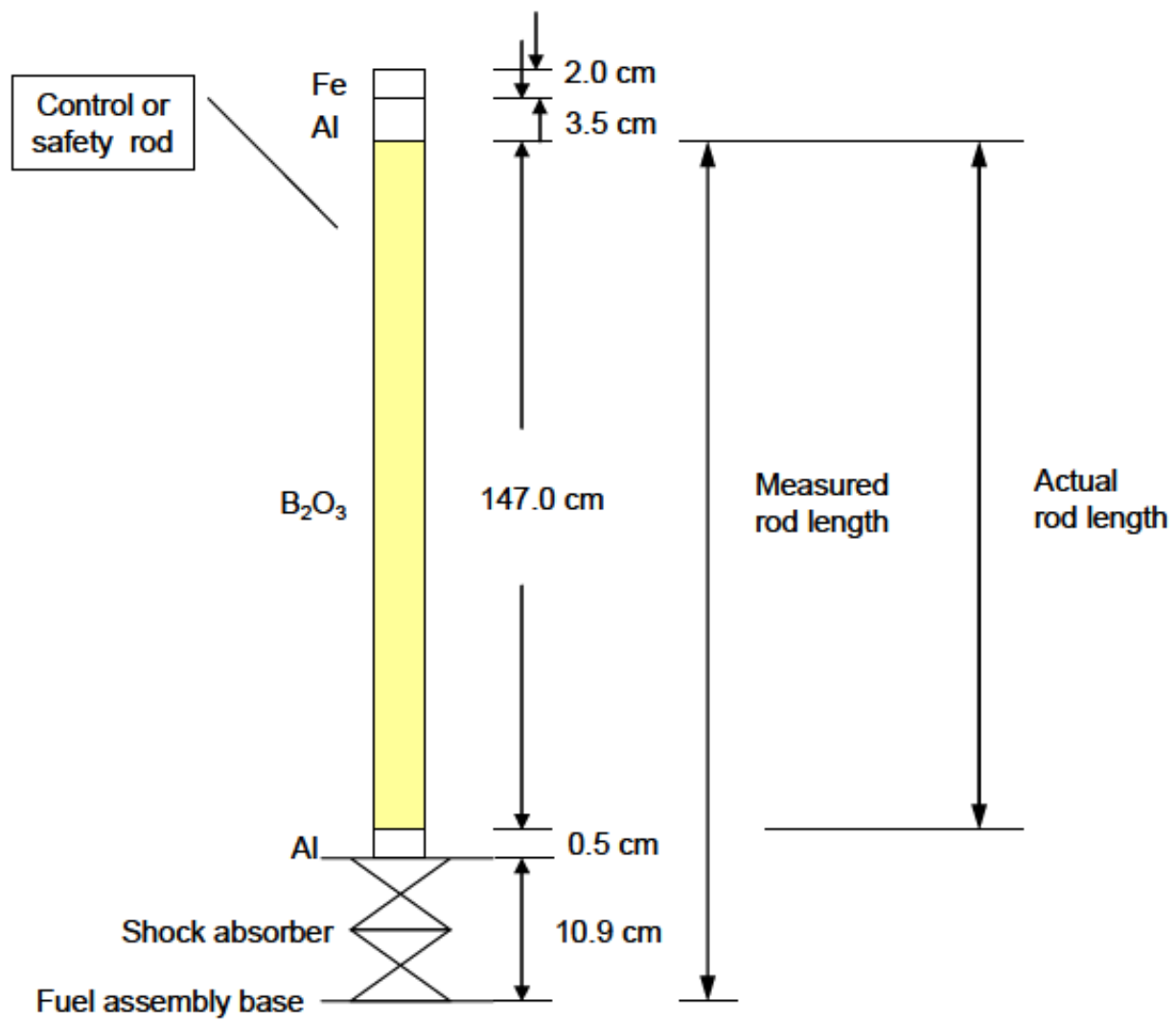

Figure 22. Actual Position of Control (Safety) Rod (Actual Position $=$ Measured Position $-11.4 \mathrm{~cm}$ ). 


\subsection{Approximations, Assumptions and Missing Model}

The compositions for the In wire and for the Fe parts of the assemblies $\mathrm{f}, \mathrm{fs}, \mathrm{fs}$ ' and $\mathrm{fp}$ are missing in the benchmark report [1]. In the present calculations, these compositions are assumed to be the same as the In and Fe foils, respectively.

Compositions for the Ni foil are also missing. In the present calculations, this foil is assumed to be of pure Ni (atom density: 9.14401E-02 at/barn-cm).

Apparently, from the benchmark specifications, all fuel and reflector assemblies (including the assemblies with the neutron shield and beam duct, such as assemblies SV, bs', fs' and s') are inserted into the aluminum tubes. By doing so, the beam duct would be obstructed by the 5-mm thick aluminum sheets that form the tube. It must be determined if any window is open in these aluminum sheets (sides of tubes) so that the beam duct would have a $5 \mathrm{~cm} \times 5 \mathrm{~cm}$ opening without any obstruction along the entire sequence of assemblies $(15, \mathrm{U})$ to $(15, \mathrm{~K})$, and the model would be refined accordingly.

More details are needed to clarify exactly how the foils are arranged in the axial direction of the void region of assemblies "SV." Information is needed particularly on those foils at the target location that have not been modeled in the present calculations.

Since no information was provided on the assemblies containing fission chambers and UIC detectors (see Figures 1 through 8 ) these assemblies are assumed to be completely voided. On the other hand, assembly "N", that is apparently associated with a "neutron source" (see legends of Figures 1 through 8), has been simply replaced by polyethylene reflector. The assumptions made for the assemblies mentioned above should have zero or negligible impact on the calculated results.

The representation of the partial fuel assemblies can be based on the example of Assembly " 26 " given in the benchmark specifications as shown in Figure 12. However, for partial fuel assemblies with a number of fuel cells other than 26, it is not clear if one has to preserve the number of Al cells or the length of the polyethylene blocks above and below the fuel region. In the present calculations, the length of the polyethylene blocks was preserved. See for instance Figure 23 for the assumed representation of Assembly "12”.

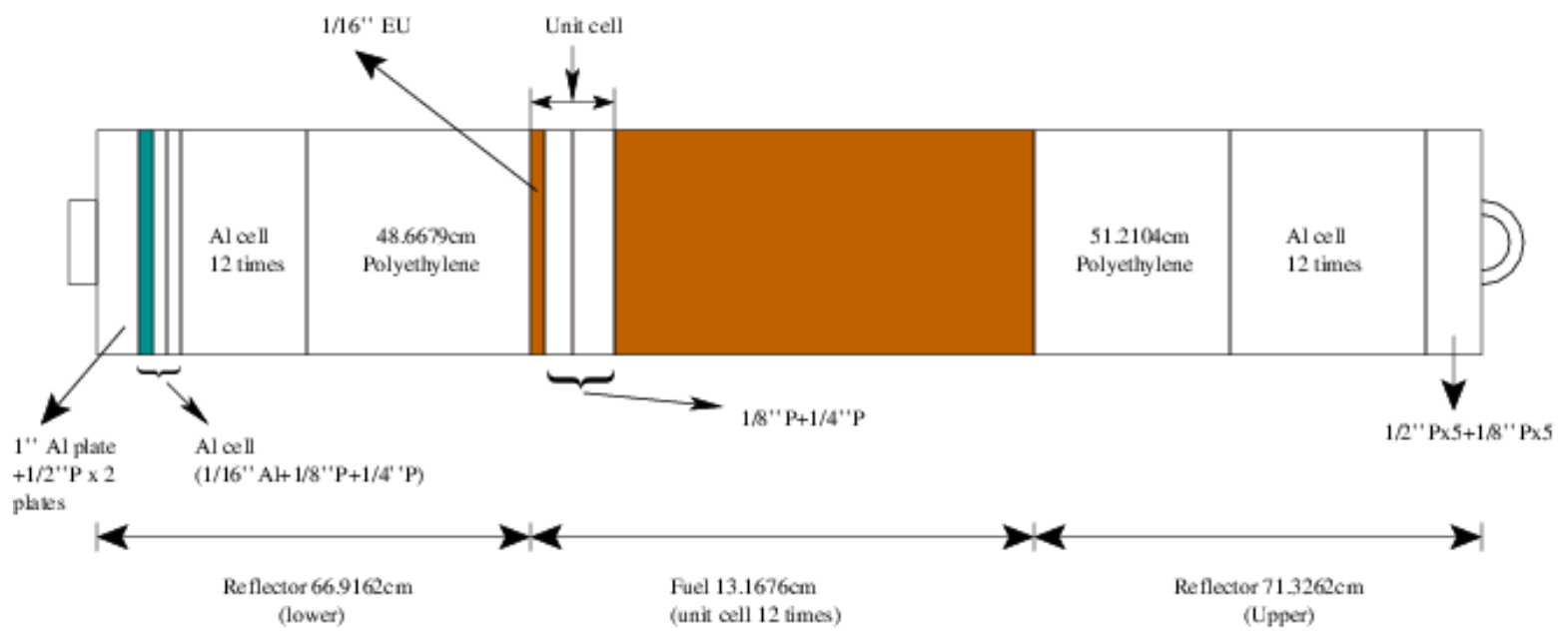

Figure 23. Adopted Representation of Assembly "12”. 


\subsection{Calculation Results}

This section presents the results of the present calculations for reactivity values and indium reaction rate distributions. Additional calculations were carried out for the analysis of the source multiplication factor, $\mathrm{k}_{\mathrm{s}}$, of the KUCA cores.

\subsubsection{Excess Reactivity and Subcriticality}

The reactivity values obtained for each configuration and for the rod positions described in Section 2.2.1 are presented in Table 2 together with the experimental results.

Table 2. Calculated and Measured Reactivity Values [pcm].

\begin{tabular}{|c|c|c|c|}
\hline Configuration & Rod Configuration & Experiment & MCNP5* \\
\hline \multirow{3}{*}{ KUCA I-1 } & Excess Reactivity & $+295 \pm 21$ & $746 \pm 8$ \\
\hline & Subcriticality & $-904 \pm 63$ & $-371 \pm 8$ \\
\hline & Critical & $0 \pm$ & $446 \pm 8$ \\
\hline \multirow{3}{*}{ KUCA I-2 } & Excess Reactivity & $+293 \pm 21$ & $695 \pm 6$ \\
\hline & \begin{tabular}{|l|} 
Subcriticality \\
\end{tabular} & $-925 \pm 65$ & $-415 \pm 6$ \\
\hline & Critical & $0 \pm$ & $422 \pm 6$ \\
\hline \multirow{3}{*}{ KUCA I-3 } & Excess Reactivity & $+20 \pm 1$ & $445 \pm 6$ \\
\hline & Subcriticality & $-1171 \pm 82$ & $-616 \pm 6$ \\
\hline & Critical & $0 \pm$ & $396 \pm 6$ \\
\hline \multirow{3}{*}{ KUCA I-4 } & Excess Reactivity & $+296 \pm 21$ & $746 \pm 6$ \\
\hline & Subcriticality & $-907 \pm 63$ & $-368 \pm 6$ \\
\hline & Critical & $0 \pm$ & $441 \pm 6$ \\
\hline \multirow{3}{*}{ KUCA II-1 } & Excess Reactivity & $143 \pm 10$ & $776 \pm 6$ \\
\hline & \begin{tabular}{|l|} 
Subcriticality \\
\end{tabular} & $-793 \pm 56$ & $-42 \pm 6$ \\
\hline & Critical & $0 \pm$ & $641 \pm 6$ \\
\hline \multirow{3}{*}{ KUCA II-2 } & Excess Reactivity & $246 \pm 17$ & $856 \pm 6$ \\
\hline & \begin{tabular}{|l|} 
Subcriticality \\
\end{tabular} & $-677 \pm 47$ & $-18 \pm 6$ \\
\hline & Critical & $0 \pm$ & $595 \pm 6$ \\
\hline \multirow{3}{*}{ KUCA II-3 } & Excess Reactivity & $37 \pm 3$ & $564 \pm 6$ \\
\hline & Subcriticality & $-893 \pm 63$ & $-343 \pm 6$ \\
\hline & Critical & $0 \pm$ & $507 \pm 6$ \\
\hline \multirow{3}{*}{ KUCA II-4 } & Excess Reactivity & $232 \pm 16$ & $934 \pm 6$ \\
\hline & Subcriticality & $-702 \pm 49$ & $48 \pm 6$ \\
\hline & Critical & $0 \pm$ & $714 \pm 6$ \\
\hline
\end{tabular}

There is a consistent discrepancy of approximately $400-500 \mathrm{pcm}$ between the calculated and experimental results for all KUCA configurations from Series I and of approximately $500-700$ pcm for all KUCA configurations from Series II. It is however important to emphasize the fact that the foils located in the void region of the fuel assemblies "SV" of the KUCA configurations II-2, II-3 and II-4 have a reactivity effect of about $800 \mathrm{pcm}$. 
In an attempt to investigate the observed discrepancies in the reactivity values, calculations were also performed with different data libraries. As shown in Table 3, for the KUCA I-1 "excess reactivity" configuration (all control and safety rods fully withdrawn) the use of JEF3.1 and ENDF/B-VI.6 data lead to about the same results obtained with the ENDF/B-VII.0 library. Only with ENDF/B-VI.0 data is the obtained reactivity value about $200 \mathrm{pcm}$ smaller than with the other libraries, reducing the discrepancy with the measured value to about $300 \mathrm{pcm}$. From these results it is concluded that the use of different nuclear data libraries would not have a significant impact on the discrepancies observed in Table 2 between the calculated and experimental results.

Note that ENDF/B-VII.0 data were used for all subsequent calculation results discussed in this report.

Table 3. Impact of Nuclear Data on Calculated Reactivity Values [pcm] for the KUCA I-1 Excess Reactivity Rod Configuration.

\begin{tabular}{|c|c|c|}
\hline Cross Section Set & Experiment & MCNP5 \\
\hline ENDF\B-VII.0 & \multirow{4}{*}{$+295 \pm 21$} & $746 \pm 8$ \\
\hline ENDF $\backslash B-V I .6$ & & $766 \pm 5$ \\
\hline ENDF $\backslash \mathrm{B}-\mathrm{VI} .0$ & & $589 \pm 6$ \\
\hline JEF3.1 & & $799 \pm 6$ \\
\hline
\end{tabular}

\subsubsection{Indium Reaction Rate Distributions}

According to the benchmark specifications, indium reaction rate distributions were calculated along the indium wire located at the core midplane between columns 16-17 from rows J-W with a $(\mathrm{d}, \mathrm{t})$ source at the tritium target location. Figure 24 shows the exact locations between columns 16 and 17 where the reaction rates were obtained.

The reaction rate distributions were calculated for the "subcritical" control rod configuration (all control rods $\mathrm{C} 1, \mathrm{C} 2$ and $\mathrm{C} 3$ fully inserted and the safety rods completely withdrawn). For the configuration KUCA II-4 the source calculation was not possible, since even full insertion of control rods $\mathrm{C} 1, \mathrm{C} 2$ and $\mathrm{C} 3$ does not bring the calculated reactivity to a negative value (subcritical state).

For the calculation of the indium reaction rate distributions, the $(d, t)$ neutron source was represented in the MCNP model as a $14 \mathrm{MeV}$ neutron source that was uniformly distributed inside a cylinder of 2.25 $\mathrm{cm}$ radius and $0.30 \mathrm{~cm}$ height, at the location of the tritium target shown in the layouts of the KUCA configurations.

For both the Series I and II configurations, the calculated indium reaction rate distributions show a similar trend with respect to the measured ones, particularly in the fuel zone (see Figures 25 through 28). In the reflector/shield region the calculations show a depression in the distributions that in some cases is not seen in the measurements and that requires further investigations. 


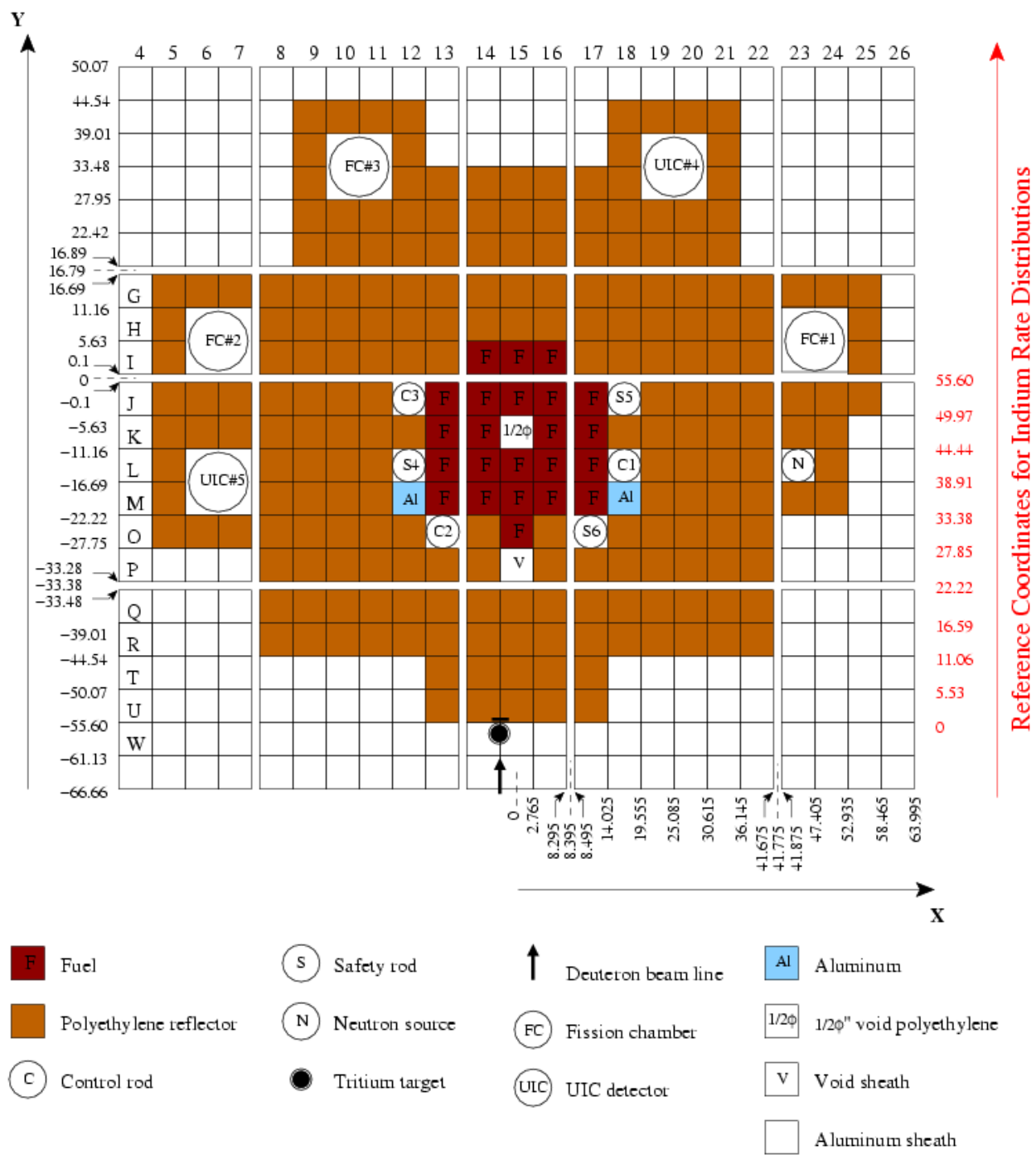

Figure 24. Indium Wire Location (16-17, J-W). 


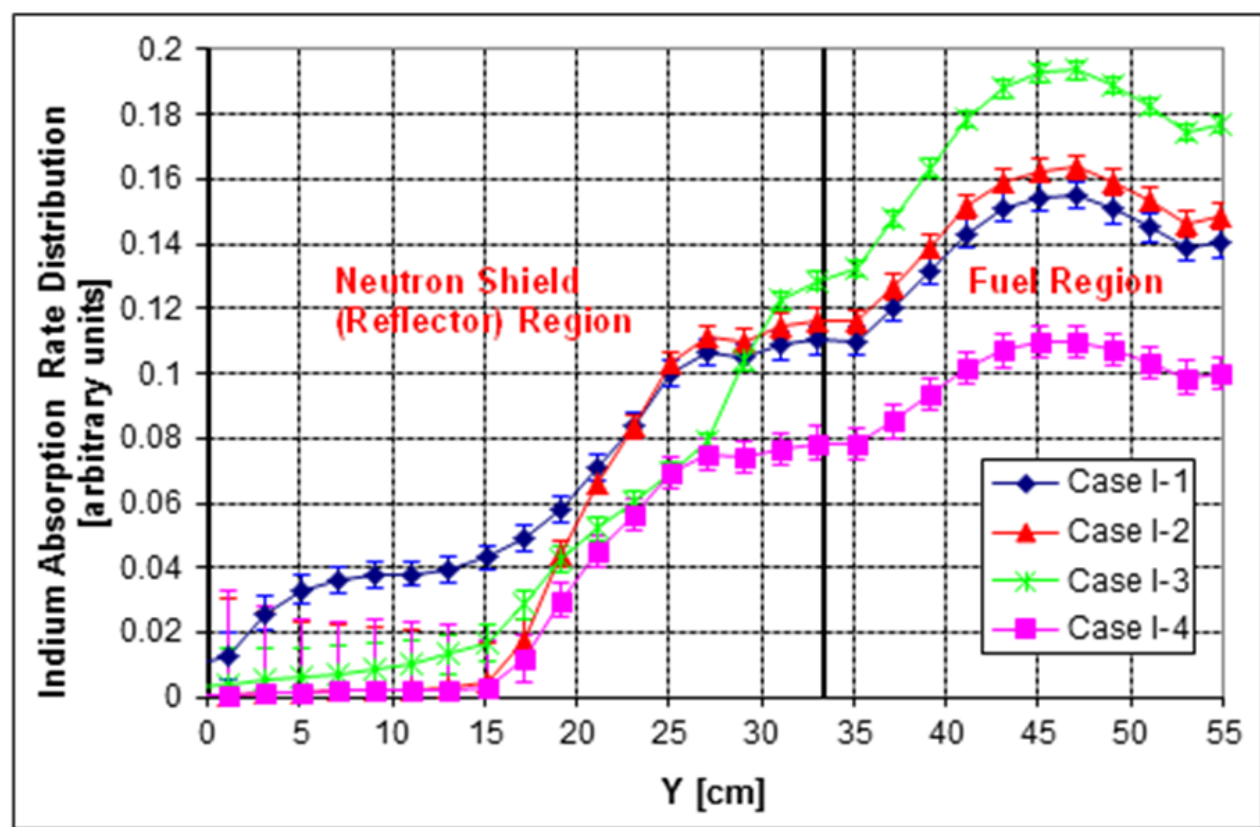

Figure 25. Calculated Indium Absorption Rate Distributions (Case I-1 to Case I-4) in MCNP Units: Rate per One Neutron and One Target Atom $\times 10^{-24} / \mathrm{cm}^{3}$.

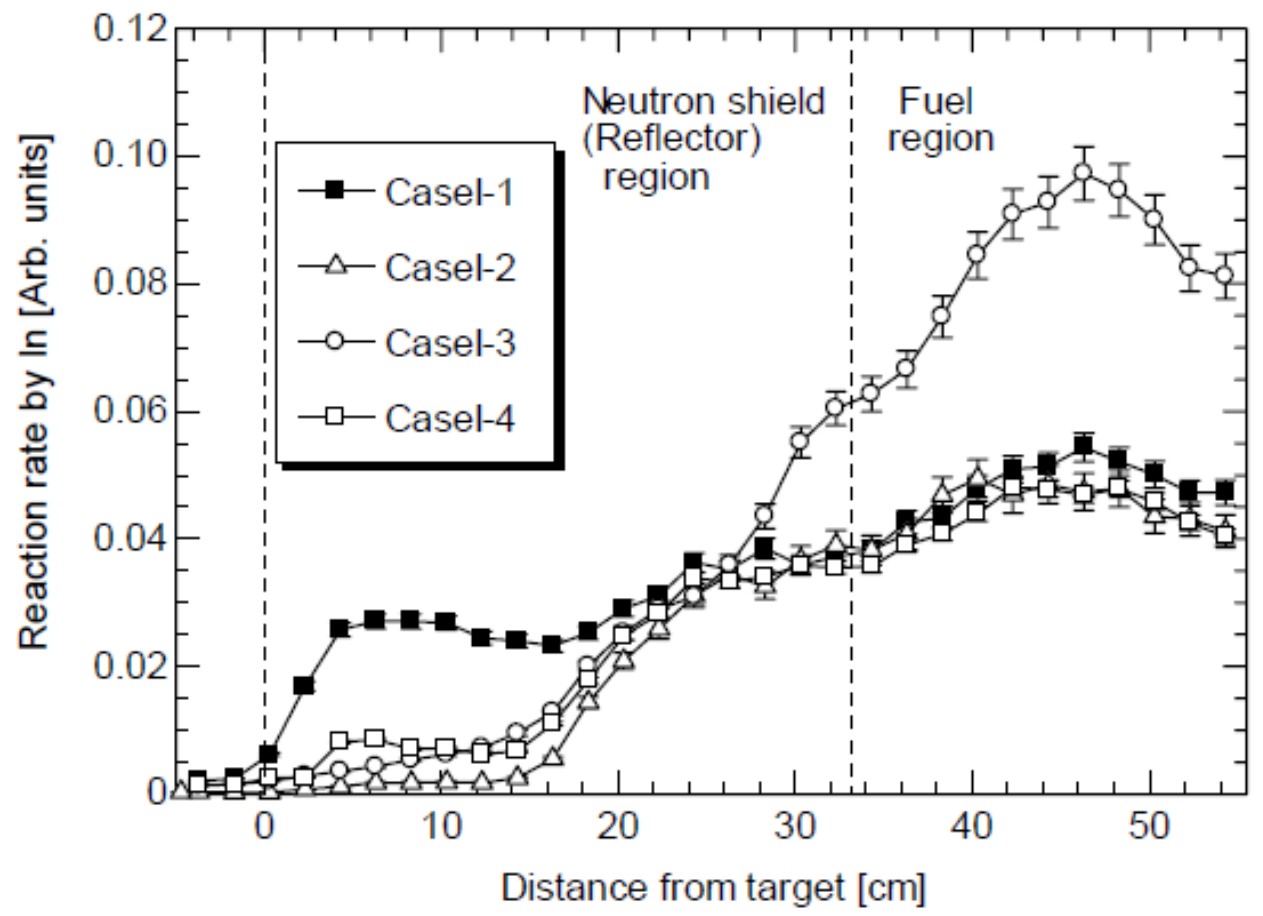

Figure 26. Measured Indium Wire Reaction Rate Distributions along the Vertical Direction Shown in Figures (Case I-1 to Case I-4). 


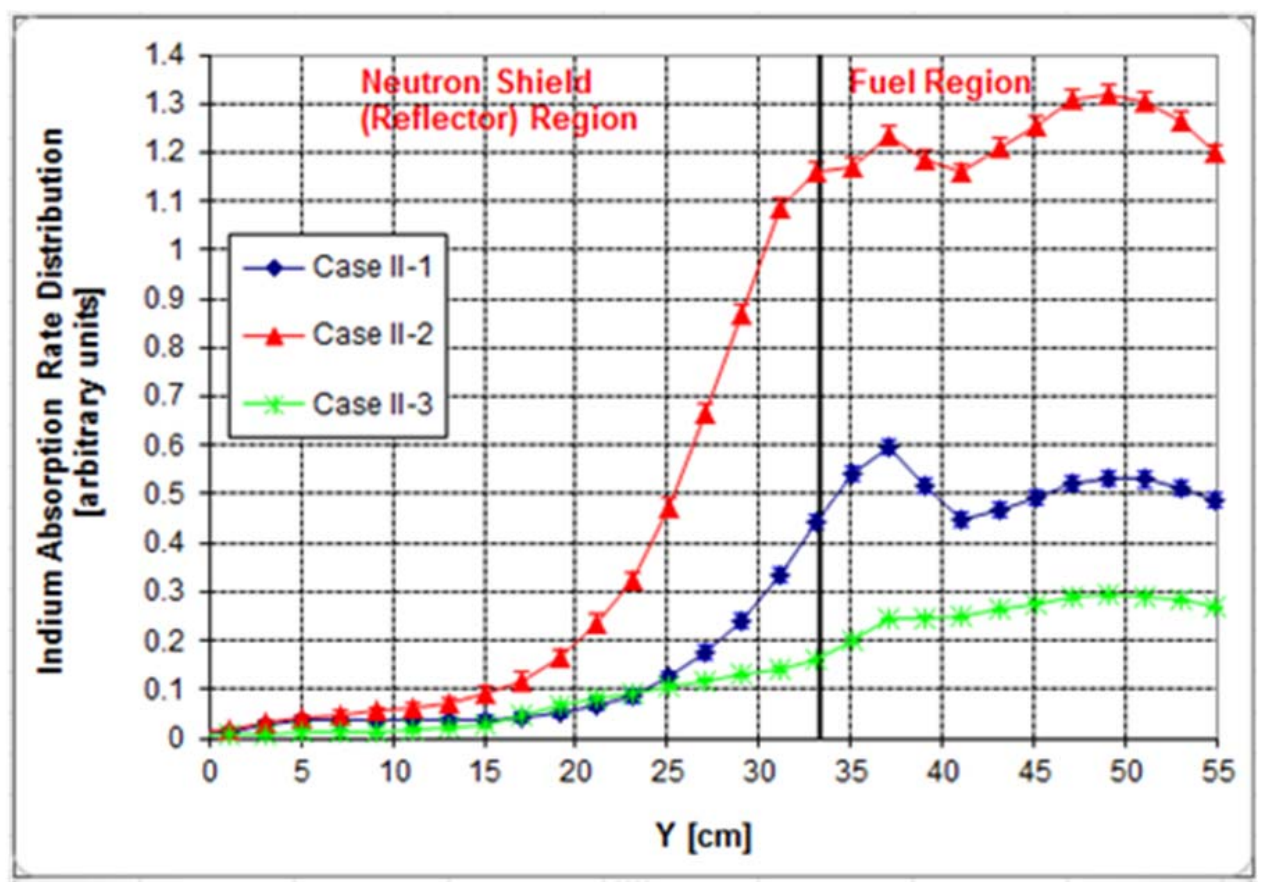

Figure 27. Calculated Indium Absorption Rate Distributions (Case II-1 to Case II-4) in MCNP Units: Rate per One Neutron and One Target Atom $\times 10^{-24} / \mathrm{cm}^{3}$.

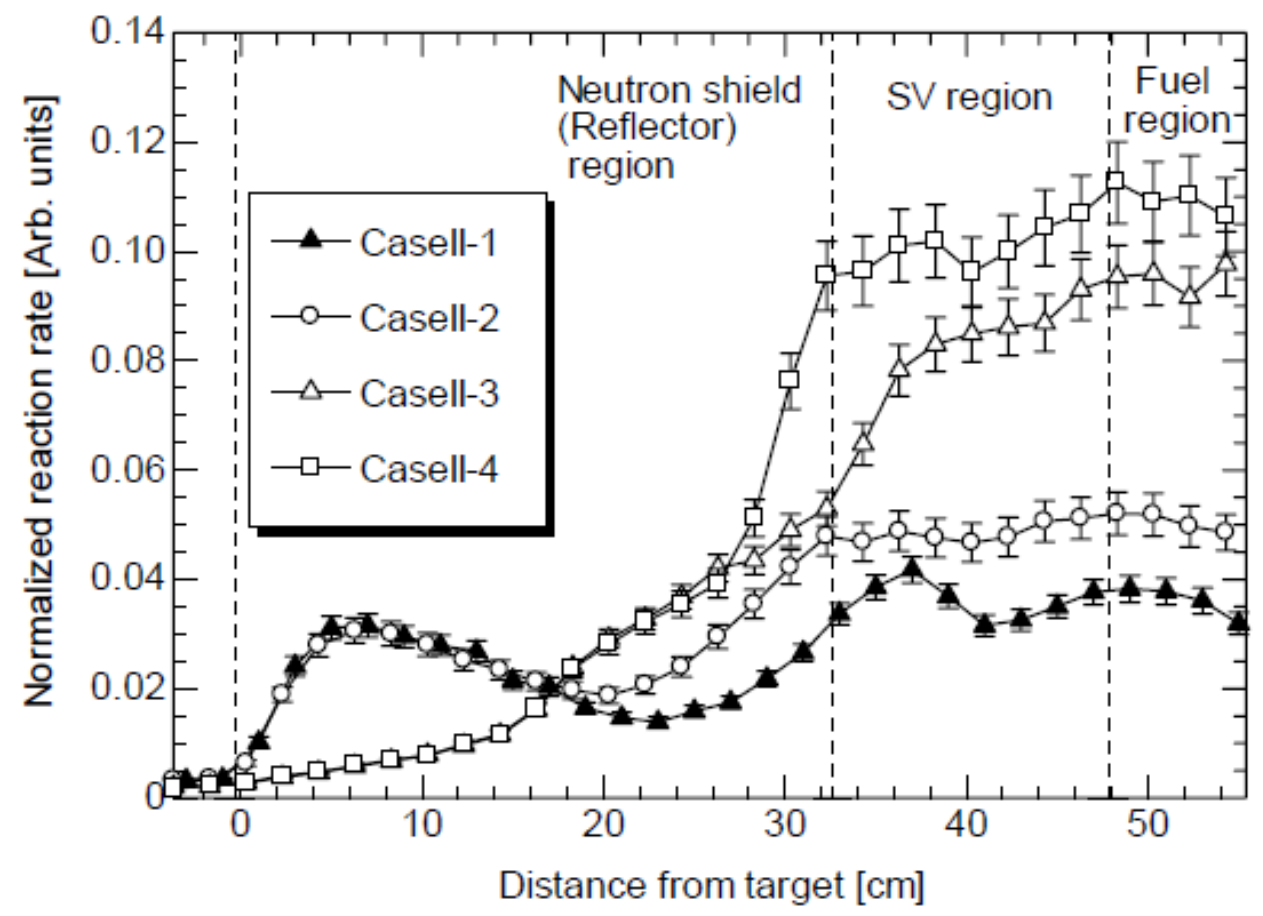

Figure 28. Measured Indium Wire Reaction Rate Distributions along the Vertical Direction Shown in Figures (Case II-1 to Case II-4). 


\subsubsection{Source Multiplication Factor}

The source multiplication factor, $\mathrm{k}_{\mathrm{s}}$, is commonly introduced in source driven systems to quantify the capability of the subcritical core to multiply the external source neutrons, dependent on the efficiency of the source itself. The source multiplication factor is defined as:

$$
k_{s}=\frac{F \Phi_{S}}{A \Phi_{S}-P_{n, 2 n}}=\frac{F \Phi_{S}}{F \Phi_{S}+S}
$$

where $\mathrm{F}$ is the multiplication factor, $\mathrm{A}$ is the loss factor (absorption plus leakage), $\mathrm{P}_{\mathrm{n}, 2 \mathrm{n}}$ is the neutron production by $(\mathrm{n}, 2 \mathrm{n})$ reactions, $\mathrm{S}$ is the external source and $\Phi_{\mathrm{s}}$ is the "source driven" flux solution of the inhomogeneous equation:

$$
A \Phi_{S}=F \Phi_{S}+S+P_{n, 2 n}
$$

The source multiplication factor is not to be confused with $\mathrm{k}_{\text {eff }}$ (the multiplication factor) which is the eigenvalue of the homogeneous (source-free) equation:

$$
A \Phi_{0}=\frac{1}{K_{\text {eff }}} F \Phi_{0}
$$

Table 4 shows the source multiplication factors and eigenvalues obtained for all Series I and II KUCA configurations. The amplitude of the calculated indium rate distributions is proportional to the $\mathrm{k}_{\mathrm{s}}$ values of the different KUCA configurations; i.e., larger $\mathrm{k}_{\mathrm{s}}$ values lead to rate distributions with larger amplitude.

Table 4. Calculated Source Multiplication Factors and Eigenvalues.

\begin{tabular}{|c|c|c|}
\hline Configuration & $\mathbf{k}_{\text {eff }}$ & $\mathbf{k}_{\mathbf{s}}$ \\
\hline KUCA I-1 & 0.99630 & 0.83314 \\
\hline KUCA I-2 & 0.99587 & 0.84010 \\
\hline KUCA I-3 & 0.99388 & 0.86137 \\
\hline KUCA I-4 & 0.99633 & 0.77988 \\
\hline KUCA II-1 & 0.99958 & 0.93974 \\
\hline KUCA II-2 & 0.99982 & 0.97684 \\
\hline KUCA II-3 & 0.99658 & 0.90560 \\
\hline KUCA II-4 & - & - \\
\hline
\end{tabular}

\section{CONVERSION OF THE KUCA CORES FROM HEU TO LEU}

This section describes the studies that were performed at Argonne to evaluate the feasibility of converting the KUCA assemblies to the use of LEU, using either U-Al alloy or U-10Mo fuel. Results presented in this section were partly included in Ref. 2.

The application of the U-Al alloy LEU fuel was modeled for the conversion of the KUCA I-1 to I-4 configurations that are described in the benchmark report. Conversion studies with U-10Mo fuel were initially performed for the KUCA I-1 configuration and then for other KUCA assemblies characterized by a large range of moderator-to-fuel volume ratios or hydrogen-to-U235 atom ratios in the core. 
In addition to a comparison of the reactivity values, the conversion from HEU to LEU was investigated through the analysis of flux spectra in relevant locations.

\subsection{Use of LEU U-AI Alloy Fuel}

Calculations were initially performed for the conversion of the KUCA I-1 configuration from HEU to LEU. For this purpose, a few fuel assemblies were added to the core region as shown in Figure 29 and the uranium enrichment of the U-Al alloy plates was reduced from $93 \%$ to $19.75 \%$, which is typically used as reference value for LEU in experimental facilities.
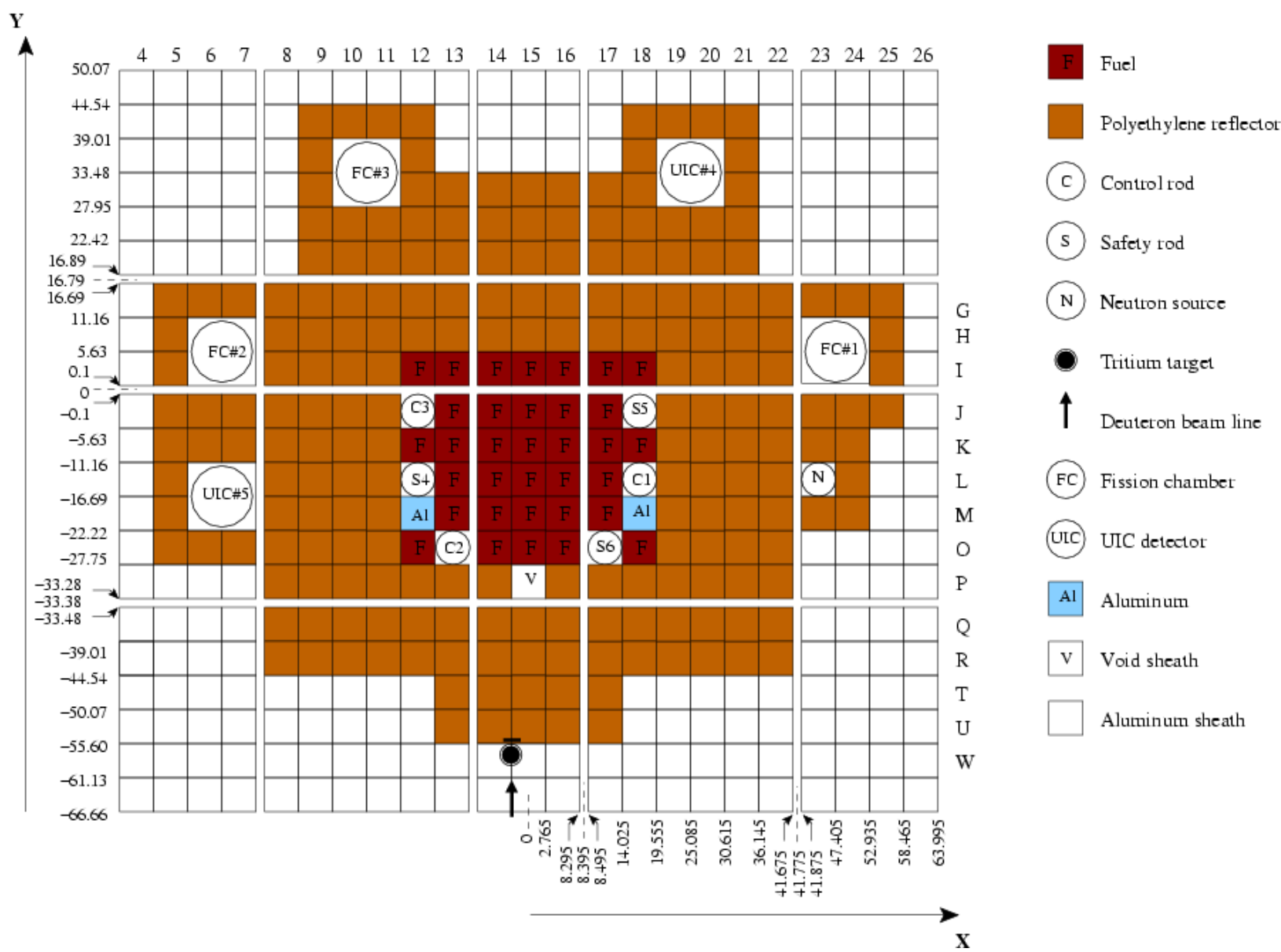

Figure 29. KUCA Configuration Series-I, Case I-1 with Additional Fuel Assemblies Using U-Al LEU Fuel.

The calculated multiplication factor for this LEU configuration is as low as 0.63097 with a typical $\mathrm{U}-\mathrm{Al}$ density (see Table 6). It was found that for the same configuration, the uranium enrichment would need to be increased to $50 \%$ to obtain a multiplication factor of 0.92280 . From the results it is obvious that the conversion of the KUCA I-1 configuration from high- to low-enriched uranium using U-Al alloy fuel would be possible only by increasing the thickness of the uranium fuel plates or by adding fuel assemblies to the core boundary or both. A series of calculations was performed to evaluate these options. No assumption was made on the constraints related to the availability of the needed materials. 
As first step, the thickness of the U-Al plates in the fuel assemblies was increased from $1 / 16$ in. to $3 / 16$ in. This increase in thickness was achieved by replacing the $1 / 8$-in. thick polyethylene plate of the fuel unit cell (see Figure 10) by a U-Al plate of the same thickness. The LEU U-Al fuel plates retain the same material properties as the HEU U-Al alloy, only the enrichment is reduced from $93 \%$ to $19.75 \%$.

Calculations were performed for all KUCA series I configurations and to obtain reasonable $\mathrm{k}_{\text {eff }}$ values, 56 LEU fuel assemblies were added as shown in Figures 30 through 33. To ensure adequate reflection, a number of polyethylene assemblies were also added. These configurations will be referred as KUCA I-1+56, KUCA I-2+56, KUCA I-3+56 and KUCA I-4+56.

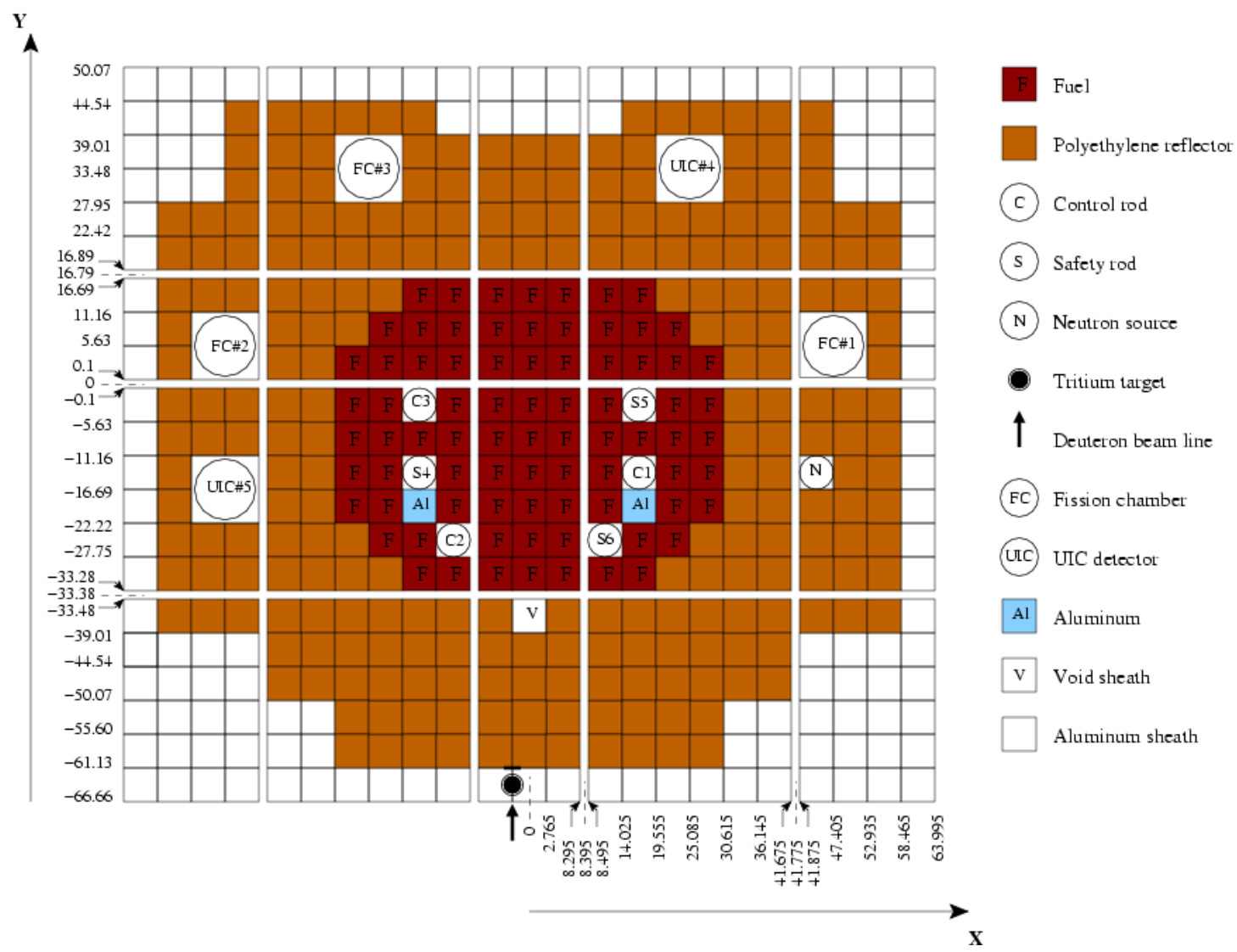

Figure 30. KUCA Configuration Series-I, Case I-1 after Adding 56 Fuel Assemblies (KUCA I-1+56). 


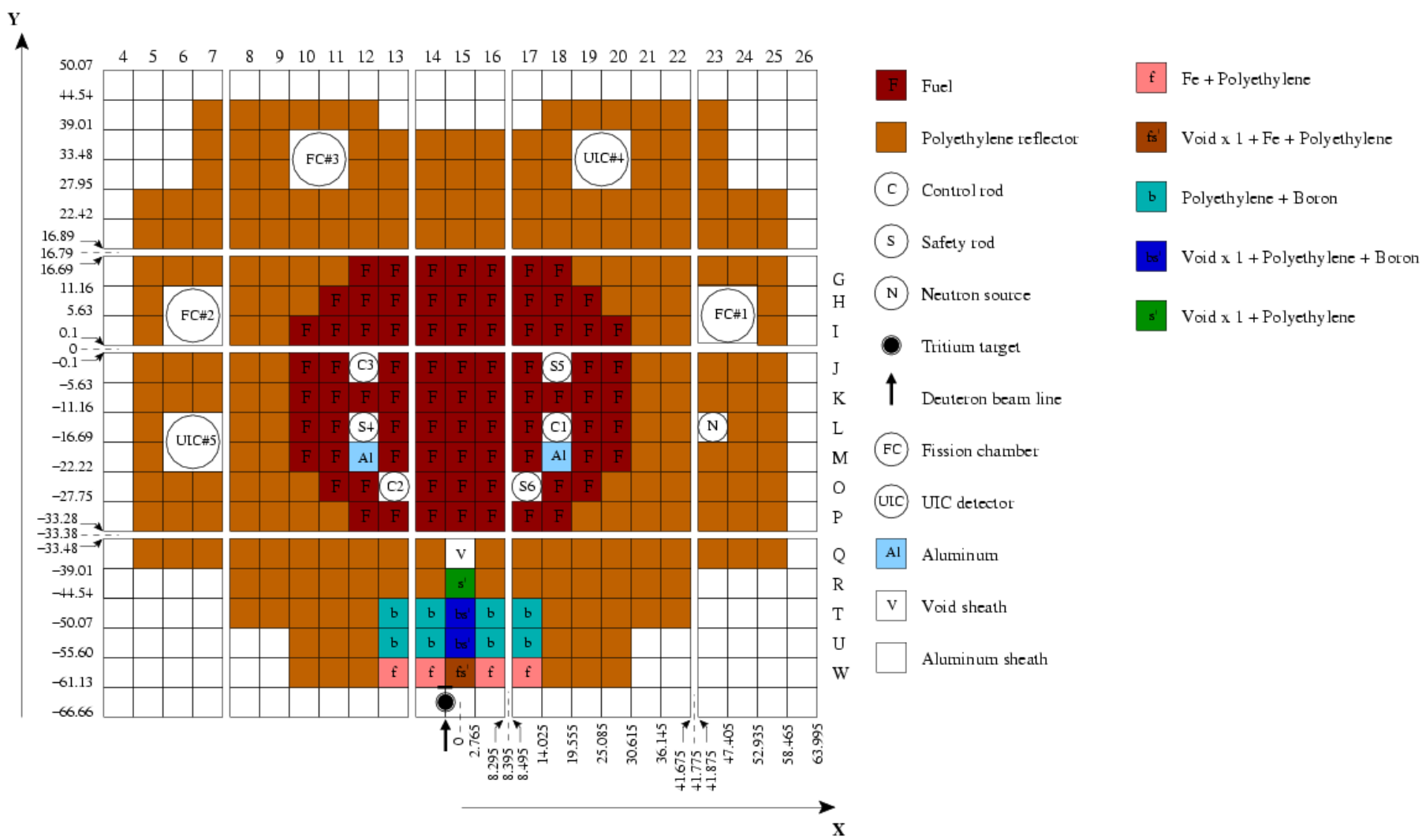

Figure 31. Configuration Series-I, Case I-2 after Adding 56 Fuel Assemblies (KUCA I-2+56).

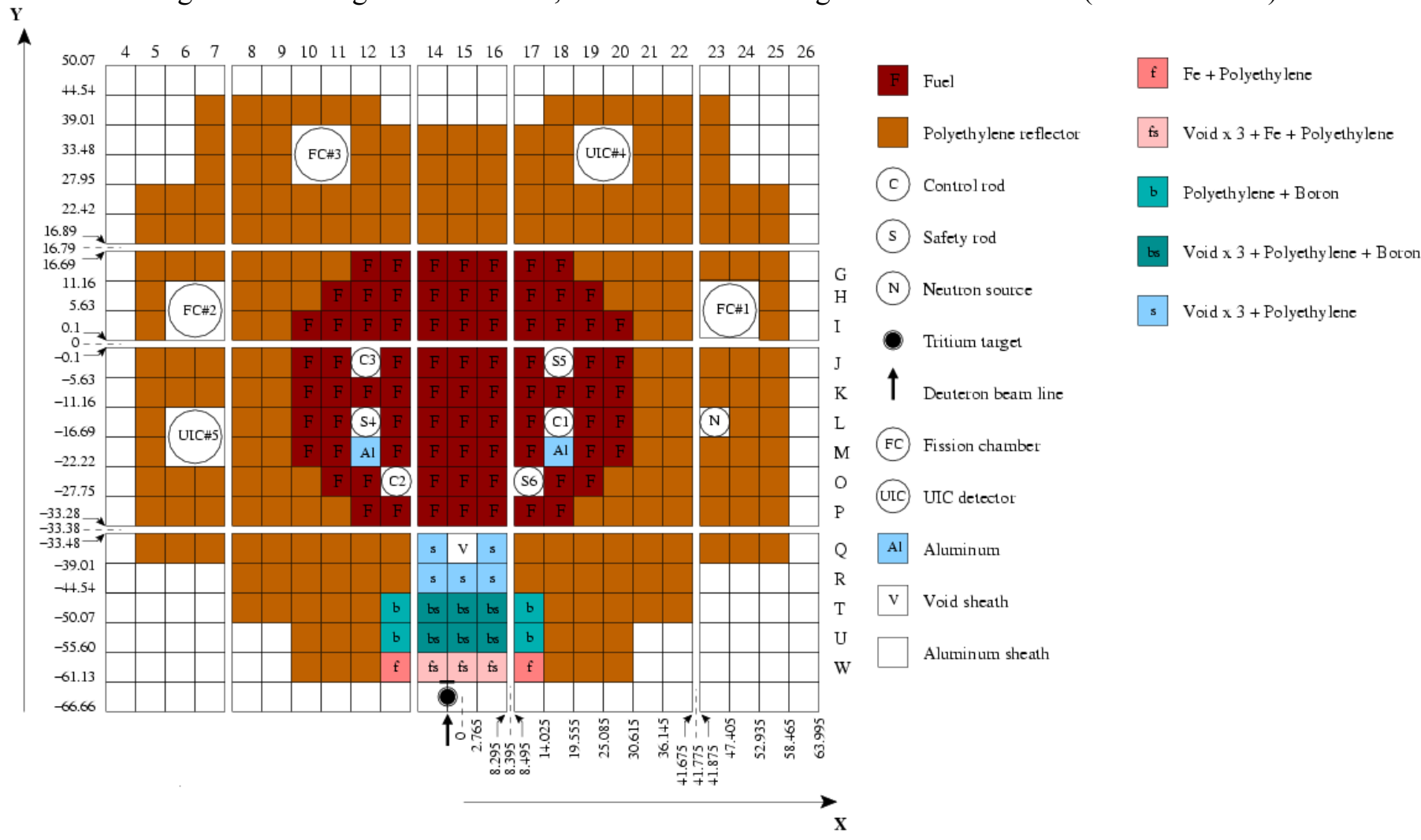

Figure 32. KUCA Configuration Series-I, Case I-3 after Adding 56 Fuel Assemblies (KUCA I-3+56). 


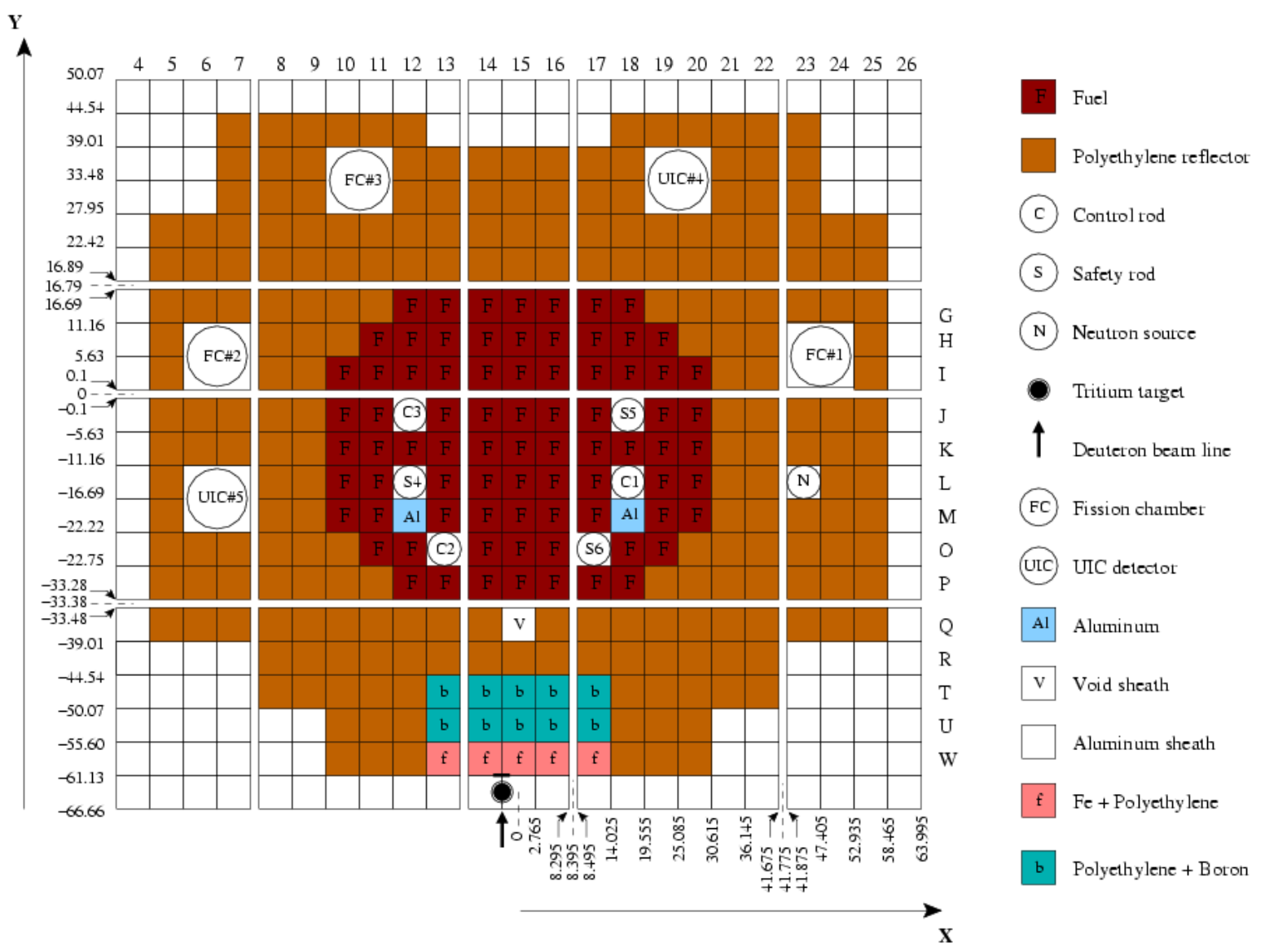

Figure 33. KUCA Configuration Series-I, Case I-4 after Adding 56 Fuel Assemblies (KUCA I-1+56).

\subsubsection{Reactivity Calculations}

For the KUCA cores presented in Figures 30 to 33, the calculated reactivity values for both the "excess reactivity" (control rods and safety rods completely out) and "subcritical" (control rods fully inserted, safety rods completely withdrawn) rod configurations are presented in Table 5.

Table 5. Calculated Reactivity [pcm] for the LEU U-Al Configurations.

\begin{tabular}{|l|l|c|}
\hline \multicolumn{1}{|c|}{ Configuration } & \multicolumn{1}{|c|}{ Rod configuration } & MCNP5 \\
\hline \multirow{2}{*}{ KUCA I-1+56 } & Excess Reactivity & $678 \pm 6$ \\
\cline { 2 - 3 } & Subcriticality & $-2857 \pm 6$ \\
\hline \multirow{2}{*}{ KUCA I-2+56 } & Excess Reactivity & $636 \pm 5$ \\
\cline { 2 - 3 } & Subcriticality & $-2891 \pm 6$ \\
\hline \multirow{2}{*}{ KUCA I-3+56 } & Excess Reactivity & $351 \pm 5$ \\
\cline { 2 - 3 } & Subcriticality & $-3134 \pm 6$ \\
\hline \multirow{2}{*}{ KUCA I-4+56 } & Excess Reactivity & $663 \pm 6$ \\
\cline { 2 - 3 } & Subcriticality & $-2870 \pm 6$ \\
\hline
\end{tabular}




\subsubsection{Flux Spectra Calculations}

For the same configurations with U-Al LEU fuel described in Table 5, flux spectra were calculated at selected positions. Specifically, flux spectra were determined in 53 energy groups at position A, $(X, Y)=(8.395 \mathrm{~cm},-2.6 \mathrm{~cm})$, along the indium wire (see Section 2.2.2 for details) and at position B, in the fuel plate of assembly $(14, \mathrm{~K})$ that is closest to the core midplane.

Calculations were performed in the subcritical control rod configuration. As shown in Figures 34 through 41, the flux energy distributions in the core region show two peaks, one at high energy around 2 $\mathrm{MeV}$ and the other at lower energies around $0.1 \mathrm{eV}$.

Figures 35, 37, 39 and 41 show the comparison of the flux spectra calculated in the same position B for the high- and low-enriched uranium configurations. It is observed that using low enriched uranium the peak at high energy decreases. This spectrum change is caused by the change in $\mathrm{H} / \mathrm{U}$ ratio in the core and it is not due to the use of LEU fuel. Generally, the use of LEU results in hardening the neutron spectrum due to increased absorption by U238.

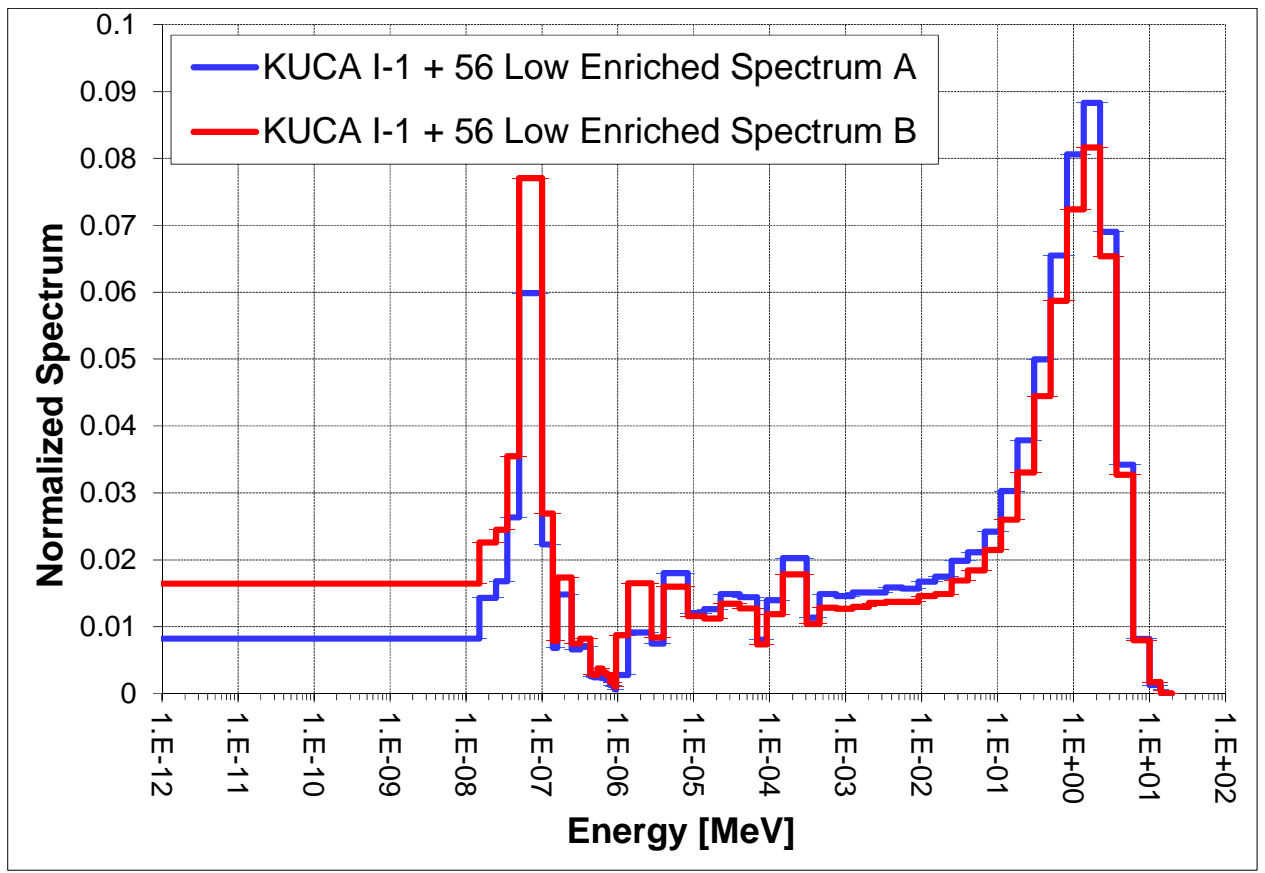

Figure 34. Flux Spectra at the Positions A and B of KUCA I-1+56 with U-Al LEU Fuel. 


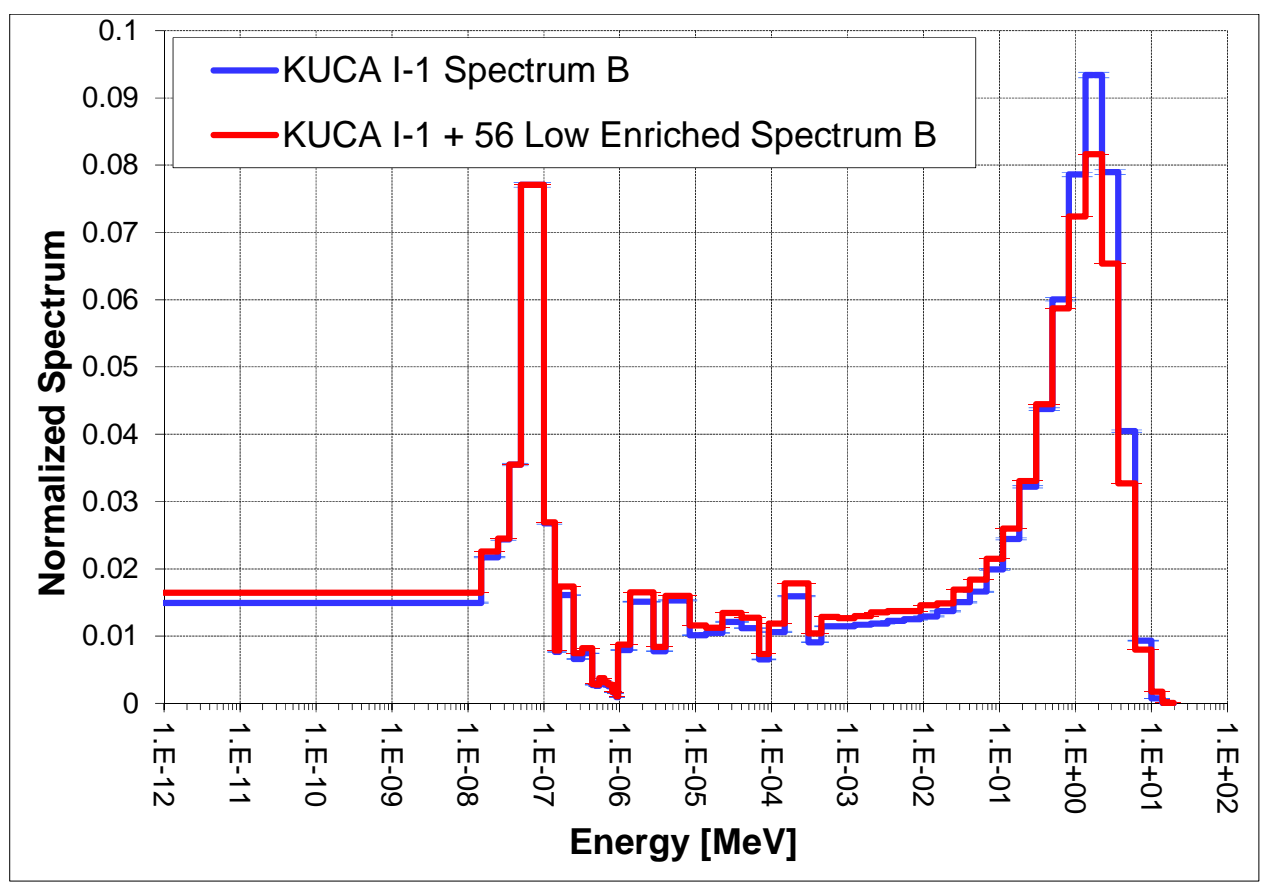

Figure 35. Flux Spectra at the Position B of KUCA I-1 HEU and KUCA I-1+56 with U-Al LEU Fuel.

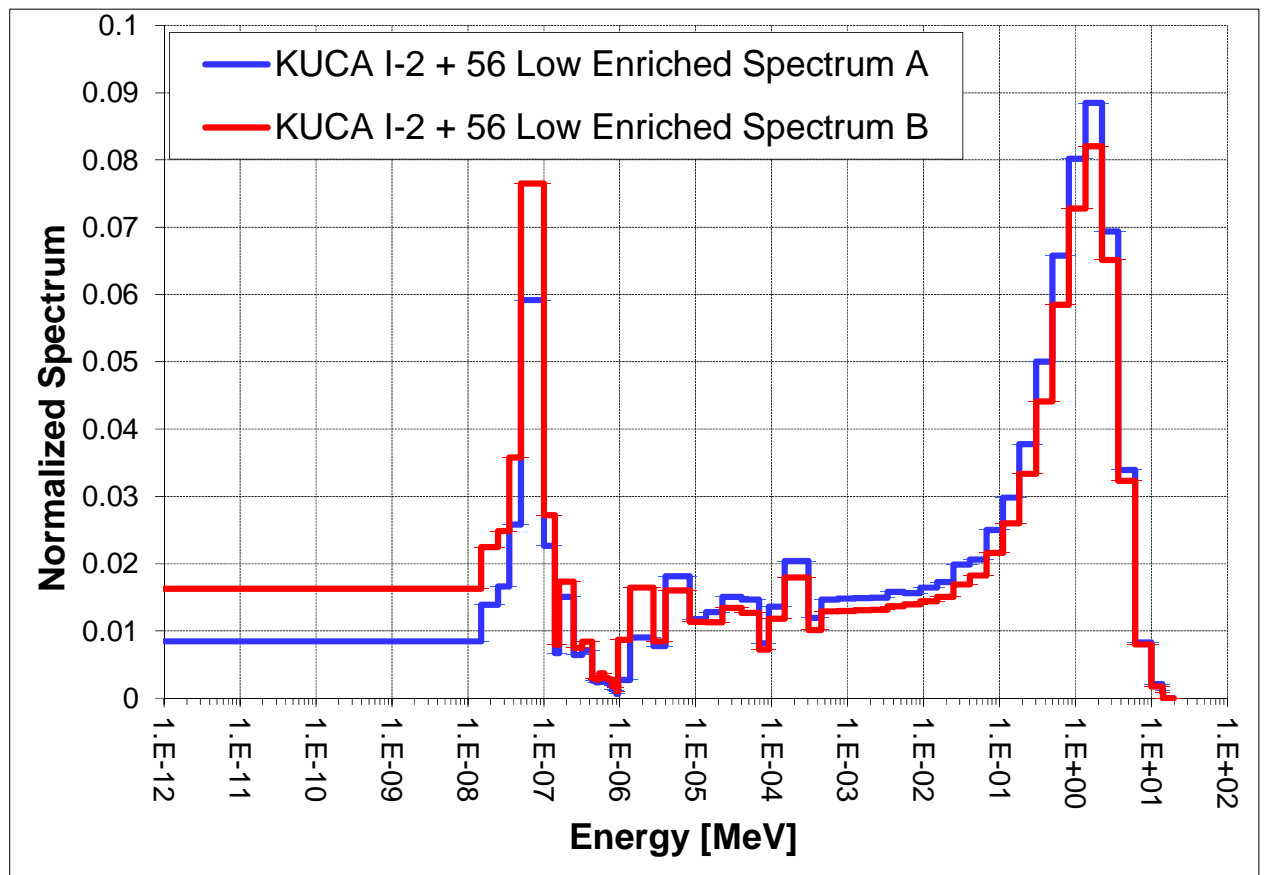

Figure 36. Flux Spectra at the Positions A and B of KUCA I-2+56 with U-A1 LEU Fuel. 


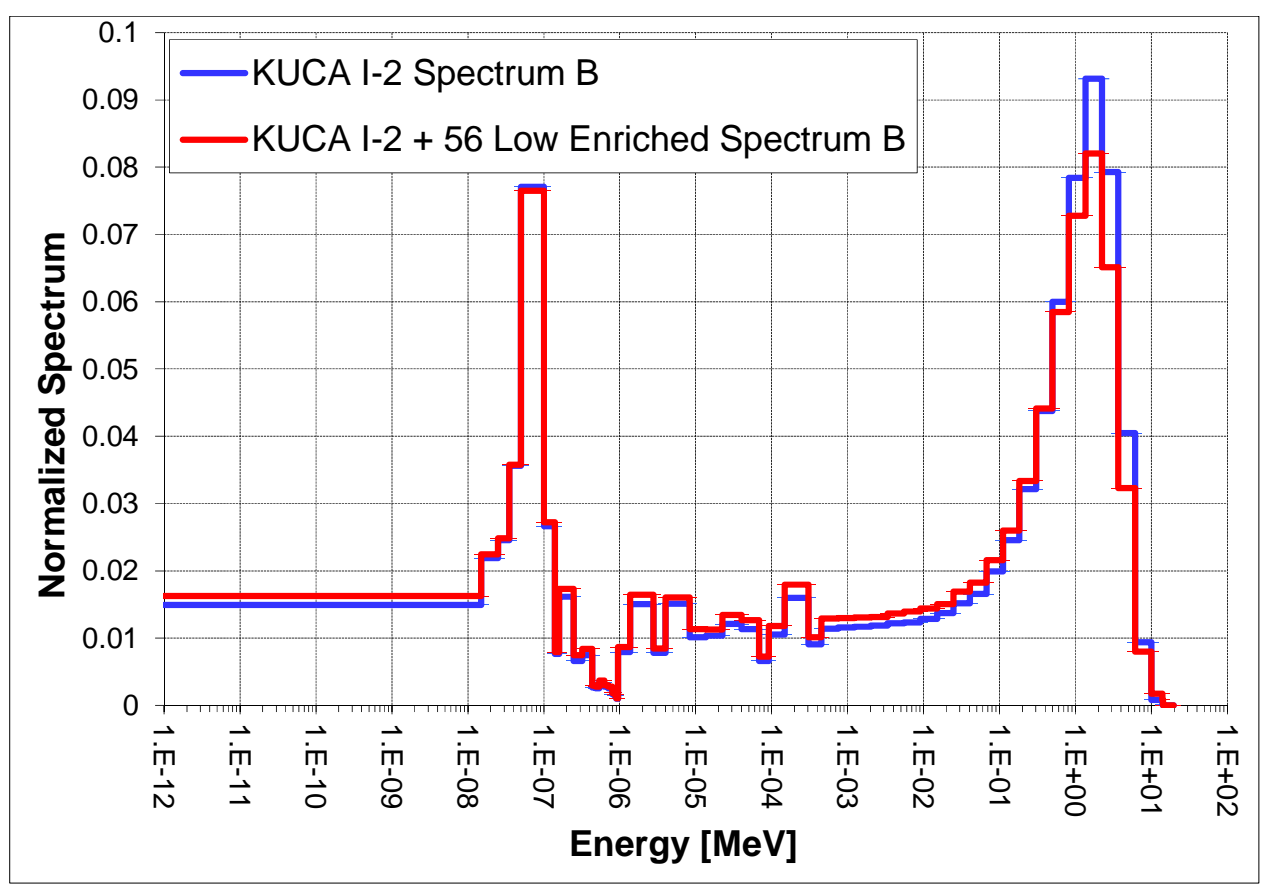

Figure 37 Flux Spectra at the Position B of KUCA I-2 HEU and KUCA I-2+56 with U-A1 LEU Fuel.

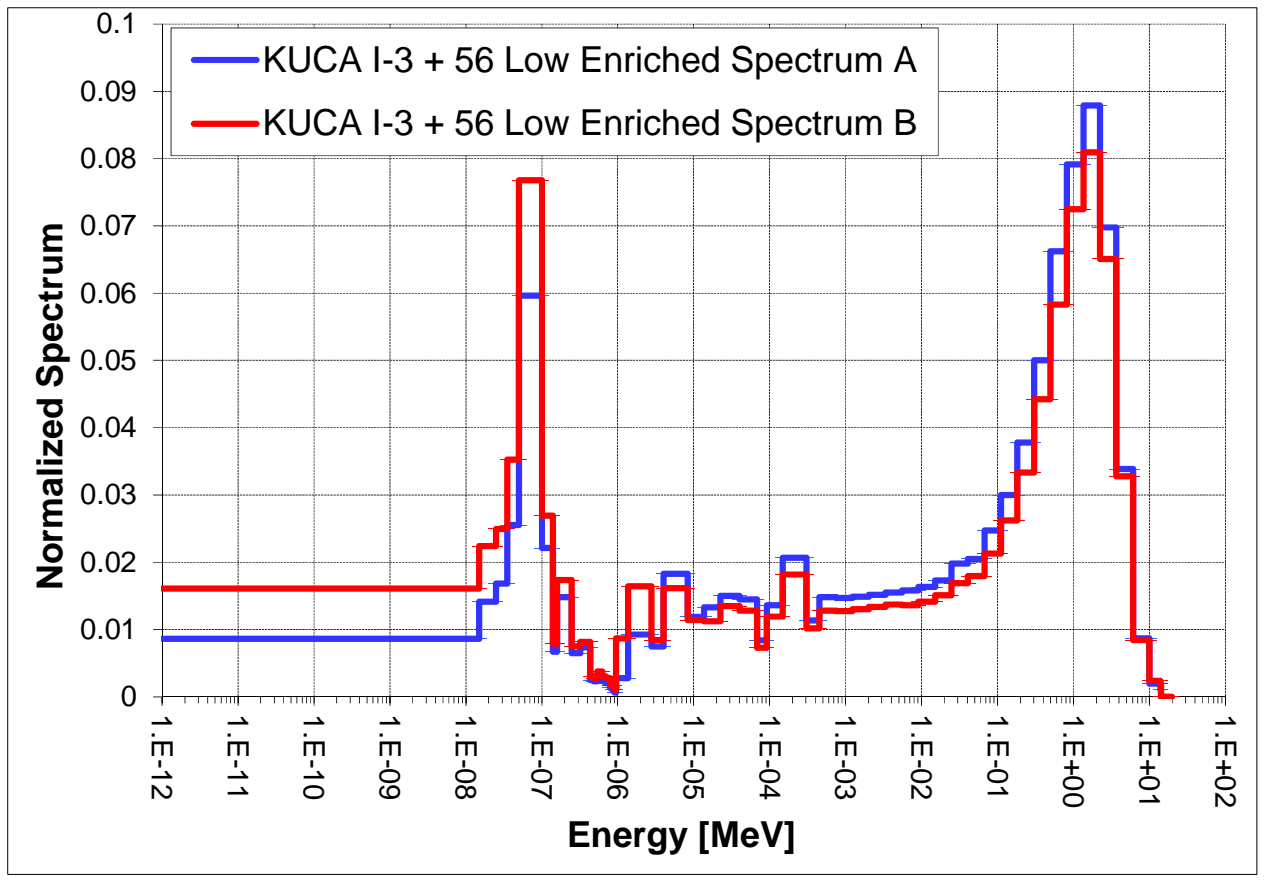

Figure 38. Flux Spectra at the Positions A and B of KUCA I-3+56 with U-Al LEU Fuel. 


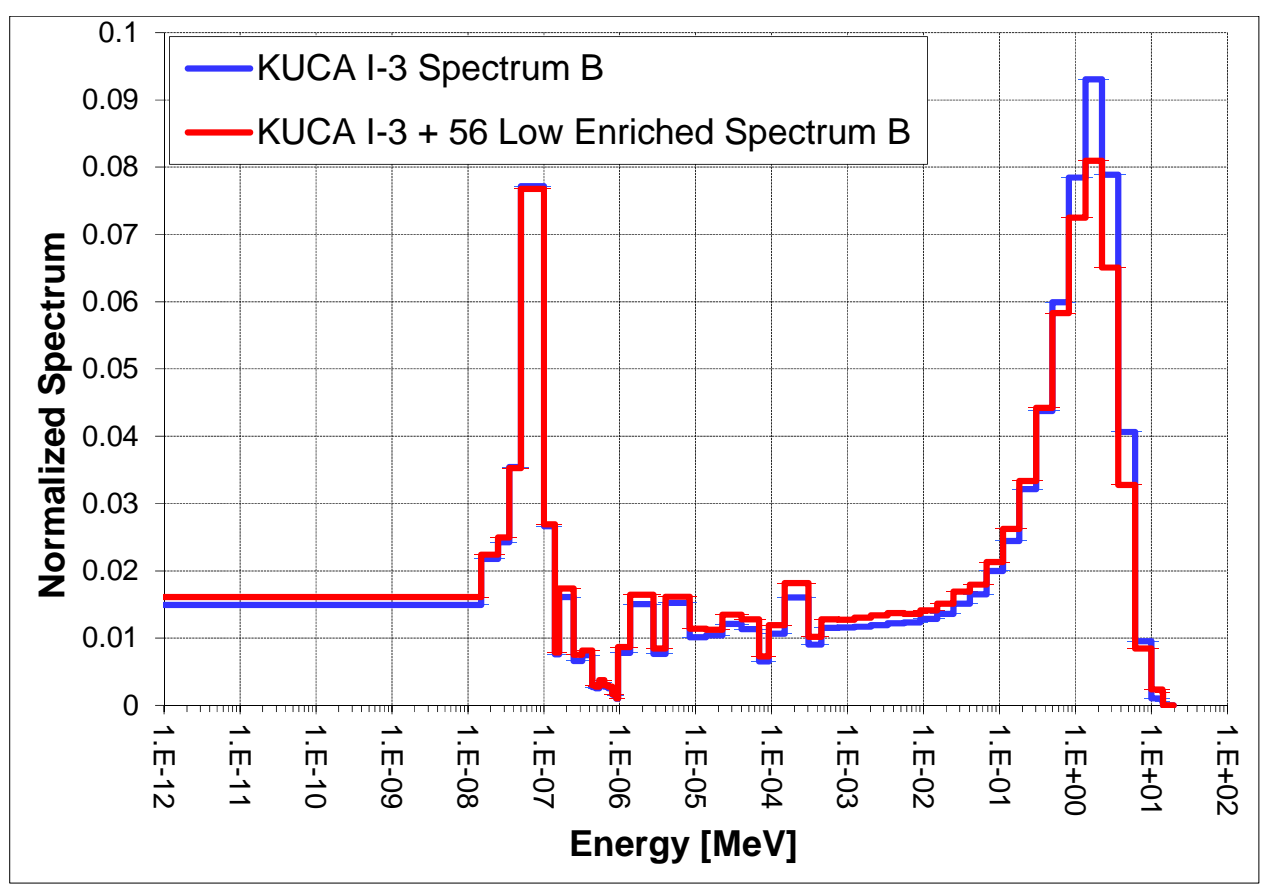

Figure 39. Flux Spectra at the Position B of KUCA I-3 HEU and KUCA I-3+56 with U-Al LEU Fuel.

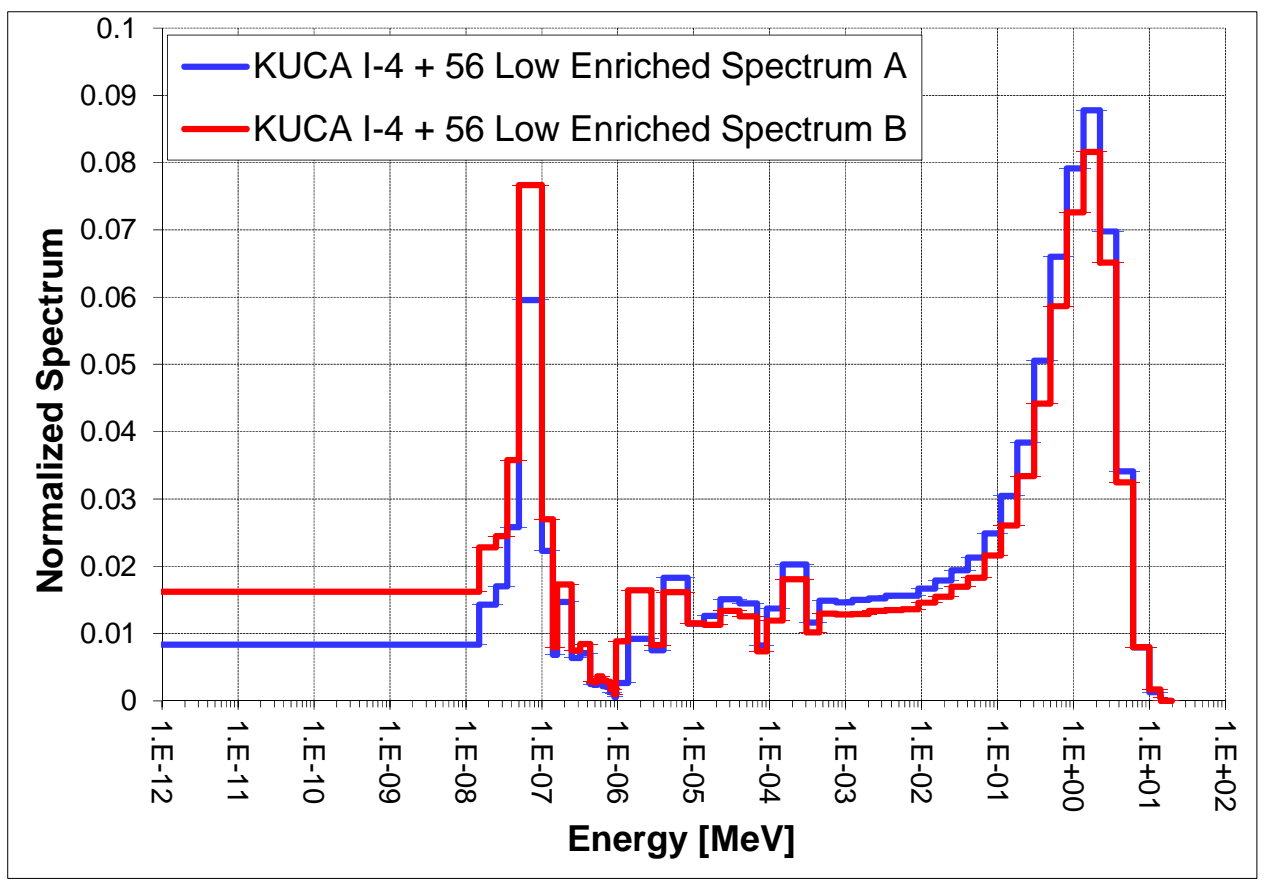

Figure 40. Flux Spectra at the Positions A and B of KUCA I-4+56 with U-Al LEU Fuel. 


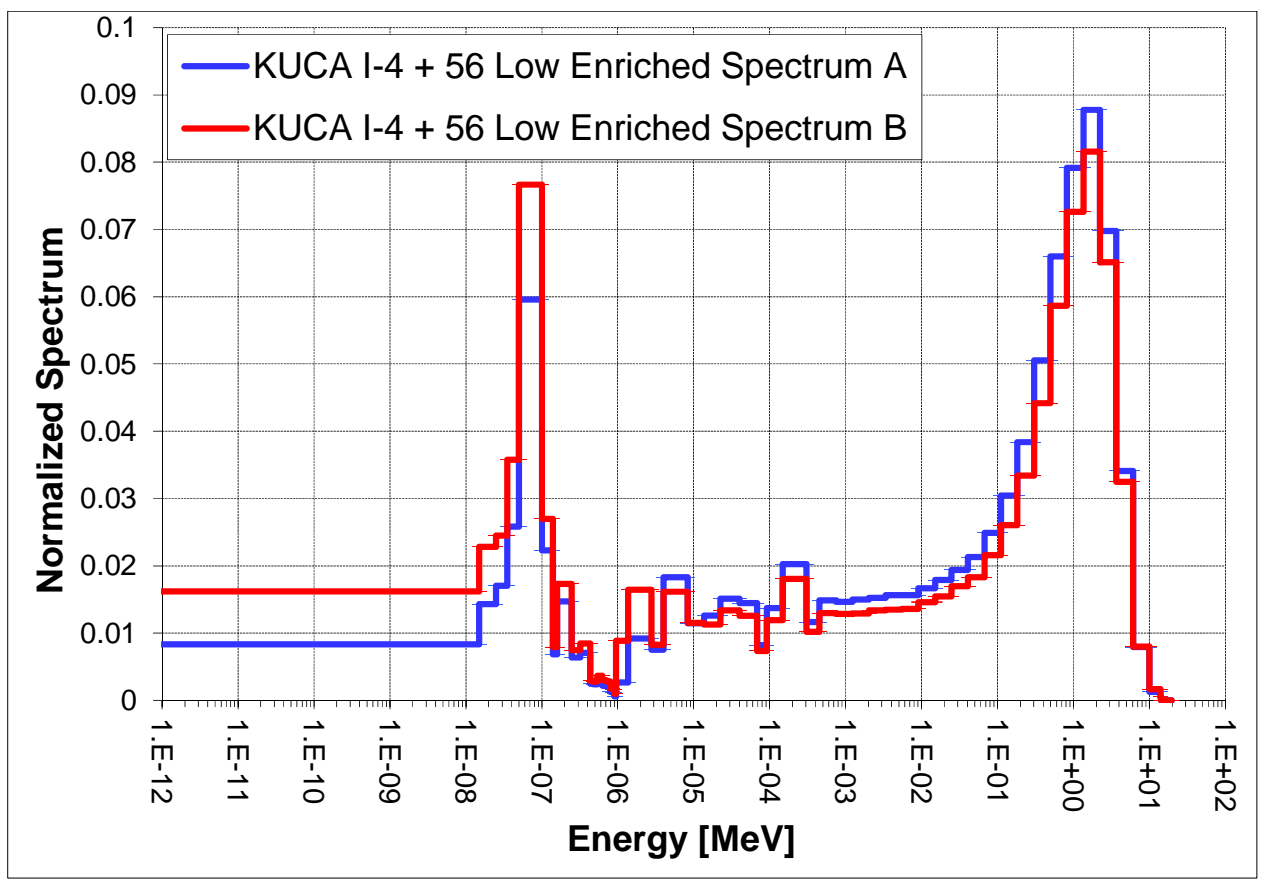

Figure 41. Flux Spectra at the Position B of KUCA I-4 HEU and KUCA I-4+56 with U-Al LEU Fuel.

\subsection{Use of LEU U-10Mo Fuel}

From the previous section it is concluded that reducing the uranium enrichment of the U-Al alloy fuel plates from $93 \%$ to $19.75 \%$ gives reasonable values for the multiplication factor only by increasing the thickness of the fuel plates and the number of fuel assemblies. Obviously, use of high density fuel materials such as U-10Mo LEU fuel can reduce the required fuel plate inventory and critical core volume, but can also significantly change the core spectrum and other core characteristics.

Table 6 shows the number densities of $\mathrm{U}-\mathrm{Al}$ and $\mathrm{U}-10 \mathrm{Mo}$ fuel with 19.75\% uranium enrichment in both cases. For comparison, the HEU (93\% enrichment) U-Al fuel compositions are also presented in Table 6. For the LEU fuel, it can be seen that the U-235 number density is $\sim 20$ times larger in the case of the U-10Mo plates.

Use of U-10Mo fuel plates was investigated for the KUCA I-1 configuration. As a first attempt, a calculation was performed by just replacing the $93 \%$ enriched U-Al plate by a $19.75 \%$ enriched U-10Mo plate. The thickness of fuel and polyethylene plates remains as shown in Figure 10. 
Table 6. Number Densities [at/(barn $\times \mathrm{cm})$ ] of High Enriched (93\%) U-Al, Low Enriched (19.75\%) U-Al and U-10Mo Fuel and Aluminum Clad.

\begin{tabular}{|c|c|c|c|c|c|c|c|}
\hline \multicolumn{2}{|c|}{ HEU U-Al } & \multicolumn{2}{|c|}{ LEU U-Al } & \multicolumn{2}{|c|}{ LEU U-10Mo } & \multicolumn{2}{|c|}{ Aluminum Clad } \\
\hline $\mathrm{U} 235$ & $1.50694 \mathrm{E}-03$ & $\mathrm{U} 235$ & 3.19061E-04 & U234 & $1.02479 \mathrm{E}-04$ & $\mathrm{~A} 127$ & $6.02626 \mathrm{E}-2$ \\
\hline U238 & $1.08560 \mathrm{E}-04$ & U238 & $1.29644 \mathrm{E}-03$ & U235 & 7.75124E-03 & B10 & $5.98593 \mathrm{E}-7$ \\
\hline Al27 & $5.56436 \mathrm{E}-02$ & Al27 & $5.56436 \mathrm{E}-02$ & $\mathrm{U} 236$ & 1.79769E-04 & B11 & $2.40941 \mathrm{E}-6$ \\
\hline SUM & $5.72591 \mathrm{E}-02$ & SUM & $5.72591 \mathrm{E}-02$ & $\mathrm{U} 238$ & $3.08187 \mathrm{E}-02$ & & \\
\hline & & & & Mo92 & $1.58542 \mathrm{E}-03$ & & \\
\hline & & & & Mo94 & $9.88218 \mathrm{E}-04$ & & \\
\hline & & & & Mo95 & $1.70080 \mathrm{E}-03$ & & \\
\hline & & & & Mo96 & $1.78200 \mathrm{E}-03$ & & \\
\hline & & & & Mo97 & $1.02027 \mathrm{E}-03$ & & \\
\hline & & & & Mo98 & $2.57791 \mathrm{E}-03$ & & \\
\hline & & & & Mo100 & $1.02881 \mathrm{E}-03$ & & \\
\hline & & & & SUM & 4.95356E-02 & & \\
\hline
\end{tabular}

As expected, the calculated reactivity value with the "subcritical" rod configuration (all safety rods completely withdrawn and control rods $\mathrm{C} 1, \mathrm{C} 2$ and C3 fully inserted) increased from $-371 \pm 8 \mathrm{pcm}$ (highenriched U-Al case) to $12341 \pm 7 \mathrm{pcm}$ (low-enriched U-10Mo case) indicating that the use of nominal density U-10Mo plates would keep the LEU core subcritical only by significantly reducing the thickness of the fuel plates or the number of fuel assemblies. Given these options, the thickness of the U-10Mo plates was reduced so that the U-235 mass in the fuel plate remains the same as the U-Al HEU plate. Since the XY dimensions of the plate are the same in both HEU and LEU assemblies, the thickness is changed according to the ratio of the U235 densities in the HEU and LEU configurations:

$$
\text { thickness_LEU }=\frac{\text { density_HEU }}{\text { density_LEU }} \times \text { thickness_HEU }=\frac{1.50694 E-03}{7.75124 E-03} \times 0.1587=0.0309 \mathrm{~cm}
$$

Two separate approaches were used for the arrangement of the U-10Mo foils.

For the first approach, no cladding is used for the U-10Mo foils. In order to preserve the total extension (i.e. $1.0973 \mathrm{~cm}$ ) of the fuel unit cell, the thickness of the first polyethylene plate in the unit cell was increased from $0.3086 \mathrm{~cm}$ to $0.4364 \mathrm{~cm}$ as shown in Figure 42.

The option to add Al clad to the U-10Mo foils was then considered in a separate approach (see Table 6 for the compositions of the aluminum clad used for the present studies; this composition is representative of the Al used for other U-10Mo LEU foils and contains a concentration of 20 ppm boron). In this case, the thickness of the U-10Mo plates is always fixed so that the U-235 mass in the fuel plate remains the same of the U-Al HEU core. However, with respect to the previous approach the thickness of the cladding plates is determined so that the thickness of the polyethylene plates also remains the same as in the U-Al HEU core (see Figure 43). 


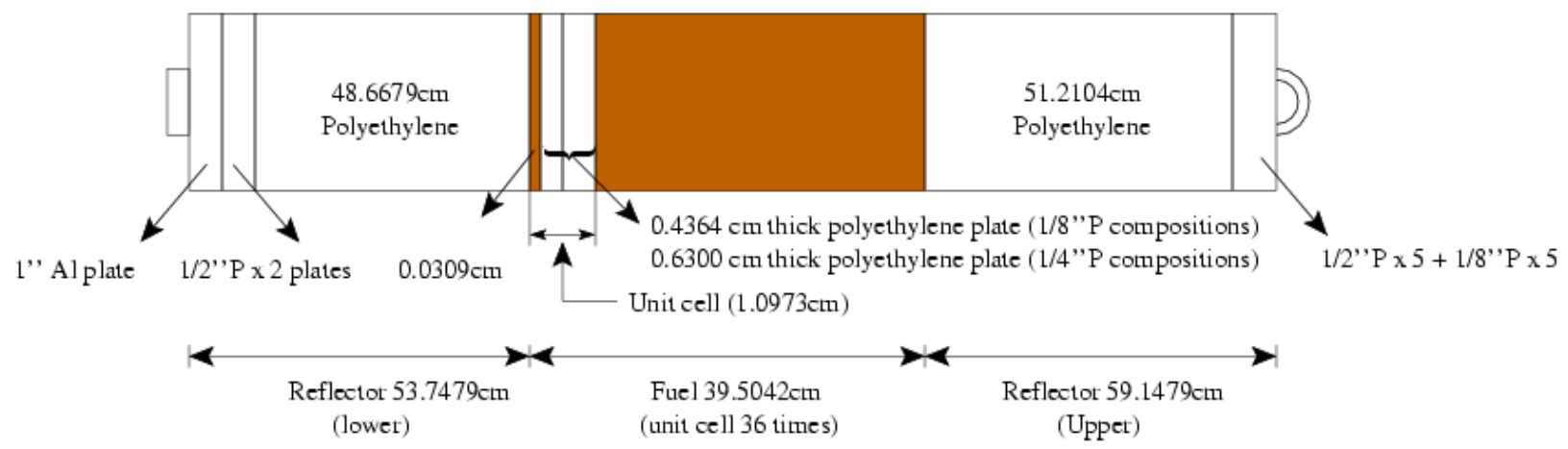

Figure 42. Sideways View of Fuel Assembly "F” Using LEU U-10Mo Plates without Al Clad.

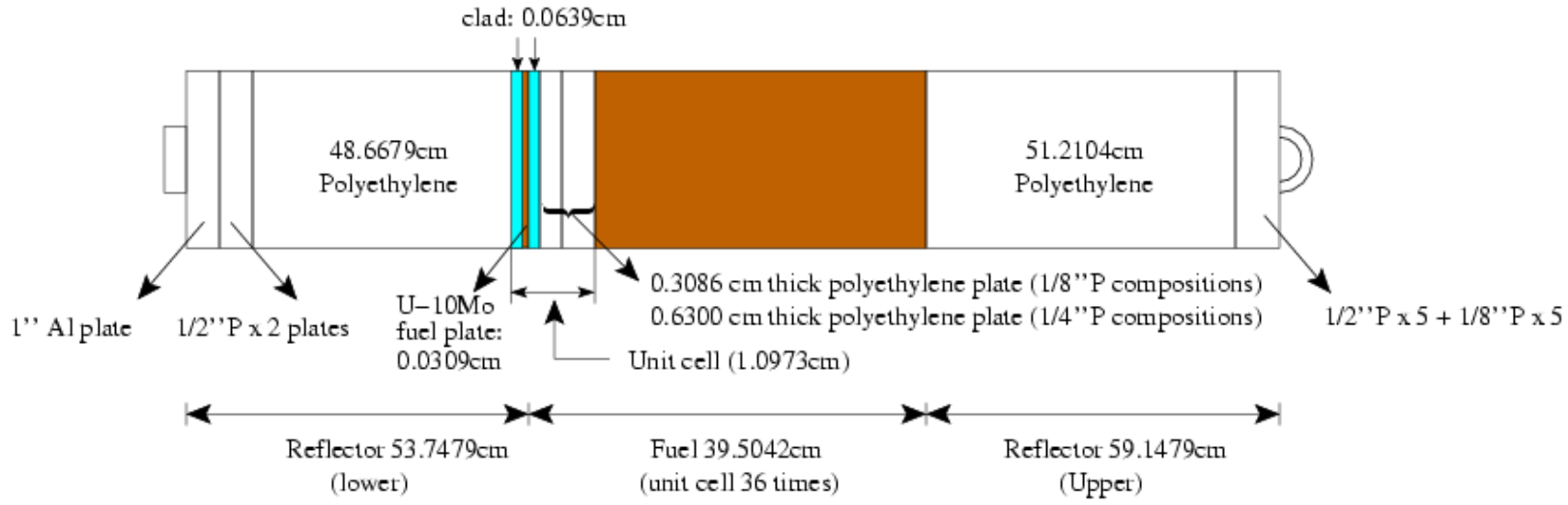

Figure 43. Sideways View of Fuel Assembly "F" Using LEU U-10Mo Plates with Al Clad.

\subsubsection{Reactivity Calculations}

For both LEU U-10Mo KUCA I-1 configurations discussed above, calculations were performed in both "excess reactivity" and "subcritical" rod configurations. Calculated reactivity values are presented in Table 7. For comparison, the reactivity of the HEU core is also given in Table 7. It is observed that by preserving the U235 mass, the LEU U-10Mo configuration gives smaller reactivity values due to the increased $\mathrm{H} / \mathrm{U}$ volume ratio. Additionally, the use of $\mathrm{Al}$ clad has a negative reactivity effect of about 4000 pcm.

Table 7. Calculated and Measured Reactivity (pcm, using ENDF/B-VII.0 Data).

\begin{tabular}{|c|c|c|c|c|}
\hline Configuration & Rod Configuration & $\begin{array}{c}\text { LEU U-10Mo Plate - } \\
\text { No Clad }\end{array}$ & $\begin{array}{c}\text { LEU U-10Mo Plate - } \\
\text { With Clad }\end{array}$ & HEU U-Al Plate \\
\hline \multirow{2}{*}{ KUCA I-1 } & Excess Reactivity & $98 \pm 6$ & $-3629 \pm 6$ & $746 \pm 8$ \\
\cline { 2 - 5 } & Subcritical & $-792 \pm 6$ & $-4782 \pm 6$ & $-371 \pm 8$ \\
\hline
\end{tabular}

\subsubsection{Flux Spectra Calculations}

Flux spectra were determined in 53 energy groups for the KUCA I-1 configurations using LEU U-10Mo fuel with and without Al clad. Calculations were performed with the "subcritical" control rod configuration characterized by the safety rods completely withdrawn and the control rods C1, C2 and C3 fully inserted. 
Particularly, flux spectra were determined at position $A,(X, Y)=(8.395 \mathrm{~cm} ;-2.6 \mathrm{~cm})$, along the indium wire (see Section 2.2.2 for details) and in position B, in the fuel plate of the assembly $(14, \mathrm{~K})$ that is closest to the core midplane. Results are presented in Figures 44 and 45 for the two cases without and with Al cladding, respectively. Similar to the previous KUCA configurations that have already been analyzed, flux energy distributions in the core region show two peaks, one at high energy around $2 \mathrm{MeV}$ and the other at lower energies around $0.1 \mathrm{eV}$. In both cases, with or without Al clad, the flux spectra in position $\mathrm{B}$ show enhanced peaks at $2 \mathrm{MeV}$ and $0.1 \mathrm{eV}$ and a decreased distribution in the range $3-300$ $\mathrm{eV}$ with respect to the neutron spectrum at position $\mathrm{A}$.

Figure 46 shows the comparison of the flux spectra calculated in position B in the HEU and in the three LEU configurations, using U-Al plates (with 56 additional fuel assemblies) and U-10Mo plates with and without cladding. It is observed that the configuration using LEU U-Al fuel shows a smaller peak at 2 $\mathrm{MeV}$ but an enhanced distribution in the range $3-300 \mathrm{eV}$ with respect to the other configurations. On the other hand, the LEU configuration using U-10Mo plates and Al cladding shows a smaller peak at $0.1 \mathrm{eV}$.

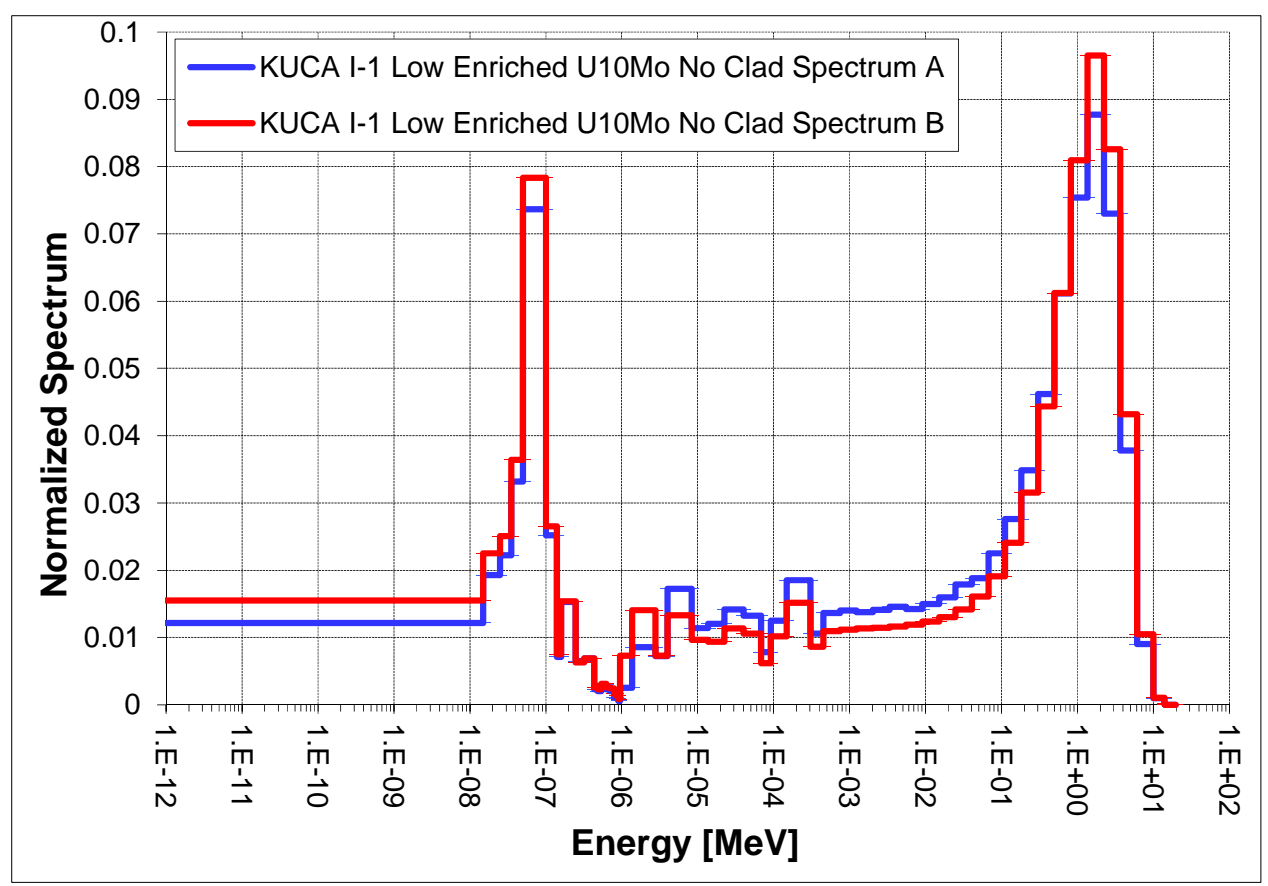

Figure 44. Flux Spectra at Positions A and B of KUCA I-1 with LEU U-10Mo and No Cladding. 


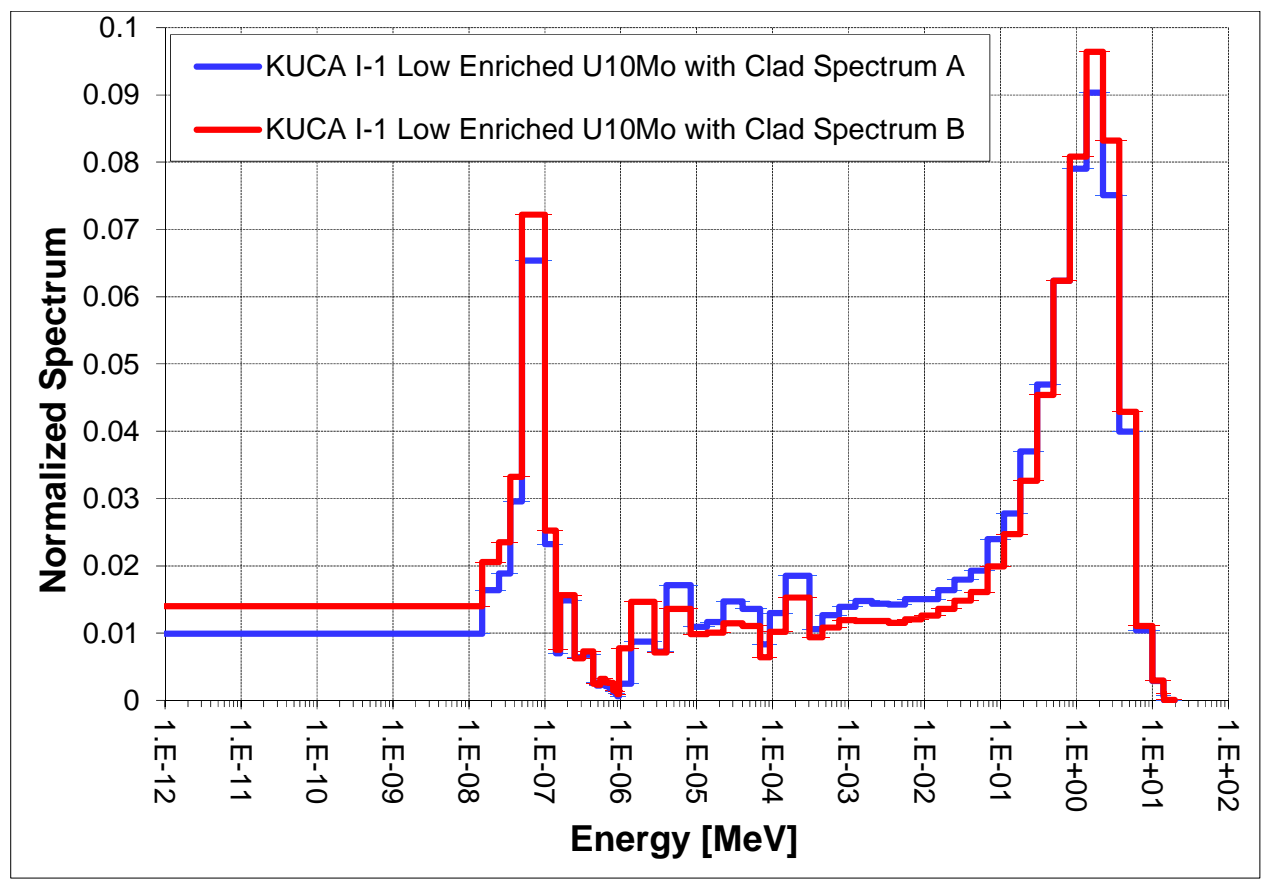

Figure 45. Flux Spectra at Positions A and B of KUCA I-1 with LEU U-10Mo and Al Cladding.

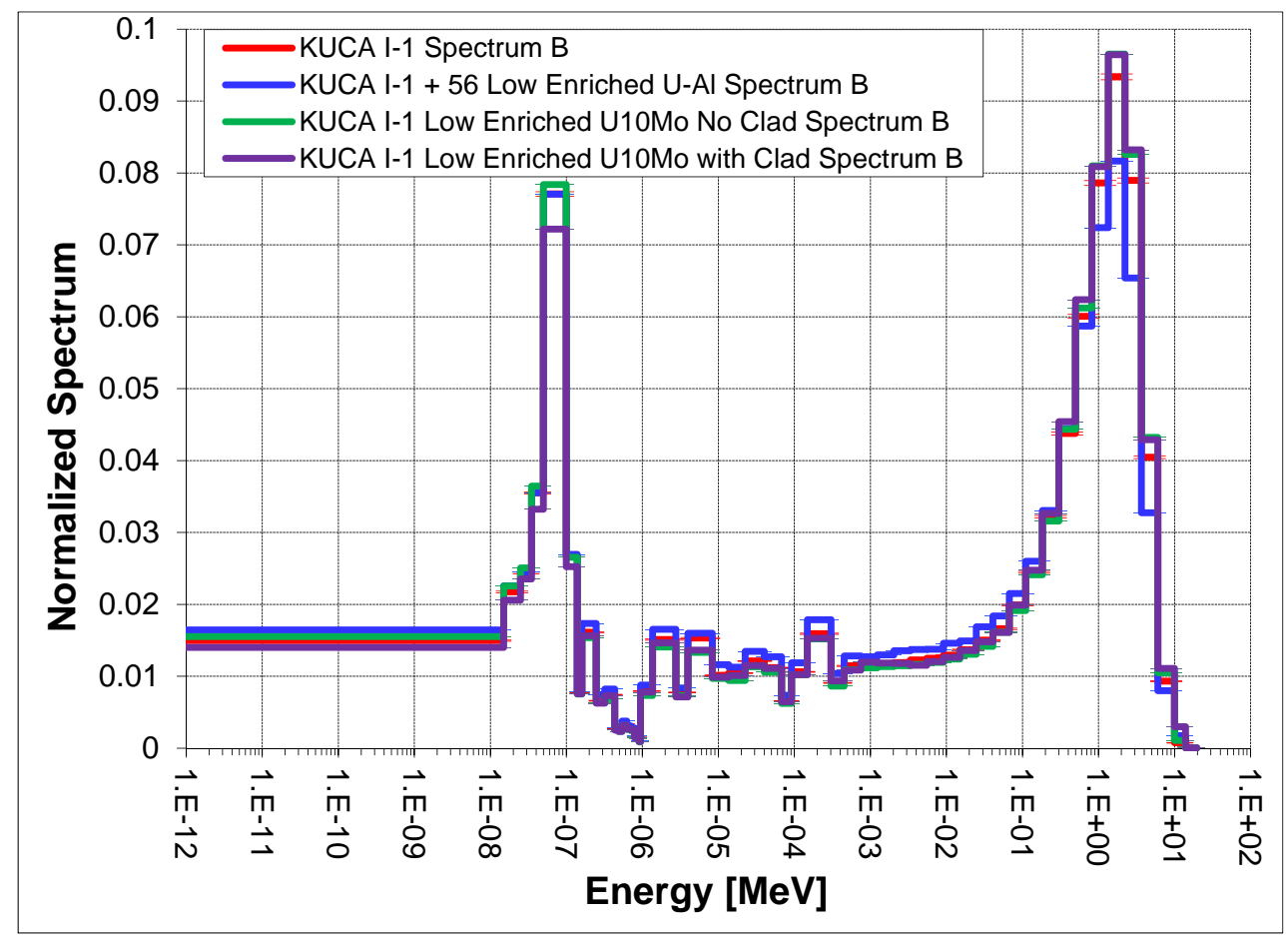

Figure 46. Flux Spectra at Position B of HEU and LEU KUCA I-1 Configurations. 


\subsection{Feasibility Studies on the Conversion of KUCA Type-A Cores with Different Moderator-to-Fuel Volume Ratios in the Unit Cell}

As requested by the KURRI experimentalist team, feasibility studies were performed for five "typeA" KUCA cores designated A3/8''P36EU, B2/8'P48EU, B1/8''P80EU, B1/8'P60EU-EU and B1/8' 'P48EU-EU-EU, which are characterized by different moderator-to-fuel volume ratios $\left(\mathrm{V}_{\mathrm{m}} / \mathrm{V}_{\mathrm{f}}\right)$ and different H-to-U235 atom ratios (H/U5) in the fuel unit cell. In these designators, the fractional value (e.g., 1/8") specifies the thickness of the polyethylene in the unit cell; the "P" value indicates the number of times the unit cell is repeated in the core region of the assembly (e.g., P80); and the number of times "EU" is repeated indicates the number of uranium plates in the unit cell. Results of this section were partly included in Ref. 3.

Summary descriptions of the cores of the proposed configurations were provided by KURRI. The received documentation contained pictures of the core layouts (core only, without surrounding polyethylene reflector) and fuel assemblies.

Figure 47 shows the core layouts, while Figures 48 through 52 show the cross-sectional views of the fuel assemblies and unit cells. From the first to the last configuration the $\mathrm{V}_{\mathrm{m}} / \mathrm{V}_{\mathrm{f}}$ ratio (and consequently the H/U5 atom ratio) decreases by a factor of about 10 .

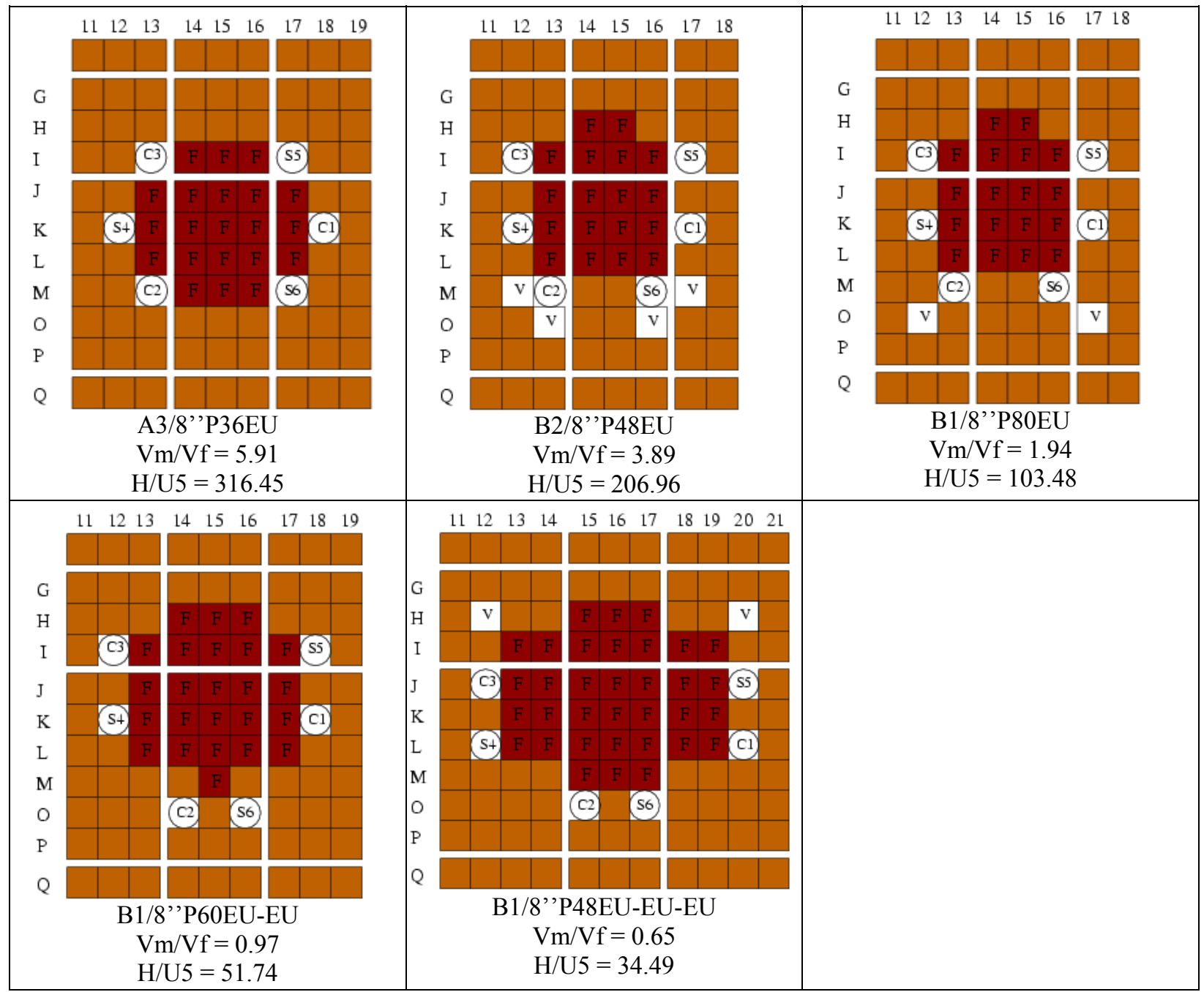

Figure 47. Layouts of the Investigated KUCA cores. 


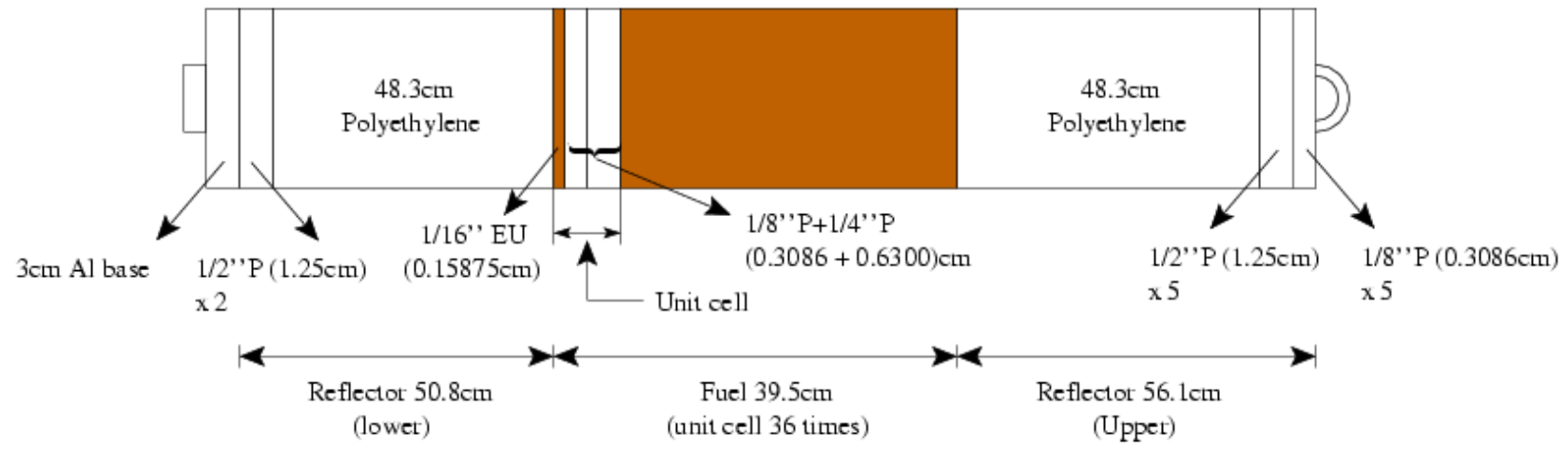

P: Polyethylene Plate

EU: EU Plate

Figure 48. Cross Sectional View of KUCA Fuel Assembly A3/8”P36EU - $\left(\mathrm{V}_{\mathrm{m}} / \mathrm{V}_{\mathrm{f}}=5.91\right.$ $\mathrm{H} / \mathrm{U} 5=316.45)$.

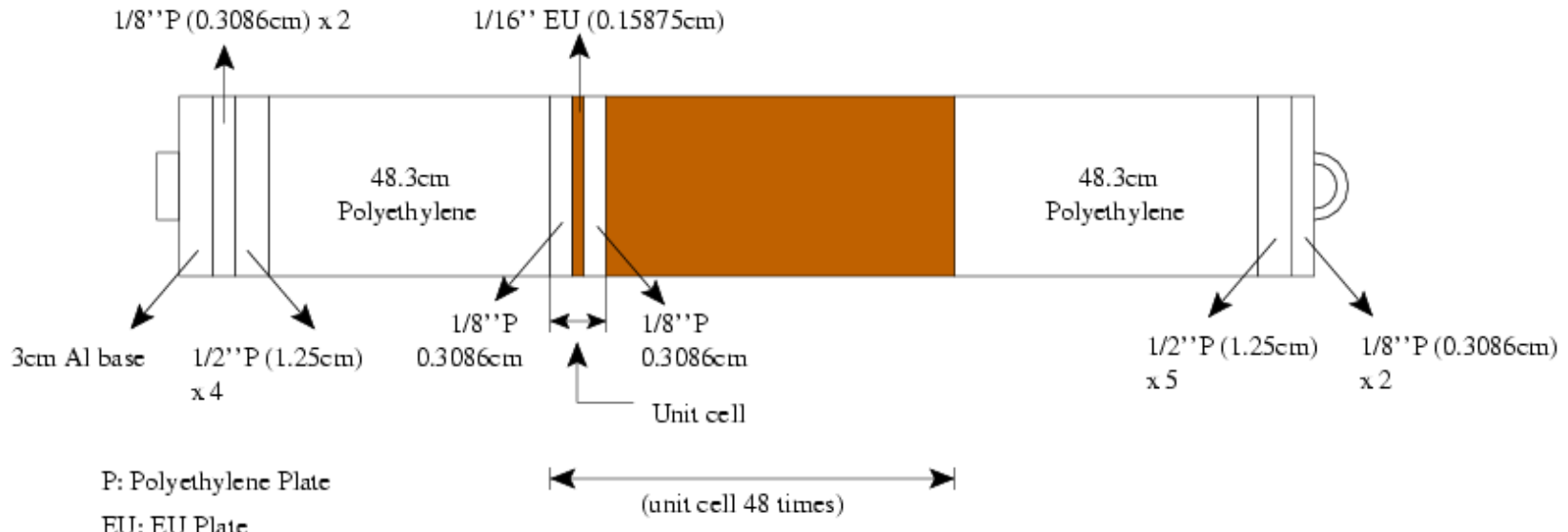

Figure 49. Cross Sectional View of KUCA Fuel Assembly B2/8"P48EU - $\left(\mathrm{V}_{\mathrm{m}} / \mathrm{V}_{\mathrm{f}}=3.89\right.$ $\mathrm{H} / \mathrm{U} 5=206.96)$.

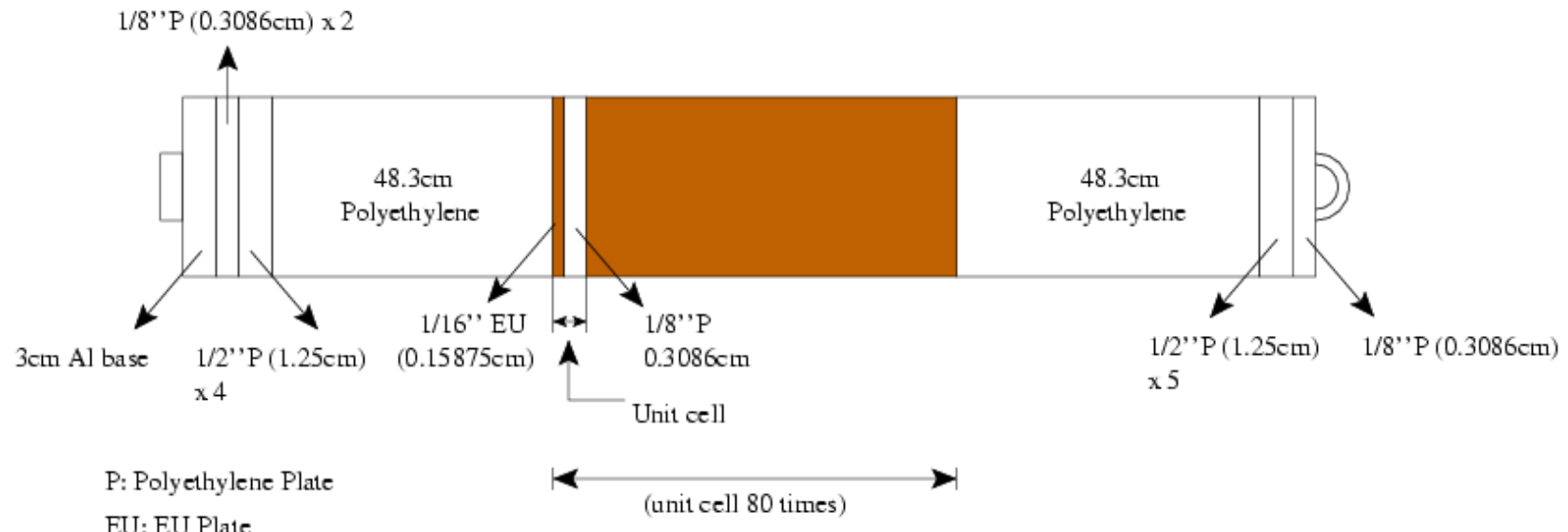

Figure 50. Cross Sectional View of KUCA Fuel Assembly B1/8'P80EU - $\left(\mathrm{V}_{\mathrm{m}} / \mathrm{V}_{\mathrm{f}}=1.94\right.$ $\mathrm{H} / \mathrm{U} 5=103.48)$. 


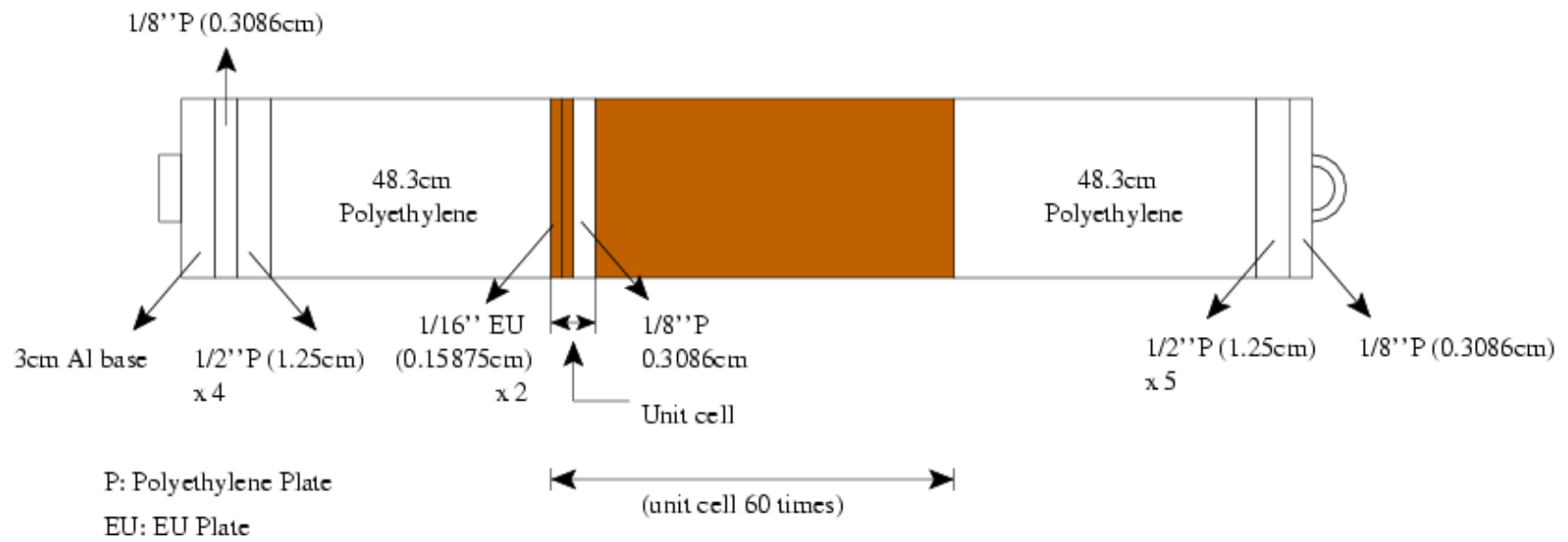

Figure 51. Cross Sectional View of KUCA Fuel Assembly B1/8"P60EU-EU - $\left(\mathrm{V}_{\mathrm{m}} / \mathrm{V}_{\mathrm{f}}=0.97\right.$ $\mathrm{H} / \mathrm{U} 5=51.74)$.

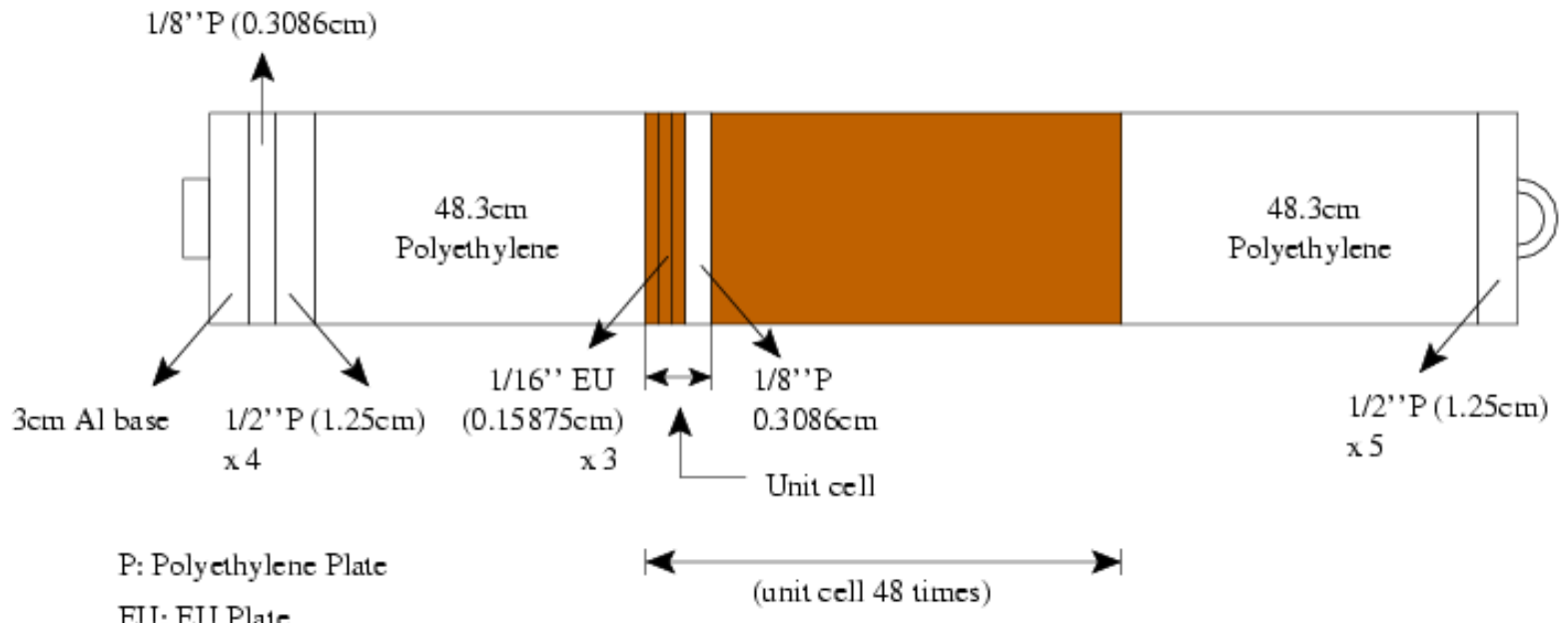

Figure 52. Cross Sectional View of KUCA Fuel Assembly B1/8"P48EU-EU-EU - $\left(\mathrm{V}_{\mathrm{m}} / \mathrm{V}_{\mathrm{f}}=0.65\right.$ $\mathrm{H} / \mathrm{U} 5=34.49)$.

In the absence of additional details, a number of assumptions had to be made in order to perform calculations of the proposed configurations. Specifically, the following assumptions were made:

1. As mentioned above, information on the external boundary of the polyethylene reflector surrounding the core of all proposed configurations was not provided. Thus, the reflector boundary was kept as in the KUCA I-1 configuration of the benchmark report (see Figure 53 for the case of the KUCA A3/8' 'P36EU configuration). By doing so, some KUCA configurations have more polyethylene reflector assemblies than others (i.e. the reflector dimension is not consistent among the configurations analyzed).

2. The compositions of all materials employed (1/16" EU plates, $1 / 2$ ", $1 / 4$ "' and $1 / 8$ " polyethylene plates, polyethylene blocks, control and safety rods, aluminum tubes) were also taken from the KUCA benchmark specifications. It is noted that in the benchmark specifications, the compositions of the 1/16" EU plates have no impurities (see Table 6). 
3. The three control rods and the three safety rods were also modeled according to the benchmark specifications. Additionally, in the absence of any indication of the control rod position, calculations were performed for the two states that were considered in the benchmark report, i.e. the "excess reactivity" rod configuration with all control and safety rods completely withdrawn and the "subcritical" rod configuration with all safety rods completely withdrawn and control rods $\mathrm{C} 1, \mathrm{C} 2$ and $\mathrm{C} 3$ fully inserted.

4. The documentation provided by KURRI for the KUCA A3/8''P36EU, B2/8''P48EU, B1/8''P80EU, B1/8''P60EU-EU and B1/8''P48EU-EU-EU configurations include a table with the experimental reactivity values. Since no indication was found, it is assumed that those reactivity values were obtained in the "excess reactivity" rod configuration.

5. The gaps between the assemblies for flux wire arrangements were also kept as described in the KUCA benchmark report. Additionally, the indium wire located at the core midplane between the assemblies $(16,17-\mathrm{J}, \mathrm{W})$ was kept in the present KUCA configurations as well.

Certainly, the changes that the actual configurations would imply for reflector boundary, material compositions, assembly gaps, etc., can be considered of negligible interest for the scope of the present studies on the feasibility of the conversion of the KUCA cores from high- to low-enriched uranium. However, for a better comparison of experimental and calculated $\mathrm{k}_{\text {eff }}$ values, the following additional information would be needed:

1. Exact position of control and safety rods for the determination of the measured $\mathrm{k}_{\mathrm{eff}}$ values;

2. Detailed description of non uniform gaps for flux wires;

3. Impurities of the HEU plates.

Then, for the feasibility studies on the conversion of the proposed KUCA cores from HEU to LEU it would be advisable to know if there are any constraints on the LEU fuel to be used (fuel type, dimension of the plates, material inventory, etc.). For the present analysis, the LEU KUCA cores were loaded with U-10Mo foils (see Section 3.3.1. for more details).

The feasibility studies on the conversion of the proposed KUCA cores from HEU to LEU included analysis of the flux spectra. In this case it was not known if there are any specifications or preferences by the KUCA team on the exact position where flux spectra should be tallied and which group structure is to be used. For the present work, flux spectra were obtained in 53 energy groups and in the positions described in Section 3.3.3. 


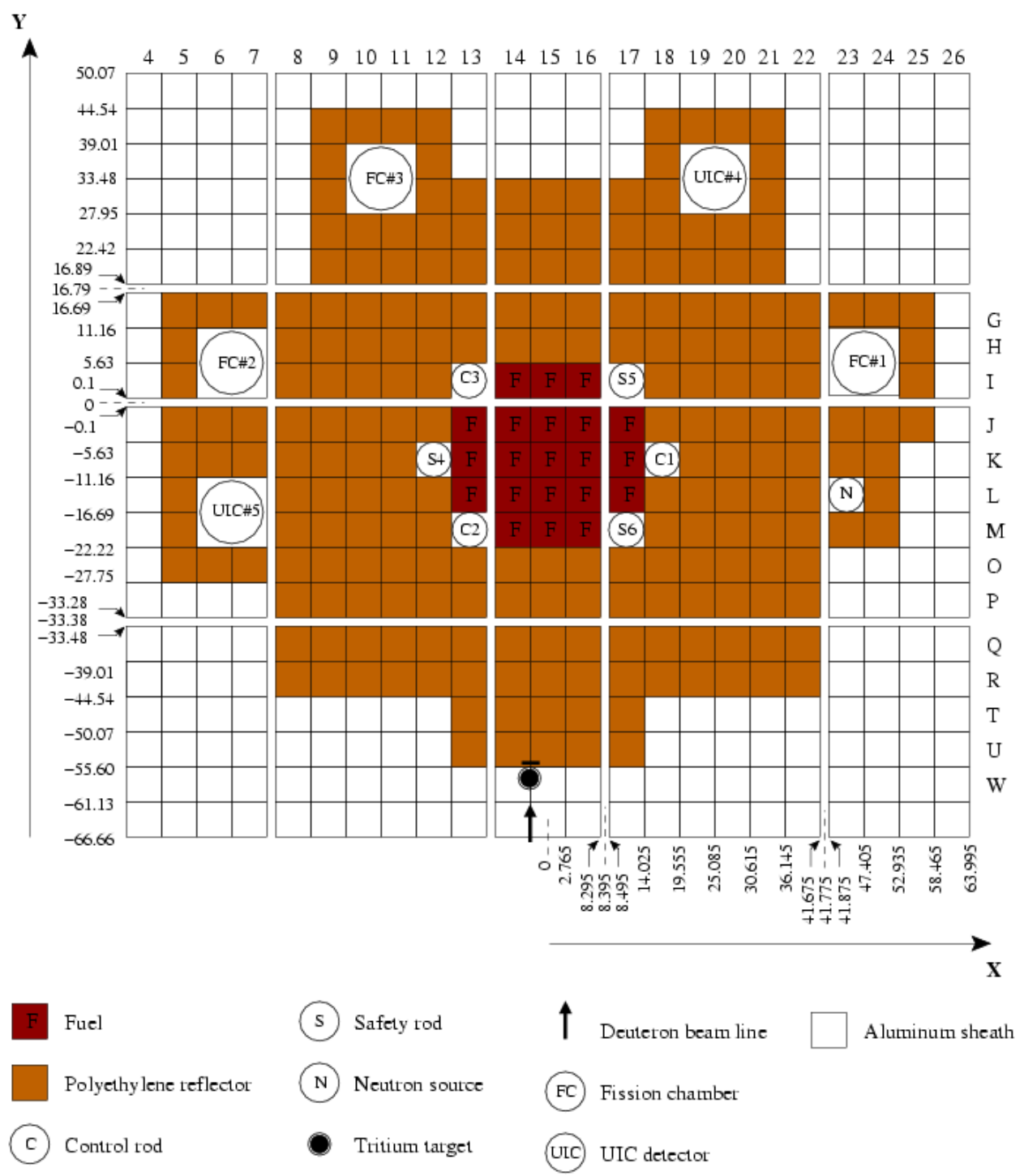

Figure 53. KUCA A3/8'’P36EU: Detail of Reflector Layout Kept the Same for all Configurations.

\subsubsection{Approaches Used for the Conversion from HEU to LEU}

For the conversion of the proposed KUCA cores from HEU to LEU, each 1/16-in. HEU plate was replaced with a single LEU foil of U-10Mo clad by aluminum on both sides (see Case A in Figure 54). All polyethylene plates remain exactly the same as the HEU configuration. In a more sophisticated approach, one may also consider having an aluminum edge all around the LEU foil in order to prevent cracking (see Case B in Figure 54). Concerning the dimensions, it seems there are no constraints officially imposed by the fabricators, however it was assumed that the thickness of both the U-10Mo foil and Al clad cannot be less than 10 mils. Less well defined are the recommendations on the width of the aluminum edge that was fixed to a minimum of 100 mils for the present study. The compositions that were used for the U-10Mo foils and aluminum clad are the same as those given in Table 6. 

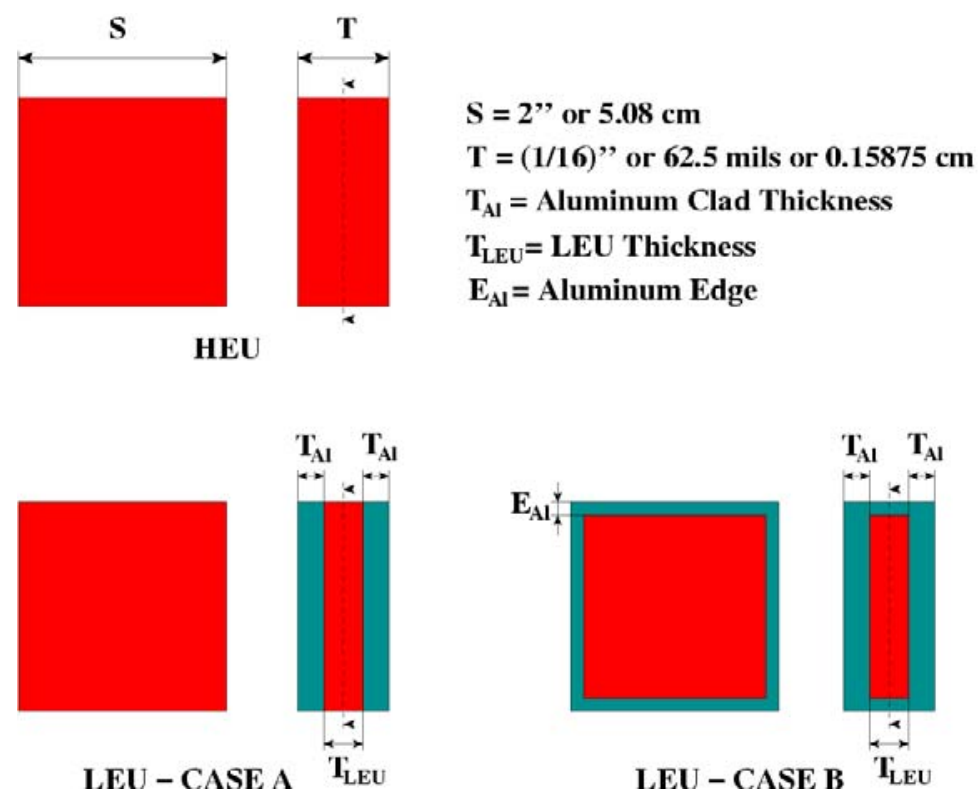

Figure 54. HEU and U-10Mo LEU fuel plate.

\subsubsection{Reactivity Calculations}

The arrangements of both cases A and B were considered. All control and safety rods were assumed to be fully withdrawn ("excess reactivity" rod configuration).

The goal of the study was to determine the dimensions of the U-10Mo foils necessary to keep the same reactivity as the corresponding HEU configuration. For this purpose, the reactivity of the LEU configurations was first determined with conditions of maximum fuel loading, i.e., the thickness of the Al clad is reduced to the minimum allowed $(10$ mils $)$, and consequently the thickness of the U-10Mo foils is fixed to the maximum value of 42.5 mils, so that the total extension of $1 / 16$ in.' (i.e., 62.5 mils) of the HEU fuel plate being replaced is preserved. Calculations were performed with no aluminum edge (condition of maximum loading in Case A described above) and with an aluminum edge of 100 mils (condition of maximum loading in the Case B described above). The results obtained using MCNP5 and ENDF/B-VII.0 data are presented in Table 8 for each configuration. For comparison, the reactivity values (both calculated and measured) of the corresponding HEU configurations are also presented in Table 8.

It can be seen that for the KUCA A3/8''P36EU and B2/8''P48EU max-loading configurations with and without the aluminum edge, the multiplication factor $\left(\mathrm{k}_{\text {eff }}\right)$ values obtained in the LEU case are larger than the $\mathrm{k}_{\text {eff }}$ values obtained in the HEU cases, as would be desirable. An excess reactivity, in fact, would allow one to reduce the thickness of the U-10Mo foils in order to get the same $k_{\text {eff }}$ as the HEU configuration and eventually would also leave the option to adjust the dimensions of the U-10Mo foil for the purpose of improving other neutronic features, such as the neutron spectra, etc. 
Table 8. Calculated (Experimental) Multiplication Factor Values of HEU and U-10Mo LEU KUCA Configurations.

\begin{tabular}{|c|c|c|c|}
\hline Configuration & Loading Type & $\begin{array}{l}\text { Plate Dimensions (mils); } \\
\qquad V_{\mathrm{m}} / V_{\mathrm{f}} ; \mathbf{H} / \mathrm{U} 5\end{array}$ & $\begin{array}{l}\mathbf{k}_{\text {eff }}: \text { Calculation } \\
\text { (Experiment) }\end{array}$ \\
\hline \multirow{6}{*}{$\begin{array}{c}\text { KUCA } \\
\text { A3/8'"P36EU }\end{array}$} & HEU & $\begin{array}{l}\mathrm{T}=62.5 ; \mathrm{V}_{\mathrm{m}} / \mathrm{V}_{\mathrm{f}}=5.91 \\
\mathrm{H} / \mathrm{U} 5=316.45\end{array}$ & $\begin{array}{c}1.00402 \pm 0.00006 \\
(1.0008)\end{array}$ \\
\hline & $\begin{array}{l}\text { LEU no Al Edge: } \\
\text { max loading }\end{array}$ & $\begin{array}{l}\mathrm{T}_{\mathrm{LEU}}=42.5 ; \mathrm{T}_{\mathrm{Al}}=10 ; \mathrm{E}_{\mathrm{Al}}=0 \\
\mathrm{~V}_{\mathrm{m}} / \mathrm{V}_{\mathrm{f}}=8.69 \mathrm{H} / \mathrm{U} 5=90.47\end{array}$ & $1.10934 \pm 0.00007$ \\
\hline & $\begin{array}{l}\text { LEU no Al Edge: } \\
\text { same H/U5 as HEU }\end{array}$ & $\begin{array}{l}\mathrm{T}_{\mathrm{LEU}}=12.15 ; \mathrm{T}_{\mathrm{Al}}=21.17 ; \mathrm{E}_{\mathrm{Al}}=0 \\
\mathrm{~V}_{\mathrm{m}} / \mathrm{V}_{\mathrm{f}}=30.41 \quad \mathrm{H} / \mathrm{U} 5=316.45\end{array}$ & $0.96027 \pm 0.00006$ \\
\hline & $\begin{array}{l}\text { LEU no Al Edge: } \\
\text { same }_{\text {sff }} \text { as HEU }\end{array}$ & $\begin{array}{l}\mathrm{T}_{\mathrm{LEU}}=16 ; \mathrm{T}_{\mathrm{Al}}=23.25 ; \mathrm{E}_{\mathrm{Al}}=0 \\
\mathrm{~V}_{\mathrm{m}} / \mathrm{V}_{\mathrm{f}}=23.10 \quad \mathrm{H} / \mathrm{U} 5=240.32\end{array}$ & $1.00585 \pm 0.00006$ \\
\hline & $\begin{array}{l}\text { LEU with Al Edge: } \\
\text { max loading }\end{array}$ & $\begin{array}{l}\mathrm{T}_{\mathrm{LEU}}=42.5 ; \mathrm{T}_{\mathrm{Al}}=10 ; \mathrm{E}_{\mathrm{Al}}=100 \\
\mathrm{~V}_{\mathrm{m}} / \mathrm{V}_{\mathrm{f}}=10.73 ; \mathrm{H} / \mathrm{U} 5=111.70\end{array}$ & $1.07876 \pm 0.00007$ \\
\hline & $\begin{array}{l}\text { LEU with Al Edge: } \\
\text { same } \mathrm{k}_{\text {eff }} \text { as HEU }\end{array}$ & $\begin{array}{l}\mathrm{T}_{\mathrm{LEU}}=22 ; \mathrm{T}_{\mathrm{Al}}=20.25 ; \mathrm{E}_{\mathrm{Al}}=100 \\
\mathrm{~V}_{\mathrm{m}} / \mathrm{V}_{\mathrm{f}}=20.74 ; \quad \mathrm{H} / \mathrm{U} 5=215.78\end{array}$ & $1.00640 \pm 0.00006$ \\
\hline \multirow{6}{*}{$\begin{array}{c}\text { KUCA } \\
\text { B2/8'’P48EU }\end{array}$} & HEU & $\mathrm{T}=62.5 ; \mathrm{V}_{\mathrm{m}} / \mathrm{V}_{\mathrm{f}}=3.89 ; \mathrm{H} / \mathrm{U} 5=206.96$ & $\begin{array}{c}0.99769 \pm 0.00006 \\
(1.0010)\end{array}$ \\
\hline & $\begin{array}{l}\text { LEU no Al Edge: } \\
\text { max loading }\end{array}$ & $\begin{array}{l}\mathrm{T}_{\mathrm{LEU}}=42.5 ; \mathrm{T}_{\mathrm{Al}}=10 ; \mathrm{E}_{\mathrm{Al}}=0 \\
\mathrm{~V}_{\mathrm{m}} / \mathrm{V}_{\mathrm{f}}=5.72 ; \mathrm{H} / \mathrm{U} 5=59.17\end{array}$ & $1.05199 \pm 0.00007$ \\
\hline & $\begin{array}{l}\text { LEU no Al Edge: } \\
\text { same H/U5 as HEU }\end{array}$ & $\begin{array}{l}\mathrm{T}_{\mathrm{LEU}}=12.15 ; \mathrm{T}_{\mathrm{Al}}=21.17 ; \mathrm{E}_{\mathrm{Al}}=0 \\
\mathrm{~V}_{\mathrm{m}} / \mathrm{V}_{\mathrm{f}}=20.00 ; \mathrm{H} / \mathrm{U} 5=206.96\end{array}$ & $0.94585 \pm 0.00006$ \\
\hline & $\begin{array}{l}\text { LEU no Al Edge: } \\
\text {-same } k_{\text {eff }} \text { as HEU }\end{array}$ & $\begin{array}{l}\mathrm{T}_{\mathrm{LEU}}=19 ; \mathrm{T}_{\mathrm{Al}}=21.75 ; \mathrm{E}_{\mathrm{Al}}=0 \\
\mathrm{~V}_{\mathrm{m}} / \mathrm{V}_{\mathrm{f}}=12.79 ; \mathrm{H} / \mathrm{U} 5=132.35\end{array}$ & $0.99706 \pm 0.00006$ \\
\hline & $\begin{array}{l}\text { LEU with Al Edge: } \\
\text { max loading }\end{array}$ & $\begin{array}{l}\mathrm{T}_{\mathrm{LEU}}=42.5 ; \mathrm{T}_{\mathrm{Al}}=10 ; \mathrm{E}_{\mathrm{Al}}=100 \\
\mathrm{~V}_{\mathrm{m}} / \mathrm{V}_{\mathrm{f}}=7.06 ; \mathrm{H} / \mathrm{U} 5=73.05\end{array}$ & $1.02899 \pm 0.00007$ \\
\hline & $\begin{array}{l}\text { LEU with Al Edge: } \\
\text { same } k_{\text {eff }} \text { as HEU }\end{array}$ & $\begin{array}{l}\mathrm{T}_{\mathrm{LEU}}=28 ; \mathrm{T}_{\mathrm{Al}}=17.25 ; \mathrm{E}_{\mathrm{Al}}=100 \\
\mathrm{~V}_{\mathrm{m}} / \mathrm{V}_{\mathrm{f}}=10.71 ; \mathrm{H} / \mathrm{U} 5=110.88\end{array}$ & $0.99958 \pm 0.00007$ \\
\hline \multirow{4}{*}{$\begin{array}{c}\text { KUCA } \\
\text { B1/8'’P80EU }\end{array}$} & HEU & $\mathrm{T}=62.5 ; \mathrm{V}_{\mathrm{m}} / \mathrm{V}_{\mathrm{f}}=1.94 ; \mathrm{H} / \mathrm{U} 5=103.48$ & $\begin{array}{c}0.99882 \pm 0.00007 \\
(1.0015)\end{array}$ \\
\hline & $\begin{array}{l}\text { LEU no Al Edge: } \\
\text { max loading }\end{array}$ & $\begin{array}{l}\mathrm{T}_{\mathrm{LEU}}=42.5 ; \mathrm{T}_{\mathrm{Al}}=10 ; \mathrm{E}_{\mathrm{Al}}=0 \\
\mathrm{~V}_{\mathrm{m}} / \mathrm{V}_{\mathrm{f}}=2.86 ; \mathrm{H} / \mathrm{U} 5=29.58\end{array}$ & $0.99611 \pm 0.00007$ \\
\hline & $\begin{array}{l}\text { LEU no Al Edge: } \\
\text { same H/U5 as HEU }\end{array}$ & $\begin{array}{l}\mathrm{T}_{\mathrm{LEU}}=12.15 ; \mathrm{T}_{\mathrm{Al}}=21.17 ; \mathrm{E}_{\mathrm{Al}}=0 \\
\mathrm{~V}_{\mathrm{m}} / \mathrm{V}_{\mathrm{f}}=10.00 ; \mathrm{H} / \mathrm{U} 5=103.48\end{array}$ & $0.93177 \pm 0.00007$ \\
\hline & $\begin{array}{l}\text { LEU with Al Edge: } \\
\text { max loading }\end{array}$ & $\begin{array}{l}\mathrm{T}_{\mathrm{LEU}}=42.5 ; \mathrm{T}_{\mathrm{Al}}=10 ; \mathrm{E}_{\mathrm{Al}}=100 \\
\mathrm{~V}_{\mathrm{m}} / \mathrm{V}_{\mathrm{f}}=3.53 ; \mathrm{H} / \mathrm{U} 5=36.52\end{array}$ & $0.97932 \pm 0.00007$ \\
\hline \multirow{4}{*}{$\begin{array}{c}\text { KUCA } \\
\text { B1/8'’P60EU-EU }\end{array}$} & HEU & $\mathrm{T}=62.5 ; \mathrm{V}_{\mathrm{m}} / \mathrm{V}_{\mathrm{f}}=0.97 ; \mathrm{H} / \mathrm{U} 5=51.74$ & $\begin{array}{c}1.00020 \pm 0.00007 \\
(1.0010)\end{array}$ \\
\hline & $\begin{array}{l}\text { LEU no Al Edge: } \\
\text { max loading }\end{array}$ & $\begin{array}{l}\mathrm{T}_{\mathrm{LEU}}=42.5 ; \mathrm{T}_{\mathrm{Al}}=10 ; \mathrm{E}_{\mathrm{Al}}=0 \\
\mathrm{~V}_{\mathrm{m}} / \mathrm{V}_{\mathrm{f}}=1.43 ; \mathrm{H} / \mathrm{U} 5=14.79\end{array}$ & $0.99348 \pm 0.00006$ \\
\hline & $\begin{array}{l}\text { LEU no Al Edge: } \\
\text { same H/U5 as HEU }\end{array}$ & $\begin{array}{l}\mathrm{T}_{\mathrm{LEU}}=12.15 ; \mathrm{T}_{\mathrm{Al}}=21.17 ; \mathrm{E}_{\mathrm{Al}}=0 \\
\mathrm{~V}_{\mathrm{m}} / \mathrm{V}_{\mathrm{f}}=5.00 \mathrm{H} / \mathrm{U} 5=51.74\end{array}$ & $0.92730 \pm 0.00007$ \\
\hline & $\begin{array}{l}\text { LEU with Al Edge: } \\
\text { max loading }\end{array}$ & $\begin{array}{l}\mathrm{T}_{\mathrm{LEU}}=42.5 ; \mathrm{T}_{\mathrm{Al}}=10 ; \mathrm{E}_{\mathrm{Al}}=100 \\
\mathrm{~V}_{\mathrm{m}} / \mathrm{V}_{\mathrm{f}}=1.76 ; \mathrm{H} / \mathrm{U} 5=18.26\end{array}$ & $0.97635 \pm 0.00006$ \\
\hline \multirow{4}{*}{$\begin{array}{c}\text { KUCA } \\
\text { B1/8,'P48EU-EU-EU }\end{array}$} & HEU & $\mathrm{T}=62.5 ; \mathrm{V}_{\mathrm{m}} / \mathrm{V}_{\mathrm{f}}=0.65 ; \mathrm{H} / \mathrm{U} 5=34.49$ & $\begin{array}{c}1.00114 \pm 0.00007 \\
(1.0015)\end{array}$ \\
\hline & $\begin{array}{l}\text { LEU no Al Edge: } \\
\text { max loading }\end{array}$ & $\begin{array}{l}\mathrm{T}_{\mathrm{LEU}}=42.5 ; \mathrm{T}_{\mathrm{Al}}=10 ; \mathrm{E}_{\mathrm{Al}}=0 \\
\mathrm{~V}_{\mathrm{m}} / \mathrm{V}_{\mathrm{f}}=0.95 ; \mathrm{H} / \mathrm{U} 5=9.86\end{array}$ & $1.00863 \pm 0.00005$ \\
\hline & $\begin{array}{l}\text { LEU no Al Edge: } \\
\text { same H/U5 as HEU }\end{array}$ & $\begin{array}{l}\mathrm{T}_{\mathrm{LEU}}=12.15 ; \mathrm{T}_{\mathrm{Al}}=21.17 ; \mathrm{E}_{\mathrm{Al}}=0 \\
\mathrm{~V}_{\mathrm{m}} / \mathrm{V}_{\mathrm{f}}=3.33 ; \mathrm{H} / \mathrm{U} 5=34.49\end{array}$ & $0.92533 \pm 0.00006$ \\
\hline & $\begin{array}{l}\text { LEU with Al Edge: } \\
\text { max loading }\end{array}$ & $\begin{array}{l}\mathrm{T}_{\mathrm{LEU}}=42.5 ; \mathrm{T}_{\mathrm{Al}}=10 ; \mathrm{E}_{\mathrm{Al}}=100 \\
\mathrm{~V}_{\mathrm{m}} / \mathrm{V}_{\mathrm{f}}=1.18 ; \mathrm{H} / \mathrm{U} 5=12.17\end{array}$ & $0.98812 \pm 0.00006$ \\
\hline
\end{tabular}


In Table 8, it can be also noted that the multiplication factor values of the LEU configurations relative to the values of the corresponding HEU cores decrease sharply with decreasing $\mathrm{V}_{\mathrm{m}} / \mathrm{V}_{\mathrm{f}}$ or $\mathrm{H} / \mathrm{U}$.

In particular, in the case of no aluminum edge, calculations have been performed for a specific thickness of the U-10Mo foils that preserves the same H/U5 as the corresponding HEU configuration. It can be seen that for KUCA A3/8''P36EU (high H/U5) the $\mathrm{k}_{\text {eff }}$ obtained in the LEU case is $4000 \mathrm{pcm}$ less than the calculated value in the HEU case due to a combination of effects, including harder spectrum, shielding effects in the U-10Mo foil and absorption in the aluminum clad. Reducing the H/U5 ratio makes these effects become more and more relevant. For the configuration of lowest H/U5, i.e., KUCA B1/8' P48EU-EU-EU, the $\mathrm{k}_{\text {eff }}$ obtained in the LEU case is $\sim 8000 \mathrm{pcm}$ less than the calculated value in the HEU case. For this reason, as it can be seen in Table 8, for the LEU configurations with low H/U5 (i.e., KUCA B1/8'P80EU, B1/8'P60EU-EU and B1/8''P48EU-EU-EU), only the conditions of maximum loading without the aluminum edge would assure a reactivity value more or less comparable to that of the corresponding HEU cores.

However, for these configurations different solutions could be envisaged so that the desired $\mathrm{k}_{\mathrm{eff}}$ in the LEU cases can be achieved with U-10Mo foil dimensions that are smaller than the maximum allowed. As an example, one may consider adding some fuel assemblies at the core boundary. Or, as in the case of KUCA B1/8'P60EU-EU and B1/8' P48EU-EU-EU, adjacent LEU plates could be merged into a single plate, eliminating the need for some of the Al cladding. As an example, Table 9 shows the $\mathrm{k}_{\text {eff }}$ results for KUCA B1/8''P80EU after the addition of two fuel assemblies and for KUCA B1/8'P60EU-EU and B1/8' P48EU-EU-EU after merging the adjacent 1/16-in. LEU plates according to the scheme illustrated in Figure 55.
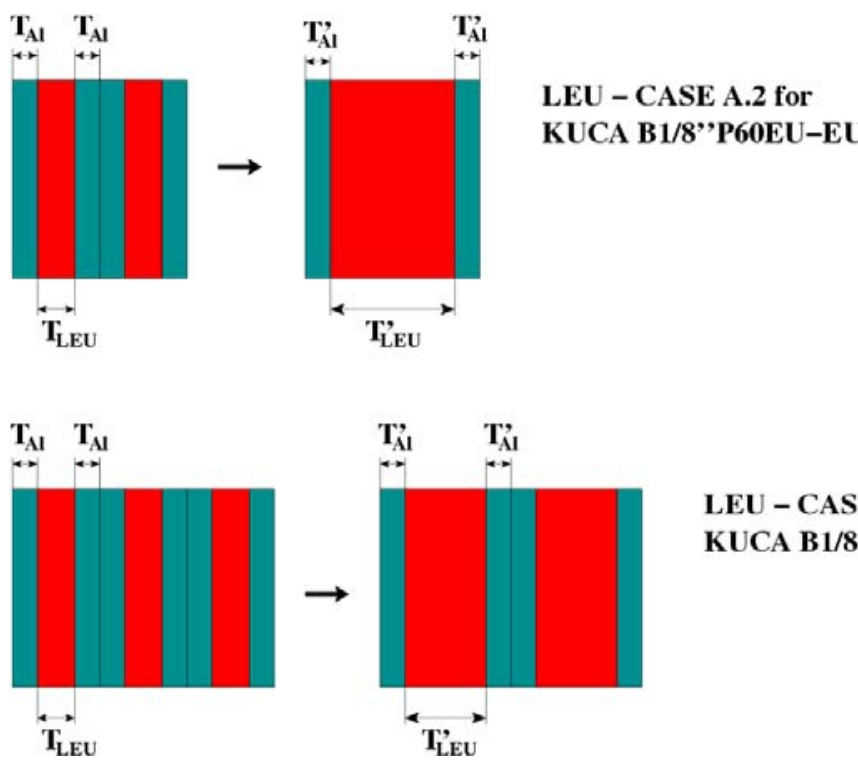

LEU - CASE A.2 for

KUCA B1/8''P48EU-EU-EU

Figure 55. Alternative LEU Fuel Loading for KUCA B1/8',P60EU-EU and B1/8'’P48EU-EU-EU.

In the studies discussed so far on the conversion feasibility of the five selected KUCA configurations from HEU to LEU, all control and safety rods were assumed to be fully withdrawn ("excess reactivity" rod configuration). Calculations have been also performed for the "subcritical" control rod configuration (control rods fully inserted and safety rods completely withdrawn), in order to investigate any change of the control rod worth between the HEU and LEU cases. 
Table 9. Calculated Multiplication Factor Values of U-10Mo LEU KUCA Configurations.

\begin{tabular}{|c|l|c|}
\hline Configuration & \multicolumn{1}{|c|}{ Loading Type } & $\mathbf{k}_{\text {eff }}$ Calculation \\
\hline $\begin{array}{c}\text { KUCA } \\
\text { B1/8'P80EU }\end{array}$ & LEU no Al Edge, 2 assemblies added: max loading & $1.01129 \pm 0.00007$ \\
\cline { 2 - 3 } $\begin{array}{c}\text { KUCA } \\
\text { B1/8'P60EU-EU }\end{array}$ & LEU with 100 mils Al Edge, 2 assemblies added: max loading & $0.99579 \pm 0.00007$ \\
\cline { 2 - 3 } & $\begin{array}{l}\text { LEU no Al Edge, merging 2 LEU plates in 1: max loading } \\
\text { loading }\end{array}$ & $1.01020 \pm 0.00006$ \\
\hline $\begin{array}{c}\text { KUCA } \\
\text { B1/8',P48EU-EU-EU }\end{array}$ & LEU no Al Edge, merging 3 LEU plates in 2: max loading & $1.02424 \pm 0.00006$ \\
\cline { 2 - 3 } & $\begin{array}{l}\text { LEU with 100 mils Al Edge merging 3 LEU plates in 2: max } \\
\text { loading }\end{array}$ & $1.00221 \pm 0.00006$ \\
\hline
\end{tabular}

The fourth column of Table 10 shows the results that were obtained for the "excess reactivity" rod configuration for the HEU cores and the LEU cores where the thickness of the U-10Mo foils was optimized to give a $\mathrm{k}_{\text {eff }}$ comparable to that of the corresponding HEU cases.

For both HEU and LEU configurations, the fifth column of Table 10 shows the multiplication factor values obtained in the "subcritical" control rod configuration. Finally, the sixth column of Table 10, obtained from the difference of the multiplication factor values in the "excess reactivity" and "subcritical" rod configurations, gives for each KUCA core an indication of the reactivity change resulting from the insertion of the three control rods used in KUCA.

It can be seen that the control rod worth in the LEU cores is smaller than that obtained in the corresponding HEU cores. This result was expected due to the harder spectrum of the LEU configurations with respect to the HEU configurations. However, in Table 10 it can be also noted that this difference in the reactivity worths between the HEU and LEU cases increases remarkably when going to configurations with low moderator-to-fuel volume ratios. For instance, for the A3/8' $P 36 \mathrm{EU}$ configuration the difference in the reactivity worth between the HEU and LEU cores is $\sim 100$ and $\sim 200 \mathrm{pcm}$ without and with the use of the aluminum edge in the LEU case, respectively. On the contrary, for the P1/8' P48EU-EU-EU configuration the difference in the reactivity worth between the HEU and LEU cores is $\sim 600$ and $\sim 500$ pcm without and with the use of the aluminum edge in the LEU case, respectively.

Similarly, Table 11 compares the $k_{\text {eff }}$ values of "excess reactivity" and "subcritical" control rod configurations obtained for the alternative loadings of the LEU configurations with low H/U5 (i.e., KUCA B1/8''P80EU, B1/8',P60EU-EU and B1/8' 'P48EU-EU-EU) that were presented in Table 9. 
Table 10. Calculated Multiplication Factor Values of HEU and LEU KUCA Cores in Reactivity Excess and Subcritical Rod Configuration.

\begin{tabular}{|c|c|c|c|c|c|}
\hline Configuration & Loading Type & $\begin{array}{l}\text { Plate Dimensions (mils); } \\
\qquad V_{m} / V_{f} ; H / U 5\end{array}$ & \begin{tabular}{|c|} 
Excess \\
Reactivity Rod \\
Configuration \\
$\mathbf{k}_{\text {eff }}:$ Calculation
\end{tabular} & $\begin{array}{l}\text { Subcritical Rod } \\
\text { Configuration } \\
\mathbf{k}_{\text {eff: }} \text { Calculation }\end{array}$ & $\Delta \mathbf{k}_{\text {eff }}$ \\
\hline \multirow{3}{*}{$\begin{array}{c}\text { KUCA } \\
\text { A3/8'’P36EU }\end{array}$} & HEU & $\begin{array}{l}\mathrm{T}=62.5 ; \\
\mathrm{V}_{\mathrm{m}} / \mathrm{V}_{\mathrm{f}}=5.91 ; \mathrm{H} / \mathrm{U} 5=316.45\end{array}$ & $\begin{array}{c}1.00402 \\
\pm 0.00006\end{array}$ & $\begin{array}{c}0.98522 \\
\pm 0.00006 \\
\end{array}$ & 0.01880 \\
\hline & $\begin{array}{l}\text { LEU no Al Edge: } \\
\text { same }_{\text {kff }} \text { as HEU }\end{array}$ & $\begin{array}{l}\mathrm{T}_{\mathrm{LEU}}=16 ; \mathrm{T}_{\mathrm{Al}}=23.25 ; \mathrm{E}_{\mathrm{Al}}=0 \\
\mathrm{~V}_{\mathrm{m}} / \mathrm{V}_{\mathrm{f}}=23.10 \mathrm{H} / \mathrm{U} 5=240.32\end{array}$ & $\begin{array}{c}1.00585 \\
\pm 0.00006\end{array}$ & $\begin{array}{c}0.98821 \\
\pm 0.00006\end{array}$ & 0.01764 \\
\hline & $\begin{array}{l}\text { LEU with Al Edge: } \\
\text { same } k_{\text {eff }} \text { as HEU }\end{array}$ & $\begin{array}{l}\mathrm{T}_{\mathrm{LEU}}=22 ; \mathrm{T}_{\mathrm{Al}}=20.25 ; \mathrm{E}_{\mathrm{Al}}=100 \\
\mathrm{~V}_{\mathrm{m}} / \mathrm{V}_{\mathrm{f}}=20.74 ; \quad \mathrm{H} / \mathrm{U} 5=215.78\end{array}$ & $\begin{array}{c}1.00640 \\
\pm 0.00006\end{array}$ & $\begin{array}{c}0.98951 \\
\pm 0.00006 \\
\end{array}$ & 0.01689 \\
\hline \multirow{3}{*}{$\begin{array}{c}\text { KUCA } \\
\text { B2/8'’P48EU }\end{array}$} & HEU & $\begin{array}{l}\mathrm{T}=62.5 ; \\
\mathrm{V}_{\mathrm{m}} / \mathrm{V}_{\mathrm{f}}=3.89 ; \mathrm{H} / \mathrm{U} 5=206.96\end{array}$ & $\begin{array}{c}0.99769 \\
\pm 0.00006\end{array}$ & $\begin{array}{c}0.98254 \\
\pm 0.00006\end{array}$ & 0.01515 \\
\hline & $\begin{array}{l}\text { LEU no Al Edge: } \\
\text { same }_{\text {eff }} \text { as HEU }\end{array}$ & $\begin{array}{l}\mathrm{T}_{\mathrm{LEU}}=19 ; \mathrm{T}_{\mathrm{Al}}=21.75 ; \mathrm{E}_{\mathrm{Al}}=0 \\
\mathrm{~V}_{\mathrm{m}} / \mathrm{V}_{\mathrm{f}}=12.79 ; \mathrm{H} / \mathrm{U} 5=132.35\end{array}$ & $\begin{array}{c}0.99706 \\
\pm 0.00006\end{array}$ & $\begin{array}{c}0.98256 \\
\pm 0.00006\end{array}$ & 0.01450 \\
\hline & $\begin{array}{l}\text { LEU with Al Edge: } \\
\text { same }_{\text {eff }} \text { as HEU }\end{array}$ & $\begin{array}{l}\mathrm{T}_{\mathrm{LEU}}=28 ; \mathrm{T}_{\mathrm{Al}}=17.25 ; \mathrm{E}_{\mathrm{Al}}=100 \\
\mathrm{~V}_{\mathrm{m}} / \mathrm{V}_{\mathrm{f}}=10.71 ; \mathrm{H} / \mathrm{U} 5=110.88\end{array}$ & $\begin{array}{c}0.99958 \\
\pm 0.00007\end{array}$ & $\begin{array}{c}0.98621 \\
\pm 0.00006\end{array}$ & 0.01337 \\
\hline \multirow{3}{*}{$\begin{array}{c}\text { KUCA } \\
\text { B1/8'’P80EU }\end{array}$} & HEU & $\begin{array}{l}\mathrm{T}=62.5 ; \\
\mathrm{V}_{\mathrm{m}} / \mathrm{V}_{\mathrm{f}}=1.94 ; \mathrm{H} / \mathrm{U} 5=103.48\end{array}$ & $\begin{array}{r}0.99882 \\
\pm 0.00007 \\
\end{array}$ & $\begin{array}{c}0.97758 \\
\pm 0.00007 \\
\end{array}$ & 0.02124 \\
\hline & $\begin{array}{l}\text { LEU no Al Edge: } \\
\text { max loading }\end{array}$ & $\begin{array}{l}\mathrm{T}_{\mathrm{LEU}}=42.5 ; \mathrm{T}_{\mathrm{Al}}=10 ; \mathrm{E}_{\mathrm{Al}}=0 \\
\mathrm{~V}_{\mathrm{m}} / \mathrm{V}_{\mathrm{f}}=2.86 ; \mathrm{H} / \mathrm{U} 5=29.58\end{array}$ & $\begin{array}{c}0.99611 \\
\pm 0.00007\end{array}$ & $\begin{array}{c}0.97833 \\
\pm 0.00007\end{array}$ & 0.01778 \\
\hline & $\begin{array}{l}\text { LEU with Al Edge: } \\
\text { max loading }\end{array}$ & $\begin{array}{l}\mathrm{T}_{\mathrm{LEU}}=42.5 ; \mathrm{T}_{\mathrm{Al}}=10 ; \mathrm{E}_{\mathrm{Al}}=100 \\
\mathrm{~V}_{\mathrm{m}} / \mathrm{V}_{\mathrm{f}}=3.53 ; \mathrm{H} / \mathrm{U} 5=36.52\end{array}$ & $\begin{array}{c}0.97932 \\
\pm 0.00007 \\
\end{array}$ & $\begin{array}{c}0.96214 \\
\pm 0.00007 \\
\end{array}$ & 0.01718 \\
\hline \multirow{3}{*}{$\begin{array}{c}\text { KUCA } \\
\text { B1/8'’P60EU- } \\
\text { EU }\end{array}$} & HEU & $\begin{array}{l}\mathrm{T}=62.5 ; \\
\mathrm{V}_{\mathrm{m}} / \mathrm{V}_{\mathrm{f}}=0.97 ; \mathrm{H} / \mathrm{U} 5=51.74\end{array}$ & $\begin{array}{c}1.00020 \\
\pm 0.00007\end{array}$ & $\begin{array}{c}0.98268 \\
\pm 0.00007\end{array}$ & 0.01767 \\
\hline & $\begin{array}{l}\text { LEU no Al Edge: } \\
\text { max loading } \\
\end{array}$ & $\begin{array}{l}\mathrm{T}_{\mathrm{LEU}}=42.5 ; \mathrm{T}_{\mathrm{Al}}=10 ; \mathrm{E}_{\mathrm{Al}}=0 \\
\mathrm{~V}_{\mathrm{m}} / \mathrm{V}_{\mathrm{f}}=1.43 ; \mathrm{H} / \mathrm{U} 5=14.79\end{array}$ & $\begin{array}{c}0.99348 \\
\pm 0.00006\end{array}$ & $\begin{array}{c}0.98052 \\
\pm 0.00006\end{array}$ & 0.01296 \\
\hline & $\begin{array}{l}\text { LEU with Al Edge: } \\
\text { max loading }\end{array}$ & $\begin{array}{l}\mathrm{T}_{\mathrm{LEU}}=42.5 ; \mathrm{T}_{\mathrm{Al}}=10 ; \mathrm{E}_{\mathrm{Al}}=100 \\
\mathrm{~V}_{\mathrm{m}} / \mathrm{V}_{\mathrm{f}}=1.76 ; \mathrm{H} / \mathrm{U} 5=18.26\end{array}$ & $\begin{array}{r}0.97635 \\
\pm 0.00006 \\
\end{array}$ & $\begin{array}{c}0.96323 \\
\pm 0.00006 \\
\end{array}$ & 0.01312 \\
\hline \multirow{3}{*}{$\begin{array}{c}\text { KUCA } \\
\text { B1/8'P48EU- } \\
\text { EU-EU }\end{array}$} & HEU & $\begin{array}{l}\mathrm{T}=62.5 ; \\
\mathrm{V}_{\mathrm{m}} / \mathrm{V}_{\mathrm{f}}=0.65 ; \mathrm{H} / \mathrm{U} 5=34.49\end{array}$ & $\begin{array}{c}1.00114 \\
\pm 0.00007\end{array}$ & $\begin{array}{c}0.98543 \\
\pm 0.00007\end{array}$ & 0.01571 \\
\hline & $\begin{array}{l}\text { LEU no Al Edge: } \\
\text { max loading }\end{array}$ & $\begin{array}{l}\mathrm{T}_{\mathrm{LEU}}=42.5 ; \mathrm{T}_{\mathrm{Al}}=10 ; \mathrm{E}_{\mathrm{Al}}=0 \\
\mathrm{~V}_{\mathrm{m}} / \mathrm{V}_{\mathrm{f}}=0.95 ; \mathrm{H} / \mathrm{U} 5=9.86\end{array}$ & $\begin{array}{c}1.00863 \\
\pm 0.00005 \\
\end{array}$ & $\begin{array}{c}0.99878 \\
\pm 0.00005 \\
\end{array}$ & 0.00985 \\
\hline & $\begin{array}{l}\text { LEU with Al Edge: } \\
\text { max loading }\end{array}$ & $\begin{array}{l}\mathrm{T}_{\mathrm{LEU}}=42.5 ; \mathrm{T}_{\mathrm{Al}}=10 ; \mathrm{E}_{\mathrm{Al}}=100 \\
\mathrm{~V}_{\mathrm{m}} / \mathrm{V}_{\mathrm{f}}=1.18 ; \mathrm{H} / \mathrm{U} 5=12.17\end{array}$ & $\begin{array}{c}0.98812 \\
\pm 0.00006\end{array}$ & $\begin{array}{c}0.97768 \\
\pm 0.00006 \\
\end{array}$ & 0.01044 \\
\hline
\end{tabular}

Table 11. Calculated Multiplication Factor Values of the Alternative Loadings of LEU KUCA Cores with Low H/U5 in Excess Reactivity and Subcritical Rod Configuration.

\begin{tabular}{|c|c|c|c|c|}
\hline Configuration & Loading Type & $\begin{array}{c}\text { Excess Reactivity } \\
\text { Rod Configuration } \\
\text { keff: Calculation }^{\text {ed }} \\
\end{array}$ & $\begin{array}{c}\text { Subcritical } \\
\text { Rod Configuration } \\
\mathbf{k}_{\text {eff: }} \text { Calculation } \\
\end{array}$ & $\Delta \mathbf{k}_{\text {eff }}$ \\
\hline \multirow{2}{*}{$\begin{array}{c}\text { KUCA } \\
\text { B1/8'’P80EU }\end{array}$} & $\begin{array}{l}\text { LEU no Al Edge, } \\
2 \text { assemblies added: max loading }\end{array}$ & $1.01129 \pm 0.00007$ & $0.99212 \pm 0.00007$ & 0.01917 \\
\hline & $\begin{array}{l}\text { LEU with } 100 \text { mils Al Edge, } \\
2 \text { assemblies added: max loading }\end{array}$ & $0.99579 \pm 0.00007$ & $0.97686 \pm 0.00007$ & 0.01893 \\
\hline \multirow{2}{*}{$\begin{array}{c}\text { KUCA } \\
\text { B1/8'’P60EU-EU }\end{array}$} & $\begin{array}{l}\text { LEU no Al Edge, } \\
\text { merging } 2 \text { LEU plates in 1: max loading }\end{array}$ & $1.01020 \pm 0.00006$ & $0.99843 \pm 0.00006$ & 0.01177 \\
\hline & $\begin{array}{l}\text { LEU with } 100 \text { mils Al Edge, } \\
\text { merging } 2 \text { LEU plates in 1: max loading }\end{array}$ & $0.99159 \pm 0.00006$ & $0.97924 \pm 0.00006$ & 0.01235 \\
\hline \multirow{2}{*}{$\begin{array}{c}\text { KUCA } \\
\text { B1/8'’P48EU-EU-EU }\end{array}$} & $\begin{array}{l}\text { LEU no Al Edge, } \\
\text { merging } 3 \text { LEU plates in } 2: \text { max loading }\end{array}$ & $1.02424 \pm 0.00006$ & $1.01512 \pm 0.00006$ & 0.00912 \\
\hline & $\begin{array}{l}\text { LEU with } 100 \text { mils Al Edge, } \\
\text { merging } 3 \text { LEU plates in } 2: \text { max loading }\end{array}$ & $1.00221 \pm 0.00006$ & $0.99233 \pm 0.00006$ & 0.00988 \\
\hline
\end{tabular}




\subsubsection{Flux Spectra Calculations}

Flux spectra were obtained in a central assembly (see Table 12 for the exact location of the assemblies) of the proposed KUCA cores and were determined as average values in a specific region of the LEU foil (or HEU plate) closest to the core midplane. This region has a square section of $1 \mathrm{~cm}$ side and an axial extension that corresponds to the thickness of the LEU foil (or HEU plate). All flux spectra were obtained for the "subcritical" control rod configuration (controls rods in / safety rods out) using a 53 energy group structure.

Table 12. Location of Assemblies for Flux Spectra Determination in the KUCA Cores.

\begin{tabular}{|c|c|}
\hline Configuration & Assembly Location ${ }^{(a)}$ \\
\hline KUCA A3/8''P36EU & $(\mathrm{K}, 15)$ \\
\hline KUCA B2/8''P48EU & $(\mathrm{K}, 15)$ \\
\hline KUCA B1/8''P80EU & $(\mathrm{J}, 15)$ \\
\hline KUCA B1/8''P60EU-EU & $(\mathrm{J}, 15)$ \\
\hline KUCA B1/8''P48EU-EU-EU & $(\mathrm{J}, 15)$ \\
\hline${ }^{\text {(a) }}$ Refer to Figure 53 for a graphical view of the assembly locations. \\
\hline
\end{tabular}

Figure 56 shows the flux spectra of the five KUCA cores under study with HEU loadings, while Figure 57 shows the flux spectra of the corresponding LEU cores characterized by the same H/U5 atom ratio in the fuel unit cells. Then, for a better comparison the flux spectra obtained in the HEU and LEU cases with the same H/U5 are presented separately for each configuration in Figures 58 through 62.

It is observed that, as expected, the LEU configurations show a harder flux spectrum than that obtained in the corresponding HEU configurations. However, reducing the H/U5 atom ratio in the LEU fuel unit cell results in a less hard spectrum with respect to the HEU configurations. 


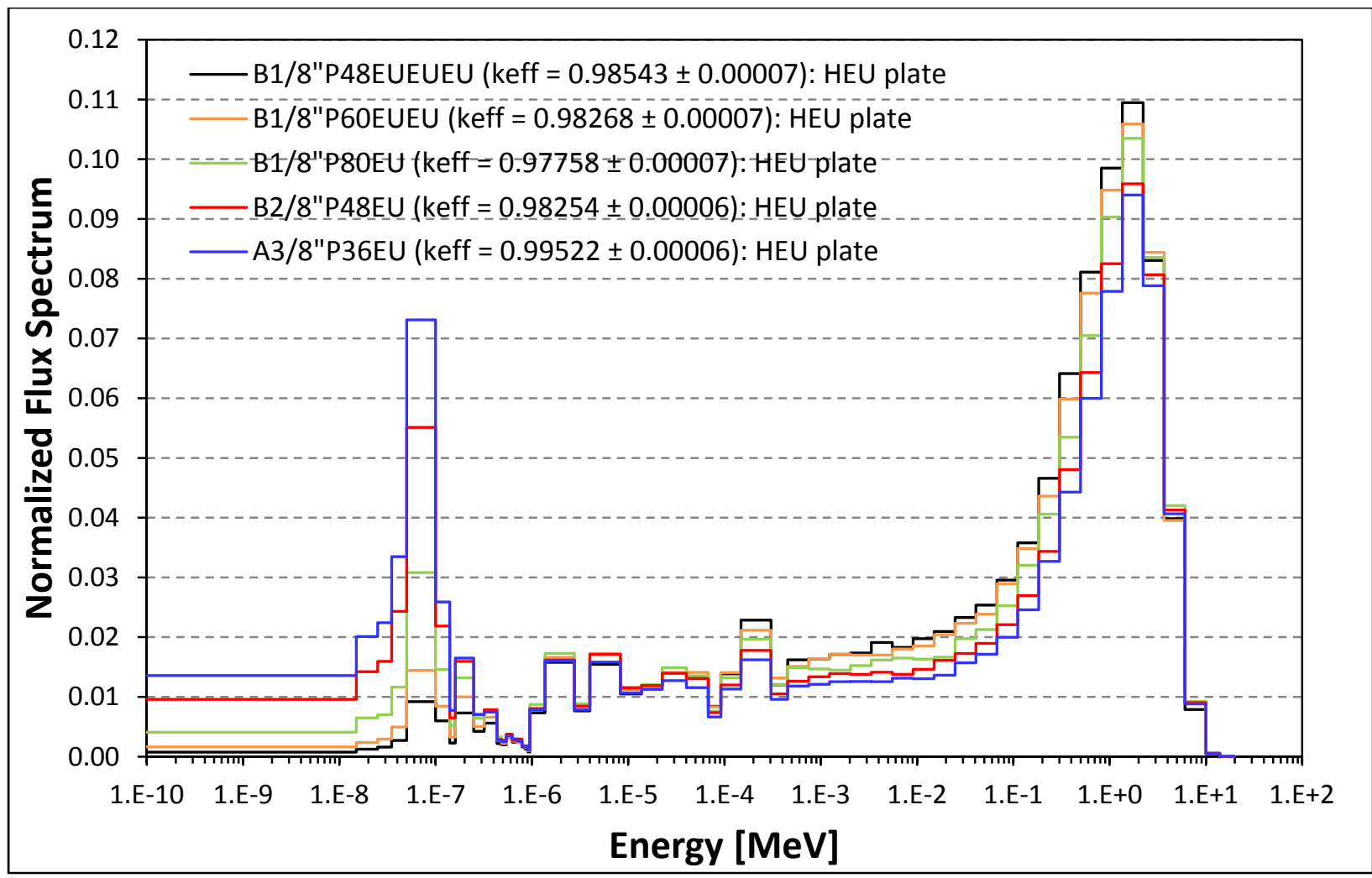

Figure 56. Flux Spectra Comparison for the KUCA HEU Configurations.

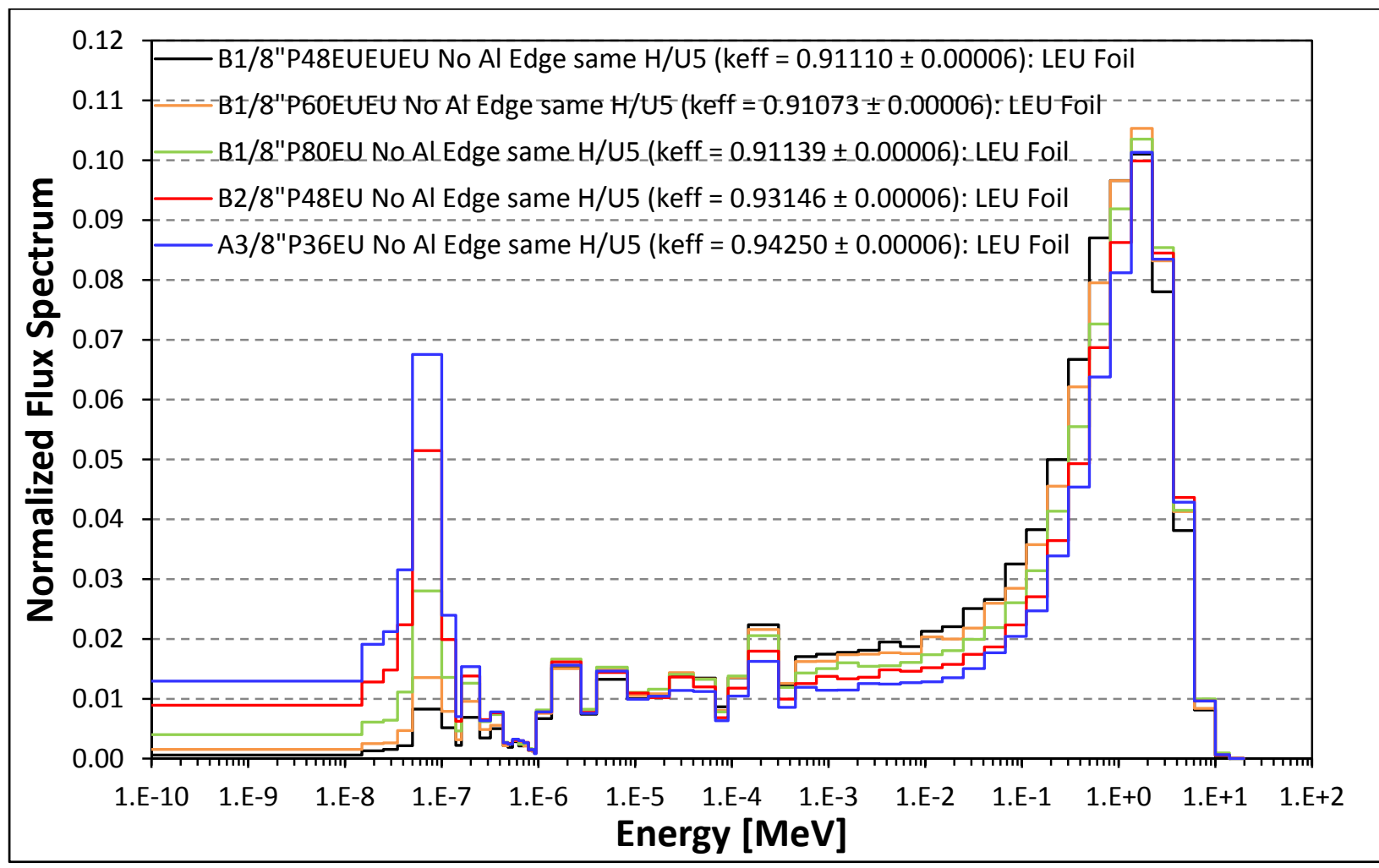

Figure 57. Flux Spectra Comparison for the KUCA LEU Configurations with the Same H-to-U235 Atom Ratios in the Fuel Unit Cell of the Corresponding HEU Configurations. 


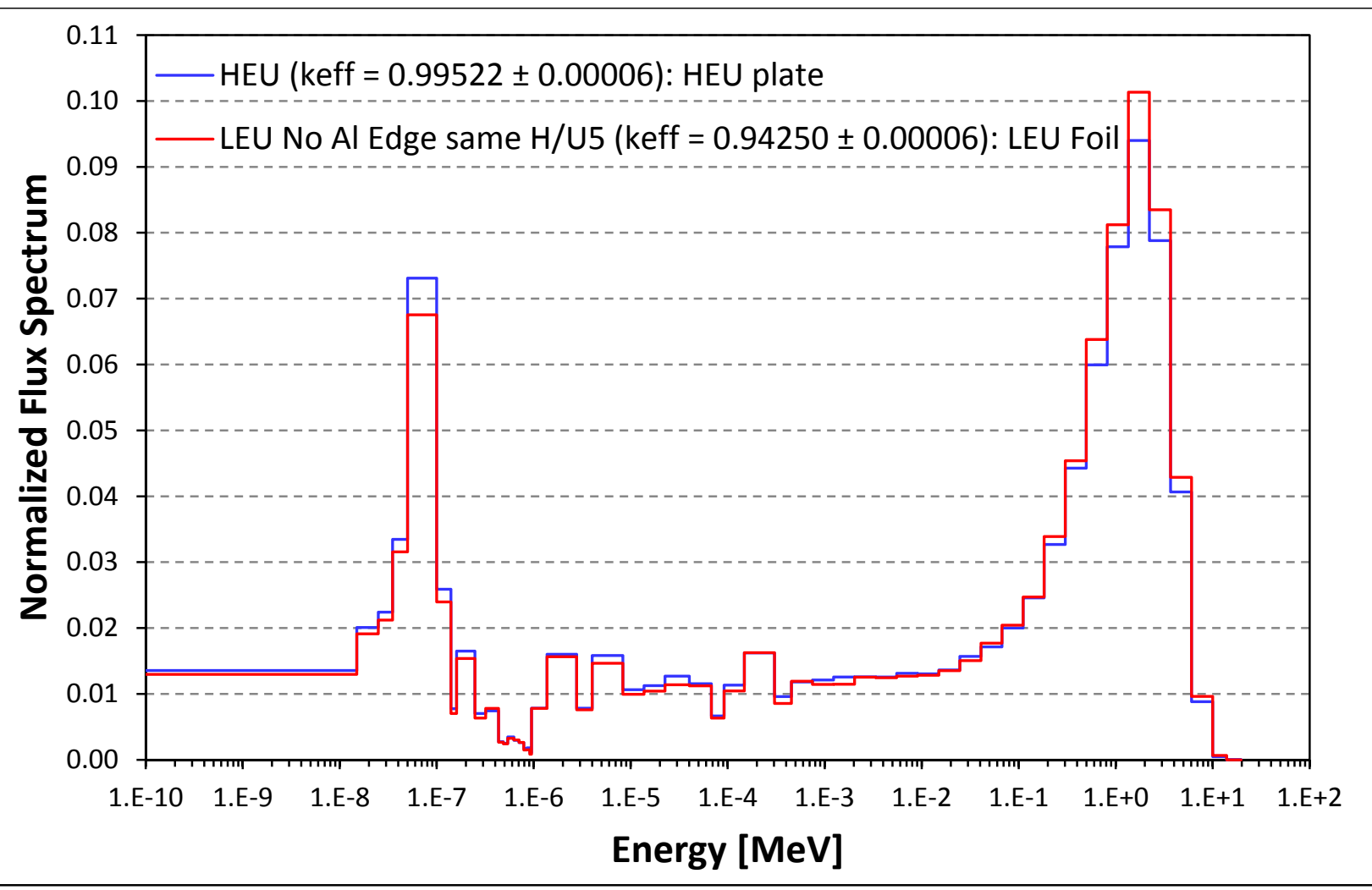

Figure 58. Flux Spectra Comparison for the KUCA A3/8''P36EU Configuration in the HEU and LEU Cases with the Same H-to-U235 Atom Ratios (H/U5 = 316.45) in the Fuel Unit Cell.

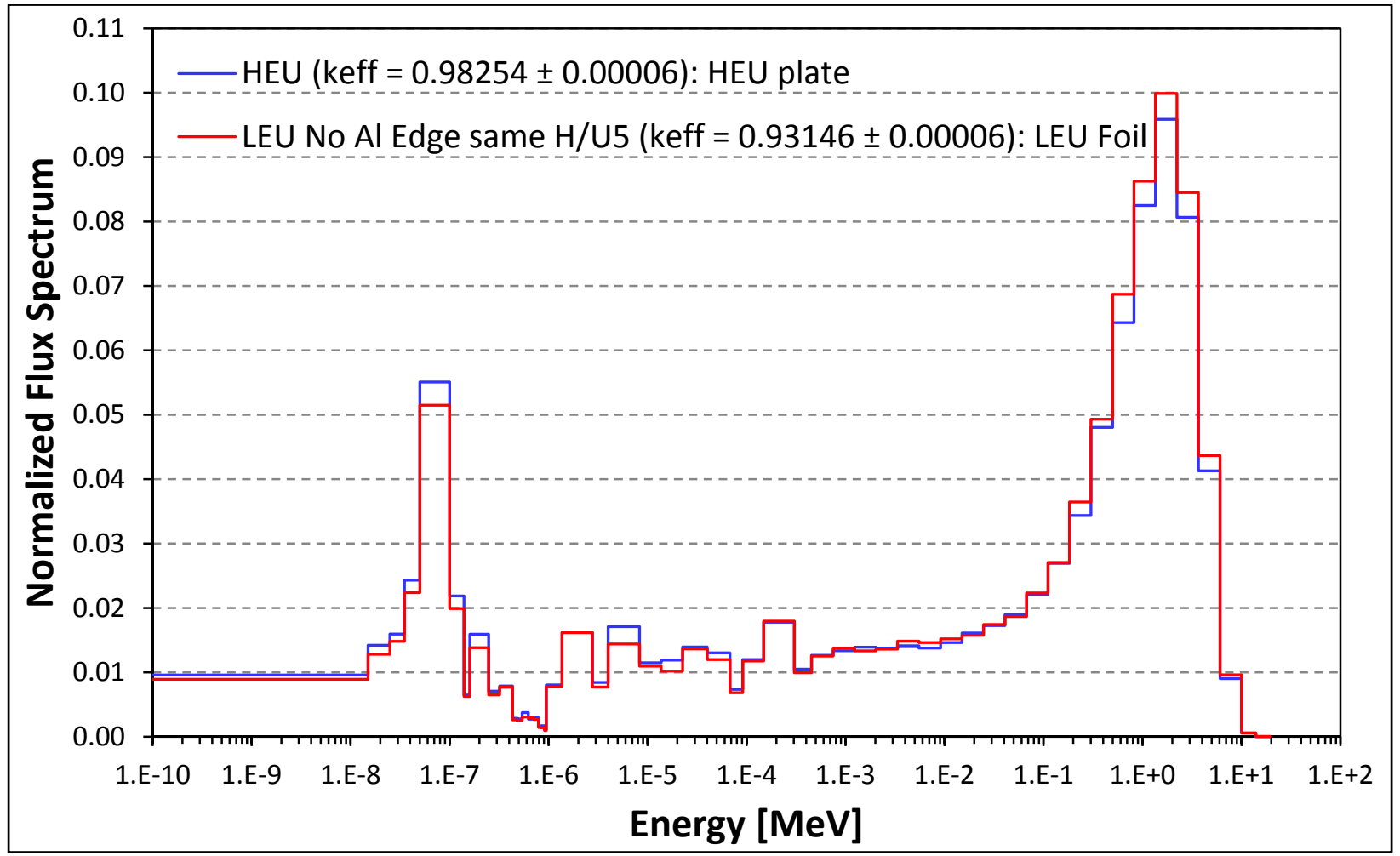

Figure 59. Flux Spectra Comparison for the KUCA B2/8''P48EU Configuration in the HEU and LEU Cases with the Same H-to-U235 Atom Ratios (H/U5 = 206.96) in the Fuel Unit Cell. 


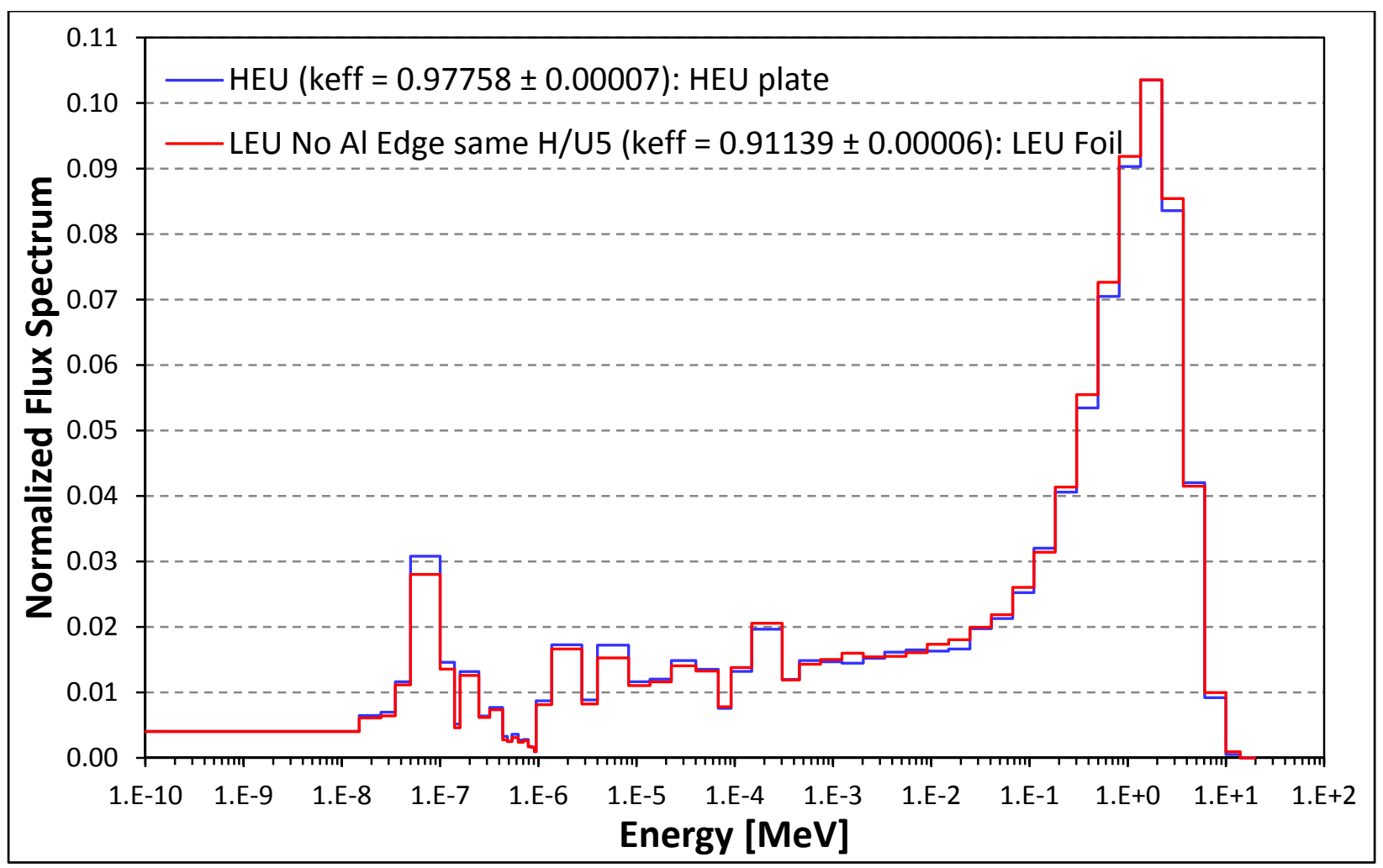

Figure 60. Flux Spectra Comparison for the KUCA B1/8'"P80EU Configuration in the HEU and LEU Cases with the Same H-to-U235 Atom Ratios $(\mathrm{H} / \mathrm{U} 5=103.48)$ in the Fuel Unit Cell.

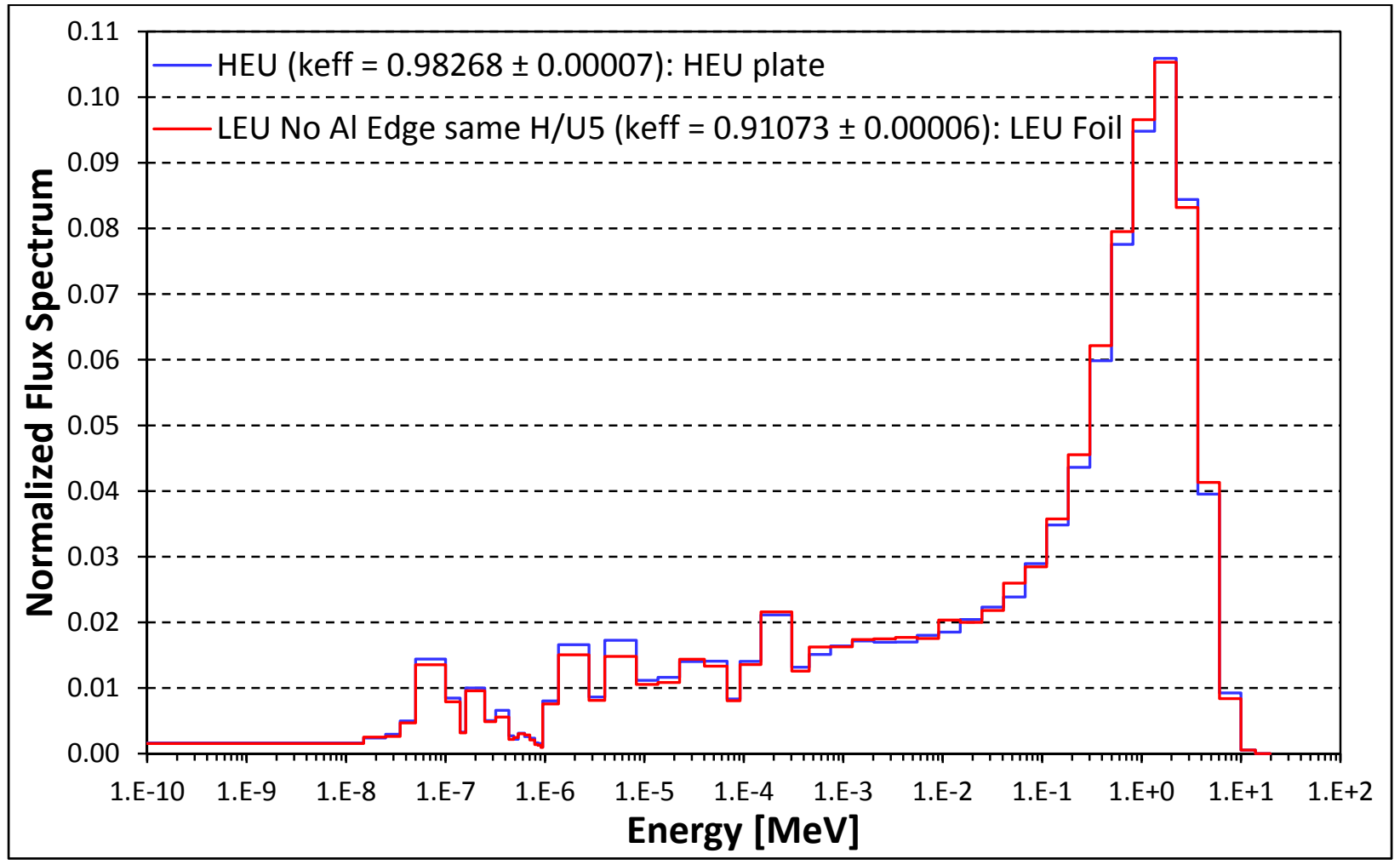

Figure 61. Flux Spectra Comparison for the KUCA B1/8' 'P60EU-EU Configuration in the HEU and LEU Cases with the Same H-to-U235 Atom Ratios $(\mathrm{H} / \mathrm{U} 5=51.74)$ in the Fuel Unit Cell. 


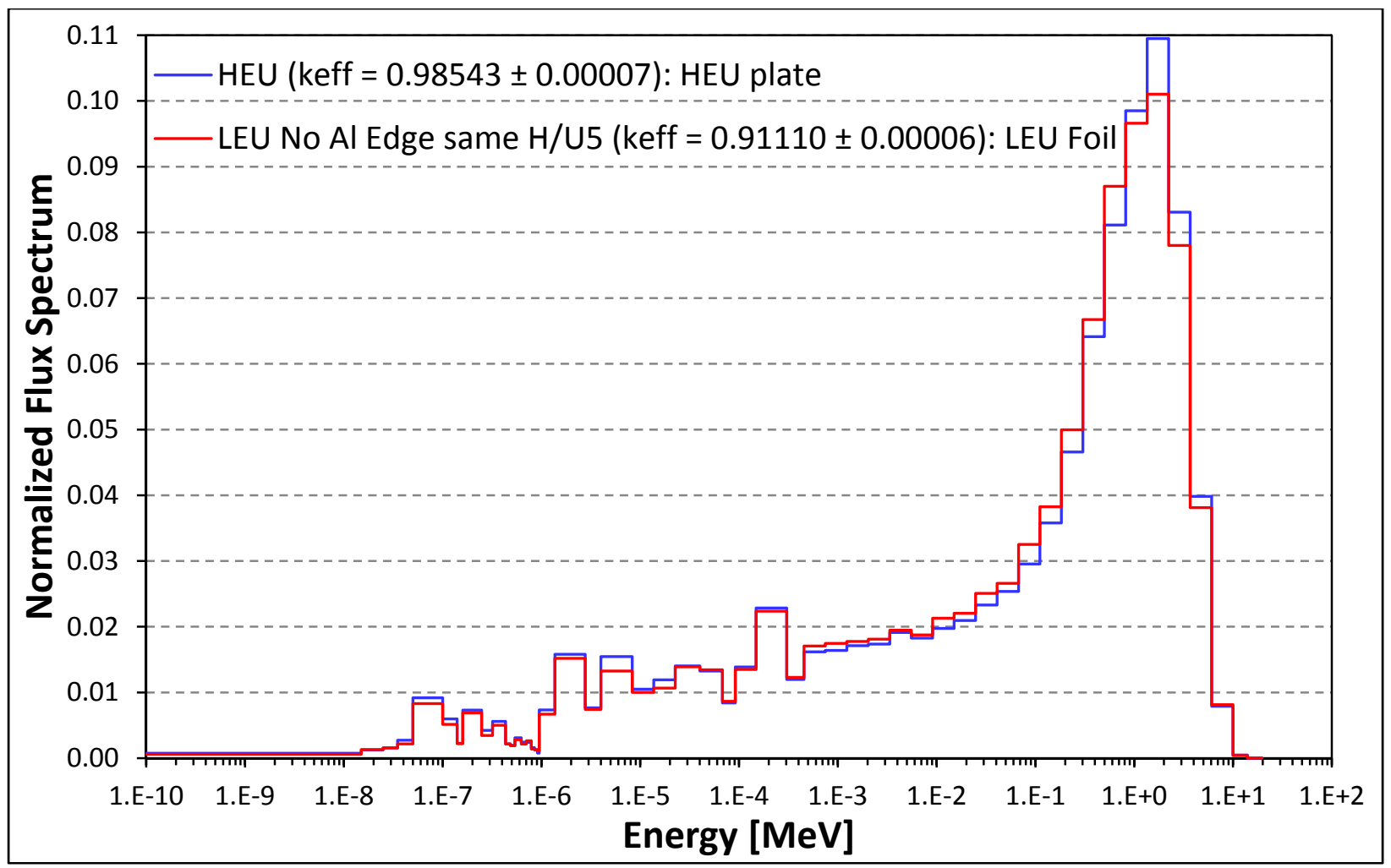

Figure 62. Flux Spectra Comparison for the KUCA B1/8''P48EU-EU-EU Configuration in the HEU and LEU Cases with the Same H-to-U235 Atom Ratios $(\mathrm{H} / \mathrm{U} 5=34.49)$ in the Fuel Unit Cell.

Calculations were also performed to analyze the impact on neutron flux spectra due to variations in the thickness of the U-10Mo foils of the LEU KUCA configurations. For this purpose, flux spectra were calculated for the A3/8''P36EU and B1/8''P80EU KUCA configurations using U-10Mo foils of three different thicknesses, specifically 10-, 16- and 22-mils thick for A3/8''P36EU and 30-, 36- and 42-mils thick for B1/8'’P80EU.

Additionally, for the A3/8''P36EU and B1/8''P80EU KUCA configurations using U-10Mo foils of 22 mils and 42 mils thickness, the impact on flux spectra due to the use of the 100 mils aluminum edge all around the LEU foil was also investigated.

As shown in Figures 63 through 66, harder neutron spectra are obtained with thicker U-10Mo foils or by adding the 100 mils aluminum edge.

Finally, for the KUCA configuration B1/8"P60EU-EU flux spectra were compared between the case of maximum loading and the case where the two adjacent LEU plates in the fuel unit cell are merged into a single plate, according to the scheme illustrated in Figure 55. Iterative calculations were first performed in order to determine the thickness of the resulting LEU foil after merging the adjacent plates that would preserve more or less the same reactivity as the initial LEU configuration with the condition of maximum loading. All calculations were performed with the subcritical control rod configuration. As shown in Table 13, for the B1/8"P60EU-EU configuration more or less the same reactivity value that was obtained in the condition of maximum loading would be achieved if the two LEU foils are merged into a single foil with a thickness of 83 mils.

Figure 67 shows that the flux spectra calculated for the LEU B1/8"P60EU-EU configuration with conditions of maximum loading and in the LEU configuration obtained by merging the two LEU foils into a single foil with a thickness that preserves the same reactivity are practically the same. In fact, as shown in Table 13 the change in the LEU loading between the two LEU configurations leaves the moderator-to-fuel volume ratio and the H-to-U235 atom ratio in the cores practically unchanged. 


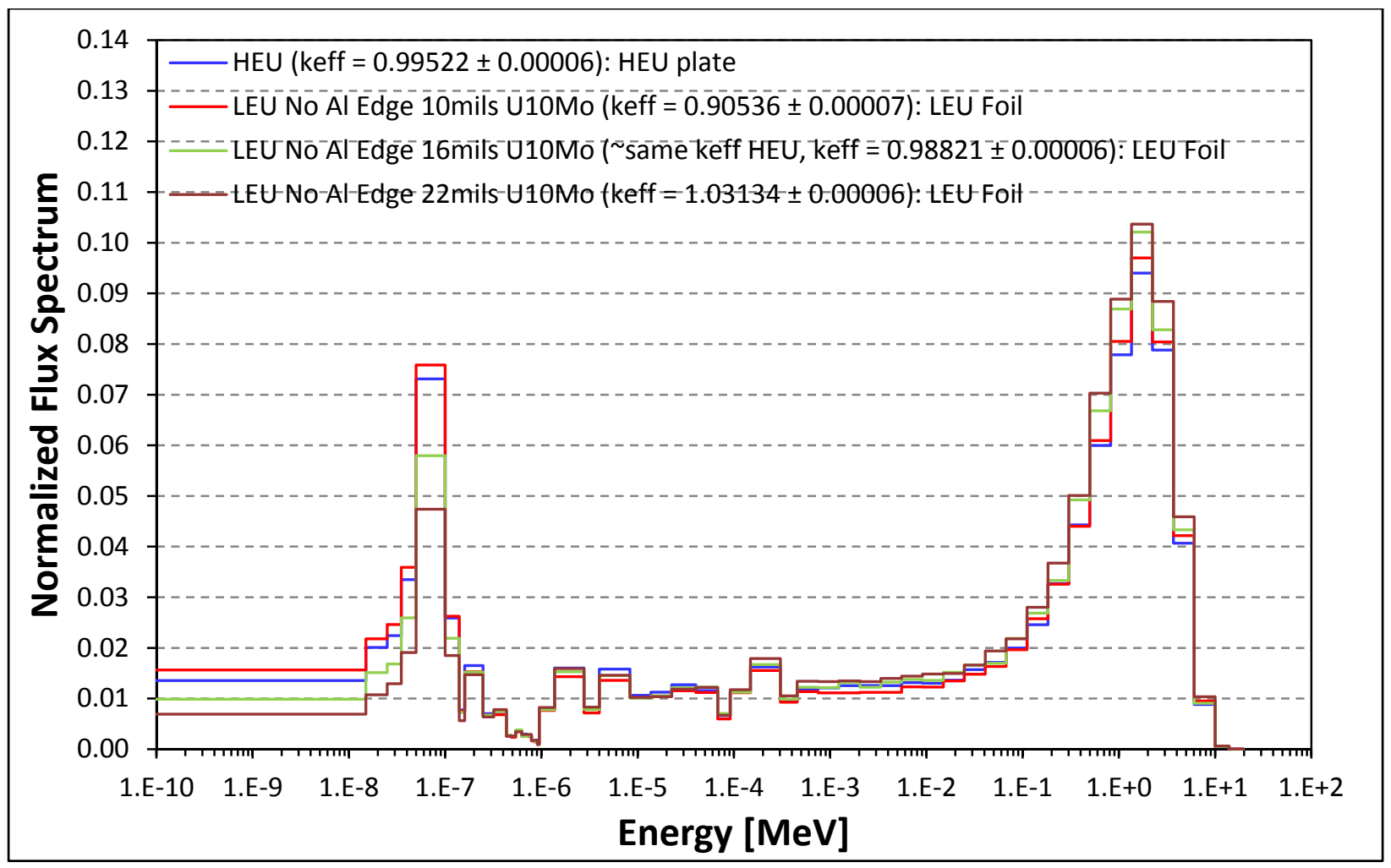

Figure 63. Flux Spectra Comparison for the KUCA A3/8''P36EU Configuration in the HEU Case and the LEU Cases with Different Thicknesses of the U-10Mo Foil.

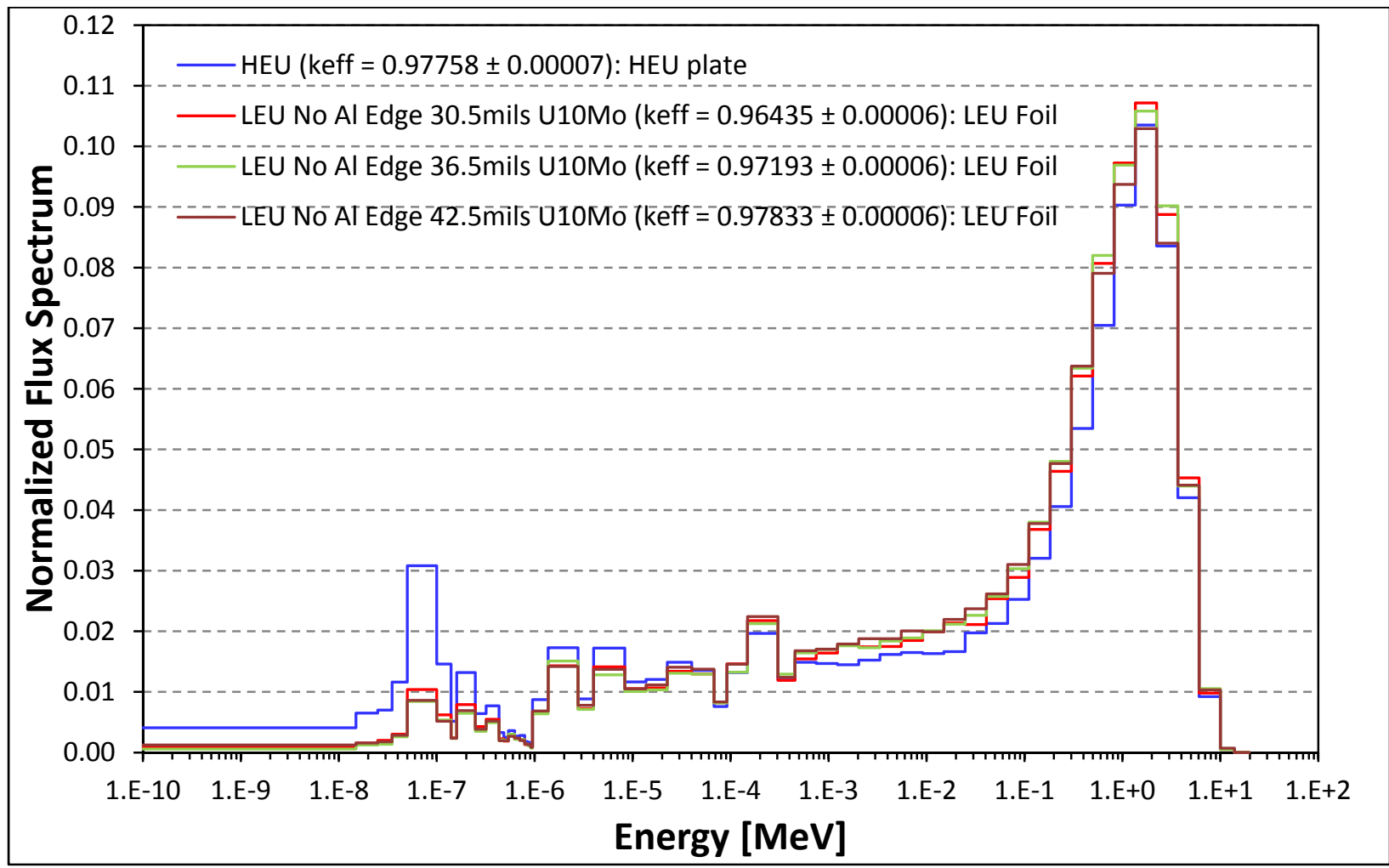

Figure 64. Flux Spectra Comparison for the KUCA B1/8''P80EU Configuration in the HEU Case and the LEU Cases with Different Thicknesses of the U-10Mo Foil. 


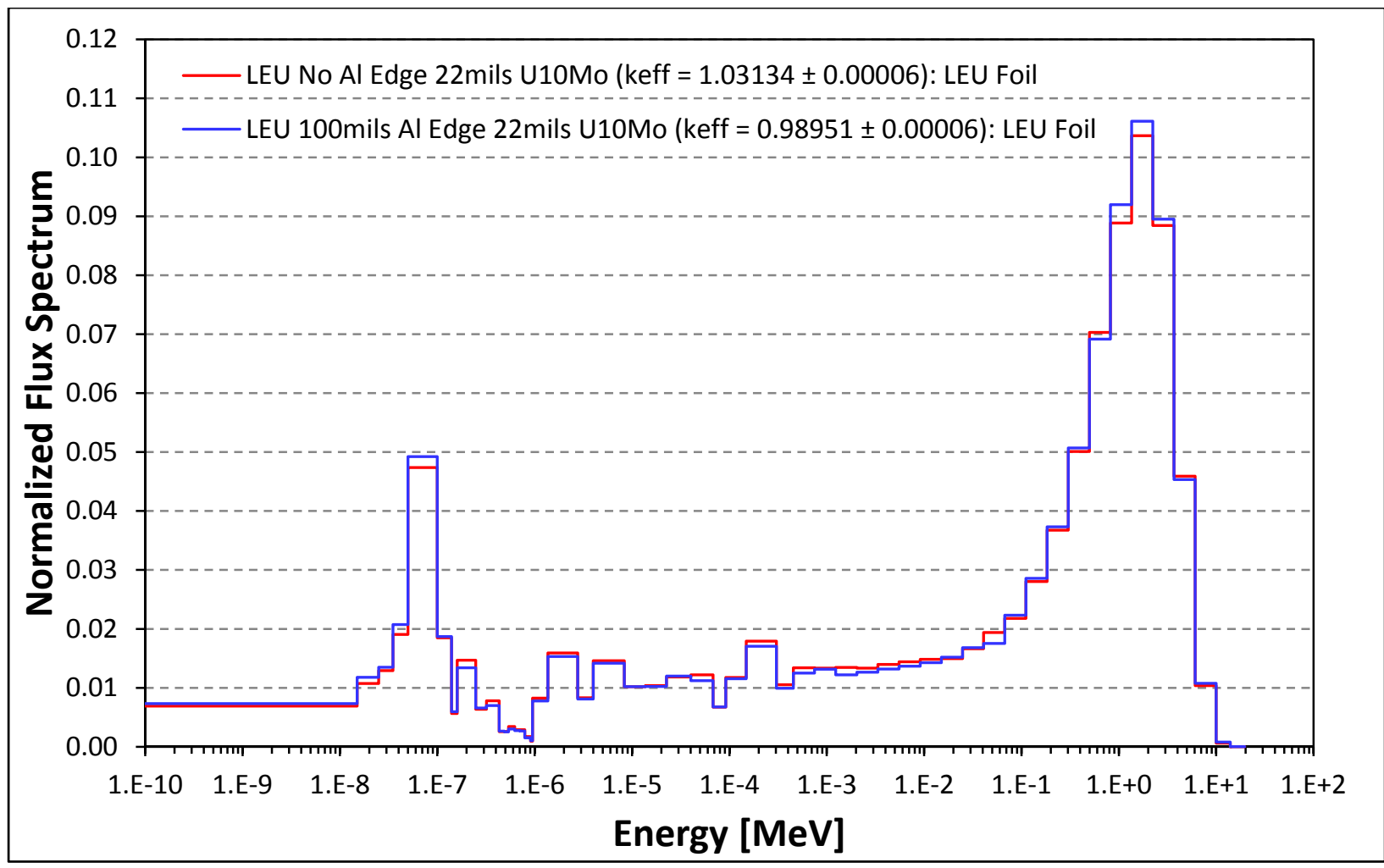

Figure 65. Flux Spectra Comparison for the LEU KUCA A3/8''P36EU Configuration With and Without Aluminum Edge Around the U-10Mo Foils.

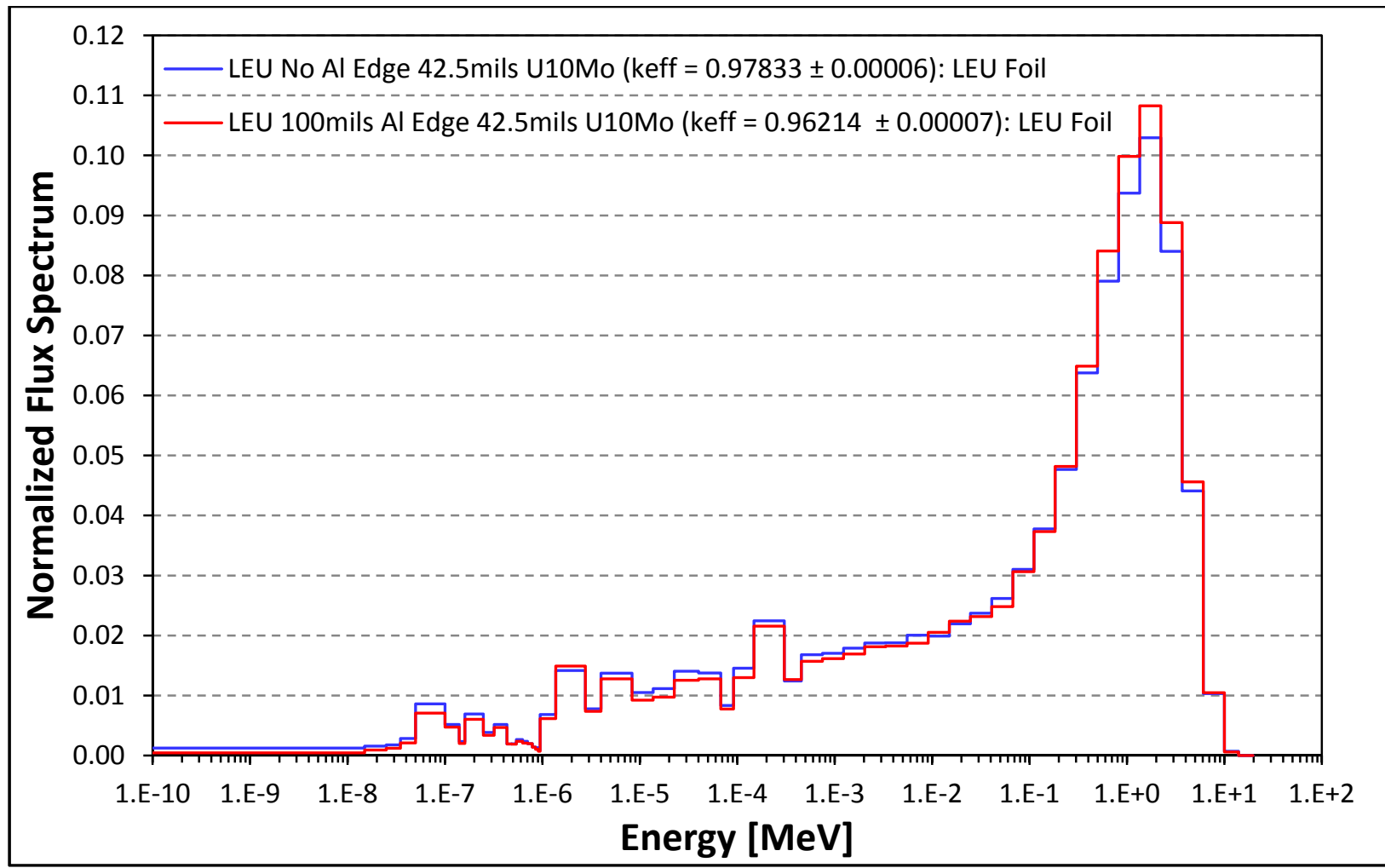

Figure 66. Flux Spectra Comparison for the LEU KUCA B1/8''P80EU Configuration With and Without Aluminum Edge Around the U-10Mo Foils. 
Table 13. Calculated Multiplication Factor Values for KUCA B1/8"P60EU-EU in the Subcritical Rod Configuration.

\begin{tabular}{|c|c|c|c|}
\hline Configuration & Loading Type & $\begin{array}{c}\text { Plate Dimensions (mils); } \mathbf{V}_{\mathrm{m}} / \mathbf{V}_{\mathrm{f}} ; \\
\mathbf{H} / \mathbf{U} 5\end{array}$ & $\mathbf{k}_{\text {eff: }}$ Calculation \\
\hline \multirow{3}{*}{$\begin{array}{c}\text { KUCA } \\
\text { B1/8'’P60EU-EU }\end{array}$} & HEU & $\mathrm{T}=62.5 ; \mathrm{V}_{\mathrm{m}} / \mathrm{V}_{\mathrm{f}}=0.97 ; \mathrm{H} / \mathrm{U} 5=51.74$ & $0.98268 \pm 0.00007$ \\
\hline & $\begin{array}{l}\text { LEU no Al Edge: } \\
\text { max loading }\end{array}$ & $\begin{array}{l}\mathrm{T}_{\mathrm{LEU}}=42.5 ; \mathrm{T}_{\mathrm{Al}}=10 ; \mathrm{E}_{\mathrm{Al}}=0 \\
\mathrm{~V}_{\mathrm{m}} / \mathrm{V}_{\mathrm{f}}=1.43 ; \mathrm{H} / \mathrm{U} 5=14.79\end{array}$ & $0.98052 \pm 0.00006$ \\
\hline & $\begin{array}{l}\text { LEU no Al Edge Merging } 2 \text { foils into } \\
\text { 1: } \sim \text { same } k_{\text {eff }} \text { of LEU, no Al Edge, } \\
\text { max loading }\end{array}$ & $\begin{array}{l}\mathrm{T}_{\mathrm{LEU}}=83 ; \mathrm{T}_{\mathrm{Al}}=21 ; \mathrm{E}_{\mathrm{Al}}=0 \\
\mathrm{~V}_{\mathrm{m}} / \mathrm{V}_{\mathrm{f}}=1.46 \quad \mathrm{H} / \mathrm{U} 5=15.15\end{array}$ & $0.97951 \pm 0.00006$ \\
\hline
\end{tabular}

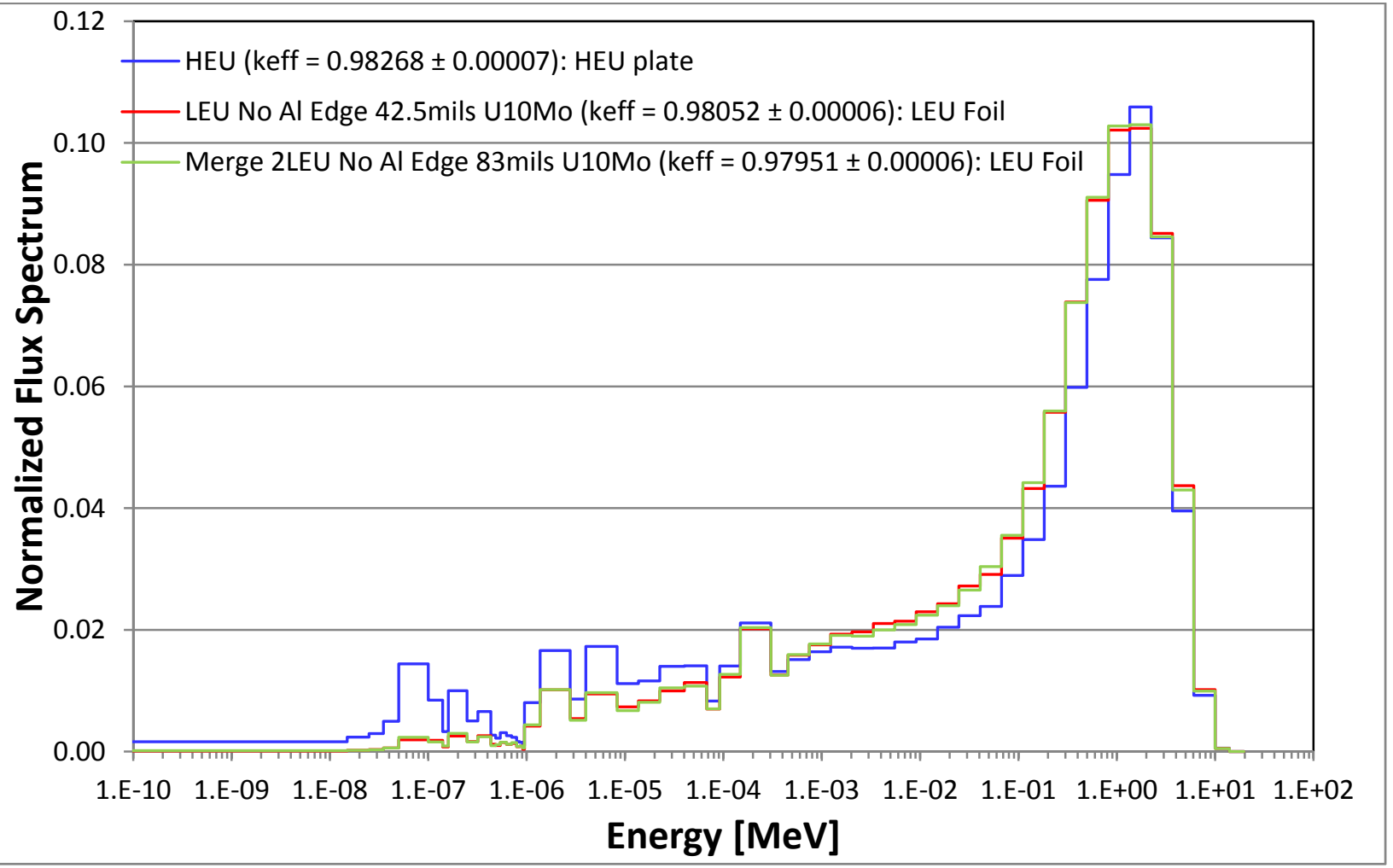

Figure 67. Flux Spectra Comparison for the KUCA B1/8''P60EU-EU Configuration with HEU and LEU Loadings of Same $\mathrm{k}_{\mathrm{eff}}$. 


\section{CONCLUSIONS}

The KUCA experiments were designed to establish measurement techniques for neutronic parameters in subcritical systems and to investigate the accuracy of the neutronic design of an ADSR. Due to the continuing interest in non-proliferation issues, new studies are being performed at KURRI to investigate the feasibility of converting the KUCA cores to the use of LEU fuel.

The KUCA cores consist of the solid-moderated and -reflected type-A and -B cores, and of the watermoderated and -reflected type-C core. The present document describes the results of the analysis carried out at Argonne on the KUCA type-A cores. In particular, calculated results of the KUCA benchmark assembly and of the feasibility studies on the conversion of the KUCA dry cores from HEU to LEU are discussed.

Calculations were performed with MCNP5 using ENDF/B-VII.0 nuclear data. The MCNP model was developed by explicitly describing all single plates, both for the polyethylene and the uranium.

Based on the benchmark specifications, reactivity calculations were performed with three different control rod configurations. The calculations show a consistent discrepancy between the calculated and experimental results of about $400-500 \mathrm{pcm}$ for all KUCA configurations from Series I and of about 500 $700 \mathrm{pcm}$ for all KUCA configurations from Series II. It is however important to emphasize the fact that the foils located in the void region of the fuel assemblies "SV" of the KUCA configurations II-2, II-3 and II-4 have a reactivity effect of about $800 \mathrm{pcm}$. The use of different nuclear data libraries was shown to not have a significant impact on the discrepancies observed between the calculated and experimental results.

Indium rate distributions were calculated along the indium wire located at the core midplane with a $(\mathrm{d}, \mathrm{t})$ source in place. For the Series I and II configurations, the calculated indium rate distributions show reasonable agreement with the measurements in the shape of the distribution, particularly in the fuel zone. In the reflector/shield region the calculations show a depression in the distributions that in some cases is not seen in the measurements.

Calculations were performed to evaluate the conversion of the KUCA "type A" cores from HEU to LEU using both U-Al and U-10Mo LEU fuel. In the case of U-10Mo fuel, five "type-A" cores were considered with different moderator-to-fuel volume ratios $\left(\mathrm{V}_{\mathrm{m}} / \mathrm{V}_{\mathrm{f}}\right)$ and different H-to-U235 atom ratios (H/U5) in the fuel unit cell as requested by the KUCA team. The option to add an aluminum clad and an aluminum edge to the U-10Mo foils was also considered.

With the same H/U5 in the fuel unit cell, the LEU configurations give a reactivity value lower than what is obtained for the corresponding HEU configurations, and this discrepancy increases with decreasing moderator to fuel volume ratio $\left(\mathrm{V}_{\mathrm{m}} / \mathrm{V}_{\mathrm{f}}\right)$ and $\mathrm{H} / \mathrm{U} 5$. As a consequence, for the LEU configurations with low $\mathrm{H} / \mathrm{U} 5$ a reactivity value more or less comparable to that of the corresponding HEU cores can be only achieved in the conditions of maximum loading (i.e., the thickness of the aluminum clad is reduced to the minimum allowed of 10 mils) and without the aluminum edge. However, for these configurations different solutions, like adding fuel assemblies at the core boundary or merging adjacent LEU plates into a single plate, could be envisaged so that the desired $\mathrm{k}_{\mathrm{eff}}$ in the LEU cases can be achieved with U-10Mo foil dimensions that are smaller than the maximum allowed.

The feasibility studies on the conversion of the KUCA cores from HEU to LEU was also carried out with an extensive analysis of flux spectra distributions in relevant position of the assemblies. Small shifts in the spectra, typical of other HEU-to-LEU conversion studies, are seen in the comparisons presented in this report. While further study of the KUCA cores is necessary to compare power levels, reactivity coefficients and other performance parameters, none of the results presented here indicate any reason that the conversion of the KUCA dry cores to LEU cannot be performed successfully. 


\section{REFERENCES}

1. Cheolho Pyeon, "Experimental Benchmarks for Accelerator Driven Subcritical Reactor (ADSR) at Kyoto University Critical Assembly (KUCA)," Kyoto University Research Reactor Institute, Japan, November 2007.

2. Gerardo Aliberti, Hironobu Unesaki and Cheol-Ho Pyeon, "Analysis of KUCA type-A Cores," RERTR 2012, Warsaw, Poland, October 14-17, 2012.

3. Gerardo Aliberti, James A. Morman, John G. Stevens, Hironobu Unesaki and Cheol-Ho Pyeon, "On the Conversion of KUCA Type-A Cores from HEU to LEU Using U10Mo Foils," ANS Winter Meeting, Washington, D.C., November 10-14, 2013. 


\section{APPENDIX. MCNP INPUT FOR KUCA I-1 WITH SUBCRITICAL ROD CONFIGURATION}

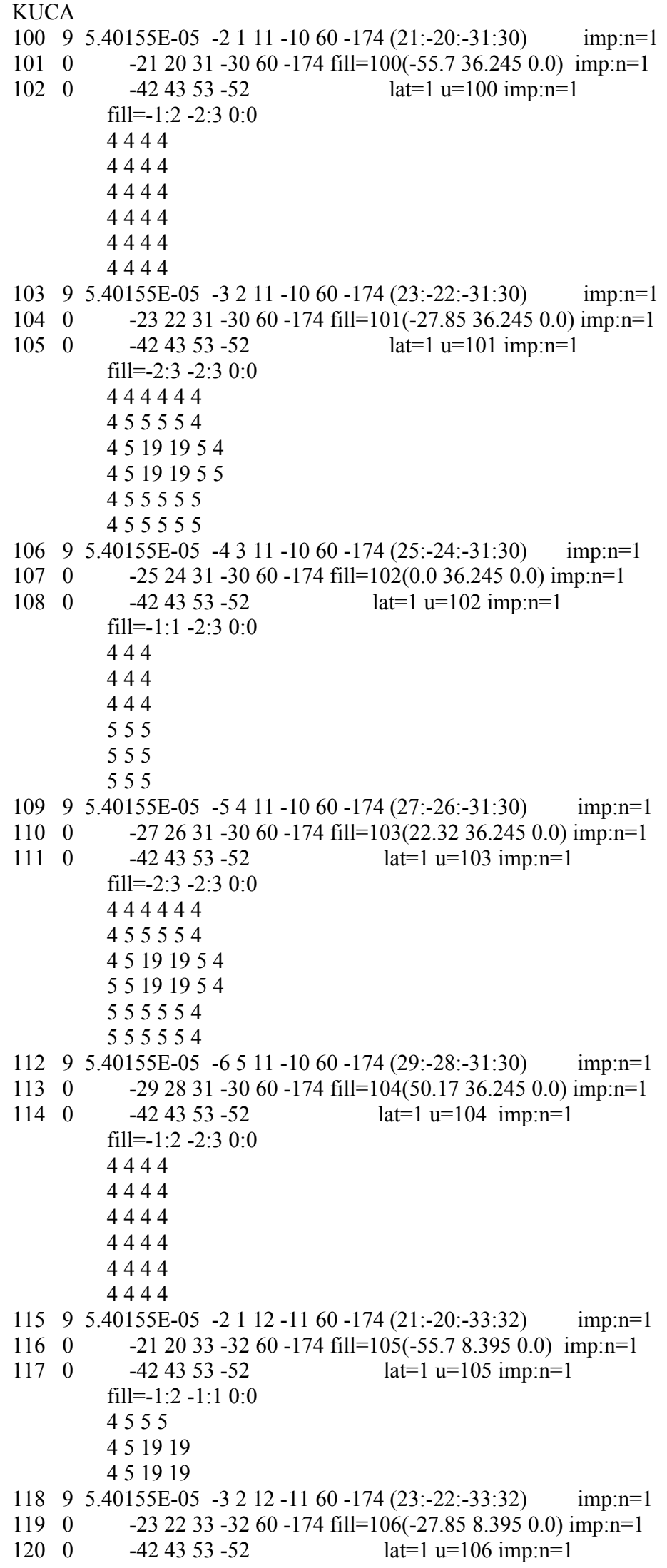


fill $=-2: 3-1: 10: 0$

555555

555555

555555

$12195.40155 \mathrm{E}-05-4312-1160-174(25:-24:-33: 32) \quad$ imp:n=1

$1220 \quad-252433-3260-174$ fill $=107(0.08 .3950 .0)$ imp:n=1

$1230 \quad-424353-52 \quad$ lat=1 u=107 imp:n=1

fill=-1:1 $-1: 10: 0$

555

555

111

1249 5.40155E-05 -5 412 -11 60 -174 (27:-26:-33:32) imp:n=1

$1250 \quad-272633-3260-174$ fill=108(22.32 8.3950 .0$)$ imp:n=1

$1260 \quad-424353-52 \quad$ lat=1 u=108 imp:n=1

fill $=-2: 3-1: 10: 0$

555555

555555

555555

$12795.40155 \mathrm{E}-05-6512-1160-174(29:-28:-33: 32) \quad$ imp:n=1

$1280 \quad-292833-3260-174$ fill=109(50.17 8.395 0.0) imp:n=1

$1290 \quad-424353-52 \quad$ lat=1 u=109 imp:n=1

fill=-1:2 $-1: 1 \quad 0: 0$

5554

191954

191954

1309 5.40155E-05 -2 $113-1260-174(21:-20:-35: 34) \quad$ imp:n=1

$1310 \quad-212035-3460-174$ fill $=110(-55.7-13.9250 .0)$ imp:n=1

$1320 \quad-424353-52 \quad$ lat=1 $\mathrm{u}=110 \mathrm{imp}: \mathrm{n}=1$

fill=-1:2 $-2: 3 \quad 0: 0$

4555

4555

451919

451919

4555

4444

$13395.40155 \mathrm{E}-05-3213-1260-174(23:-22:-35: 34) \quad$ imp:n=1

$1340 \quad-232235-3460-174$ fill=111(-27.85 -13.925 0.0) imp:n=1

$1350 \quad-424353-52 \quad$ lat=1 u=111 imp:n=1

fill $=-2: 3-2: 30: 0$

5555211

555551

555561

5555181

5555521

555555

$13695.40155 \mathrm{E}-05 \quad 313-4313-1260-174(25:-24:-35: 34) \quad$ imp:n=1

$1370 \quad 313-252435-3460-174$ fill=112(-0.0 - 0 -13.925 0.0) imp:n=1

$1380 \quad-424353-52 \quad$ lat=1 u=112 imp:n=1

fill=-1:1 $-2: 30: 0$

111

1201

111

111

515

545

1399 5.40155E-05 $313-5413-1260-174(27:-26:-35: 34) \quad$ imp:n=1

$140 \quad 0 \quad 313-272635-3460-174$ fill=113(22.32 $-13.9250 .0)$ imp:n=1

$1410 \quad-424353-52 \quad$ lat=1 $\mathrm{u}=113 \mathrm{imp}: \mathrm{n}=1$

fill=-2:3 $-2: 3 \quad 0: 0$

165555

155555

1215555

1185555

655555

555555 
1429 5.40155E-05 -6 $513-1260-174(29:-28:-35: 34) \quad$ imp:n=1

$1430 \quad-292835-3460-174$ fill=114(50.17 $-13.9250 .0)$ imp:n=1

$1440 \quad-424353-52 \quad$ lat=1 u=114 imp:n=1

fill=-1:2 $-2: 3 \quad 0: 0$

5554

5544

5544

5544

4444

4444

1459 5.40155E-05 -2 $114-1360-174(21:-20:-37: 36) \quad$ imp:n=1

$1460 \quad-212037-3660-174$ fill=115(-55.7 $-47.3050 .0)$ imp:n=1

$1470 \quad-424353-52 \quad$ lat=1 $\mathrm{u}=115 \mathrm{imp}: \mathrm{n}=1$

fill=-1:2 $-2: 3 \quad 0: 0$

4444

4444

4444

4444

4444

4444

1489 5.40155E-05 -3 2 14 -13 $60-174(23:-22:-37: 36) \quad$ imp:n=1

$1490 \quad-232237-3660-174$ fill=116(-27.85 $-47.3050 .0)$ imp:n=1

$150 \quad 0 \quad-424353-52 \quad$ lat=1 u=116 imp:n=1

fill $=-2: 3 \quad-2: 3 \quad 0: 0$

555555

555555

444445

444445

444444

444444

$15195.40155 \mathrm{E}-05313-4314-1360-174$ (25:-24:-37:36) imp:n=1

$1520 \quad 313-252437-3660-174$ fill=117(0.0 - 077.3050 .0$)$ imp:n=1

$1530 \quad-424353-52 \quad$ lat $=1 \mathrm{u}=117 \mathrm{imp}: \mathrm{n}=1$

fill=-1:1 $-2: 30: 0$

555

555

555

555

444

444

1549 5.40155E-05 $313-5414-1360-174$ (27:-26:-37:36) imp:n=1

$1550 \quad 313-272637-3660-174$ fill=118(22.32 $-47.3050 .0)$ imp:n=1

$1560 \quad-424353-52 \quad$ lat=1 u=118 imp:n=1

fill $=-2: 3-2: 3 \quad 0: 0$

555555

555555

544444

544444

444444

444444

$15795.40155 \mathrm{E}-05-6514-1360-174(29:-28:-37: 36) \quad$ imp:n=1

$1580 \quad-292837-3660-174$ fill=119(50.17 $-47.3050 .0)$ imp:n=1

$1590 \quad-424353-52 \quad$ lat=1 u=119 imp:n=1

fill $=-1: 2 \quad-2: 3 \quad 0: 0$

4444

4444

4444

4444

4444

4444

$\begin{array}{llllll}160 & 7 & 6.00385 \mathrm{E}-02 & -31331214-12 \quad \text { imp:n=1 }\end{array}$

$16195.40155 \mathrm{E}-05-31231114-12 \quad$ imp:n=1

$162113.83231 \mathrm{E}-02 \quad-311 \quad 14-12 \quad$ imp:n=1

$1630 \quad$ (6:-1:-14:10:-60:174) imp: $n=0$

c 


$$
\begin{aligned}
& \text { c DEFINITION OF UNIVERSES: ASSEMBLY F } \\
& 200 \quad 76.00385 \mathrm{E}-02 \quad 41-4051-50 \quad-61 \mathrm{u}=1 \mathrm{imp}: \mathrm{n}=1 \\
& 2012 \text { 1.20984E-01 } 41-4051-50 \quad 61 \quad-62 \quad \mathrm{u}=1 \text { imp:n=1 } \\
& 202 \quad 5 \text { 1.20013E-01 } 41-4051-50 \quad 62-63 \quad u=1 \text { imp:n=1 } \\
& 203 \quad 1 \text { 5.72591E-02 } 41-4051-50 \quad 63-64 u=1 \text { imp:n=1 } \\
& 204 \quad 4 \text { 1.20325E-01 } 41-4051-50 \quad 64-65 \quad \mathrm{u}=1 \mathrm{imp}: \mathrm{n}=1 \\
& 2053 \text { 1.21307E-01 } 41-4051-50 \quad 65-66 \quad u=1 \text { imp:n=1 } \\
& 206 \quad 15.72591 \mathrm{E}-02 \quad 41-4051-50 \quad 66 \quad-67 \quad \mathrm{u}=1 \text { imp:n=1 } \\
& 2074 \text { 1.20325E-01 } 41-4051-50 \quad 67 \quad-68 \quad u=1 \text { imp:n=1 } \\
& 208 \quad 3 \text { 1.21307E-01 } 41-4051-50 \quad 68 \quad-69 u=1 \text { imp:n=1 } \\
& 209 \text { 1 5.72591E-02 } 41-4051-50 \quad 69-70 \quad u=1 \text { imp:n=1 } \\
& 210 \quad 4 \quad 1.20325 \mathrm{E}-01 \quad 41-4051-50 \quad 70 \quad-71 \quad \mathrm{u}=1 \text { imp:n=1 } \\
& 2113 \text { 1.21307E-01 } 41-4051-50 \quad 71-72 \quad u=1 \text { imp:n=1 } \\
& 212 \quad 15.72591 \mathrm{E}-02 \quad 41-4051-50 \quad 72 \quad-73 \quad \mathrm{u}=1 \text { imp:n=1 } \\
& 2134 \text { 1.20325E-01 } 41-4051-50 \quad 73-74 \quad \mathrm{u}=1 \text { imp:n=1 } \\
& 2143 \text { 1.21307E-01 } 41-4051-50 \quad 74-75 \quad u=1 \text { imp:n=1 } \\
& 215 \text { 1 5.72591E-02 } 41-4051-50 \quad 75 \quad-76 \quad u=1 \text { imp:n=1 } \\
& 2164 \text { 1.20325E-01 } 41-4051-50 \quad 76-77 \quad u=1 \text { imp:n=1 } \\
& 217 \quad 3 \text { 1.21307E-01 } 41-4051-50 \quad 77 \quad-78 \quad u=1 \text { imp:n=1 } \\
& 218 \text { 1 5.72591E-02 } 41-4051-50 \quad 78 \quad-79 \quad \mathrm{u}=1 \text { imp:n=1 } \\
& 2194 \text { 1.20325E-01 } 41-4051-50 \quad 79 \quad-80 \quad u=1 \text { imp:n=1 } \\
& 220 \quad 3 \quad 1.21307 \mathrm{E}-01 \quad 41-4051-50 \quad 80-81 \quad \mathrm{u}=1 \mathrm{imp}: \mathrm{n}=1 \\
& 221 \quad 15.72591 \mathrm{E}-02 \quad 41-4051-50 \quad 81 \quad-82 \quad \mathrm{u}=1 \text { imp:n=1 } \\
& 2224 \text { 1.20325E-01 } 41-4051-50 \quad 82 \quad-83 \quad \mathrm{u}=1 \text { imp:n=1 } \\
& 223 \quad 3 \text { 1.21307E-01 } 41-4051-50 \quad 83-84 \quad \mathrm{u}=1 \text { imp:n=1 } \\
& 224 \quad 15.72591 \mathrm{E}-02 \quad 41-4051-50 \quad 84 \quad-85 \quad \mathrm{u}=1 \text { imp:n=1 } \\
& 2254 \text { 1.20325E-01 } 41-4051-50 \quad 85 \quad-86 \quad \mathrm{u}=1 \text { imp:n=1 } \\
& 226 \quad 3 \text { 1.21307E-01 } 41-4051-50 \quad 86 \quad-87 \quad u=1 \text { imp:n=1 } \\
& 227 \quad 15.72591 \mathrm{E}-02 \quad 41-4051-50 \quad 87 \quad-88 \quad \mathrm{u}=1 \mathrm{imp}: \mathrm{n}=1 \\
& 2284 \text { 1.20325E-01 } 41-4051-50 \quad 88 \quad-89 \quad \mathrm{u}=1 \text { imp:n=1 } \\
& 2293 \text { 1.21307E-01 } 41-4051-50 \quad 89-90 \quad u=1 \text { imp:n=1 } \\
& 230 \quad 1 \text { 5.72591E-02 } 41-4051-50 \quad 90 \quad-91 \quad u=1 \text { imp:n=1 } \\
& 231 \quad 4 \text { 1.20325E-01 } 41-4051-50 \quad 91 \quad-92 \quad u=1 \text { imp:n=1 } \\
& 232 \quad 3 \text { 1.21307E-01 } 41-4051-50 \quad 92-93 \quad u=1 \text { imp:n=1 } \\
& 233 \text { 1 5.72591E-02 } 41-4051-50 \quad 93 \quad-94 \quad \mathrm{u}=1 \text { imp:n=1 } \\
& 234 \quad 4 \text { 1.20325E-01 } 41-4051-50 \quad 94 \quad-95 \quad \mathrm{u}=1 \mathrm{imp}: \mathrm{n}=1 \\
& 235 \quad 3 \quad 1.21307 \mathrm{E}-01 \quad 41-4051-50 \quad 95 \quad-96 \quad \mathrm{u}=1 \text { imp:n=1 } \\
& 236 \quad 15.72591 \mathrm{E}-02 \quad 41-4051-50 \quad 96 \quad-97 \quad \mathrm{u}=1 \text { imp:n=1 } \\
& 2374 \text { 1.20325E-01 } 41-4051-50 \quad 97-98 \quad \mathrm{u}=1 \mathrm{imp}: \mathrm{n}=1 \\
& 238 \quad 3 \quad 1.21307 \mathrm{E}-01 \quad 41-4051-50 \quad 98 \quad-99 \quad \mathrm{u}=1 \mathrm{imp}: \mathrm{n}=1 \\
& 239 \quad 15.72591 \mathrm{E}-02 \quad 41-4051-50 \quad 99-100 \quad \mathrm{u}=1 \mathrm{imp}: \mathrm{n}=1 \\
& 240 \quad 4 \text { 1.20325E-01 } 41-4051-50 \quad 100-101 \quad u=1 \text { imp:n=1 } \\
& 24131.21307 \mathrm{E}-01 \quad 41-4051-50 \quad 101-102 \mathrm{u}=1 \text { imp:n=1 } \\
& 242 \quad 15.72591 \mathrm{E}-02 \quad 41-4051-50 \quad 102-103 \quad \mathrm{u}=1 \mathrm{imp}: \mathrm{n}=1 \\
& 2434 \text { 1.20325E-01 } 41-4051-50 \quad 103-104 \quad \mathrm{u}=1 \text { imp:n=1 } \\
& 244 \quad 3 \text { 1.21307E-01 } 41-4051-50 \quad 104-105 \mathrm{u}=1 \text { imp:n=1 } \\
& 245 \quad 1 \quad 5.72591 \mathrm{E}-02 \quad 41-4051-50 \quad 105-106 \quad \mathrm{u}=1 \mathrm{imp}: \mathrm{n}=1 \\
& 2464 \text { 1.20325E-01 } 41-4051-50 \quad 106-107 \quad \mathrm{u}=1 \mathrm{imp}: \mathrm{n}=1 \\
& 247 \quad 3 \text { 1.21307E-01 } 41-4051-50 \quad 107-108 \quad \mathrm{u}=1 \text { imp:n=1 } \\
& 248 \quad 15.72591 \mathrm{E}-02 \quad 41-4051-50 \quad 108-109 \quad \mathrm{u}=1 \mathrm{imp}: \mathrm{n}=1 \\
& 2494 \text { 1.20325E-01 } 41-4051-50 \quad 109-110 \quad \mathrm{u}=1 \text { imp:n=1 } \\
& 250 \quad 3 \quad 1.21307 \mathrm{E}-01 \quad 41-4051-50 \quad 110-111 \quad \mathrm{u}=1 \text { imp:n=1 } \\
& 251 \quad 1 \text { 5.72591E-02 } 41-4051-50 \quad 111-112 \quad \mathrm{u}=1 \text { imp:n=1 } \\
& 2524 \text { 1.20325E-01 } 41-4051-50 \quad 112-113 \quad \mathrm{u}=1 \text { imp:n=1 } \\
& 253 \quad 3 \quad 1.21307 \mathrm{E}-01 \quad 41-4051-50 \quad 113-114 \quad \mathrm{u}=1 \text { imp:n=1 } \\
& 254 \quad 15.72591 \mathrm{E}-02 \quad 41-4051-50 \quad 114-115 \quad \mathrm{u}=1 \mathrm{imp}: \mathrm{n}=1 \\
& 2554 \text { 1.20325E-01 } 41-4051-50 \quad 115-116 \quad \mathrm{u}=1 \text { imp:n=1 } \\
& 256 \quad 31.21307 \mathrm{E}-01 \quad 41-4051-50 \quad 116-117 \mathrm{u}=1 \mathrm{imp}: \mathrm{n}=1 \\
& 257 \text { 1 5.72591E-02 } 41-4051-50 \quad 117-118 \quad \mathrm{u}=1 \text { imp:n=1 } \\
& 258 \quad 4 \text { 1.20325E-01 } 41-4051-50 \quad 118-119 \quad \mathrm{u}=1 \text { imp:n=1 } \\
& 25931.21307 \mathrm{E}-01 \quad 41-4051-50 \quad 119-120 \quad \mathrm{u}=1 \mathrm{imp}: \mathrm{n}=1 \\
& 260 \quad 1 \text { 5.72591E-02 } 41-4051-50 \quad 120-121 \quad u=1 \text { imp:n=1 } \\
& 2614 \text { 1.20325E-01 } 41-4051-50 \quad 121-122 \quad \mathrm{u}=1 \text { imp:n=1 } \\
& 262 \quad 3 \quad 1.21307 \mathrm{E}-01 \quad 41-4051-50 \quad 122-123 \quad \mathrm{u}=1 \quad \mathrm{imp}: \mathrm{n}=1 \\
& 26315.72591 \mathrm{E}-02 \quad 41-4051-50 \quad 123-124 \quad \mathrm{u}=1 \text { imp:n=1 }
\end{aligned}
$$


$264 \quad 4$ 1.20325E-01

$265 \quad 3 \quad 1.21307 \mathrm{E}-01$

$266 \quad 15.72591 \mathrm{E}-02$

$267 \quad 4$ 1.20325E-01

$268 \quad 3 \quad 1.21307 \mathrm{E}-01$

$269 \quad 1$ 5.72591E-02

$270 \quad 4$ 1.20325E-01

$271 \quad 3 \quad 1.21307 \mathrm{E}-01$

$272 \quad 1$ 5.72591E-02

$273 \quad 4$ 1.20325E-01

$274 \quad 3$ 1.21307E-01

$275 \quad 15.72591 \mathrm{E}-02$

$276 \quad 4$ 1.20325E-01

$277 \quad 3$ 1.21307E-01

$278 \quad 1$ 5.72591E-02

$279 \quad 4$ 1.20325E-01

$280 \quad 3$ 1.21307E-01

$281 \quad 1$ 5.72591E-02

$282 \quad 4 \quad 1.20325 \mathrm{E}-01$

$283 \quad 3$ 1.21307E-01

$284 \quad 1$ 5.72591E-02

$285 \quad 4$ 1.20325E-01

$286 \quad 3$ 1.21307E-01

$287 \quad 1$ 5.72591E-02

$288 \quad 4$ 1.20325E-01

$289 \quad 3$ 1.21307E-01

$290 \quad 1$ 5.72591E-02

$291 \quad 4$ 1.20325E-01

$292 \quad 3$ 1.21307E-01

$293 \quad 1$ 5.72591E-02

$294 \quad 4$ 1.20325E-01

$295 \quad 3$ 1.21307E-01

$296 \quad 1$ 5.72591E-02

$297 \quad 4$ 1.20325E-01

$298 \quad 31.21307 \mathrm{E}-01$

$299 \quad 1$ 5.72591E-02

$300 \quad 4$ 1.20325E-01

$301 \quad 3$ 1.21307E-01

$302 \quad 1$ 5.72591E-02

$303 \quad 4$ 1.20325E-01

$304 \quad 3$ 1.21307E-01

$305 \quad 1$ 5.72591E-02

$306 \quad 4$ 1.20325E-01

$307 \quad 31.21307 \mathrm{E}-01$

$308 \quad 1$ 5.72591E-02

$309 \quad 4$ 1.20325E-01

$310 \quad 31.21307 \mathrm{E}-01$

3115 1.20013E-01

$\begin{array}{lll}312 & 2 & 1.20984 \mathrm{E}-01\end{array}$

$31341.20325 \mathrm{E}-01$

$314 \quad 95.40155 \mathrm{E}-05$

$31576.00385 \mathrm{E}-02$

$316 \quad 95.40155 \mathrm{E}-05$

c DEFINITION OF U

$350 \quad 7$ 6.00385E-02

$351 \quad 2$ 1.20984E-01

$352 \quad 5$ 1.20013E-01

$353 \quad 1$ 5.72591E-02

$354 \quad 4$ 1.20325E-01

$355 \quad 3$ 1.21307E-01

$356 \quad 1$ 5.72591E-02

$357 \quad 4$ 1.20325E-01

$358 \quad 3$ 1.21307E-01

$359 \quad 1$ 5.72591E-02

$360 \quad 4$ 1.20325E-01
$41-4051-50 \quad 124-125 \mathrm{u}=1$ imp:n=1 $41-4051-50 \quad 125-126 \quad u=1$ imp:n=1 $41-40 \begin{array}{llllll}51 & -50 & 126 & -127 & \mathrm{u}=1 & \mathrm{imp}: \mathrm{n}=1\end{array}$

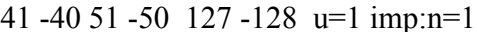

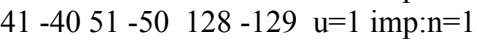
$41-4051-50 \quad 129-130 \quad u=1$ imp:n=1 $41-4051-50 \quad 130-131 \quad u=1$ imp:n=1 $41-4051-50 \quad 131-132 \quad u=1$ imp:n=1 $41-4051-50 \quad 132-133 \quad u=1$ imp:n=1 $41-40 \begin{array}{llllll}51 & -50 & 133 & -134 & \mathrm{u}=1 & \mathrm{imp}: \mathrm{n}=1\end{array}$ $41-4051-50 \quad 134-135 \quad u=1$ imp:n=1

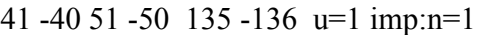
$41-4051-50 \quad 136-137 \quad u=1$ imp:n=1

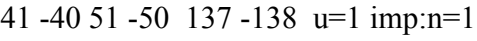
$\begin{array}{lllllll}4 & -40 & 51 & -50 & 138 & -139 & \mathrm{u}=1 \\ \mathrm{imp} & \mathrm{n}=1\end{array}$ $41-4051-50 \quad 139-140 \quad u=1$ imp:n=1 $41-4051-50 \quad 140-141 \quad u=1$ imp:n=1 $41-4051 \quad-50 \quad 141-142 \quad u=1$ imp:n=1 $41-4051-50 \quad 142-143 \quad u=1 \quad i m p: n=1$ $41-4051-50 \quad 143-144 \quad u=1$ imp:n=1 $41-4051-50 \quad 144-145 \quad u=1$ imp:n=1 $41-4051-50 \quad 145-146 \quad u=1$ imp:n=1 $41-4051-50 \quad 146-147 \quad u=1$ imp:n=1 $41-4051-50 \quad 147-148 \quad \mathrm{u}=1$ imp:n=1 $41-4051-50148-149$ u=1 imp:n=1 $41-4051-50 \quad 149-150 \quad u=1$ imp:n=1 $41-4051-50 \quad 150-151 \quad \mathrm{u}=1$ imp:n=1 $41-4051-50 \quad 151-152 \quad u=1$ imp:n=1 $41-4051-50 \quad 152-153 \quad u=1$ imp:n=1 $41-4051-50 \quad 153-154 \quad \mathrm{u}=1$ imp:n=1 $41-4051-50 \quad 154-155 \quad u=1$ imp:n=1 $41-4051-50 \quad 155-156 \quad u=1$ imp:n=1 $41-4051-50 \quad 156-157 \quad u=1$ imp:n=1 $41-4051-50 \quad 157-158 \quad u=1$ imp:n=1 $41-40 \begin{array}{llllll}-50 & 158 & -159 & \mathrm{u}=1 & \mathrm{imp}: \mathrm{n}=1\end{array}$ $41-4051-50 \quad 159-160 \quad u=1$ imp:n=1 $41-4051-50 \quad 160-161 \quad u=1$ imp:n=1 $41-4051-50 \quad 161-162 \quad \mathrm{u}=1$ imp:n=1 $41-4051-50 \quad 162-163 \quad \mathrm{u}=1$ imp:n=1 $41-4051-50 \quad 163-164 \quad u=1$ imp:n=1 $41-4051-50 \quad 164-165 \quad u=1$ imp:n=1 $41-4051-50 \quad 165-166 u=1$ imp:n=1 $41-4051-50 \quad 166-167 \quad u=1$ imp:n=1 $41-4051-50 \quad 167-168 \quad u=1$ imp:n=1 $41-4051-50 \quad 168-169 \quad u=1$ imp:n=1 $41-4051-50 \quad 169-170 \quad u=1$ imp:n=1 $41-4051-50 \quad 170-171 \quad u=1$ imp:n=1 $41-4051-50 \quad 171-172 \quad u=1$ imp:n=1 $41-4051-50 \quad 172-173 \quad u=1$ imp:n=1 $41-4051-50 \quad 173 \quad u=1$ imp:n=1 $(-41: 40:-51: 50) 45-4455-54 \mathrm{u}=1 \mathrm{imp}: \mathrm{n}=1$ $(-45: 44:-55: 54) 47-4657-56 u=1$ imp:n=1 $(-47: 46:-57: 56) \quad u=1 \mathrm{imp}: \mathrm{n}=1$ NIVERSES: ASSEMBLY SV $41-4051-50 \quad-61 \mathrm{u}=2 \mathrm{imp}: \mathrm{n}=1$ $41-4051-50 \quad 61-200 u=2$ imp:n=1 $41-4051-50 \quad 200-201 \quad u=2$ imp:n=1 $41-4051-50 \quad 201-202 \quad \mathrm{u}=2$ imp:n=1 $\begin{array}{lllllll}4 & -40 & 51 & -50 & 202 & -203 & \mathrm{u}=2 \\ \mathrm{imp} & \mathrm{n}=1\end{array}$ $41-4051-50 \quad 203-204 \quad \mathrm{u}=2$ imp:n=1 $41-4051-50 \quad 204-205$ u=2 imp:n=1 $41-4051-50 \quad 205-206 u=2$ imp:n=1 $41-4051-50 \quad 206-207 \quad u=2$ imp:n=1 $41-4051-50 \quad 207-208$ u=2 imp:n=1 $41-4051-50 \quad 208-209 u=2$ imp:n=1 
3613 1.21307E-01

$362 \quad 15.72591 \mathrm{E}-02$

$36341.20325 \mathrm{E}-01$

$364 \quad 3 \quad 1.21307 \mathrm{E}-01$

$\begin{array}{lll}365 & 1 & 5.72591 \mathrm{E}-02\end{array}$

$366 \quad 4$ 1.20325E-01

$367 \quad 3 \quad 1.21307 \mathrm{E}-01$

$368 \quad 15.72591 \mathrm{E}-02$

$369 \quad 4$ 1.20325E-01

$370 \quad 31.21307 \mathrm{E}-01$

$371 \quad 15.72591 \mathrm{E}-02$

$372 \quad 4$ 1.20325E-01

$\begin{array}{lll}373 & 3 & 1.21307 \mathrm{E}-01\end{array}$

$374 \quad 15.72591 \mathrm{E}-02$

$375 \quad 4 \quad 1.20325 \mathrm{E}-01$

$\begin{array}{lll}376 & 3 & 1.21307 \mathrm{E}-01\end{array}$

$377 \quad 1$ 5.72591E-02

$378 \quad 4$ 1.20325E-01

$379 \quad 3$ 1.21307E-01

$380 \quad 1$ 5.72591E-02

$381 \quad 4$ 1.20325E-01

$382 \quad 3 \quad 1.21307 \mathrm{E}-01$

$383 \quad 15.72591 \mathrm{E}-02$

$384 \quad 4$ 1.20325E-01

$385 \quad 3 \quad 1.21307 \mathrm{E}-01$

$386 \quad 15.72591 \mathrm{E}-02$

$387 \quad 4$ 1.20325E-01

$388 \quad 3$ 1.21307E-01

$389 \quad 1$ 5.72591E-02

$390 \quad 4$ 1.20325E-01

$391 \quad 3$ 1.21307E-01

$392 \quad 1 \quad 5.72591 \mathrm{E}-02$

$393 \quad 4$ 1.20325E-01

$394 \quad 3$ 1.21307E-01

$395 \quad 1$ 5.72591E-02

$396 \quad 4$ 1.20325E-01

$397 \quad 3$ 1.21307E-01

$398 \quad 1$ 5.72591E-02

$399 \quad 4$ 1.20325E-01

$400 \quad 3$ 1.21307E-01

$401 \quad 95.40155 \mathrm{E}-05$

$31341-4051-50249-250)$

$402 \quad 15.72591 \mathrm{E}-02$

$403 \quad 4$ 1.20325E-01

$404 \quad 3$ 1.21307E-01

$405 \quad 1$ 5.72591E-02

$406 \quad 4$ 1.20325E-01

$407 \quad 3$ 1.21307E-01

$408 \quad 1$ 5.72591E-02

$409 \quad 4$ 1.20325E-01

$410 \quad 3 \quad 1.21307 \mathrm{E}-01$

$411 \quad 1$ 5.72591E-02

$412 \quad 4$ 1.20325E-01

$413 \quad 3 \quad 1.21307 \mathrm{E}-01$

$414 \quad 15.72591 \mathrm{E}-02$

$415 \quad 4$ 1.20325E-01

$416 \quad 3 \quad 1.21307 \mathrm{E}-01$

$417 \quad 15.72591 \mathrm{E}-02$

$418 \quad 4$ 1.20325E-01

$419 \quad 3$ 1.21307E-01

$420 \quad 1$ 5.72591E-02

$421 \quad 4$ 1.20325E-01

$422 \quad 3$ 1.21307E-01

$423 \quad 1$ 5.72591E-02

$424 \quad 41.20325 \mathrm{E}-01$
$41-4051-50209-210 u=2$ imp:n=1 $41-4051-50 \quad 210-211$ u=2 imp:n=1 $41-40 \begin{array}{rlllll}51 & -50 & 211 & -212 & \mathrm{u}=2 & \mathrm{imp}: \mathrm{n}=1\end{array}$

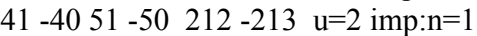
$41-4051-50 \quad 213-214 u=2$ imp:n=1 $\begin{array}{lllllll}41 & -40 & 51 & -50 & 214 & -215 & \mathrm{u}=2 \\ \mathrm{imp}: \mathrm{n}=1\end{array}$ $41-4051-50 \quad 215-216 \quad u=2$ imp:n=1 $41-4051-50216-217 \quad u=2$ imp:n=1 $41-40 \begin{array}{rllll}51 & -50 & 217 & -218 u=2 & \mathrm{imp}: \mathrm{n}=1\end{array}$ $41-4051-50 \quad 218-219 u=2$ imp:n=1 $41-4051-50 \quad 219-220 \quad u=2$ imp:n=1 $41-40 \begin{array}{rlllll}-50 & 220 & -221 & \mathrm{u}=2 & \mathrm{imp}: \mathrm{n}=1\end{array}$ $41-4051-50 \quad 221-222 \quad u=2$ imp:n=1

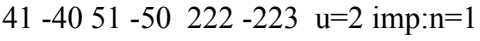
$41-40 \begin{array}{lllll}51 & -50 & 223 & -224 & \mathrm{u}=2 \\ \mathrm{imp}: \mathrm{n}=1\end{array}$ $41-4051-50 \quad 224-225$ u=2 imp:n=1 $41-4051-50 \quad 225-226 u=2$ imp:n=1 $41-40 \begin{array}{rlllll}4 & -50 & 226 & -227 & \mathrm{u}=2 & \mathrm{imp}: \mathrm{n}=1\end{array}$

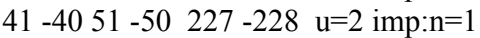
$41-40 \begin{array}{rlllll}-50 & 228 & -229 u=2 & \text { imp:n}=1\end{array}$ $\begin{array}{lllllll}4 & -40 & 51 & -50 & 229 & -230 & \mathrm{u}=2 \\ \mathrm{imp} & \mathrm{n}=1\end{array}$

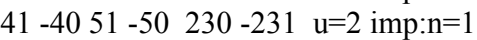
$41-4051-50 \quad 231-232 u=2$ imp:n=1 $\begin{array}{llllllll}4 & -40 & 51 & -50 & 232 & -233 & \mathrm{u}=2 & \mathrm{imp}: \mathrm{n}=1\end{array}$ $41-4051-50 \quad 233-234 u=2$ imp:n=1 $41-4051-50 \quad 234-235$ u=2 imp:n=1 $41-4051-50 \quad 235-236 u=2$ imp:n=1 $41-4051-50 \quad 236-237 \quad u=2$ imp:n=1 $41-4051-50 \quad 237-238$ u=2 imp:n=1 $\begin{array}{lllllll}4 & -40 & 51 & -50 & 238 & -239 & \mathrm{u}=2 \\ \mathrm{imp} & \mathrm{n}=1\end{array}$ $41-4051-50 \quad 239-240 \quad u=2$ imp:n=1 $41-4051-50 \quad 240-241 \quad u=2$ imp:n=1 $41-4051-50 \quad 241-242 \quad \mathrm{u}=2$ imp:n=1 $41-4051-50 \quad 242-243 \quad u=2$ imp:n=1 $41-40 \begin{array}{rlllll}-50 & 243 & -244 u=2 & \mathrm{imp}: \mathrm{n}=1\end{array}$ $41-4051-50 \quad 244-245 \quad u=2$ imp:n=1 $41-4051-50 \quad 245-246 u=2$ imp:n=1 $41-4051-50 \quad 246-247 \quad u=2$ imp:n=1 $\begin{array}{lllllll}4 & -40 & 51 & -50 & 247 & -248 & \mathrm{u}=2 \\ \mathrm{imp} & \mathrm{n}=1\end{array}$

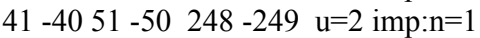
$(-302: 301:-306: 305)$

$41-4051-50 \quad 250-251 \quad u=2$ imp:n=1 $41-4051-50 \quad 251-252 u=2$ imp:n=1 $41-4051-50 \quad 252-253 \quad u=2$ imp:n=1 $41-40 \begin{array}{llllll}-50 & 253 & -254 & \mathrm{u}=2 & \mathrm{imp}: \mathrm{n}=1\end{array}$ $41-40 \begin{array}{rlllll}-50 & 254 & -255 \mathrm{u}=2 \mathrm{imp}: \mathrm{n}=1\end{array}$ $41-4051-50 \quad 255-256 u=2$ imp:n=1 $41-4051-50 \quad 256-257 \mathrm{u}=2 \mathrm{imp}: \mathrm{n}=1$ $41-40 \begin{array}{rllll}-50 & 257 & -258 & \mathrm{u}=2 & \mathrm{imp}: \mathrm{n}=1\end{array}$ $\begin{array}{lllllll}4 & -40 & 51 & -50 & 258 & -259 & \mathrm{u}=2 \\ \mathrm{imp}: \mathrm{n}=1\end{array}$ $41-40 \begin{array}{lllll}51 & -50 & 259 & -260 u=2 & \mathrm{imp}: \mathrm{n}=1\end{array}$ $41-4051-50 \quad 260-261 \quad u=2$ imp:n=1 $41-4051-50 \quad 261-262 \quad u=2$ imp:n=1 $41-40 \begin{array}{llllll}-50 & 262 & -263 & \mathrm{u}=2 & \mathrm{imp}: \mathrm{n}=1\end{array}$ $\begin{array}{lllllll}4 & -40 & 51 & -50 & 263 & -264 & \mathrm{u}=2 \\ \mathrm{imp} & \mathrm{n}=1\end{array}$ $41-4051-50 \quad 264-265 u=2$ imp:n=1 $41-4051-50 \quad 265-266 u=2$ imp:n=1 $41-4051-50 \quad 266-267 \quad u=2$ imp:n=1 $41-4051-50 \quad 267-268$ u=2 imp:n=1 $41-40 \begin{array}{llllll}51 & -50 & 268 & -269 & \mathrm{u}=2 & \mathrm{imp}: \mathrm{n}=1\end{array}$ $\begin{array}{lllllll}4 & -40 & 51 & -50 & 269 & -270 & u=2 \\ \text { imp:n}=1\end{array}$

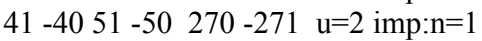
$41-4051-50 \quad 271-272 u=2$ imp:n=1 $\begin{array}{lllllll}41 & -40 & 51 & -50 & 272 & -273 & u=2 \\ \text { imp:n}=1\end{array}$ 
$425 \quad 3 \quad 1.21307 \mathrm{E}-01$ $426 \quad 1$ 5.72591E-02

$427 \quad 4$ 1.20325E-01

$428 \quad 3$ 1.21307E-01

$429 \quad 1$ 5.72591E-02

$430 \quad 4$ 1.20325E-01

$\begin{array}{lll}431 & 3 & 1.21307 \mathrm{E}-01\end{array}$

$432 \quad 15.72591 \mathrm{E}-02$

$433 \quad 4$ 1.20325E-01

$434 \quad 3 \quad 1.21307 \mathrm{E}-01$

$435 \quad 1$ 5.72591E-02

$436 \quad 4$ 1.20325E-01

$\begin{array}{lll}437 & 3 & 1.21307 \mathrm{E}-01\end{array}$

$438 \quad 1$ 5.72591E-02

$439 \quad 41.20325 \mathrm{E}-01$

$440 \quad 3$ 1.21307E-01

$441 \quad 1$ 5.72591E-02

$442 \quad 41.20325 \mathrm{E}-01$

$443 \quad 3$ 1.21307E-01

$444 \quad 1$ 5.72591E-02

$445 \quad 4 \quad 1.20325 \mathrm{E}-01$

$446 \quad 3$ 1.21307E-01

$447 \quad 1$ 5.72591E-02

$448 \quad 4$ 1.20325E-01

$449 \quad 3$ 1.21307E-01

$450 \quad 5$ 1.20013E-01

$\begin{array}{lll}451 & 21.20984 \mathrm{E}-01\end{array}$

$452 \quad 4$ 1.20325E-01

$453 \quad 95.40155 \mathrm{E}-05$

$454 \quad 76.00385 \mathrm{E}-02$

$455 \quad 95.40155 \mathrm{E}-05$

$456 \quad 76.00385 \mathrm{E}-02$

$457 \quad 95.40155 \mathrm{E}-05$

$458 \quad 113.83231 \mathrm{E}-02$

$459 \quad 76.00385 \mathrm{E}-02$
$41-4051-50 \quad 273-274 \quad \mathrm{u}=2$ imp:n=1

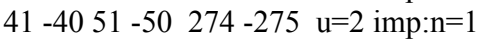
$41-40 \begin{array}{llllll}5 & -50 & 275 & -276 & \mathrm{u}=2 & \mathrm{imp}: \mathrm{n}=1\end{array}$ $41-4051-50 \quad 276-277 \quad u=2$ imp:n=1 $41-4051-50 \quad 277-278$ u=2 imp:n=1 $\begin{array}{lllllll}4 & -40 & 51 & -50 & 278 & -279 & u=2 \\ \text { imp:n}=1\end{array}$ $41-4051-50 \quad 279-280 u=2$ imp:n=1

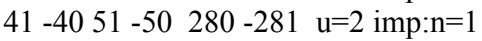
$41-40 \begin{array}{rlllll}-50 & 281 & -282 & \mathrm{u}=2 & \mathrm{imp}: \mathrm{n}=1\end{array}$

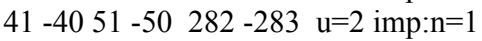
$41-4051-50 \quad 283-284 \quad u=2$ imp:n=1 $41-4051-50 \quad 284-285$ u=2 imp:n=1 $41-4051-50 \quad 285-286 \quad u=2$ imp:n=1 $41-4051-50 \quad 286-287 \quad u=2$ imp:n=1 $41-4051-50 \quad 287-288$ u=2 imp:n=1 $\begin{array}{lllllll}4 & -40 & 51 & -50 & 288 & -289 & \mathrm{u}=2 \\ \mathrm{imp}: \mathrm{n}=1\end{array}$ $41-4051-50 \quad 289-290 u=2$ imp:n=1 $41-4051-50 \quad 290-291$ u=2 imp:n=1 $41-4051-50 \quad 291-292$ u=2 imp:n=1 $41-4051-50 \quad 292-293$ u=2 imp:n=1 $41-4051-50 \quad 293-294 u=2$ imp:n=1 $41-4051-50 \quad 294-295$ u=2 imp:n=1 $41-4051-50 \quad 295-296 u=2$ imp:n=1 $41-4051-50 \quad 296-297 \quad u=2$ imp:n=1 $41-4051-50 \quad 297-298$ u=2 imp:n=1 $41-4051-50 \quad 298-299$ u=2 imp:n=1 $41-4051-50 \quad 299-300 \quad u=2$ imp:n=1 $\begin{array}{llllll}41 & -40 & 51 & -50 & 300 \quad \mathrm{u}=2 \text { imp: } \mathrm{n}=1\end{array}$ $(-41: 40:-51: 50) 31345-4455-54 \mathrm{u}=2 \mathrm{imp}: \mathrm{n}=1$ $(-45: 44:-55: 54) 31347-4657-56 u=2$ imp:n=1 $(-47: 46:-57: 56) 313 \quad u=2$ imp:n=1 $-313312 \quad u=2$ imp: $n=1$ $-312311 \quad u=2$ imp: $n=1$ $-311 \quad u=2$ imp: $n=1$

$302-301306-305249-250$

$(-304: 303:-306: 305:-309: 310) \quad u=2$ imp: $n=1$

$460 \quad 95.40155 \mathrm{E}-05 \quad 313304-303306-305309-310 \quad \mathrm{u}=2$ imp:n=1 c DEFINITION OF UNIVERSES: ASSEMBLY 26

$490 \quad 76.00385 \mathrm{E}-02 \quad 41-4051-50 \quad-61 \quad \mathrm{u}=3 \mathrm{imp}: \mathrm{n}=1$

4912 1.20984E-01 $41-4051-50 \quad 61 \quad-62 \quad \mathrm{u}=3$ imp:n=1

$492 \quad 7 \quad 6.00385 \mathrm{E}-02 \quad 41-4051-50 \quad 62-340 \quad \mathrm{u}=3$ imp:n=1

4934 1.20325E-01 $41-4051-50 \quad 340-341 \quad u=3$ imp:n=1

$494 \quad 3$ 1.21307E-01 $41-4051-50 \quad 341-342 \quad \mathrm{u}=3$ imp: $n=1$

$495 \quad 7 \quad 6.00385 \mathrm{E}-02 \quad 41-4051-50 \quad 342-343 \quad \mathrm{u}=3$ imp:n=1

4964 1.20325E-01 $41-4051-50 \quad 343-344 \quad \mathrm{u}=3$ imp:n=1

$497 \quad 3$ 1.21307E-01 $41-4051-50 \quad 344-345 \quad \mathrm{u}=3$ imp: $n=1$

$498 \quad 76.00385 \mathrm{E}-02 \quad 41-4051-50 \quad 345-346 \mathrm{u}=3 \mathrm{imp}: \mathrm{n}=1$

4994 1.20325E-01 $41-4051-50 \quad 346-347 \quad \mathrm{u}=3$ imp:n=1

$500 \quad 3 \quad 1.21307 \mathrm{E}-01 \quad 41-4051-50 \quad 347-348 \quad \mathrm{u}=3$ imp:n=1

$501 \quad 76.00385 \mathrm{E}-02 \quad 41-4051-50 \quad 348-349 \quad \mathrm{u}=3 \mathrm{imp}: \mathrm{n}=1$

5024 1.20325E-01 $41-4051-50 \quad 349-350 \quad \mathrm{u}=3$ imp:n=1

$503 \quad 31.21307 \mathrm{E}-01 \quad 41-4051-50 \quad 350-351 \quad \mathrm{u}=3$ imp:n=1

$504 \quad 7 \quad 6.00385 \mathrm{E}-02 \quad 41-4051-50 \quad 351-352 \quad \mathrm{u}=3$ imp:n=1

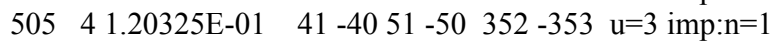

$\begin{array}{llllllllll}506 & 3 & 1.21307 \mathrm{E}-01 & 41 & -40 & 51 & -50 & 353 & -354 & \mathrm{u}=3 \\ \mathrm{imp}: \mathrm{n}=1\end{array}$

$507 \quad 5 \quad 1.20013 \mathrm{E}-01 \quad 41-4051-50 \quad 354-355 \quad \mathrm{u}=3$ imp:n=1

$508 \quad 15.72591 \mathrm{E}-02 \quad 41-4051-50 \quad 355-356 \quad \mathrm{u}=3 \mathrm{imp}: \mathrm{n}=1$

5094 1.20325E-01 $41-4051-50 \quad 356-357 \quad \mathrm{u}=3$ imp:n=1

$510 \quad 3 \quad 1.21307 \mathrm{E}-01 \quad 41-4051-50 \quad 357-358 \quad \mathrm{u}=3 \mathrm{imp}: \mathrm{n}=1$

$511 \quad 15.72591 \mathrm{E}-02 \quad 41-4051-50 \quad 358-359 \quad \mathrm{u}=3 \mathrm{imp}: \mathrm{n}=1$

$512 \quad 4$ 1.20325E-01 $41-4051-50 \quad 359-360 \quad u=3$ imp:n=1

$513 \quad 3$ 1.21307E-01 $41-4051-50 \quad 360-361 \quad u=3$ imp:n=1

$514 \quad 15.72591 \mathrm{E}-02 \quad 41-4051-50 \quad 361-362 \quad \mathrm{u}=3$ imp:n=1

$515 \quad 4$ 1.20325E-01 $41-4051-50 \quad 362-363 \quad \mathrm{u}=3$ imp:n=1

$516 \quad 3 \quad 1.21307 \mathrm{E}-01 \quad 41-4051-50 \quad 363-364 \quad \mathrm{u}=3$ imp:n=1 
$517 \quad 15.72591 \mathrm{E}-02$ $518 \quad 4$ 1.20325E-01

$519 \quad 3$ 1.21307E-01

$520 \quad 15.72591 \mathrm{E}-02$

$521 \quad 4$ 1.20325E-01

$522 \quad 31.21307 \mathrm{E}-01$

$523 \quad 15.72591 \mathrm{E}-02$

$524 \quad 41.20325 \mathrm{E}-01$

$525 \quad 31.21307 \mathrm{E}-01$

$\begin{array}{ll}526 & 15.72591 \mathrm{E}-02\end{array}$

$527 \quad 4$ 1.20325E-01

$528 \quad 31.21307 \mathrm{E}-01$

$529 \quad 15.72591 \mathrm{E}-02$

$530 \quad 4$ 1.20325E-01

$\begin{array}{lll}531 & 3 & 1.21307 \mathrm{E}-01\end{array}$

$\begin{array}{lll}532 & 1 & 5.72591 \mathrm{E}-02\end{array}$

$533 \quad 4$ 1.20325E-01

$534 \quad 3$ 1.21307E-01

$\begin{array}{lll}535 & 1 & 5.72591 \mathrm{E}-02\end{array}$

$536 \quad 4$ 1.20325E-01

$537 \quad 3 \quad 1.21307 \mathrm{E}-01$

$538 \quad 1$ 5.72591E-02

$539 \quad 41.20325 \mathrm{E}-01$

$540 \quad 31.21307 \mathrm{E}-01$

$541 \quad 1$ 5.72591E-02

$542 \quad 41.20325 \mathrm{E}-01$

$543 \quad 31.21307 \mathrm{E}-01$

$544 \quad 1$ 5.72591E-02

$545 \quad 4$ 1.20325E-01

$546 \quad 31.21307 \mathrm{E}-01$

$547 \quad 1$ 5.72591E-02

$548 \quad 4$ 1.20325E-01

$549 \quad 31.21307 \mathrm{E}-01$

$550 \quad 1$ 5.72591E-02

$551 \quad 4$ 1.20325E-01

$552 \quad 3$ 1.21307E-01

$553 \quad 1$ 5.72591E-02

$554 \quad 4$ 1.20325E-01

$555 \quad 31.21307 \mathrm{E}-01$

$556 \quad 1$ 5.72591E-02

$557 \quad 4$ 1.20325E-01

$558 \quad 31.21307 \mathrm{E}-01$

$559 \quad 1$ 5.72591E-02

$560 \quad 4$ 1.20325E-01

$561 \quad 3 \quad 1.21307 \mathrm{E}-01$

$562 \quad 1$ 5.72591E-02

$56341.20325 \mathrm{E}-01$

$56431.21307 \mathrm{E}-01$

$565 \quad 1$ 5.72591E-02

$56641.20325 \mathrm{E}-01$

$567 \quad 31.21307 \mathrm{E}-01$

$568 \quad 1$ 5.72591E-02

5694 1.20325E-01

$570 \quad 31.21307 \mathrm{E}-01$

$571 \quad 15.72591 \mathrm{E}-02$

$572 \quad 4$ 1.20325E-01

$573 \quad 3$ 1.21307E-01

$574 \quad 1$ 5.72591E-02

$575 \quad 4$ 1.20325E-01

$576 \quad 3$ 1.21307E-01

$577 \quad 1$ 5.72591E-02

$578 \quad 41.20325 \mathrm{E}-01$

$579 \quad 31.21307 \mathrm{E}-01$

$580 \quad 15.72591 \mathrm{E}-02$

$581 \quad 4$ 1.20325E-01
$41-4051-50364-365 \mathrm{u}=3$ imp:n=1 $41-4051-50 \quad 365-366 u=3$ imp:n=1 $41-40 \begin{array}{lllllll}51 & -50 & 366 & -367 & \mathrm{u}=3 & \mathrm{imp}: \mathrm{n}=1\end{array}$ $\begin{array}{lllllll}4 & -40 & 51 & -50 & 367 & -368 & \mathrm{u}=3 \\ \mathrm{imp}: \mathrm{n}=1\end{array}$ $41-4051-50368-369 u=3$ imp:n=1 $\begin{array}{llllllll}41 & -40 & 51 & -50 & 369 & -370 & \mathrm{u}=3 & \mathrm{imp}: \mathrm{n}=1\end{array}$ $\begin{array}{lllllll}4 & -40 & 51 & -50 & 370 & -371 & \mathrm{u}=3 \\ \mathrm{imp}: \mathrm{n}=1\end{array}$

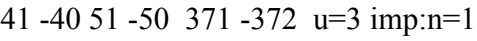
$\begin{array}{lllllll}4 & -40 & 51 & -50 & 372 & -373 & u=3 \\ \text { imp:n=1 }\end{array}$ $\begin{array}{llllll}4 & -40 & 51 & -50 & 373 & -374 \quad u=3 \\ \text { imp: } n=1\end{array}$ $\begin{array}{lllllll}41 & -40 & 51 & -50 & 374 & -375 & u=3 \\ \text { imp:n}=1\end{array}$ $41-4051-50 \quad 375-376 u=3$ imp:n=1 $\begin{array}{llllll}4 & -40 & 51 & -50 & 376 & -377 \quad u=3 \\ \text { imp: } n=1\end{array}$ $\begin{array}{lllllll}41 & -40 & 51 & -50 & 377 & -378 & u=3 \\ \text { imp:n} & =1\end{array}$ $\begin{array}{lllllll}41 & -40 & 51 & -50 & 378 & -379 & \mathrm{u}=3 \\ \mathrm{imp}: \mathrm{n}=1\end{array}$ $\begin{array}{llllll}4 & -40 & 51 & -50 & 379 & -380 \quad u=3 \\ \text { imp:n}=1\end{array}$ $\begin{array}{llllllll}41 & -40 & 51 & -50 & 380 & -381 & \mathrm{u}=3 & \mathrm{imp}: \mathrm{n}=1\end{array}$ $\begin{array}{llllllll}4 & -40 & 51 & -50 & 381 & -382 & \mathrm{u}=3 & \mathrm{imp}: \mathrm{n}=1\end{array}$ $41-4051-50 \quad 382-383$ u=3 imp:n=1 $\begin{array}{lllllll}4 & -40 & 51 & -50 & 383 & -384 & \mathrm{u}=3 \\ \mathrm{imp}: \mathrm{n}=1\end{array}$ $\begin{array}{lllllll}41 & -40 & 51 & -50 & 384 & -385 & \mathrm{u}=3 \\ \mathrm{imp} & \mathrm{n}=1\end{array}$ $41-4051-50 \quad 385-386 u=3$ imp:n=1 $41-4051-50 \quad 386-387 \quad u=3$ imp:n=1 $\begin{array}{lllllll}4 & -40 & 51 & -50 & 387 & -388 & \mathrm{u}=3 \\ \mathrm{imp}: \mathrm{n}=1\end{array}$

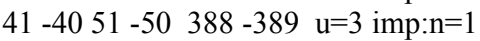
$41-4051-50 \quad 389-390 \quad u=3$ imp:n=1 $\begin{array}{lllllll}4 & -40 & 51 & -50 & 390 & -391 & \mathrm{u}=3 \\ \mathrm{imp}: \mathrm{n}=1\end{array}$ $41-4051-50 \quad 391-392 \quad u=3$ imp:n=1 $41-4051-50 \quad 392-393$ u=3 imp:n=1 $41-4051-50 \quad 393-394 \quad u=3$ imp:n=1

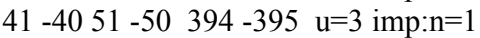
$41-4051-50 \quad 395-396 u=3$ imp:n=1 $41-4051-50 \quad 396-397 \quad u=3$ imp:n=1

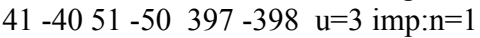
$\begin{array}{lllllll}41 & -40 & 51 & -50 & 398 & -399 & u=3 \\ \text { imp:n}=1\end{array}$

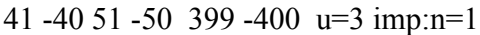
$41-4051-50 \quad 400-401 \quad u=3$ imp:n=1 $41-40 \begin{array}{llllll}51 & -50 & 401 & -402 \quad \mathrm{u}=3 & \mathrm{imp}: \mathrm{n}=1\end{array}$ $41-4051-50 \quad 402-403 \quad \mathrm{u}=3$ imp:n=1

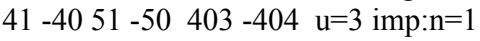
$41-40 \begin{array}{llllll}51 & -50 & 404 & -405 & \mathrm{u}=3 & \mathrm{imp}: \mathrm{n}=1\end{array}$ $41-4051-50 \quad 405-406 \mathrm{u}=3$ imp:n=1 $41-4051-50 \quad 406-407 \quad u=3$ imp:n=1 $41-4051-50 \quad 407-408 \quad u=3$ imp:n=1 $41-4051-50 \quad 408-409 \quad u=3$ imp:n=1 $41-4051-50 \quad 409-410 \quad u=3$ imp:n=1 $\begin{array}{lllllll}41 & -40 & 51 & -50 & 410 & -411 & u=3 \\ \text { imp:n}=1\end{array}$ $41-4051-50 \quad 411-412 \quad u=3$ imp:n=1 $41-4051-50 \quad 412-413 \quad u=3$ imp:n=1 $41-40 \begin{array}{lllll}51 & -50 & 413 & -414 \quad \mathrm{u}=3 \text { imp:n=1 }\end{array}$ $41-4051-50 \quad 414-415 \quad u=3$ imp:n=1 $41-4051-50 \quad 415-416 u=3$ imp:n=1 $41-4051-50 \quad 416-417 \quad u=3$ imp:n=1 $41-4051-50 \quad 417-418 \quad u=3$ imp:n=1 $41-40 \begin{array}{llllll}51 & -50 & 418 & -419 & \mathrm{u}=3 & \mathrm{imp}: \mathrm{n}=1\end{array}$ $\begin{array}{lllllll}41 & -40 & 51 & -50 & 419 & -420 & \mathrm{u}=3 \\ \mathrm{imp}: \mathrm{n}=1\end{array}$ $41-4051-50 \quad 420-421 \quad u=3$ imp:n=1 $41-4051-50 \quad 421-422 \quad u=3$ imp:n=1 $\begin{array}{lllllll}41 & -40 & 51 & -50 & 422 & -423 & \mathrm{u}=3 \\ \mathrm{imp}: \mathrm{n}=1\end{array}$ $41-4051-50 \quad 423-424 \quad \mathrm{u}=3$ imp:n=1 $41-4051-50 \quad 424-425 \quad u=3$ imp:n=1 $41-4051-50 \quad 425-426 \quad u=3$ imp:n=1 $41-4051-50 \quad 426-427 \quad u=3$ imp:n=1 $41-4051-50 \quad 427-428 \quad u=3$ imp:n=1

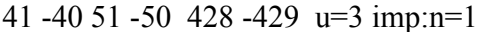




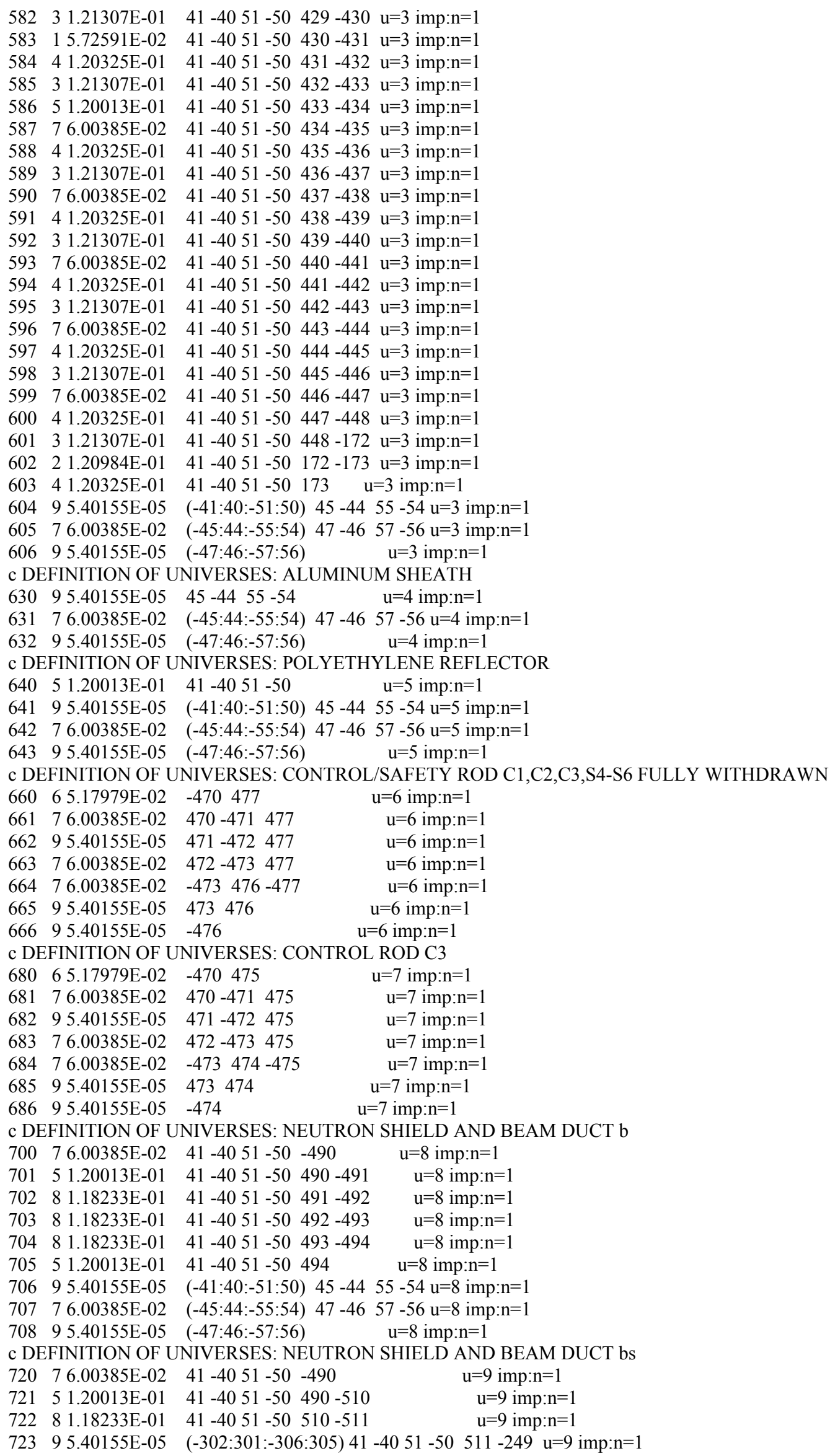


$724 \quad 95.40155 \mathrm{E}-05 \quad(-302: 301:-306: 305)$

$$
41-4051-50 \quad 249-250 \quad u=9 \text { imp:n=1 }
$$

$72595.40155 \mathrm{E}-05 \quad(-302: 301:-306: 305) 41-4051-50 \quad 250-512$ u=9 imp:n=1

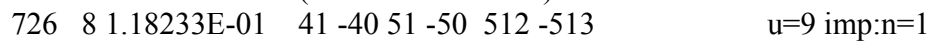

$\begin{array}{llllll}727 & 5 & 1.20013 \mathrm{E}-01 & 41-40 & 51-50 \quad 513\end{array}$

$728 \quad 95.40155 \mathrm{E}-05 \quad(-41: 40:-51: 50) 45-4455-54$

$72976.00385 \mathrm{E}-02 \quad(-45: 44:-55: 54) 47-4657-56$

$730 \quad 95.40155 \mathrm{E}-05 \quad(-47: 46:-57: 56)$

$\mathrm{u}=9$ imp:n=1

$\mathrm{u}=9$ imp:n=1 $\mathrm{u}=9$ imp:n=1

$73276.00385 \mathrm{E}-02 \quad 302-301306-305511-249$

$\mathrm{u}=9$ imp:n=1

$733 \quad 95.40155 \mathrm{E}-05$

$(-304: 303:-306: 305:-514: 515) \quad u=9$ imp:n=1

$73476.00385 \mathrm{E}-02$

$304-303306-305514-515 \quad u=9$ imp:n=1

$735 \quad 95.40155 \mathrm{E}-05$

$302-301306-305249-250$

$(-304: 303:-306: 305:-309: 310) \quad u=9$ imp: $n=1$

$73676.00385 \mathrm{E}-02$

$304-303306-305309-310$

$\mathrm{u}=9$ imp:n=1

$302-301306-305250-512$

$(-304: 303:-306: 305:-516: 517) \quad u=9$ imp:n=1

$737 \quad 95.40155 \mathrm{E}-05 \quad 304-303 \quad 306-305516-517$ $\mathrm{u}=9$ imp: $\mathrm{n}=1$

c DEFINITION OF UNIVERSES: NEUTRON SHIELD AND BEAM DUCT $\mathrm{f}$

$74076.00385 \mathrm{E}-02 \quad 41-4051-50-490 \quad \mathrm{u}=10 \mathrm{imp}: \mathrm{n}=1$

$741 \quad 5 \quad 1.20013 \mathrm{E}-01 \quad 41-4051-50 \quad 490-530 \quad \mathrm{u}=10 \mathrm{imp}: \mathrm{n}=1$

$\begin{array}{lllllllll}742 & 8 & 1.18233 \mathrm{E}-01 & 41 & -40 & 51 & -50 & 530 & -531\end{array}$

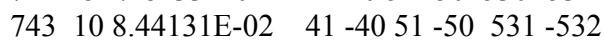

$\mathrm{u}=10 \mathrm{imp}: \mathrm{n}=1$

$\mathrm{u}=10$ imp:n=1

$\begin{array}{lllllllllll}744 & 10 & 8.44131 \mathrm{E}-02 & 41 & -40 & 51 & -50 & 532 & -511\end{array}$

$\mathrm{u}=10 \mathrm{imp}: \mathrm{n}=1$

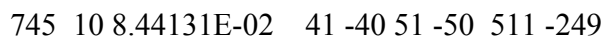

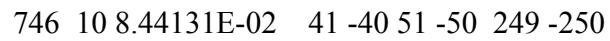

$\mathrm{u}=10$ imp:n=1

$\begin{array}{lllllllll}747 & 10 & 8.44131 \mathrm{E}-02 & 41 & -40 & 51 & -50 & 250 & -512\end{array}$

$\mathrm{u}=10 \mathrm{imp}: \mathrm{n}=1$

$\mathrm{u}=10 \mathrm{imp}: \mathrm{n}=1$

$\mathrm{u}=10 \mathrm{imp}: \mathrm{n}=1$

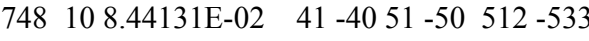

$\mathrm{u}=10 \mathrm{imp}: \mathrm{n}=1$

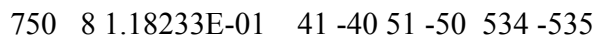

$\mathrm{u}=10$ imp:n=1

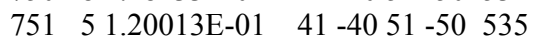

$752 \quad 95.40155 \mathrm{E}-05 \quad(-41: 40:-51: 50) 45-4455-54$

$\mathrm{u}=10$ imp:n=1

$\mathrm{u}=10 \mathrm{imp}: \mathrm{n}=1$

$753 \quad 7$ 6.00385E-02 (-45:44:-55:54) $47-46 \quad 57-56$

$75495.40155 \mathrm{E}-05 \quad(-47: 46:-57: 56)$ $\mathrm{u}=10 \mathrm{imp}: \mathrm{n}=1$

c DEFINITION OF UNIVERSES: NEUTRON SHIELD AND BEAM DUCT fs

$\begin{array}{llllll}765 & 7 & 6.00385 \mathrm{E}-02 & 41-40 & 51-50 & -490 \quad \mathrm{u}=11 \mathrm{imp}: \mathrm{n}=1\end{array}$

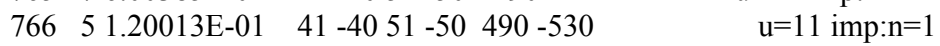

$76781.18233 \mathrm{E}-01 \quad 41-4051-50530-531 \quad \mathrm{u}=11$ imp:n=1

$768 \quad 108.44131 \mathrm{E}-02 \quad 41-4051-50531-532 \quad \mathrm{u}=11 \mathrm{imp}: \mathrm{n}=1$

$769108.44131 \mathrm{E}-02 \quad 41-4051-50 \quad 532-511 \quad \mathrm{u}=11 \mathrm{imp}: \mathrm{n}=1$

$770 \quad 9$ 5.40155E-05 (-302:301:-306:305) 41 -40 51 -50 511 -249 u=11 imp:n=1

$771 \quad 95.40155 \mathrm{E}-05 \quad(-302: 301:-306: 305)$

$$
41-4051-50249-250 \quad u=11 \text { imp:n=1 }
$$

$77295.40155 \mathrm{E}-05 \quad(-302: 301:-306: 305) 41-4051 \quad-50 \quad 250-512 \mathrm{u}=11 \mathrm{imp}: \mathrm{n}=1$

$\begin{array}{lllllllll}773 & 10 & 8.44131 \mathrm{E}-02 & 41 & -40 & 51 & -50 & 512 & -533\end{array}$

$774 \quad 108.44131 \mathrm{E}-02 \quad 41-4051-50 \quad 533 \quad-534$

$\begin{array}{lllllllll}775 & 8 & 1.18233 \mathrm{E}-01 & 41 & -40 & 51 & -50 & 534 & -535\end{array}$

$776 \quad 5$ 1.20013E-01 $41-4051-50 \quad 535$

$777 \quad 95.40155 \mathrm{E}-05 \quad(-41: 40:-51: 50) 45-4455-54$

$778 \quad 76.00385 \mathrm{E}-02 \quad(-45: 44:-55: 54) 47-4657-56$

$779 \quad 95.40155 \mathrm{E}-05$

$78176.00385 \mathrm{E}-02$

$(-47: 46:-57: 56)$

$\mathrm{u}=11$ imp:n=1

$\mathrm{u}=11 \mathrm{imp}: \mathrm{n}=1$

$\mathrm{u}=11 \mathrm{imp}: \mathrm{n}=1$

$\mathrm{u}=11 \mathrm{imp}: \mathrm{n}=1$

$\mathrm{u}=11$ imp:n=1

$\mathrm{u}=11$ imp:n=1

$302-301306-305511-249$

$\mathrm{u}=11 \mathrm{imp}: \mathrm{n}=1$

$782 \quad 95.40155 \mathrm{E}-05$

(-304:303:-306:305:-514:515) u=11 imp:n=1

$783 \quad 76.00385 \mathrm{E}-02$

$304-303306-305514-515$

$\mathrm{u}=11 \mathrm{imp}: \mathrm{n}=1$

$302-301306-305249-250$

(-304:303:-306:305:-309:310) u=11 imp: $n=1$

$784 \quad 95.40155 \mathrm{E}-05$

$304-303306-305309-310$

$\mathrm{u}=11$ imp:n=1

$78576.00385 \mathrm{E}-02$

$302-301306-305250-512$

$(-304: 303:-306: 305:-516: 517) u=11$ imp:n=1

$78695.40155 \mathrm{E}-05 \quad 304-303306-305516-517 \quad \mathrm{u}=11 \mathrm{imp}: \mathrm{n}=1$

c DEFINITION OF UNIVERSES: NEUTRON SHIELD AND BEAM DUCT $\mathrm{s}$

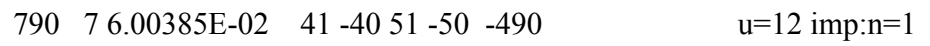

$79151.20013 \mathrm{E}-01 \quad 41-4051-50490-511 \quad \mathrm{u}=12 \mathrm{imp}: \mathrm{n}=1$

7929 5.40155E-05 (-302:301:-306:305) $41-4051-50 \quad 511-249 \mathrm{u}=12$ imp:n=1

$793 \quad 95.40155 \mathrm{E}-05 \quad(-302: 301:-306: 305)$ 


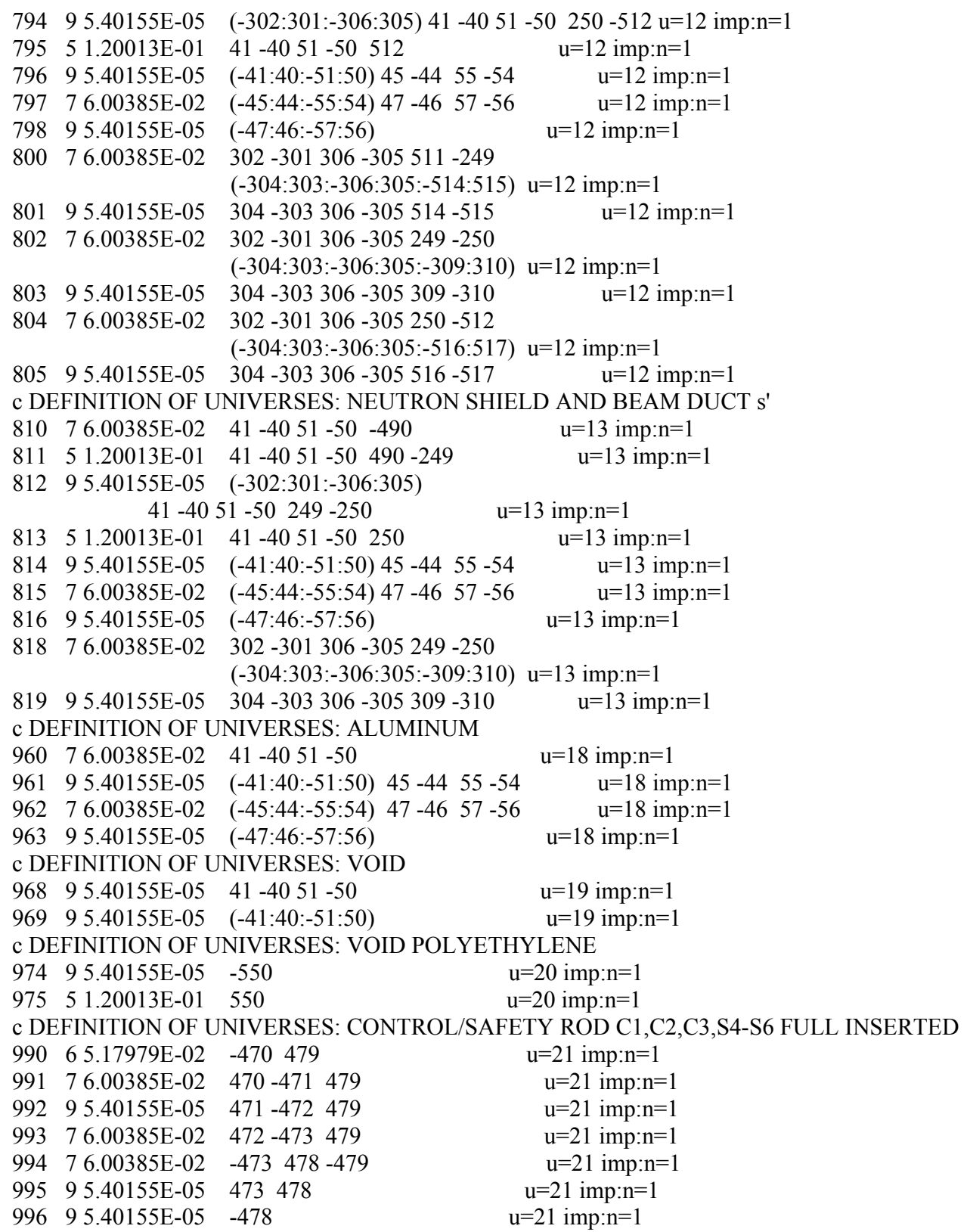

c Surface cards

$\begin{array}{ccc}1 & \text { px } & -64.095 \\ 2 & \text { px } & -41.775 \\ 3 & \text { px } & -8.395 \\ 4 & \text { px } & 8.395 \\ 5 & \text { px } & 41.775 \\ 6 & \text { px } & 64.095 \\ 10 & \text { py } & 50.17 \\ 11 & \text { py } & 16.79 \\ 12 & \text { py } & 0.0 \\ 13 & \text { py } & -33.38 \\ 14 & \text { py } & -66.76 \\ 20 & \text { px } & -63.995 \\ 21 & \text { px } & -41.875 \\ 22 & \text { px } & -41.675 \\ 23 & \text { px } & -8.495 \\ 24 & \text { px } & -8.295 \\ 25 & \text { px } & 8.295 \\ 26 & \text { px } & 8.495\end{array}$




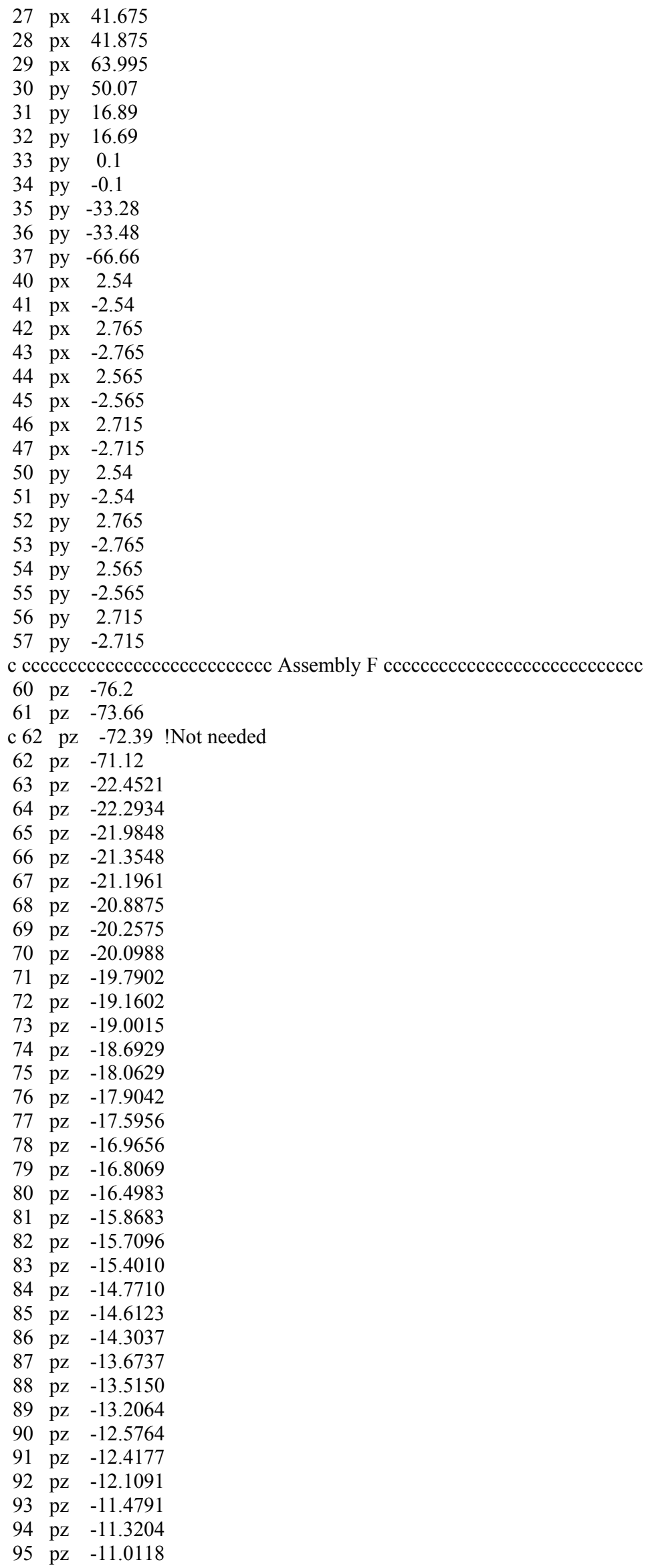




\begin{tabular}{|c|c|c|}
\hline & $\mathrm{pz}$ & \\
\hline & $\mathrm{pz}$ & 202 \\
\hline & $\mathrm{pz}$ & -9.9145 \\
\hline 9 & $\mathrm{pz}$ & -9.2845 \\
\hline 00 & $\mathrm{pz}$ & -9.1258 \\
\hline & $\mathrm{pz}$ & -8.8172 \\
\hline & $\mathrm{pz}$ & -8.1872 \\
\hline & $\mathrm{pz}$ & -8.0285 \\
\hline & $\mathrm{pz}$ & -7.7199 \\
\hline 55 & $\mathrm{pz}$ & -7.0899 \\
\hline & $\mathrm{pz}$ & -6.9312 \\
\hline & $\mathrm{pz}$ & -6.6226 \\
\hline 18 & $\mathrm{pz}$ & -5.9926 \\
\hline 19 & $\mathrm{pz}$ & -5.8339 \\
\hline 0 & $\mathrm{pz}$ & -5.5253 \\
\hline & $\mathrm{pz}$ & -4.8953 \\
\hline & $\mathrm{pz}$ & -4.7366 \\
\hline 13 & $\mathrm{pz}$ & -4.4280 \\
\hline & $\mathrm{pz}$ & -3.7980 \\
\hline & $\mathrm{pz}$ & -3.6393 \\
\hline & $\mathrm{pz}$ & -3.3307 \\
\hline 7 & $\mathrm{pz}$ & -2.7007 \\
\hline & $\mathrm{pz}$ & -2.5420 \\
\hline & $\mathrm{pz}$ & -2.2334 \\
\hline 20 & $\mathrm{pz}$ & -1.6034 \\
\hline 21 & $\mathrm{pz}$ & -1.4447 \\
\hline 2 & $\mathrm{pz}$ & -1.1361 \\
\hline 23 & $\mathrm{pz}$ & -0.5061 \\
\hline 24 & $\mathrm{pz}$ & -0.3474 \\
\hline 25 & $\mathrm{pz}$ & -0.0388 \\
\hline 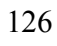 & $\mathrm{pz}$ & 0.5912 \\
\hline 27 & $\mathrm{pz}$ & 0.7499 \\
\hline 28 & $\mathrm{pz}$ & 1.0585 \\
\hline 28 & $\mathrm{pz}$ & 1.6885 \\
\hline 30 & $\mathrm{pz}$ & 1.8472 \\
\hline & $\mathrm{pz}$ & 2.1558 \\
\hline & $\mathrm{pz}$ & 2.7858 \\
\hline 3 & $\mathrm{pz}$ & 2.9445 \\
\hline & $\mathrm{pz}$ & 3.2531 \\
\hline 3 & $\mathrm{pz}$ & 3.8831 \\
\hline 36. & $\mathrm{pz}$ & 4.0418 \\
\hline 7 & $\mathrm{pz}$ & 4.3504 \\
\hline 38 & $\mathrm{pz}$ & 4.9804 \\
\hline & $\mathrm{pz}$ & 5.1391 \\
\hline 40 & $\mathrm{pz}$ & 5.4477 \\
\hline & $\mathrm{pz}$ & 6.0777 \\
\hline 42 & $\mathrm{pz}$ & 6.2364 \\
\hline 43 & $\mathrm{pz}$ & 6.5450 \\
\hline 14 & $\mathrm{pz}$ & 7.1750 \\
\hline & $\mathrm{pz}$ & 7.3337 \\
\hline 140 & $\mathrm{pz}$ & 7.6423 \\
\hline 147 & $\mathrm{pz}$ & 8.2723 \\
\hline 148 & $\mathrm{pz}$ & 8.4310 \\
\hline & $\mathrm{pz}$ & 8.7396 \\
\hline & $\mathrm{pz}$ & 9.3696 \\
\hline 151 & $\mathrm{pz}$ & 9.5283 \\
\hline 152 & $\mathrm{pz}$ & 9.8369 \\
\hline & $\mathrm{pz}$ & 10.4669 \\
\hline & $\mathrm{pz}$ & 10.6256 \\
\hline & $\mathrm{pz}$ & 10.9342 \\
\hline 12 & $\mathrm{pz}$ & 11.5642 \\
\hline 157 & $\mathrm{pz}$ & 11.7229 \\
\hline & $\mathrm{pz}$ & 12.0315 \\
\hline & $\mathrm{pz}$ & 12.6615 \\
\hline & & 12.8202 \\
\hline
\end{tabular}


$161 \mathrm{pz} 13.1288$

$162 \mathrm{pz} \quad 13.7588$

$163 \mathrm{pz} 13.9175$

$164 \mathrm{pz} 14.2261$

$165 \mathrm{pz} \quad 14.8561$

$166 \mathrm{pz} 15.0148$

$167 \mathrm{pz} 15.3234$

$168 \mathrm{pz} 15.9534$

$169 \mathrm{pz} 16.1121$

$170 \mathrm{pz} 16.4207$

c $171 \mathrm{pz} 17.0507$ !this was the exact point, but I use the bench specification

$171 \mathrm{pz} 17.0521$

$172 \mathrm{pz} \quad 68.2625$

$173 \mathrm{pz} 74.6125$

174 pz 76.2

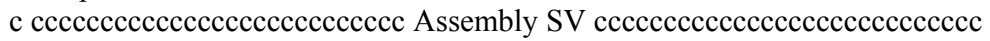

c $200 \mathrm{pz}-73.66$ !see surface 61

c 200 pz -72.39 !not needed

c $200 \mathrm{pz}-71.12$ ! this was the exact point, but I use the bench specification

$200 \mathrm{pz}-71.1199$

201 pz -22.7574

$202 \mathrm{pz}-22.5987$

$203 \mathrm{pz}-22.2901$

204 pz -21.6601

$205 \mathrm{pz}-21.5014$

206 pz -21.1928

207 pz -20.5628

208 pz -20.4041

$209 \mathrm{pz}-20.0955$

$210 \mathrm{pz}-19.4655$

$211 \mathrm{pz}-19.3068$

212 pz -18.9982

213 pz -18.3682

$214 \mathrm{pz}-18.2095$

215 pz -17.9009

$216 \mathrm{pz} \quad-17.2709$

217 pz -17.1122

218 pz -16.8036

$219 \mathrm{pz}-16.1736$

$220 \mathrm{pz} \quad-16.0149$

$221 \mathrm{pz}-15.7063$

$222 \mathrm{pz}-15.0763$

$223 \mathrm{pz}-14.9176$

$224 \mathrm{pz}-14.6090$

$225 \mathrm{pz}-13.9790$

$226 \mathrm{pz}-13.8203$

$227 \mathrm{pz} \quad-13.5117$

228 pz -12.8817

$229 \mathrm{pz}-12.7230$

$230 \mathrm{pz} \quad-12.4144$

$231 \mathrm{pz}-11.7844$

$232 \mathrm{pz}-11.6257$

233 pz -11.3171

$234 \mathrm{pz}-10.6871$

$235 \mathrm{pz}-10.5284$

236 pz -10.2198

$237 \mathrm{pz} \quad-9.5898$

238 pz -9.4311

$239 \mathrm{pz}-9.1225$

$240 \mathrm{pz} \quad-8.4925$

$241 \mathrm{pz}-8.3338$

242 pz -8.0252

$243 \mathrm{pz}-7.3952$

$244 \mathrm{pz}-7.2365$

$245 \mathrm{pz}-6.9279$ 


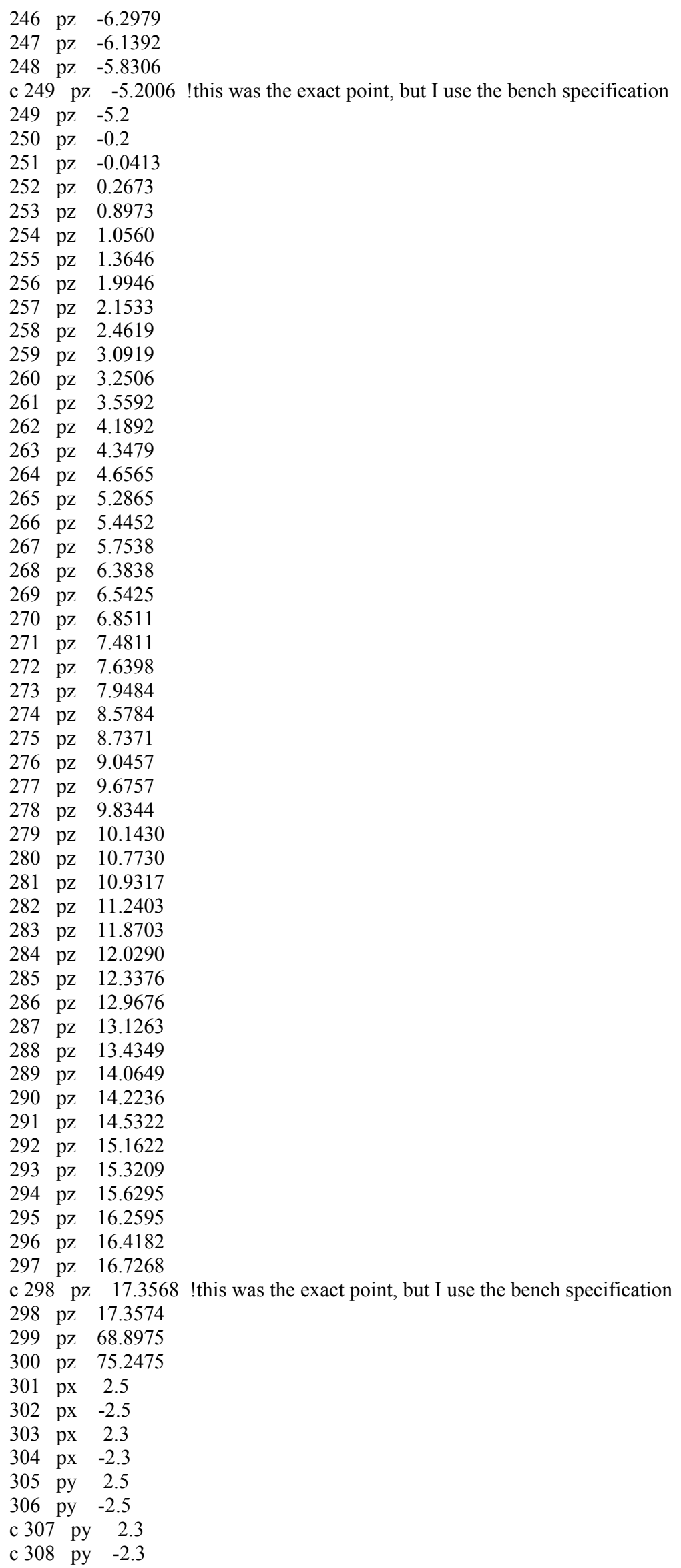


$309 \mathrm{pz}-5$.

$310 \mathrm{pz}-0.4$

$311 \mathrm{c} / \mathrm{y} \quad 8.395-2.70 .075$

$312 \mathrm{c} / \mathrm{y} \quad 8.395-2.70 .1$

$313 \mathrm{c} / \mathrm{y} \quad 8.395-2.70 .11$

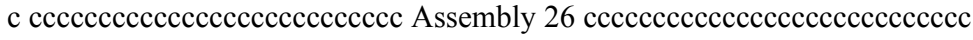

c $340 \mathrm{pz}-73.66$ !see surface 61

c 340 pz -72.39 !not needed

c 340 pz -71.12 !see surface 62

$340 \mathrm{pz}-70.9613$

$341 \mathrm{pz}-70.6438$

$342 \mathrm{pz}-70.0088$

$343 \mathrm{pz}-69.8501$

$344 \mathrm{pz}-69.5326$

$345 \mathrm{pz}-68.8976$

$346 \mathrm{pz}-68.7389$

$347 \mathrm{pz} \quad-68.4214$

$348 \mathrm{pz}-67.7864$

$349 \mathrm{pz}-67.6277$

$350 \mathrm{pz}-67.3102$

$351 \mathrm{pz}-66.6752$

$352 \mathrm{pz}-66.5165$

$353 \mathrm{pz}-66.1990$

c $354 \mathrm{pz}-65.5640$ !this was the exact point, but I use the bench specification

$354 \mathrm{pz}-65.6333$

$355 \mathrm{pz}-16.9654$

$356 \mathrm{pz}-16.8067$

$357 \mathrm{pz} \quad-16.4981$

$358 \mathrm{pz}-15.8681$

$359 \mathrm{pz}-15.7094$

$360 \mathrm{pz}-15.4008$

361 pz -14.7708

$362 \mathrm{pz}-14.6121$

$363 \mathrm{pz}-14.3035$

$364 \mathrm{pz}-13.6735$

$365 \mathrm{pz}-13.5148$

$366 \mathrm{pz}-13.2062$

$367 \mathrm{pz}-12.5762$

$368 \mathrm{pz}-12.4175$

$369 \mathrm{pz}-12.1089$

$370 \mathrm{pz}-11.4789$

$371 \mathrm{pz}-11.3202$

$372 \mathrm{pz}-11.0116$

$373 \mathrm{pz}-10.3816$

374 pz -10.2229

$375 \mathrm{pz}-9.9143$

376 pz -9.2843

$377 \mathrm{pz} \quad-9.1256$

$378 \mathrm{pz} \quad-8.8170$

379 pz $\quad-8.1870$

380 pz -8.0283

381 pz -7.7197

$382 \mathrm{pz}-7.0897$

$383 \mathrm{pz}-6.9310$

$384 \mathrm{pz}-6.6224$

$385 \mathrm{pz} \quad-5.9924$

$386 \mathrm{pz}-5.8337$

$387 \mathrm{pz}-5.5251$

388 pz -4.8951

389 pz -4.7364

$390 \mathrm{pz}-4.4278$

$391 \mathrm{pz}-3.7978$

$392 \mathrm{pz}-3.6391$

$393 \mathrm{pz}-3.3305$

$394 \mathrm{pz}-2.7005$ 


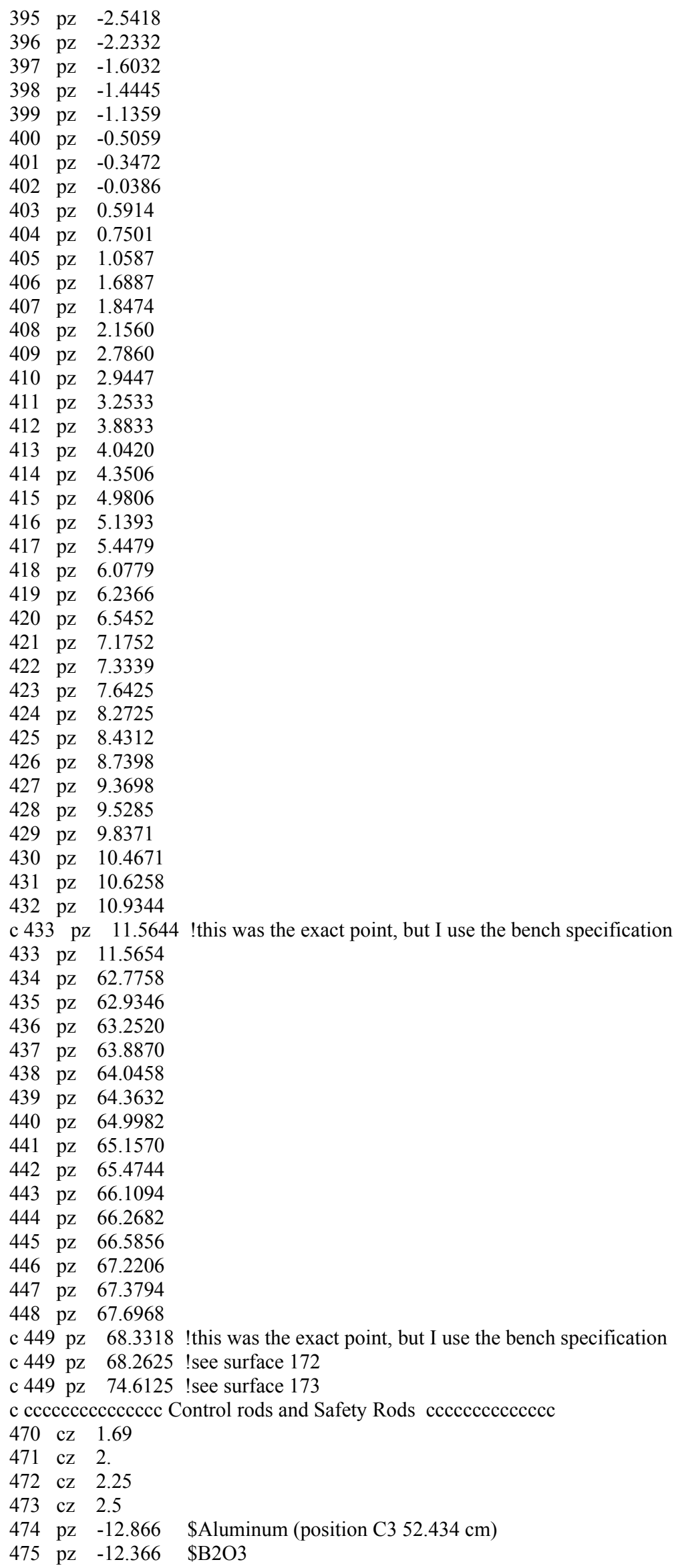




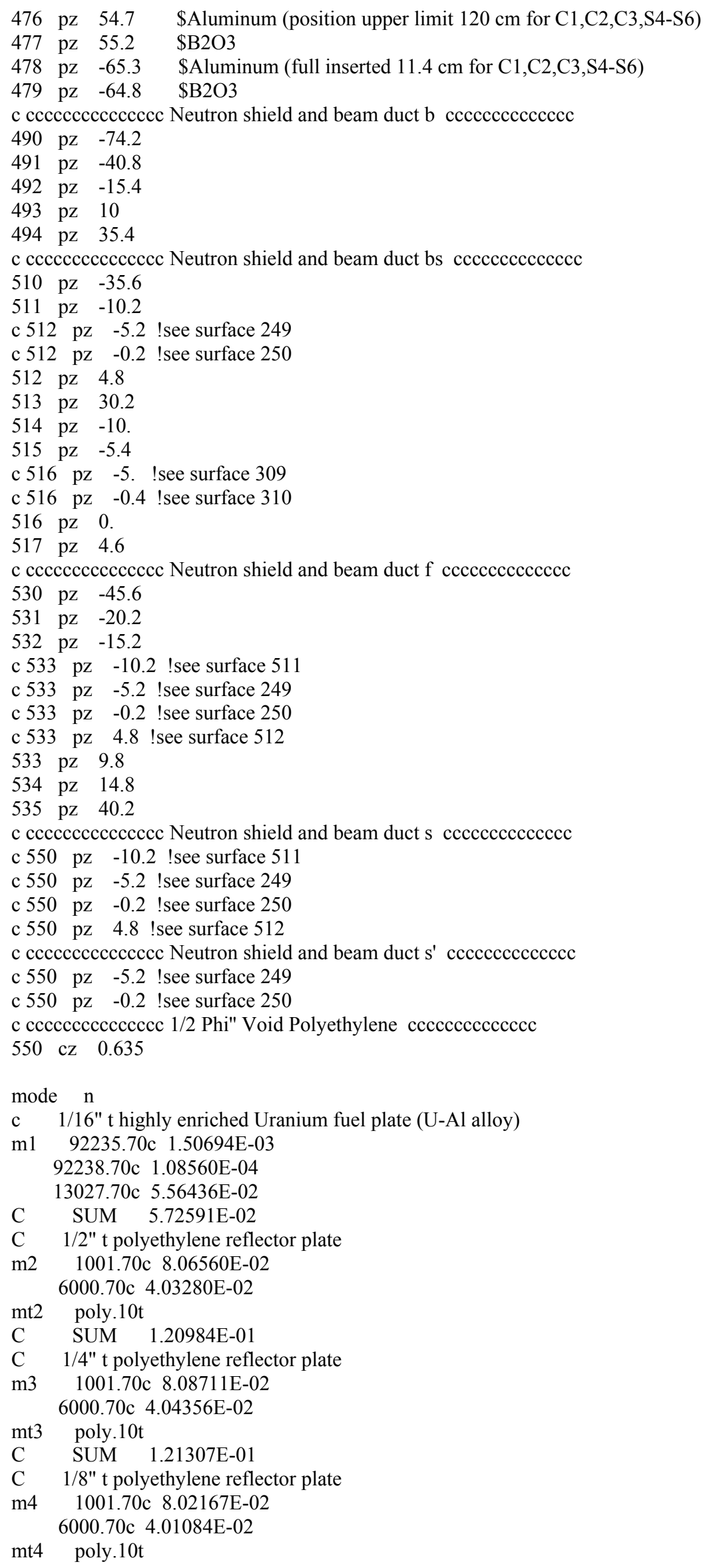




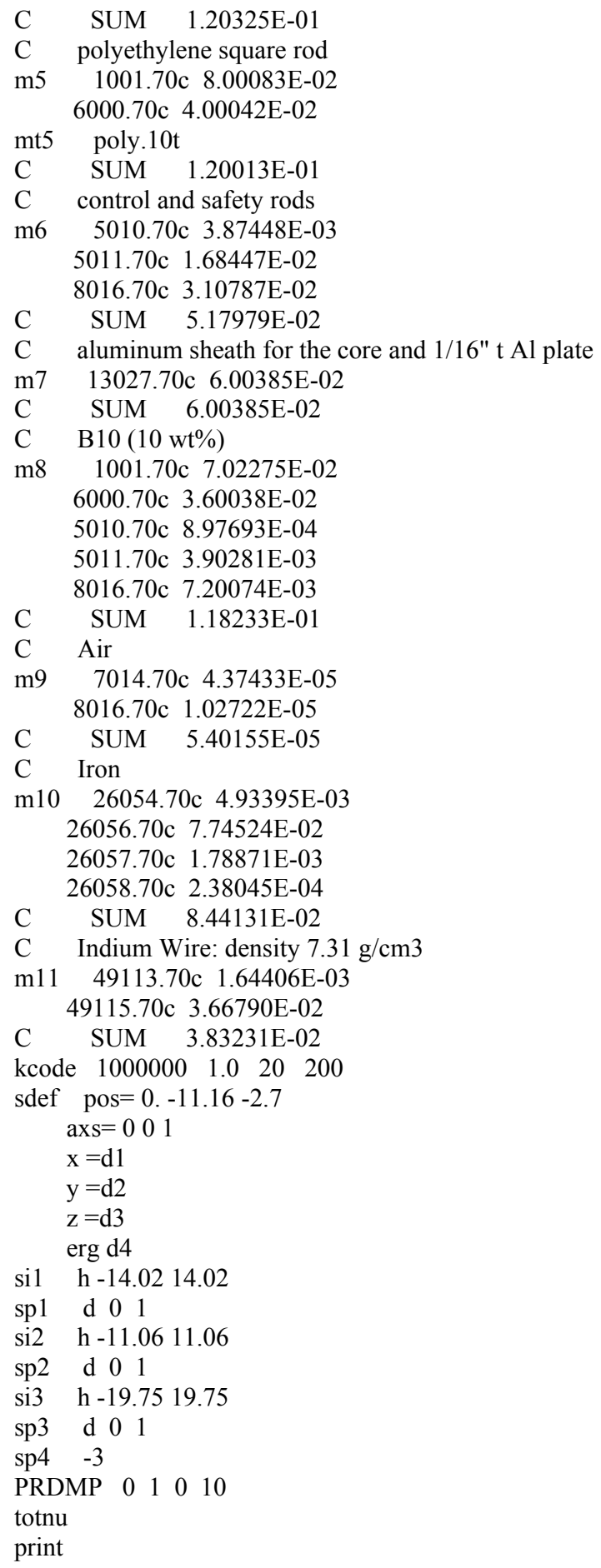


Argonne

Nuclear Engineering Division

Argonne National Laboratory

9700 South Cass Avenue, Bldg. 208

Argonne, IL 60439

ww.anl.gov

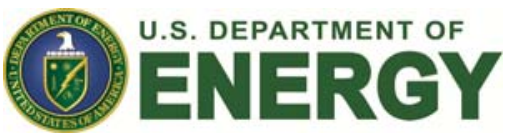

Argonne National Laboratory is a U.S. Department of Energy laboratory managed by UChicago Argonne, LLC 